Ministry of Transport and Communication of Ukraine

Dnipropetrovsk National University of Railway Transport named after Academician V. Lazaryan

L. MANASHKIN, S. MYAMLIN, V. PRIKHODKO

\title{
Oscillation Dampers and Shock Absorbers in Railway Vehicles (Mathematical Models)
}

Monograph 
Reviewed by:

Doctor of Technical Science, Professor Georgiy Ivanovich BOGOMAZ, the Department Head in Technical Mechanics Institute under the National Academy of Ukraine, Dnipropetrovsk, Ukraine

Doctor of Technical Science, Professor Valeriy Mikhaylovich BUBNOV, the General Designer in Car Building of Azovmash PJSC, Mariupol, Ukraine

Recommended for publishing by the decision of the Academic Council of Dnipropetrovsk National University of Railway Transport named after Academician V. Lazaryan (Protocol No. 13 of 25.06.2007)

The Monograph deals with the simulation of oscillation damping units - the shock absorbers and oscillation dampers. Various types of draft gears are considered including their structural features and mathematical models describing their operation. The test methods for oscillation dampers and draft gears are described together with the test results processing techniques.

The book is issued for the scientists and designers researching and developing various shock absorbing units in railway vehicles. It may be useful for postgraduate, master degree and other students studying the structure and dynamics of the railways rolling stock and industrial transport.

Figures: 82. Tables: 10. Bibliography: 216 issues.

L. A. Manashkin

M23 Oscillation Dampers and Shock Absorbers in Railway Vehicles (Mathematical Models) / L. A. Manashkin, S. V. Myamlin, V. I. Prikhodko. - Dnipropetrovsk: 2007. $-180 \mathrm{p}$.

ISBN

(C) ManashkinL. A., Myamlin S. V., Prikhodko V. I. 2007 


\section{INTRODUCTION}

This monograph brings to the experts' notice the mathematical modeling of draft gears and shock absorbers. The mathematic description of these units functioning that can be used when studying the vehicles dynamics is connected with the specific features of their structure.

Wedged friction draft gears with steel friction elements tend to lock if friction is not stabilized. Therefore, when modeling dynamic process in a train, it was typical to assume the gears compression forces subject to the identification of their qualitative and quantitative train dynamic process parameters, but not the forces that resulted directly from the specific features of their structure. In some publications [3,101,102], these parameters are called integral. The same publications showed that, actually, they were just some static characteristic of the gears. The experience of transitional train motion modes (standing start, braking, motion in vertical track alignment breaks, coupled cars collisions) dynamic processes simulation evidences the appropriateness of such characteristics utilization when determining the forces acting on the train vehicles.

The design of Mark plate type spring friction draft gears described in Freight Car Draft Arrangements Manual, 2003 Wabtec Corporation, and (PMK) draft gears [103] include elements (special lubrication and metal-ceramic parts) that significantly increase the energy capacity and stabilizing functioning of these draft gears. The correlation of these elements geometry with the gears force characteristics in general is detailed in publication [103].

The ideas of a friction draft gear mathematical simulation presented in Chapter 2 are used in Chapter 3 when building the flat and spatial car bogie friction shock absorber model. The fundamental correlation of vertical and transverse horizontal oscillation produced by friction forces is shown.

When modeling hydraulic and pneumatic (Chapters 4-9) draft gears, shock absorbers and dampers, stationary and non-stationary thermodynamic processes in the respective environment are considered. The processes occurring in the real gas and in the systems with variable working body weight are analyzed. The difference in draft gears and shock absorbers modeling results arising due to real gas environment versus ideal gas environment is demonstrated. New, formally derived, approximating equation and calculation algorithm of real gas state are suggested that can be used for theoretical studies and the units of interest modeling. It is noted that the optimal parameters of such units in quasi-stationary and shock loading conditions are different. Hydraulic and pneumatic shock absorbers mathematic models are applicable to vehicles motion simulation under conditions of stationary and, simultaneously, shock vibration excitation.

Closing Chapter 10 deals with experimental test methods for vehicles and the test results analysis.

The authors hope the book will be interesting and useful to scientists, engineers, experts and students who study the shock energy absorption and oscillation damping when modeling the dynamics of both individual vehicles and 
railway vehicles in a train, and would be happy to receive any suggestions and remarks at their address:

2 Academician Lazaryan St., DIIT (DNURT) office 222, Dnepropetrovsk 49010, Ukraine. E-mail: sergeymyamlin@gmail.com

This book brings to the experts' notice the mathematical modeling of units (the dampers or shock absorbers) used for reducing the dynamic forces produced by impact and vibration effects in cars. From the wide variety of units applied here only those that carry out direct absorption of energy are described, i.e. the authors exclude from consideration the dynamic oscillation dampers [1], which action is based on the application of additional mechanical oscillatory systems.

Oscillation dampers transform kinetic energy of vehicle individual parts or whole vehicle motion both to potential energy of working medium such as fluid in absorber chamber and housing parts deformation and to thermal energy due to friction and fluid overflow through local hydraulic resistances. The main part of thus transformed kinetic energy is dissipated in form of heat and energy losses connected with the materials wear.

The oscillation absorber extension and compression may be passive, forced due to the motion of the vehicle it is attached to, and active due to accumulated potential energy. In the latter case, these units are independently returned into their initial state. Structurally, the oscillation absorbers may be integrated into elastic suspension units or into the units providing for technological and structural joining of the vehicle parts or connected in parallel with them. In addition, they may have the form of separate vehicle parts with their own units returning them to the initial position.

In this book, modeling of oscillation dampers is generally analyzed together with working return mechanisms. Such integration is convenient for synthesis of the vehicle mathematic model in whole and for writing a program for numeric integration of differential equations of the vehicle motion.

The dampers are widely used in various carriers, in railway vehicles in particular. The variety of the units is derived from their purpose. So, the vehicles suspensions should effectively absorb the oscillations due to their interaction with the base (road, water, air). Altogether, it should be born in mind that suspension deformation is produced not only by variable but also constant gravity force. A set of units should provide for the energy absorption and the vehicle protection from single emergency shocks. The set includes bumpers and sacrificing vehicle parts used for crushing and protection of the vehicle structure in whole. In some cases impacts are the part of the vehicle operation process (collisions during railway cars shunting, impact processes in railway trains, landing gears, impacts in elements of lifting and mining machines and many other examples). To protect the vehicles structure and people at such impacts special multiple action impact dampers are used.

The railway cars and locomotives are equipped with center coupler draft gears (hereinafter - draft gear) [2] to damp longitudinal impacts effect. They are used for 
absorbing the impacts occurring during car shunting movements and train motion transient mode. At the same time, the draft gear itself is the unit delivering tractive and braking efforts from one part of the train to the other. Therefore, the draft gear is not only the impact damper but also the unit, which should balance quite big static and quasi-static forces in a train. Such units participating in cars interaction should, at the same time, effectively absorb the oscillation occurring at transient train motion modes and prevent from shock waves generation in it [3].

In contrast to draft gears, dampers of flexible center sill and movable freight cars frames (hereinafter shock absorbers) almost do not transfer significant longitudinal forces. They are used only for reducing the longitudinal dynamic loads acting on the cargos at cars collisions during shunting movements and in the train.

Wide variety of shock absorbers and oscillation dampers used in railway transport, similar approach to their modeling in other mechanical engineering fields help the authors to concentrate exclusively on the shock absorbers and oscillation dampers in railway vehicles.

When operated, the shock absorbers, oscillation dampers, draft gears (hereinafter we will call them collectively the dampers) always couple two solid bodies. This means, the dampers deformations are determined by these bodies motion, more accurately by their movements, speed and acceleration. Mathematical formulation of deformations depends on the character of energy absorption and structure of the absorbing units $[2 ; 3]$.

Let us consider the mathematical model of two bodies coupling consisting of deformed elements of different physical nature.

Figure I.1 illustrates the general scheme of coupling consisting of in-series simple and complex deformed elements. The properties of the elements may vary; there may be a gap in bodies coupling.

To make it simpler, here the damper with one-dimensional deformation is depicted as the most typical case providing for in-depth analysis of mathematical modeling approaches. Mathematical models of dampers, which operation is defined by two- or three-dimensional movements of dampers fixtures with the connected bodies, will be considered individually for specific case studies.
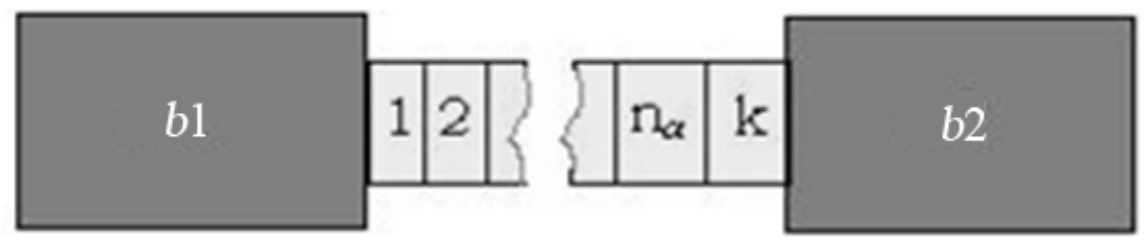

Figure I.1. General calculation model of bodies $b 1$ and $b 2$ coupling: $1,2 \ldots-$ numbers of in-series coupling elements 
Suppose $x_{1}$ and $x_{2}$ are the movements of damper coupling points with bodies 1 and 2 coupled by this damper; $v_{1}, v_{2}$ are these bodies speeds; $S$ is the force extending or compressing the damper along $x$ axis; $q=\left(x_{1}-x_{2}\right)$ is the damper extension, $\dot{q}=\left(v_{1}-v_{2}\right)$ is the rate of extension. Hereinafter we assume the damper consists of $n_{a}$ in-series elements with absolute extension values equal to $q_{i}$.

In addition to $n_{a}$ damper elements, let us introduce auxiliary element $\mathbf{k}$ with extension $q_{k}$ to simulate the damped bodies structures and the damper fixtures deformation, i. e.

$$
q=\sum_{i=1}^{n_{a}} q_{i} \operatorname{sign} q+q_{k}
$$

In addition, let us consider that the damper fixture may have gap $\delta$, which shows itself (to be specific) at the bodies coupling extension.

$\mathbf{k}$ element extension may be defined as

$$
q_{k}= \begin{cases}0, & \text { if } 0 \leq q \leq \delta ; \\ q-\delta-\sum_{i=1}^{n_{a}} a_{i} q_{i} \operatorname{sign} q, & \text { if } q>\delta ; \\ q-\sum_{i=1}^{n_{a}} a_{i} q_{i} \operatorname{sign} q, & \text { if } q<0 .\end{cases}
$$

in case the elements deformation takes place without residual deformations and deformations lagging. In expression (I.2) $a_{i}$ is the number of identical elements indexed $i$.

If the coupling contains elements returning to their initial state some time after unloading (deformation 'lagging') or some residual deformations occur, it may turn out that $\operatorname{sign} q_{k} \neq \operatorname{sign} q$ and this has no physical sense. Residual deformations of any element and deformation lagging lead to the increase of gap at extension and the gap formation at compression. The more general expression is

$$
q_{k}= \begin{cases}0, & \text { if } q q_{k}^{*} \leq 0 \\ q_{k}^{*}, & \text { if } q q_{k}^{*}>0,\end{cases}
$$

where $q_{k}^{*}$ is defined by expression (I.2).

Value $q$ is defined by solving the differential equation of specific mechanical system motion, which includes interacting bodies 1 and 2 , and $q_{i}$ values are defined by solving the differential equations of $i$ damper element state. After defining $q_{k}$, force $S$ deforming the coupling is calculated using the following expressions

$$
S=k_{k} q_{k}+\beta_{k}\left|q_{k}\right| \dot{q}_{k}
$$

or

$$
S=k_{k} q_{k}+\beta_{k} \dot{q}_{k},
$$


where $k_{k}$ is $k$ element stiffness and $\beta_{k}$ is the ratio of viscous resistance to its deformation. Usually $\beta_{k}$ is a small value and in a number of cases the viscous component of force in expressions (I.4) and (I.5) may be neglected.

In some cases (such as for friction dampers, which are discussed in the following sections), it is possible to combine a number of elements into a block or an element, for which the functional connection of deforming force value $S_{\mathrm{f}}$ with the values of its deformation $q_{\mathrm{f}}$ and deformation speed $\dot{q}_{\mathrm{f}}$ may be formulated. Value $q_{\mathrm{f}}$ is calculated using expressions (I.2) and (I.3).

So, when solving the differential equations of motion of bodies coupled with the damper or additional differential equations of state, we define, for each such coupling, one $q$ value and $n_{a}$ of $q_{i}$ values, $q_{k}$ value or $q_{\mathrm{f}}$ value, and then using expressions (I.4), (I.5) or function $S=S\left(q_{\mathrm{f}}, \dot{q}_{\mathrm{f}}\right)$, we calculate force $S$ deforming the coupling as a whole.

In some cases, the motion modes of the bodies coupled with a damper, at which plastic deformations of bodies or damper fixtures occur at $\left|q_{k}\right|>\Delta_{s}^{*}$, are considered.

When simulating such cases, $q$ values are replaced with $\left(q-\delta_{s}\right)$ in expressions (I.4) and (I.5); $\delta_{s}$ is the residual deformations value calculated at the moment when absolute values of force $S$ pass through maximum while condition $\left|q_{k}\right|>\Delta_{s}^{*}$ or $|S|>S_{s}^{*}$ $\left(\Delta_{s}^{*}\right.$ and $S_{s}^{*}$ are the coordinates of a point in diagram $q_{k}-|S|$, above which plastic deformations occur) is still met. Having designated the extension and force values corresponding to elastic limit when residual deformations $\delta_{s}=0$ as $\Delta_{s}$ and $S_{s}$, using Prandtl model and Bauschinger strengthening effect [4], we can calculate

$$
\begin{gathered}
\Delta_{s}^{*}=\Delta_{s}+\delta_{s}\left(1-k_{k s} / k_{k}\right)^{-1} \operatorname{sign} S ; \quad S_{s}^{*}=S_{s}+\Delta_{s}^{*} k_{k s} \operatorname{sign}\left(S \delta_{s}\right) ; \\
\delta_{s}=\left(|S|_{\max }-S_{s}\right)\left(k_{k s}^{-1}-k_{k}^{-1}\right) \operatorname{sign} q,
\end{gathered}
$$

where $k_{k s}$ is $k$ element stiffness coefficient in plastoelastic deformation zone. In cases when instead of formulae (I.4) or (I.5) function $S=S\left(q_{\mathrm{f}}, \dot{q}_{\mathrm{f}}\right)$ is used, its formulae shall be supplemented with the following expression

$$
S=\left[S_{s}^{*}+k_{k s}\left(\left|q_{\mathrm{f}}\right|-\Delta_{s}^{*}\right)\right] \operatorname{sign}\left(q_{\mathrm{f}}-\delta_{s}\right),
$$

if $\left(|S|>S_{s}^{*}\right) \cap\left(\left(q_{\mathrm{f}}-\delta_{s}\right) \dot{q}_{\mathrm{f}}>0\right)$.

The following sections of this book offer the physical representation of shock absorbers (draft gears) and oscillation dampers in railway vehicle bogies. The authors deliberately limited the range of objects under consideration by the most typical cases discussing the issues inevitably arising in connection with their calculation, design, and simulation.

The material is presented in the order of ascending complexity of mathematical models. 


\section{STRUCTURES OF DAMPING SYSTEMS IN RAILWAY VEHICLES}

This book considers the design diagrams and complete mathematical models helping to analyze the operation of shock absorbers and other oscillation damping systems in railway vehicles.

In addition to theoretical studies in dynamic parameters of railway vehicles improvement, the designers' and inventors' efforts are aimed at creation of new structures of oscillation damping systems, couplings between railway vehicles and between the elements of running gears of freight and passenger cars, and locomotives [5-34]. Great attention is paid to the elements ensuring the absorption of shocks and damping the oscillation that are always present at a train motion. The structures discussed in this book are selected mostly as examples of typical systems. The mathematical models of these systems elements can easily be transformed into the mathematical models of other units.

The damping units in trains may be generally categorized as follows [34]:

- car body bogie bearing systems;

- central suspension;

- axle-box suspension;

- oscillation dampers;

- shock absorbers;

- active suspension systems.

Below the most interesting to the authors' point of view structures of damping units are described and power characteristics of some of them are given.

\subsection{Car Body Bogie Bearing Systems}

The support of a car body on the bogies is realized basically through the central bearings located in central longitudinal vertical symmetry plane of the body. Such bearings are used in most car and locomotive types. In some cases, vertical load on bogies at the body side may be transferred only by side bearings as it is arranged in type TЭ3 (TE3), TЭ7 (TE7) diesel locomotives, and K series electric locomotives [35]. Bearing may be single- and two-stage if side frames or side bogie bolsters are damped relative to a wheelset. Most freight cars have single-stage spring suspension. In passenger car, refrigerator car and locomotive structures bogies with twostage spring suspension are usually used.

In addition to bearing systems, the railway vehicle bogies have elements limiting and absorbing the oscillation at longitudinal, side and angle movements of the car body relative to unsprung bogie parts.

To the authors' point of view, the bearing proposed in claim [36] significantly improves the train dynamics by damping the oscillations both in vertical and horizontal planes and ensuring the car body return to its initial position at swaying and bouncing. The bearing transfers the load from the body to the bogie frame through a swinging column with bottom spherical end that is embedded into an elastic pis- 
ton along the full working surface. This piston moves inside the cylinder, which workspace functions as a pneumatic spring. The bottom part of the cylinder may roll over the balls along the cylindrical or spherical bearing surface, which is the part of a hinge, firmly fixed at the bogie frame. Vertical oscillations are damped by an air cushion and due to the piston elasticity and elastic packing on the car body. These oscillations are damped by the piston friction occurring at its movement inside the cylinder and by heat dissipation at the air cushion compression. Horizontal oscillations are damped by the column shifts and due to the bearing rolling over along the surface.

The unit proposed for transferring the longitudinal forces from the bogie frame to the locomotive body frame [37] comprises a link made in form of two divergent ties and hingedly coupled with a medium bogie frame bolster and resilient inclined rod, which connects the link with the engine body. Hinge joint between the link and inclined rod is also connected with the front bogie frame bolster using resilient rod. Such structure provides for reduction of dynamic load on bogie frame and body frame elements of inclined rod and leads to improvement of longitudinal dynamics.

The unit proposed for transferring the transversal forces from the body to the bogie [38] is made in form of a solid flexible coupling located in grooves of four adjustment pulleys orthogonally fixed on the body frame. Center points of transverse sections of the flexible coupling are fixed on medium bogie frame bolsters and the longitudinal sections are tied together transversally using guide pulleys and linked pre-tension hinged spring mechanism. A steel wire rope, for instance, may be used as a flexible coupling. With the vehicle standing on a straight track, this structure provides for coaxial positioning of body and both bogies as the flexible coupling is balanced by the mechanism and blocks. On a curved track, to achieve the specified body fixing on bogies, the required bogies movement is ensured by longitudinal shifting of a flexible coupling accompanied with turning of adjustment and guide pulleys. At a dynamic transversal body movement in respect to the bogies, additional loading of one of the longitudinal sections occurs and is accompanied with its straightening and increased mechanism torque. Thus by the end of the resilient stroke, the transversal link resistance increases, that is nonlinear rising characteristic is achieved.

The authors of claim [39] propose the method of fixing the mechanism that absorbs the bending vibrations of the car body. For that, a damping loads or equipment, which total weight comprises 3 to 15 per cent of the car weight, are mounted under the floor of the body either sides from the car axis for $1 / 4$ of its length. The container with the load or equipment is fixed under the car on supporting structural elements using the oscillation dampers, which serve for shock absorbing and protecting the container from damages. The mathematical model of the car body and damping system is presented. 


\subsection{Central Suspension}

Work [40] proposes the improvement of central spring suspension of standard USA railroads eight-wheel car. On side longitudinal bolster 1 of four-wheel bogie (Figure 1.1) related to the axis 2, there is a depression with vertical facing stop surfaces 3 and 4, which limit the longitudinal movement of bogie bolster and are used for fixing the stop plates 5 with friction shoes 6 . They are fixed with screw elements installed in through openings 7 . Longitudinal forces are accepted by working surfaces 8 of the said shoes 6 , which are mounted on main plates 5 with welded joints 9 . The springs of such central suspension are supported by bottom platform of side bolster 1 where prismatic stop fixtures are provided to fix them in position.

The precondition for achieving satisfactory riding performance of vehicles is soft vertical and horizontal springing, maximum possible distinguishing of movements by different degrees of freedom and suppression of own frequency oscillation [41].

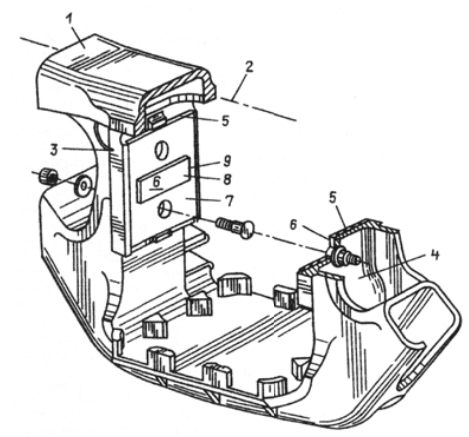

Figure 1.1. Piece of side frame of freight car four-wheel bogie

Application of pneumatic springs, which are relatively expensive, is reasonable at high speeds only in vehicles with high ratio of gross weight to tare. In addition, due to structural considerations in case of failure, there should be duplicate pneumatic suspension. Application of pneumatic springs in the second stage of suspension is interesting in perspective of rolling stock weight reduction that is evidenced by its utilization in intermediate 33 ton cars of high-speed $(200 \mathrm{~km} / \mathrm{h})$ diesel train HST (Great Britain). Among motorcars operated at high speeds, pneumatic springs are used in high-speed electric trains of Shinkansen railway service (Japan) and ART. At the same time French high-speed electric train TGV has no springs.

Flexicoil type springs in suspension system used in French bogie Y-32 and Italian Fiat significantly simplify the structure though the movements in various degrees of freedom are limited [41]. Nevertheless, these springs are, in some sense (depending on their relative thickness), deficient because their stiffness in horizontal and radial directions drops while their vertical and axial efforts grow. In addi- 
tion, big stresses occur at radial shift in these springs. However, thanks to their technical simplicity Flexicoil springs application will increase.

There is a bogie with combined first and second suspension stages. The springs are supported immediately by thrust bearings (Figure 1.2) [41]. As a result, the bogie frame is not exposed to significant vertical forces and may be made of lighter materials. In addition, such structure is better because the number of degree of freedom of oscillation system is less. The calculations show the bogie has improved characteristics in vertical and transversal planes, ensures stable vehicle motion increasing its critical speed. However, apparently, because of higher cost, the field of application of a bogie with combined suspension system will be limited by high speeds of motion only.

Figure 1.2. Suspension system of high-speed bogie resting immediately on the wheelset axis

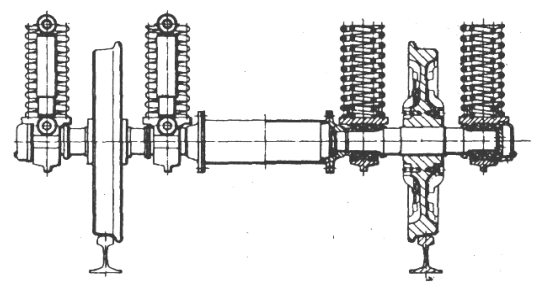

Structural and riding characteristics of bogies for non-articulated cars operated at speeds of $200 \mathrm{~km} / \mathrm{h}$ in Western Europe [41] are also of certain interest.

In claim [42] the description is given for a secondary stage of spring suspension of motor bogie, which is proposed to be located transversal to the car body in pairs. Pneumatic or hydraulic spring suspension may also be used. The springs are located angularly to vertical plane. When the body turns, centrifugal force compresses one spring and opposite moment occurs relative to longitudinal body proceeding to turn it around its longitudinal axis. Because the springs are stopped in the direction of the central vertical plane of the body, four-bar linkage is created that decreases the angle body turning around its longitudinal axis. The rubber buffer (a cross stop) located between the body protrusion and the bogie frame extension takes in the transversal forces, which occur under the action of centrifugal acceleration in a curved track. So, in the beginning, the body has certain free transversal movement until the cross stop is activated damping the transversal movements of the body in relation to the bogie.

Claim [43] proposes transversal car body springing to increase the motion safety and smoothness. Two hydraulic servo cylinders, which work in antiphase, are located between the body and the bogie. The oil feeds these cylinders from one shared master cylinder. The pipelines to the master cylinder connect the servo cylinders of hydromechanics or hydro-pneumatics actuators, which are destined for lifting the car body over the bogie. Thus, the body oscillation amplitude is reduced and the danger of the body contact with the edge of passenger boarding platforms is removed. Respectively, the master cylinder can be adjusted so as to change the car oscillation character and to increase the comfort level during the journey. 
Transversal body springing system reacts fast enough to rapid changes of the car motion character and continuously adjusts the motion in a wide range. Cross cylinders are located so that the total force generated at their operation centers the body along the vertical plane. The master cylinder is adjusted depending on the signals of control and regulation systems monitoring the car oscillation character changes. Working chambers of servo cylinders are connected with the working chambers of the master cylinder thought the pipelines. Oil pressure in accumulating springing member may be varied by changing the volume of the working chambers of the servo cylinder, of the feeding pipelines, of the accumulating springing element, and of the working chambers of the master cylinder. Threaded piston rod at the end of master cylinder is coupled with the drive wheel of electromechanical actuator activated by signals from control and regulating systems. A hydraulic accumulator is connected to one of the working chambers to reduce the interchangeable power of the master cylinder piston.

ABB Transportation Ltd. company (Great Britain) developed the passenger car body transverse oscillation limiter (Figure 1.3) with hydraulic accumulating dampers 1 and 2 provided with cushions 3 and 4 of hard rubber [44]. These dampers are mounted on rack 5 firmly fixed at body frame 6 . Body central suspension system is made basing on pneumatic springs 7 and 8 resting on the side bogie bolsters 9 and 10 . Dampers 1 and 2 interact with the same bolsters. The position of dampers 1 and 2 limiting the body transversal shifts relative to working surfaces 11 and 12 of side bolsters 9 and 10 is illustrated in the lower part of the Figure (plane view). This limiter was tested in MkIII type cars of London-Sheffield high-speed train and demonstrated good characteristics on a curved track. There are plans on widening the range of this limiter application taking into account the prospected speed increase at British passenger railways.

Pneumatic spring mounted in the central suspension system of a passenger car proposed in claim [45] ensures damping the vertical oscillations and reducing dynamic action of a car on a track. Because of the possibility of pneumatic spring stiffness adjustment, the car dynamic characteristics are significantly improved, especially at a high speed of motion or on uneven track sections, and dynamic action on a track are reduced in vertical and transversal directions. The proposed spring is small sized and may be mounted in central suspension systems of existing passenger cars and in motor cars and trailer cars of electric trains.

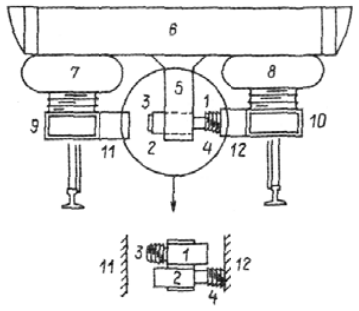

Figure 1.3. Car transversal oscillation limiter 


\subsection{Axle-Box Suspension}

Patent [46] describes an elastic vertical side bogie bearing with metal friction surfaces ensuring greater values of resistance to angle bogie movements. As a result, side stability of a freight car at higher speed is increased, i. e. the higher threshold of angle movements of bogies with bevel wheels becomes possible. In addition, the operating conditions for side bearings and their couplings and fixtures are improved. Upper parts of metal friction structures with elongated oblique geometry are coupled with elastic columns and are attached to the foot or casing end of side bearing.

There are three main areas of application of the elastomers in rolling stock [47]. First, these are the resilient members for suspension systems where rubber or metal-rubber blocks may replace such conventional resilient members as springs. As a result, significant rolling stock dynamics improvement may be achieved, especially in transversal and vertical planes. The second area is the replacement of friction units in hinges, slippers and other members that have relatively small linear or angular movements. As an example, Figure 1.4 illustrates an improvement option for typical passenger car box with roller bearings 1 and 2 . Rubber ring 5 that limits the transversal axis movements is mounted on cone extension 3 under box housing 4 .

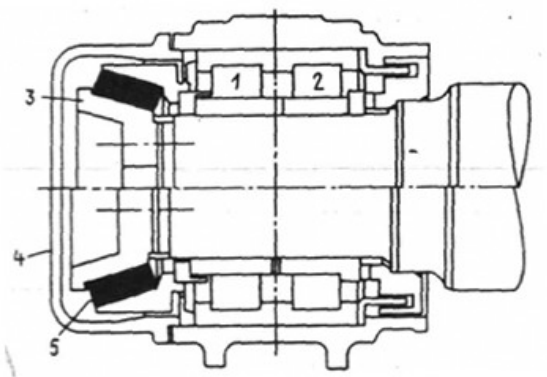

Figure 1.4. Side swaying resilient damper

The mentioned area includes various applications of rubber in links, suspensions, and hinged connection rods. The third area covers sealing and noiseattenuating pads in various rolling stock units - compressors, braking cylinders, flange couplings of pneumatic and hydraulic drives. In addition, such rubber members as rubber pads, mats, and plates are now widely used in German railways for damping freight platforms thus providing for the body floor integrity.

Article [48] describes radically new structure of damping blocks and rubber dampers, which helps to realize non-linear stiffening characteristic. With usual operating load, it is located in optimal for car dynamics zone. When the link load increases, its stiffness rapidly grows preventing from over-limit movements of bogie bolster. Another advantage is attributed to the ability to dampen the resonance loads, which becomes possible due to the non-linearity of stiffening characteristic. 
The mechanism of this phenomenon is actuated in resonance mode when the link load starts to grow rapidly leading to alteration of stiffening characteristic of the link. Undamped frequency of the oscillation system comprising the link is also increased and becomes different from the frequency of external actuating force, thus preventing from oscillation amplitude growth. This is effective only if the undamped frequency of small oscillations of the system with the link is higher than the frequency range of external actuating forces.

Railway transport operation experience shows the necessity of creation of universal standardized elastic suspensions with adjustable stiffness when assembled and at operation. The structures discussed in article [49] have approximately equal characteristics. The choice of particular scheme is determined mainly by existing set options.

The authors of patent [50] propose to improve the box unit equipped with rubber-metal members (RMM) providing for radial self-adjustment of wheelsets axes in curves. In such bogies, RMM bearing mounted on the upper cylindrical surface of the box has minimum clearance $(0.76 \mathrm{~mm})$ in longitudinal direction with upper stops of pedestal guides. Clearance size is chosen basing on the conditions of radial mount of a wheelset in $230 \mathrm{~m}$ radius curve. When choosing the conditions of radial mount of a wheelset, actual size of pedestal gap and box casing are considered. The presence of clearances in longitudinal direction between the box and the pedestal in horizontal plane passing through the axis center is also important. These clearances are monitored when installing the wheelsets on tangent track using a gauge inserted between special pedestal bushes and the box casing. Rectangular bushes are welded to internal surfaces of the pedestal and may be composed of several flat steel pads. The clearance size should be not less than $0.89 \mathrm{~mm}$.

Patent [51] gives the description of a typical hinged box (Figure 1.5) enhanced by way of its deformation stability increase in transversal direction, in particular when the train is moving in the curved track. For this, in addition to main hinge $7 a$ with resilient bush $8^{\prime}$ fixed on a bogie frame 12 , box 3 together with bearings 1 and 2 is fixed at the other end of longitudinal bogie frame bolster 12 using additional hinge 10 and connection rod 11 . The suspension resilience is ensured by spring 6 , which is mounted between frame 12 and hinge arm $3^{\prime}$ thus allowing for vertical shifts of frame 12 in relation to wheelset 13 . Several options of utilization of resilient members in working units of axle-box suspension are considered to achieve the required dynamic characteristics of elasticity and oscillation absorption.

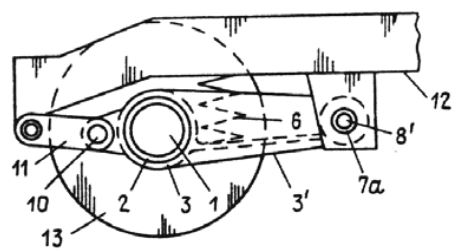

Figure 1.5. Improved hinged box 
In primary suspension by claim [52], leaf spring, which central support is hingedly coupled with the brake flange mounted on the wheelset axis, is used. One end of such leaf spring is joined with the bogie frame and the other end - with the vertical load regulator shaft. Lever box has an arm, to which hydraulic damper shaft is attached and which housing is connected with the vertical load regulator shaft. With such arrangement, the bidirectional hydraulic damper performs additional function of preliminary loader of the leaf spring and the spring serves as a reaction bar accepting longitudinal compression or extension force at braking depending on the direction of motion. Vertical load regulator is located at an acute angle to the leaf spring, thus providing for reduction of compression in spring leaves under longitudinal force action at braking.

Patent [53] proposes side bearing for a four-wheel freight bogie with separate side frames. Side supports are mounted in openings at the ends of the bogie bolster. Spherical surface of the housing having a radius of $380 \mathrm{~mm}$ is coated with Teflon and is joined with cylindrical guide of the bogie bolster opening. Vertical load from the body is transferred to two flat steel slippers. The latter are made in form of cylinders with $100 \mathrm{~mm}$ base diameter and come into blind guiding openings of the bearing, at the bottom of which disk springs are mounted. The gaps between the support housing and the bogie bolster opening walls in transversal direction make $10 \mathrm{~mm}$ each. The support friction pairs are chosen so that to provide for friction factor of 0.05 to 0.07 in support and bogie bolster junction and for friction factor of 0.35 in body and slipper junction when bogie frame moves along the body. Proposed support ensures the effective absorption of oscillations at empty car bogie nosing motion.

Work [54] proposes resilient side bearing for four-wheel freight bogie with separate side frames (Figure 1.6). Support comprises housing 28, two elastomeric blocks 32 , push slipper 50 and stop 30 . The housing is the steel molding in a form of hollow parallelepiped, which base 34 is fixed to bogie bolster with rivets 45 . Elastomeric blocks are mounted inside the housing and accept vertical load from the car body through inclined surfaces 44 of the push slipper. The elstomeric blocks structure is chosen subject to provision of optimal stiffening characteristics in vertical, lateral and longitudinal directions and fast heat removal from the slipper. The block is formed by elastomer with constant modulus of elasticity of 50 to $140 \mathrm{MPa}$ or with varied modulus along the bolster height. The stop mounted on the cylindrical base of the housing between the elastomeric blocks limits their deformation under maximum vertical load. For operation, various structural options of side bearing members are available.

Basing on invariance principle it is possible both to modernize box stage spring suspension of some engine types and to develop new mechanism for vehicles with third class frame bearing drive (in compliance with the classification by Professor Biryukov I. V. [55]) characterized by high dynamic qualities of spring suspension [56]. 


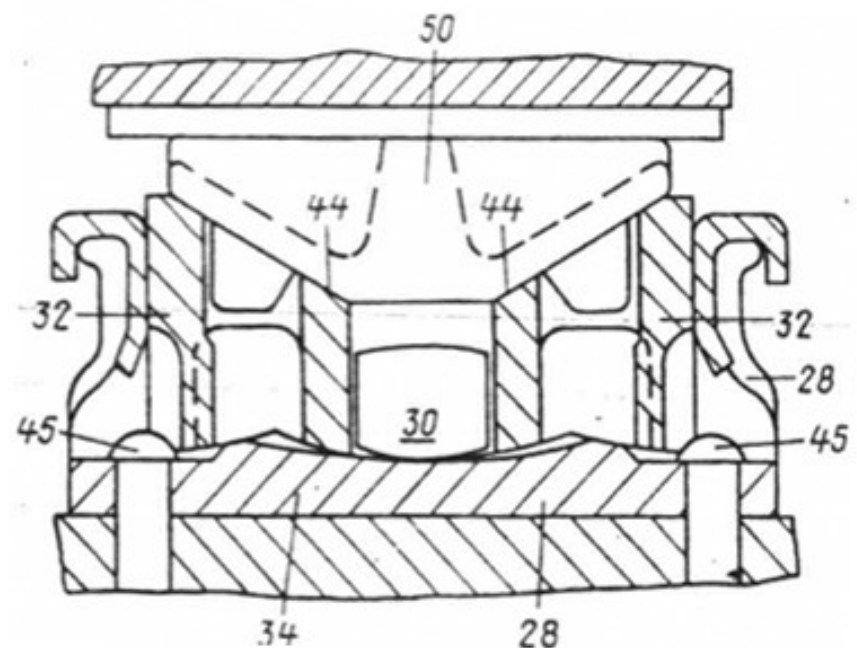

Figure 1.6. Resilient side bearing for four-wheel freight bogie

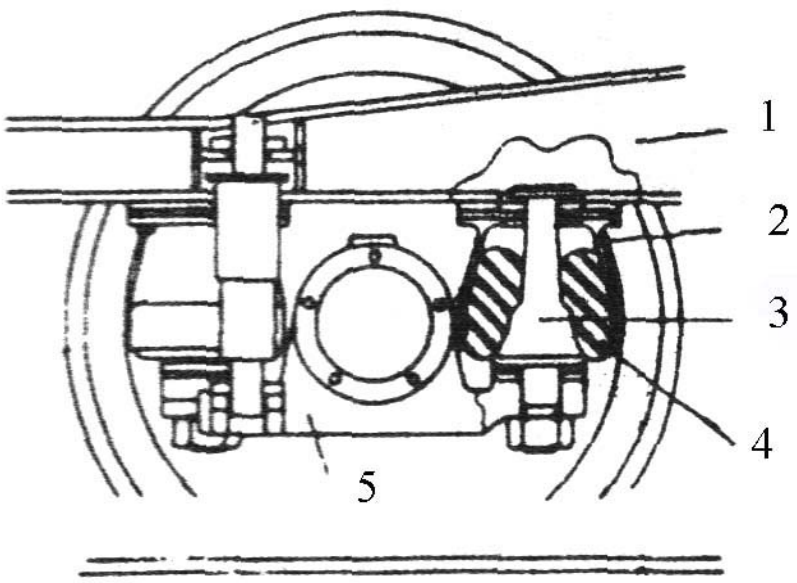

Figure 1.7. Axle-box suspension with Clouth rubber bell-shape springs 
Axle-box suspension with Clouth rubber bell-shape springs (Figure 1.7) developed by British Railways (BR) [57] was used in Series 60 freight diesel locomotive. When compared with conventional pedestal guides, this structure ensured significant economic effect at maintenance, as it did not require periodic friction unit lubrication. By calculation, the suspension stiffening characteristics in vertical and horizontal directions should have been equal. However, during operation, it was found that at certain vertical deflection of rubber springs 4 their stiffness in horizontal direction was 50 per cent less than required. In addition, rubber springs shrank gradually so no stable vertical geometry of a spring set was achieved.

After several consultations with Brush company BR has developed wound spring axle-box suspension (Figure 1.8). Here vertical deflection was provided for by way of springs 4 deformation, and rubber ring 3 installed between cylindrical guides 2 of bogie frame 1 and box tail 5 accepted the efforts acting in horizontal plane. This type of suspension was used in BP20 bogies of Series 317 and 455 electric locomotives and in CP1 and CP3 bogies of Series 56 and 58 diesel locomotives. However, there also were some remarks as for this structure when operated. To provide for small radius curved track passage at coal storage approaches the box stage stroke in Series 60 diesel locomotive was quite big. This resulted in additional stresses in rubber ring under skew-symmetrical loading and fast ring wear.

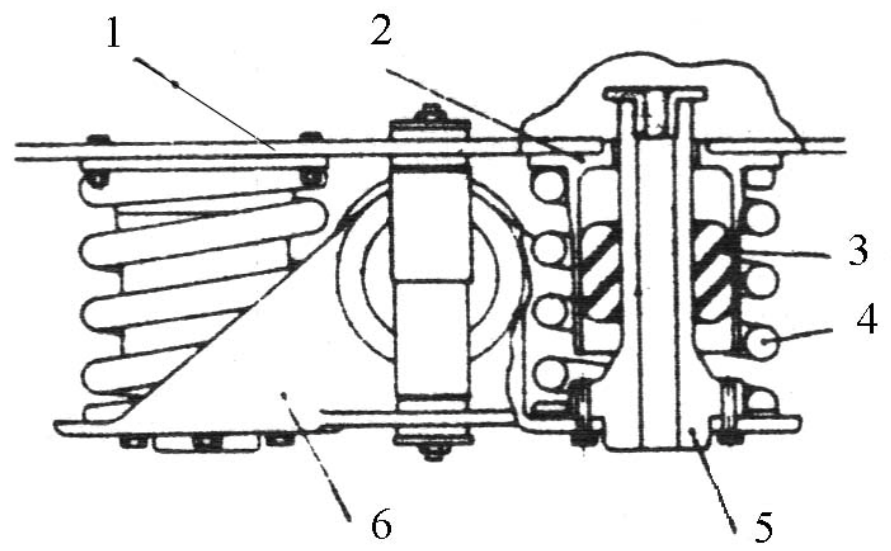

Figure 1.8. Wound spring axle-box suspension

Then, suspension structure was developed where rubber ring 4 was installed between the box guide and special bushing (Figure 1.9). With vertical deflection of springs, tail 3 moves in a guide bushing 6 and this movement results in no additional load to the rubber ring. To improve the wear resistance, the internal surface of the bushing is coated with phosphoric bronze and during operation is constantly lubricated with oil from the bushing bath. 


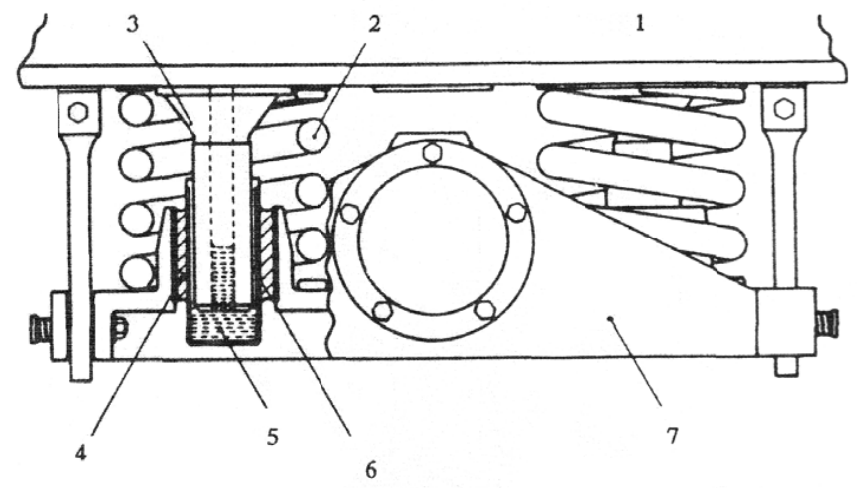

Figure 1.9. Modernized Brush axle-box suspension

This structure showed good results when tested, and presently Brush company mounts this suspension when modernizing diesel locomotives.

Claim [58] proposes car bogie axle-box suspension system with friction oscillation damper. Vertical load from the upper flange of side bogie frame bolster is transferred through the resilient member fixed in an opening to the tubular member and then through double-row springs of axle-box suspension to the bearing surface of the axle-box housing lug. Presence of the bearing surface in the tubular member creates the horizontal force component directed towards the wheel. This force generates friction forces between the tubular member vertical surface and bogie frame vertical wall and damps the oscillations of resilient member. Opposite reactive force pushes the bogie frame wall to the box housing and thus provides for the frame oscillation damping.

The disadvantage of guide links connecting the box with the engine or car bogie frame and used for transferring the traction-braking forces is in their stiffness explained by the short length of the link body. To avoid this, claim [59] offers to make the link body artificially longer. Such link almost does not limit the reciprocal vertical movements of the box and bogie frame but in longitudinal direction, i. e. when transferring traction-braking forces, it ensures the required elastic coefficient. Several options of link structure are considered including the option with longitudinal movements limiting under extension and compression. 


\subsection{Oscillation Dampers}

Analysis of structural characteristics of oscillation dampers in freight cars and their classification by various parameters are given in work [60]. Here we will just note that, in general, the developers of hydraulic oscillation dampers concentrate first of all, on their capability to change characteristics depending on the amplitude and frequency of car oscillations. Applications of new technical solutions contribute to the oscillation dampers characteristics improvement.

Report [61] describes hydraulic damper with plate valves, which have increased durability and controllability.

Patent [62] offers friction oscillation damper. The wedge member of the damper together with independent spring is located in a bogie bolster seat. Friction forces, which are proportional to the movements, occur at relative motion of the wedge member friction surface along the friction bar fixed on a side bogie frame column. Bogie bolster bears against the inclined surface of the wedge member through resilient elastomer cushion. The latter has variable thickness that gradually increases from the upper edge to the lower edge. The cushion is installed in a depression, which bottom diverges from the inclined wedge member surface to an angle of $1^{\circ}$ to $4^{\circ}$. Proposed improvement ensures uniform pressure of the wedge member to the friction bar thus decreasing its wear during operation. There are several options for elastomer cushion fixing on the inclined surface of the wedge member.

Improvement of operational qualities of the friction unit is reached in invention [63] by speed of actuation and various smoothness of frictional interaction depending on a rotation direction. The unit includes a housing, a shaft mounted so that it can be rotated relative to the housing, pressure plates spring-loaded one against the other and relationally rotating and moving along the axis. Friction members are installed so that they are coupled at least with one of the pressure plates, with the shaft and the housing. Linear drive connected with the housing is completed with mounted (capable of the linear movement against the housing) pressure member. The mechanism of linear movement transformation to rotation movement is connected with the pressure member of the linear drive and with one of the pressure plates; the second pressure plate is prevented from turning relative to the shaft. Transformation mechanism is coupled with the shaft and is made in form of selfreleasing screw pair elements, one of which is fixed relative to the shaft turn and the other - relative to the first pressure plate.

Patent [64] proposes oscillation damper applicable, mainly, for a rotary crane on rails and a flat car for heavy cargo; the damper is made in two options -with either extending or compressing connection rod. In such damper, the damping force depends on the running gear oscillation amplitude.

With tension connection rod, compression spring 4 with top support washers 23 and 5 is located between equalizer 3 and car frame 1 (Figure 1.10). On top of the support washer 5 , there is cam flange 6 located at a distance of $+a$ from the center of lever 7 with one or several holes. Tension rod 10 is connected with lever 7 by 
roller 9; through the rod, forces generated by spring 4 compression are transferred to friction bars 12 and 13 located in wheelset 11 plane. Friction bar 12 through stop 14 and guide 15 is fixed in the direction of the force and friction bar 13 is held only by guide 15 and moves in the direction of force. Resilient clamp 17 fixed on the wheelset box housing 16 is located between friction bars 12 and 13. To increase wear resistance, clamp 17 is completed with friction pieces. Friction bars 12 and 13 have openings 22 for tension connection rod 10 and clamp 17 has extended opening 19. The oscillation damper is mounted when the car is in neutral position by straining tension rod 10 using nut 21 rotated on a treaded part 20 of rod 10 until specified gap between car frame 1 and spring 4 plate 5 is achieved. In case with compression rod 25 (Figure 1.11), instead of tension rod 10 on support plate 5 of spring 4 there is cam flange 6 at a distance $-a$ from the center of lever 7 . Compression force is transferred through compressing rod 25 to pusher 24 attached to car frame 1 . Bar 17 with friction pieces 18 is connected to box casing. Damping force of proposed oscillation damper is dependent upon the running gear oscillation amplitude, and distance $c$ is reduced at specified wear of friction bars 12 and 13 due to inclined position of support plate 5 of spring 4 .

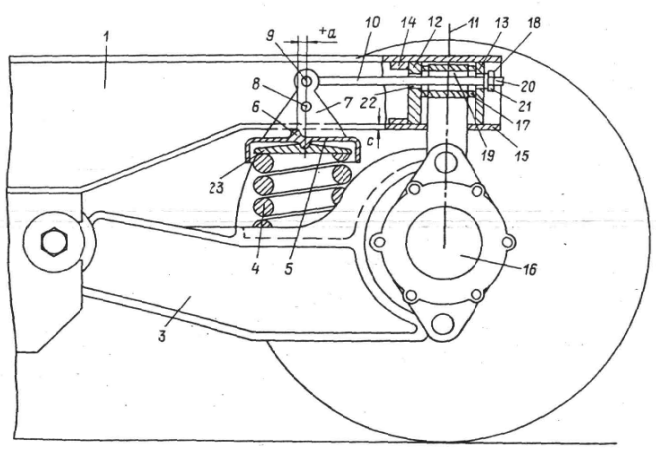

Figure 1.10. Oscillation damper by patent [64]

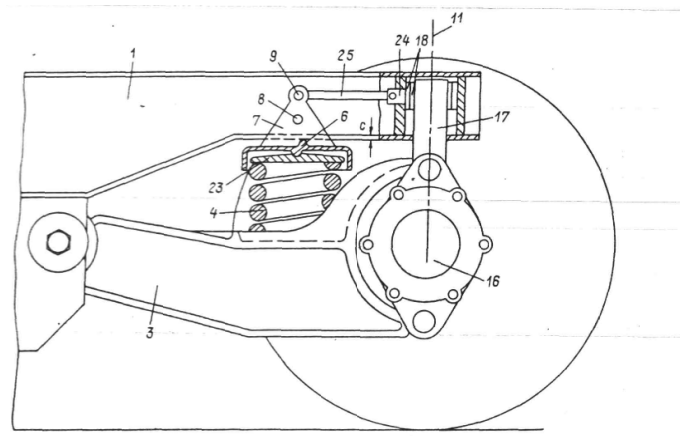

Figure 1.11. Oscillation damper by patent [64] 
Damper proposed in invention [65] comprises the following parts: the housing made of two parallel to its axis and interconnected sections formed by two pairs of L-shaped levers with slots, the spring installed in the housing, one end of which rests in the housing section, the disk to bear the other spring end, and the base. To increase the energy absorption efficiency and to achieve the longer service life the damper is completed with the ring located between the L-shaped levers pairs and interconnected with them. The ring has the guides passing through the levers slots; the guides are diametrically located with equal inclination angles and parallel axes.

The aim of invention [66] is to increase the stiffness and durability by way of making resilient members in form of two packages of plate metal springs. With such packages, it is possible to increase the damper stiffness and durability and to provide for its two-way action.

Patent [67] offers friction oscillation damper with leaf springs and single or double suspension arm. Damping is not dependent on the carload. There is a possibility of additional adjustment of damping leaf stiffness to achieve optimal oscillation damping value.

Frame 6 (Figure 1.12) of a car with axle guards 2 and spring brackets 5 bears against box 11 through double suspension arms 4 and through leaf spring 3. Horizontal oscillation damper consists of resilient leaf 7 (see Figure 1.12, $a, b$ ), which passes through opening 9 with bushing 10 located in the middle section 8 of spring bracket 5 in longitudinal direction. Holder 13 fixes the end of damping leaf 7 , which is tightened with screws 14 during the oscillation damper installation. Inside bushing 10 on holder 13 , there is repositionable flange 15 , which has seat 16 for leaf 7 at holder 13 side end. Distance $a$ for seat 16 from holder 13 is adjusted using flange 15 in compliance with the required damping leaf 7 stiffness. At free end 17 of leaf 7 , there is curved friction surface 18 , which under pressure contacts with central bridge 20 of intermediate element 21 of the leaf spring suspension arm and is located at $90^{\circ}$ angle towards action line 19 of double suspension arm 4 . With single suspension arms, each intermediate bridge of the arm has a central rib that supports damping leaf 7 . Altering distance $a$ between holder 13 and seat 16 additional adjustment of damping leaf 7 stiffness is possible in order to achieve optimal oscillation damping value.

$a$

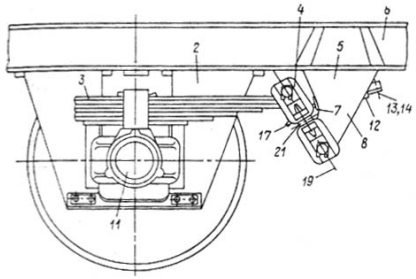

$b$

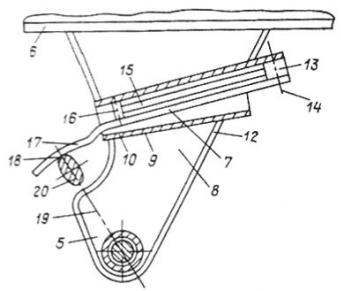

Figure 1.12. Friction oscillation damper by patent [67] 
Authors of patent [68] offer friction oscillation damper for flatcar with vertical friction surfaces. Friction bars wear does not affect the damping ability of the oscillation damper and is defined visually or with a probe by way of support plate position inspection.

Oscillation damper with vertical friction surfaces consists of internal pusher 1 (Figure 1.13 , a) attached by roller 11 on unsprung part of railway vehicle and housing 2 fixed on sprung part with the roller similar to roller 11 . Rollers 11 are located in elastic bushings 12 . Internal member 1 has two support plates 5 with through opening 9 in one of the plates for resilient members 16 , and two support plates 7 with threaded opening 10 in one of the plates. Friction bar 3 is attached to plate 5 . Precompression of resilient members 6 is achieved by adjusting screw 8 passing through slot 13 in housing 2 . Friction bars 3 and 4 wear does not affect the damping ability of the oscillation damper and is defined visually or with a probe by way of inspection support plate 5 positions on support plate 7. Rotation of support plate 5 is prevented from by stop 15 on internal member 1 . Member 1 is guided in transverse direction using slipper 16 in housing 2 .

Oscillation damper with inclined friction surfaces comprises internal pusher 1 and housing 2 (see Figure $1.13, b$ ) attached to unsprung and sprung parts through rollers 11 and bushings 12 , respectively. There is elongated opening 17 for roller 18 on internal member 1 . On housing 2 there are surfaces inclined towards one another, which friction bar 4 and support plate 5 with friction bar 3 and support plate 7 are attached to; between the plates there are resilient members 6 , which precompression is changed with clipping screw 8 . In housing 2 there are slot 19 for assessment of friction bars 3 and 4 wear and inspection opening 20 for watching an internal edges of support plates 5 and 7 . Friction surface wear is determined using graduated bar 21. The value of friction force of the oscillation damper is changed depending on the vehicle body weight. Friction bars and resilient members of the oscillation damper are chosen depending on the required vehicle oscillation damping, which maximum limit is achieved at steel friction bars. The size and the number of friction surfaces are chosen in view of minimizing the friction surfaces wear. The oscillation damper proposed in invention [69] includes wedge member consisting of two parts. First part is made in form of trihedral prisms, at least two, firmly fixed with the same angles so that their bases produce inclined surface contacting with bogie bolster. The other two facets at each prism vertex surfaces contact (through resilient cushion) with the second part of the wedge member surface, which relief has the form of the matrix of first part of the wedge member. Vertical surface of the second part of the wedge member contacts with the surface of friction slat and horizontal surface is borne against the suspension springs. The slat is coupled with the side frame. When the vehicle is moving sprung bogie part (bogie bolster) is oscillating relative to unsprung part (side frame). When the force provoking oscillation grows above the static friction force at friction surfaces of the wedge member and friction slat and when oscillation amplitude exceeds the resilient cushion deformation, the friction between the wedge member vertical surface and friction slat surface starts to work resulting in the oscillation damping. 
a)

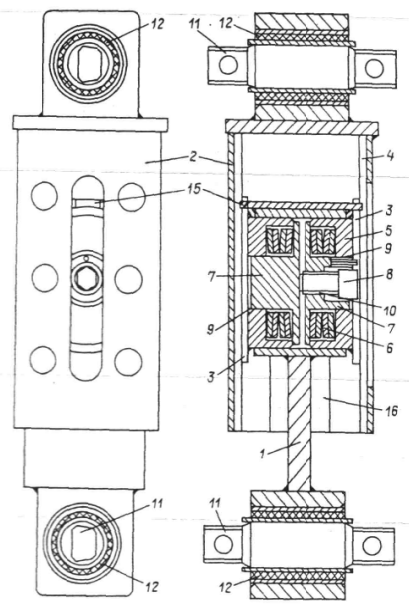

b)

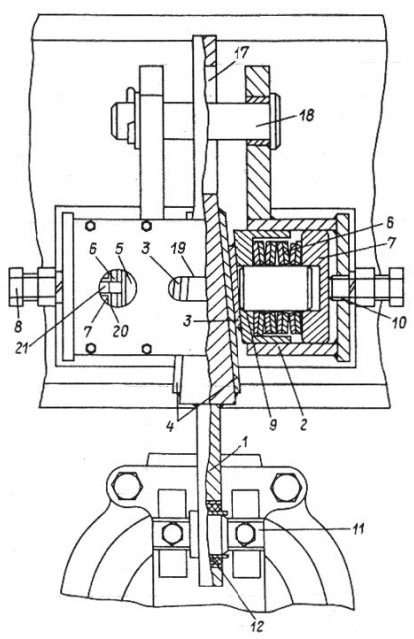

Figure 1.13. Friction oscillation damper for a flat car by patent [68]

Calculations given in report [70] showed that introduction of oscillation dampers with optimal parameters improved dynamic behavior of model ЧМЭ-3 (ChME-3) diesel locomotive, the bogie vertical dynamics coefficient not exceeding the permissible value of 0.3 in the whole range of the vehicle motion speed.

The unit proposed in author's certificate [71] transfers the load from a bogie bolster through a cushion and a pressure cone to adjustable wedges. At spring suspension deformation, these wedges move inside the tubular member and therefore friction forces develop between contacting cylindrical surfaces. With empty car, when deformation is small, the wedges movement relative to tubular member walls occurs in its upper part. The friction force is proportional to the spring contraction value. With loaded car, when deformation is increased, the wedges move into the lower part of the tubular member closer to the magnet. As the overlap of wedges and magnet increases, the force, pressing the adjustable wedges to the tubular member walls, rapidly grows under the action of the magnets attracting force, so the friction force rapidly grows, too. Thus, the introduction of magnets provides for achievement of required behavior both with loaded and empty cars.

The authors of patent [72] offer improvement of friction damper wedge member providing for thickening of the part of vertical wedge wall, which suffers from the heaviest wear at interactions with side frame columns shoes. In standard wedge members with two inclined surfaces, maximum wear is observed in the lower part of the wall. To increase the service life of such wedge member the lower part of the wall is gradually thickened due to the inclination of the wall internal surface with smooth radius of junction with base plate of the wedge member. 
Friction oscillation damper proposed in [73] contributes to improvement of dynamic behavior of a freight car. Vertical movements are transferred to the axle brass through spherical wedge member flange, spherical indentation, and carriers. Thanks to such structure, contact efforts between replaceable axle brass and a patch piece are evenly distributed providing for uniform wear of the whole working surface thus contributing to faultless operation of the absorber.

Patent [74] proposes several dampers options applicable mainly for damping vertical oscillations and mounted in an automatic coupler. As a resilient member, components of modern elastomers including rubber and plastics with desired elastic behavior of stress-strain, shear, or bending are used. As an example, Figure 1.14 illustrates the damper comprising steel rod 138 with support foot 128 . Thin wall steel cylinders 150 and 154 are put on this rod; cylinder 154 has support end 158 , and bent ends 152 and 156 couple both cylinders. Resilient members 146 of circular form are vulcanized to external surfaces of these cylinders; the members are precompressed with tightness by washer 160 attached to cylinder 150 with weld joint 166 so that damping unit has the form of set 148 of resilient members compressed between end washers 160 and 158 . When compressed, the diameter of external surfaces 144 and 168 increases, and internal cavities 170 volume decreases. The required stiffness parameters are achieved by changing the number of elastomer rings 146 or their sizes, and by the level of precompression.

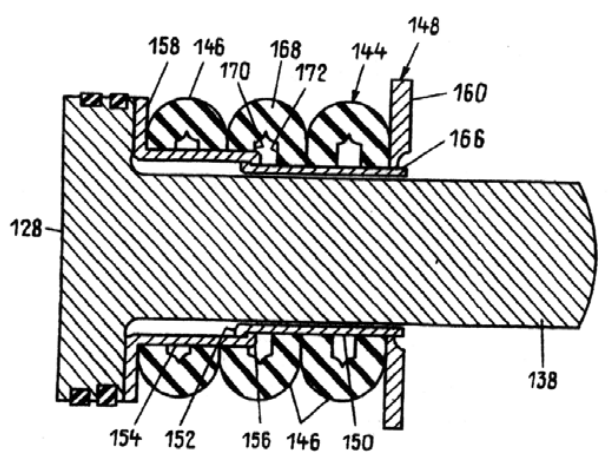

Figure 1.14. Absorber by patent [74] 


\subsection{Shock Absorbers}

Shock absorbers are used to protect both the car structure and the cargo: automatic coupler absorbing units, buffer shock absorbers, shock absorbers in cars with movable center sill, and moving deck shock absorbers [75].

Along with end draft gears, additional specialized central type damping units are used in several types of railway vehicles, functioning as carriers of highly sensitive to longitudinal shock loads cargos and in cars with movable center sill [75].

Most rolling stock in the former USSR countries is equipped with hexagon type spring-friction draft gears. These units group includes Sh-1-TM (Ш-1-TM) gears (Figure 1.15, a) installed in eight-wheel freight cars built before 1979. Starting from 1979 the mentioned cars have been mostly equipped with Sh-2-V (Ш-2-B) gears (Figure 1.15, б). For sixteen-wheel cars and sixteen-wheel diesel locomotives similar structure type Sh-2-T (Ш-2-T) gears (Figure 1.15, в) are used; these gears differ from Sh-1-TM (Ш-1-TM) and Sh-2-V (Ш-2-B) gears in size. It should be mentioned that parts of listed above gears are not interchangeable.

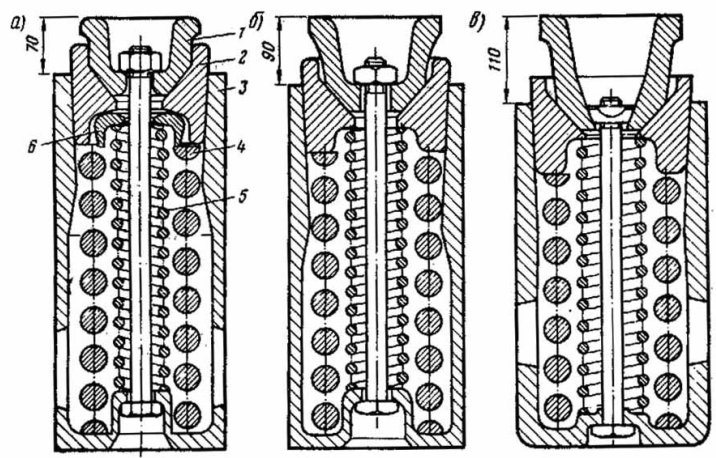

Figure 1.15. Hexagon type spring-friction draft gears Sh-1-TM (Ш-1-TM) (a), Sh-2-V (Ш-2-B) (б), Sh-2-T (Ш-2-T) (в)

Hexagon type spring-friction draft gears have housing 3 with hexagon throat where pressure cone 1 and three wedge members 2 are located. Between the wedge members and the bottom of gear housing 3 , there are bearing set springs 4 and 5 . In Sh-1-TM (Ш-1-TM) gear, there is washer 6, but this washer is not used in Sh-2-V (Ш-2-B) and Sh-2-T (Ш-2-T) gears therefore the spring height is increase.

Most $(75 \ldots 90 \%)$ of kinetic energy of colliding cars accepted by this type units is transformed generally into thermal energy of friction interaction of friction unit parts and partially into potential energy of springs 4 and 5 compression.

Draft gear Sh-1-TM (Ш-1-TM) (see Figure 1.15, a) has maximum working stroke of $70 \mathrm{~mm}$ and installation dimensions of $230 \times 318 \times 568 \mathrm{~mm}$. The gear energy capacity as delivered (with unrun surfaces) is about $25 \mathrm{~kJ}$. The energy capacity 
of the gear with run-in surfaces after one to two years of operation makes $50 \mathrm{~kJ}$ under longitudinal force of $2.5 \ldots 3 \mathrm{MN}$, which is enough for collisions of freight cars with gross weight of 84 tons, moving before collision at a rate of 2.22 $\mathrm{m} / \mathrm{sec}$.From the functional dependence of impact force quantity on the rate of collision, it can be seen that the run draft gears closes when the collision of cars occurs with a rate over $2.5 \mathrm{~m} / \mathrm{sec}$ (Figure 1.16). Closing of the gears after full usage of their working stroke leads to transfer of significant longitudinal dynamic action on the car structure and the cargo thus presenting the risk of their damaging.

Draft gear Sh-2-V (Ш-2-B) (see Figure 1.15, б) has installation dimension of $230 \times 318 \times 568 \mathrm{~mm}$ and maximum working stroke of $90 \mathrm{~mm}$. The gear energy capacity as delivered is about $25 \mathrm{~kJ}$ and the energy capacity of the gear with run-in surfaces makes $60 \mathrm{~kJ}$ under longitudinal force of $2 \mathrm{MN}$. Collisions of freight cars with gross weight of 85 tons equipped with these gears showed that a longitudinal the of $2 \mathrm{MN}$ corresponded to collision rate of $2.78 \mathrm{~m} / \mathrm{sec}$. (see Figure 1.16). Sh-2-V (Ш-2-B) gear closing occurs at car rates over $3.06 \mathrm{M} / \mathrm{sec}$.

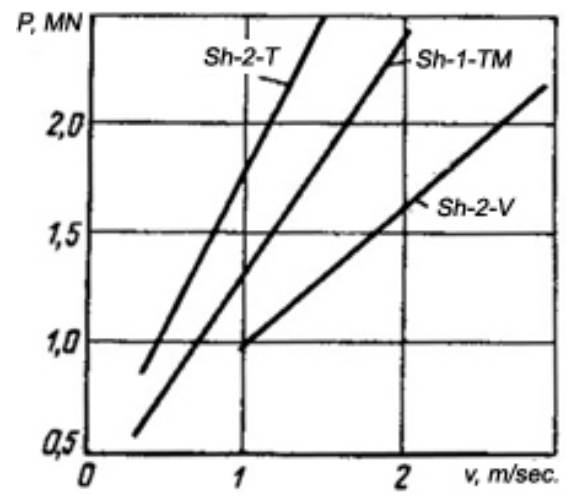

Figure 1.16. Quantities of impact force of Sh-1-TM (Ш-1-TM), Sh-2-V (Ш-2-B), and Sh-2-T (Ш-2-T) gears as a function of cars collision rate

Unrun Sh-2-T (Ш-2-T) type gears have energy capacity of about $30 \mathrm{~kJ}$. After running-in, the gears energy capacity reaches $65 \mathrm{~kJ}$ providing for collisions of sixteen-wheel cars with gross weight of 172 tons moving at a rate of up to $1.83 \mathrm{~m} / \mathrm{sec}$. under longitudinal force $P=2.5 \mathrm{MN}$ (see Figure 1.16).

TsNII-N6 (ЦНИИ-Н6) spring friction draft gear (Figure 1.17) comprises serially connected spring and spring friction parts. Spring-friction part consists of hexagon throat 9 , three friction wedge members 10 , pressure cone 11 , washer 1 , external 2 and internal 3 springs.

Spring part includes base 7 , central spring 4 , four big angle springs 8 , four small angle springs 5 , and four stop rods 6 . Springs 8 are similar to spring 3 , and spring 4 is similar to spring 2 . Small angle springs differ from big angle springs 
only by the number of turns. Big angle springs are located in throat recesses and small springs - in base recesses. Rods 6 are located inside angle springs 5 and 8 and divide them with center-thickened part. Both parts of the gear are coupled with bolt 12 and nut 13 .

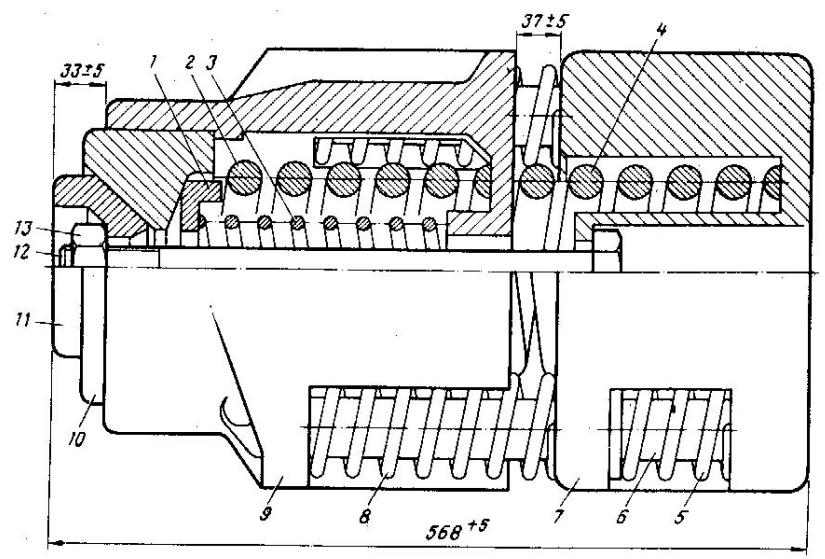

Figure 1.17. TsNII-N6 (ЦНИИ-H6) draft gear

TsNII-N6 (ЦНИИ-Н6) draft gear action is as follows. As a result of load application to the pressure cone or the gear base, the first central spring 4 (see Figure 1.17 ) and four big angle springs 8 are compressed. Then, after throat lugs 9 contact the stop rods 6 , small angle springs 5 are compressed, too. They are compressed for the size of clearance - $(37 \pm 5) \mathrm{mm}$ - between throat 9 and base 7 . At the same time, compression of spring-friction part, which initial resistance force makes about $120 \mathrm{kN}$, commences.

Therefore, due to intermediate stage of simultaneous compression of both parts in force interval of $120 \ldots 280 \mathrm{kN}$, the transfer from spring part operation to springfriction part operation takes place without abrupt unit stiffness increase.

Nominal final resistance force of run-in unit makes 1.5 MN. Actual unit closing force is mostly determined by the working friction surfaces angle of inclination within the limits of production tolerances and by friction coefficient value, which depends on the degree of these surfaces running-in. Presence of friction part also exposes the unit to the risk of seizure.

When load is released, first only spring part is straightened up, then springfriction part.

Force static characteristic (dependence of resistance force $P$ on the stroke $X$ ) of the gear (Figure 1.18) is obtained experimentally by compression in hydraulic press. 


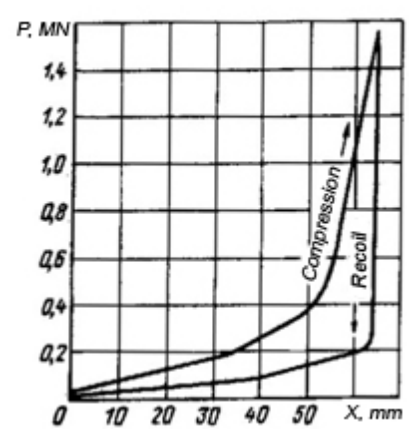

Figure 1.18. Force characteristic of TsNII-N6 (ЦНИИ-H6) gear

Spring part of the gear, which has small resistance at the beginning of compression and quite high resistance at the end, ensures smoothness of passenger train motion in normal operation conditions (frequent effort changes at the moment of starting, adjustment service brake application, etc.). With heavier operation conditions (emergency and full service brake application, occasional power jerks during train motion and car shunting), shock damping is supported by spring-friction part of the gear.

After full gear compression, the force is transferred immediately through the throat and the base without spring involvement as they, just like in Sh-1-TM (Ш-1$\mathrm{TM})$ gear, are not compressed to the turns contact even at unfavorable production tolerances and parts wear.

The unit energy capacity of $15 \ldots 24 \mathrm{~kJ}$ is sufficient for passenger trains consisting of up to 18 cars, but does not suffice the requirements of perspective operation conditions.

Coefficient of irreversible energy absorption is also dependent on actual friction parts working surfaces parameters and equals to $70 \ldots 75$ per cent. The unit weight is $169 \mathrm{~kg}$.

Foreign railways cars are equipped mostly with friction draft gears of various types. However, insufficient energy capacity, specialization by car types and commercial reasons led to creation of a wide variety of structures with different operation principles.

Under technical requirements of American railways, minimum energy capacity of an automatic coupling draft gear when run-in is specified at about $50 \mathrm{~kJ}$ under a longitudinal force of $2.23 \mathrm{MN}$.

Among end draft gears, most common are Miner and Cardwell Westinghouse spring-friction gears.

PMK-110A (ПМК-110A) draft gear (Figure 1.19) belongs to spring-friction type units where metal-ceramic plates are used as friction members in order to enhance the energy capacity and stability characteristics. These type gears are in- 
stalled in refrigerated rolling stock, flat cars for containers, and partially in sixteenwheel cars. Working stroke of PMK-110A (ПМК-110A) draft gear is $110 \mathrm{~mm}$.

Energy capacity of PMK-110A (ПМК-110A) draft gear as delivered is about $35 \mathrm{~kJ}$. Its operation under normal conditions is characterized by faster running-in than that of Sh-2-V (Ш-2-B) draft gear. Energy capacity of PMK-110A (ПMК$110 \mathrm{~A})$ draft gears with run-in surfaces under a longitudinal force of $2 \mathrm{MN}$ is $70 \ldots 85 \mathrm{~kJ}$.

In Russia, new PMКР-110 (ПМКП-110) shock absorber for railway cars is developed. It is based on production version of PMK-110A (ПMК-110A) gear, which support springs are replaced with polymeric elements (Figure 1.20) [76].

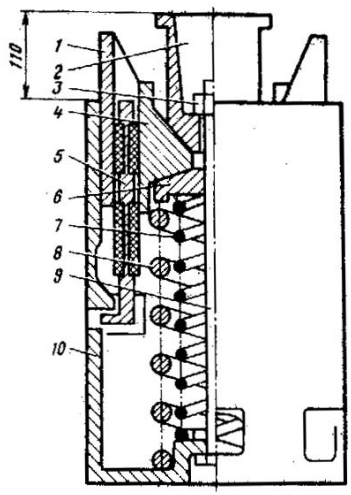

Figure 1.19. PMК-110A (ПМК-110A) spring-friction draft gear with metal-ceramic elements

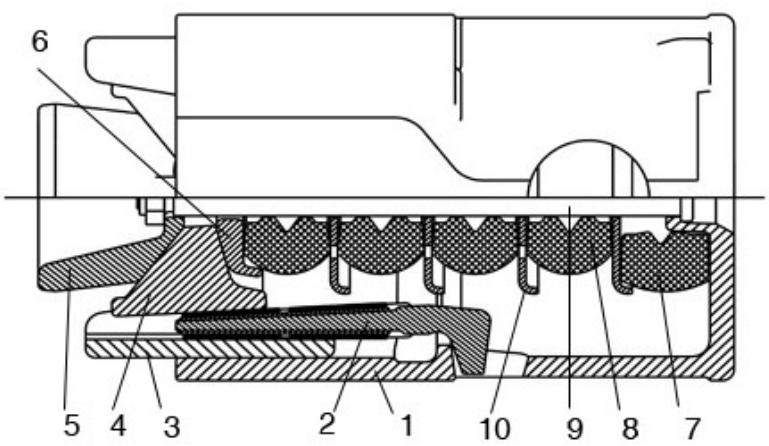

Figure 1.20. РМКР-110 (ПМКП-110) draft gear 
The gear consists of housing 1 where pressure wedge member 5 , friction wedge members 4 contacting with base plate 6 , movable friction pieces 3 , fixed friction pieces 2 with wear-proof metal-ceramic elements are located. The plate bears against the set of five resilient polymeric blocks 7,8 divided with centering bars 10 . The gear is held assembled by coupling bolt with nut 9 and has the structural stroke of $110 \mathrm{~mm}$.

Application of polymeric resilient block increases the fullness and energy capacity of absorber force characteristics. This is achieved due to increased stiffness of support set thus providing for decreasing of adjustment angles of wedge system and, respectively, stabilizing friction at auxiliary surfaces. In addition, polymers damping properties significantly reduce friction self-oscillation accompanying the gear shock compression.

Polymeric blocks are made of polyester thermoelastolayers such as Hytral (the USA), Durel (Germany), and Belast (Belarus) materials. The promising future of these materials is explained by combination of required parameters of flexibility and dissipative properties with high processibility and possibility of elements recovery at the end of their service life. The side surface profile, block internal groove, its depth and form are determined by way of calculations and tests basing on required stiffness and set of blocks pre-tension specifications, and on force characteristic factor and its stability.

Multiple tests allowed for proper choice of PMКР-110 (ПМКП-110) gear geometry providing for class $\mathrm{T} 1$ standards achievement. In comparison with PMKPOA-К23 (ПМК-ПОА-К23) serial units, similar characteristics of ПМКП-110 (PMKP-110) gears have bigger completeness thanks to reduction of friction forces steps intensity at shock compression.

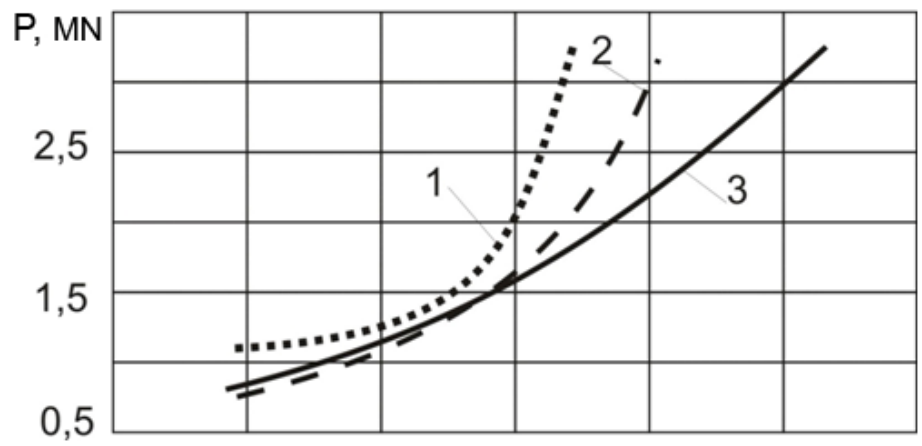

Figure 1.21. Maximum shock force as a function of initial shock rate for different draft gears: 1 - Sh-2-V (Ш-2-B); 2 - PMK-110-К-23 (ПМК-110-К-23); 3 - РМКР-110А-К23 (ПМКП-110А-К23) 
Figure 1.21 shows maximum shock forces relation to initial shock rate for different friction draft gears. Increased energy capacity of polymeric resilient support (over $20 \mathrm{~kJ}$ instead of $12 \mathrm{~kJ}$ for spring set) ensures significant increase of PMКР-110 (ПМКП-110) gear operation efficiency. Standard energy capacity of $70 \mathrm{~kJ}$ is achieved under a force of $1.95 \mathrm{MN}$, standard maximum energy capacity of $90 \mathrm{~kJ}$ is achieved under forces of 2.6...2.8 MN.

Draft gear Sh-6-TO-4 (Ш-6-TO-4) (Figure 1.22) is developed for freight eightwheel rolling stock and belongs to spring-friction type units. It has hexagon scheme of friction unit as in Sh-1-TM (Ш-1-TM) and Sh-2-V (Ш-2-B) gears, but different construction.

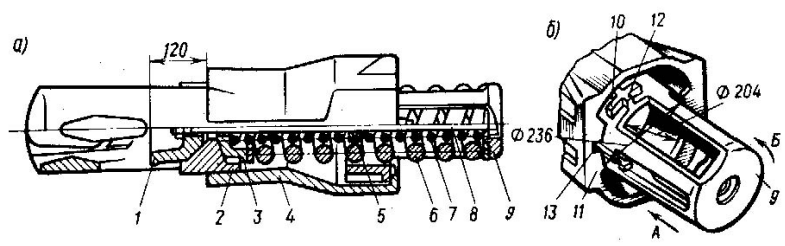

Figure 1.22. Sh-6-TO-4 (Ш-6-TO-4) draft gear

The gear consists of housing 4 (Figure 1.22,a) made as an integral part of traction clamp, removable bottom 9 , pressure cone 1 , friction wedge members 2 , support washer 3 , external spring 6 , internal springs 7 (between which intermediate washer 5 is installed), coupling bolt 3 with a nut. Working stroke makes $120 \mathrm{~mm}$. The gear energy capacity as delivered is about $40 \mathrm{~kJ}$ and after running-in it is $85 \ldots 90 \mathrm{~kJ}$ under a longitudinal force of $2 \mathrm{MN}$.

The relation of the gear compression force $P$ to collision rate $v$ (Figure 1.23) shows that a longitudinal force of $2 \mathrm{MN}$ corresponds to the collision rate of eightwheel gondola cars with gross weight of 88 tons equal to $2.92 \mathrm{~m} / \mathrm{sec}$.

Sh-6-TO-4 (Ш-6-TO-4) draft gear has increased pre-tension, which in a run-in gear makes $400 \ldots 600 \mathrm{kN}$, and this is the reason for a longer running-in period at operation.

Sh-6-TO-4 (Ш-6-TO-4) is interchangeable with Sh-1-TM (Ш-1-TM) and Sh-2V (Ш-2-B) gears by their installation dimensions. However, it should be noted that when mounting this unit on old construction cars the stop requires modernization to provide for the possibility of unrestricted location of the removable bottom between them.

Sh-6-TO-4U (Ш-6-TO-4Y) draft gear (Figure 1.24, $a$ ) is construction option of Sh-6-TO-4U (Ш-6-TO-4Y) gear. In this gear, there isn't the coupling bolt with the nut. Coupling unit of housing 1 with removable bottom 7 using dowels is shown in Figure 1.24, $b$. Sh-6-TO-4U (Ш-6-TO-4Y) draft gear is assembled in the following sequence. Housing 1 is installed vertically, clamp part down. Gear support plate 3 
is mounted on clamp stops 2 . Through the opening in the housing end inside throat 6 cone 4, friction wedges 5 are installed; washer and springs 11 and 12 are put on them. Removable bottom 10 is put on springs so that shoulders 8 are placed behind housing flanges 13 . Then draft gear springs are slightly compressed providing for insertion of dowels 9 into the housing opening until they contact whole length with the bottom cylindrical bridge. After this, the load compressing the support set of the draft gear is removed, and the dowels self-install into the thrust between housing flanges 13 and bottom shoulders 8 .

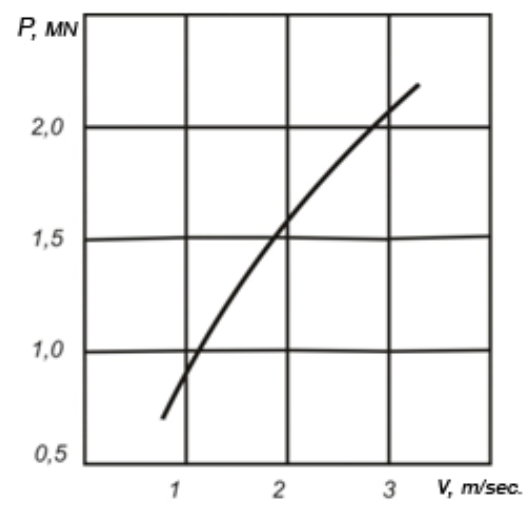

Figure 1.23. Compression force of Sh-6-TO-4 (Ш-6-TO-4) gear as a function of cars collision rate

a)

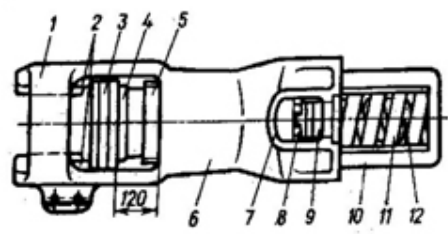

b)

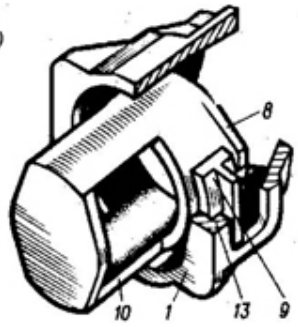

Figure1.24. Sh-6-TO-4U (Ш-6-TO-4Y) draft gear:

$a$ - general view; $b$ - housing and removable bottom coupling unit using dowel as an insert element

PF-4 (ПФ-4) draft gear (Figure 1.25) consists of box section housing 6 where replaceable friction unit interacting through central support plate 7 with support set 
is located. The draft gear housing is made as a solid molding with traction clamp. Friction unit includes wedge 12 bearing against movable wedge members 2 with its inclined surfaces, movable plates 1 installed in longitudinal direction on transversal housing ribs, fixed wedge inserts 5 and side inserts 3 , bumper spring 4 , and central support plate 7 .

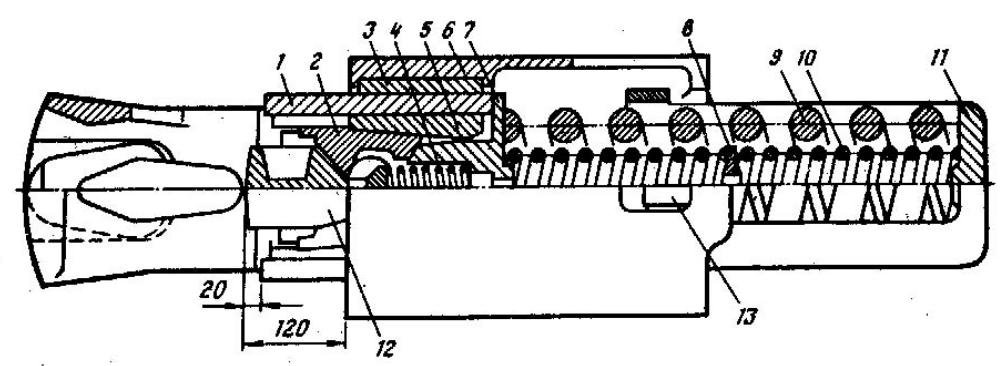

Figure 1.25. PF-4 (ПФ-4) draft gear

Supporting set of the draft gear includes power external springs 9 and internal springs 10 with intermediate washer 8 located in extension 11 , which is mounted in the housing through the opening in the bottom.

The draft gear stroke is $120 \mathrm{~mm}$. The energy capacity as delivered is $60 \ldots 70 \mathrm{~kJ}$ and after running-in $-90 \ldots 100 \mathrm{~kJ}$ under a longitudinal force of $2 \mathrm{MN}$.

PF-4 (ПФ-4) gear operation is characterized by a high rate of running-in and for operational conditions it is estimated by a period of $0.5 \ldots 1$ year.

The relation of PF-4 (ПФ-4) gear compression force $P$ and cars collision rate $v$ (Figure 1.26) shows a longitudinal force of $2 \mathrm{MN}$ matches the collision rate of eight-wheel gondola car weighing $94 \ldots 95$ tons equal to $3.07 \mathrm{~m} / \mathrm{sec}$.

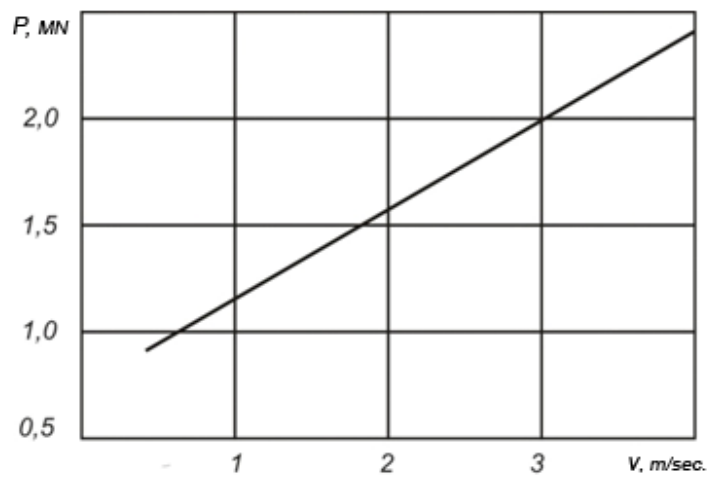

Figure 1.26. PF-4 (ПФ-4) gear compression force as a function of cars collision rate 
The draft gear functions as follows. Under the action of compressive forces from the automatic coupler through the stop plate, wedge 2 shifts the movable wedge members relative to fixed wedge-shaped inserts. In the beginning of the gear compression, plates 1 rest immovable relative to the wedge-shaped and lateral inserts 5 and 3. From the movable wedge members, the force is transferred to the central support plate, which interacts with the power springs when shifted together with the movable wedges. Such kinematics of friction unit parts corresponds to the first gear compression stage and finishes at the moment of contact between the stop plate and movable plates ends. If compression proceeds, the movable plates clutched between the fixed wedge-shaped and lateral inserts start to move. As soon as the movable plates 7 movement begins, the gear resistance force rapidly jumps up. Bumper spring provides for wedge release from movable wedge members with return gear travel after the pushing forces action ceases thus excluding the possibility of the gear wedging during release.

PGF (ПГФ) draft gear (Figure 1.27) belongs to combined type - hydro-friction - gears. It includes both friction and hydraulic units providing for shock energy absorption due to the work of friction interaction forces of friction unit parts with power spring and to the hydraulic booster resistance as a result of working liquid flow from high-pressure chamber to the low pressure chamber of the hydraulic booster.

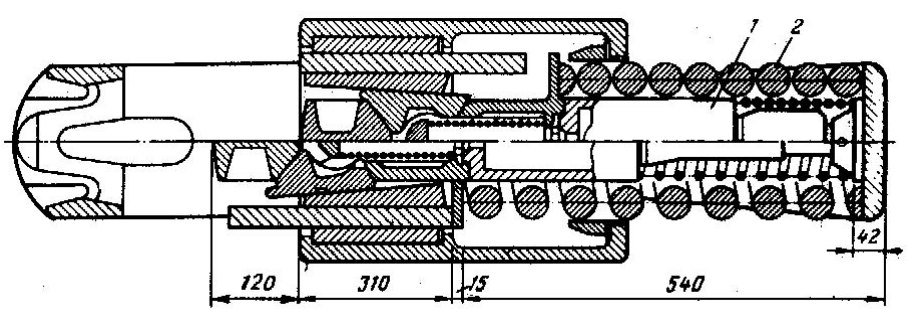

Figure 1.27. PGF-4 (ПГФ-4) draft gear

PGF (ПГФ) gear structure is similar to PF gear structure; the only difference is the availability of hydraulic booster 1 located inside external spring 2 .

PGF (ПГФ) draft gear hydraulic booster (Figure 1.28) belongs to valve type units. Its operation is characterized by automatic resistance adjustment depending on the cars collision rate. The character of the resistance change is determined by two load modes: quasi-static and dynamic.

In quasi-static gear compression mode, simultaneous compression of a hydraulic booster takes place. Hydraulic booster cylinder 2 moves relative to shaft 11 . At the same time, the working liquid (AMG-10 (АМГ-10)) flows from chamber $A$ through the port in piston 4 and the slot in differential valve 7 , which is com- 
pressed with spring 8 , and then, through discharge ports 5 , it flows to compensation chamber 6 formed by silphon 10 . In such load mode, the hydraulic booster resistance force is insignificant. This is explained by the fact that at such compression rates hydraulic resistance of control ports is small and the working liquid freely flows from chamber $A$ to compensation chamber $B$.

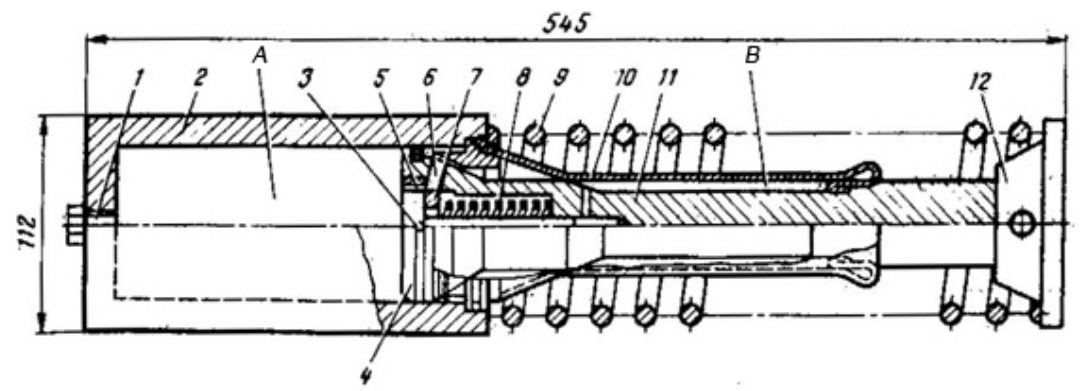

Figure 1.28. PGF (ПГФ) draft gear hydraulic booster

Under shock loads applied to the gear at cars collision during shunting and in transitional modes of train motion, hydraulic booster compression occurs at high speeds. This results in significant hydraulic resistance increase in control ports of piston 4 and pressure drop at the piston to the value the differential valve is set for. Upon reaching the mentioned pressure, differential valve 7 releases from pin 3 and discharge ports slot 6 opening is widened, through which the liquid is throttled from chamber $A$ to compensation chamber $B$.

After the action of compression forces to the hydraulic booster stops, the differential valve 7 comes to its initial position. Spring 9 installed between cylinder 2 and cover 12 returns the hydraulic booster into its initial position. At the same time, working liquid from compensation chamber 6 through port 5 and valve 7 slot flows to chamber $A$. The hydraulic cylinder is filled with the working liquid through port 1 .

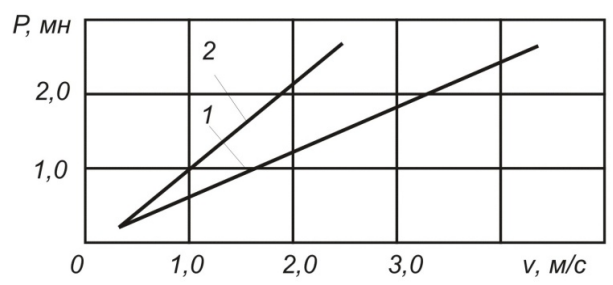

Figure 1.29. PGF (ПГФ) gear compression force as a function of the vehicles collision rate:

1 - at collision of eight-wheel gondola cars; 2 - at collision of TE (TЭ)M7 sixteen-wheel diesel locomotive with a slowed group of cars 
Characteristics of PGF (ПГФ) draft gears (Figure 1.29) are obtained by the results of the collision tests of eight-wheel gondola cars with average gross weight of 105 tons and the collision tests of TEM7 (ТЭM7) sixteen-wheel diesel locomotive weighing 180 tons interacting with a slowed group of cars. As PGF (ПГФ) draft gears tests carried out with eight-wheel cars showed, the longitudinal force of 2 $\mathrm{MN}$ matched the collision rate of $3.36 \mathrm{~m} / \mathrm{sec}$., and for sixteen-wheel rolling stock, the collision rate under $P=2.5 \mathrm{MN}$ was equal to $2.35 \mathrm{~m} / \mathrm{sec}$. The energy capacity of PGF (ПГФ) gear under a longitudinal force of $2 \mathrm{MN}$ makes $140 \ldots 150 \mathrm{~kJ}$, and under a longitudinal force of $2.5 \mathrm{MN}$ it is $170 \mathrm{~kJ}$.

Hydro-friction draft gears type $\mathrm{H}-60$ and $\mathrm{H}-100$ are developed by Cardwell Westinghouse company (the USA) basing on conventional draft gear structure using plate friction unit (Figure 1.30). Introduction of an additional hydraulic block (hydraulic booster) to the support set of the gear together with well-behaved spring-and-friction mechanism of the gear almost doubles the energy capacity of this type gear if compared with spring-friction gears type $\mathrm{H}-50$ и Н-80.

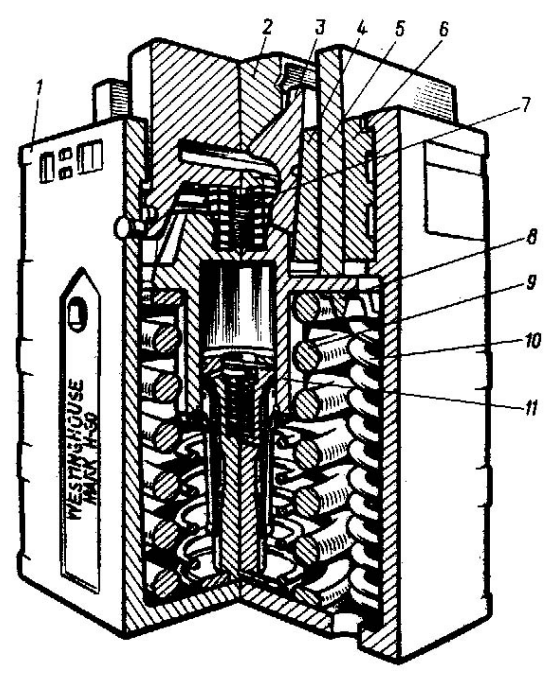

Figure 1.30. H-60 draft gear by Cardwell Westinghouse company:

1 - housing; 2 - central wedge; 3 - friction wedge; 4 - fixed wedge plate; 5 and 6 - movable and fixed friction plates, respectively; 7 - spring; 8 - support; 9 and 10 - central and angle springs, respectively; 11 - bottom washer

The gear structure includes the adjustment member made in form of straight differential valve. Hydraulic booster (hydraulic insert shown in Figure 1.31) almost does not resist in quasi-static compression mode though in shock load mode its resistance changes depending on the gear compression rate resulting in effective car 
structure and cargo protection. The gear housing is wear-proof because the friction occurs at the surface of adjacent plates (in some structural options - gear types PMK (ПМК) [78] and АРM (АПM) - the plates are overlaid with metal ceramic coat providing for significant gear characteristics enhancement). H-60 gear energy capacity is $100 \mathrm{~kJ}$ under $\sim 2.3 \mathrm{MN}$ force. This type structures can also be operated without the hydraulic insert, though having lesser energy capacity.

Hydraulic insert operates as follows. When gear is compressed, plunger 4 is immersed into cylinder 7. If compression speed is small, hydraulic insert almost does not resist because at low rates the liquid flows through constant section ports in the valve end meeting almost no resistance. As the compression force rate grows, the pressure to valve 6 supported by spring 2 increases. The spring is compressed and the valve opens the ports in plunger 4 opening free liquid flow to fabric-rubber chevron 3. Initial valve position is fixed with pin 1 . Spring 5 serves for returning the hydraulic insert into its initial position.

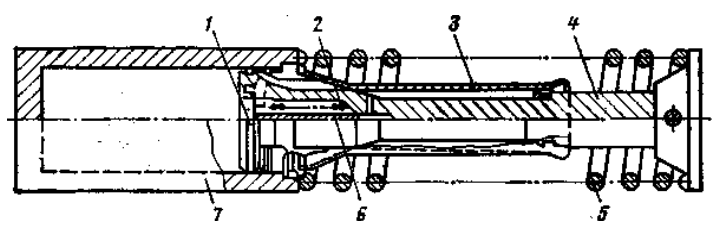

Figure 1.31. Hydro-friction draft gear hydraulic insert

Type H-60 and H-100 draft gears are widely used in freight cars for mass container and contrailer carrying. Type H-60 gear is designed for installation in a standard magazine sized $625 \mathrm{~mm}$ and H-100 gear - in a magazine sized $914 \mathrm{~mm}$. The gears stroke is 82.5 and $121.2 \mathrm{~mm}$, respectively, and their energy capacity makes $110 \ldots 120$ and $130 \ldots 140 \mathrm{~kJ}$ under a longitudinal force of $2.25 \mathrm{MN}$.

P-2П (R-2P) rubber-metal draft gear (Figure 1.32) consists of housing 1, press 2 and intermediate 4 plates, and a set of nine rubber-metal members 3. Each member has two $2 \mathrm{~mm}$ thick steel plates, between which the rubber part of the member is located; the rubber part is made of 7-ИРП-1348 (7-IRР-1348) frost-resistant rubber (65 - 80 Shore hardness) firmly bound by curing with reinforcement plates.

Rubber part of the member has a parabolic groove along the perimeter preventing from the rubber extrusion outside the reinforcement plates when the gear is fully compressed. Each member thickness is $41 \mathrm{~mm}$, transversal dimensions are 265 by $22 \mathrm{~mm}$. To prevent from relative shift of rubber-metal members when the gear is compressed, fixing flanges and respective depressions are arranged on its bottom, press and intermediate plates, and on steel plates of rubber-metal members.

The gear stroke is $70 \mathrm{~mm}$. The gear is interchangeable with TsNII-N6 (ЦНИИH6) gear and with freight car gears. 
With nominal draft gear parts and its seat dimensions when installed in a car, the initial tension is $21 \mathrm{~mm}$, which corresponds to a force of about $115 \mathrm{kN}$. The maximum force at the end of stroke does not exceed 1.3 $\mathrm{MN}$ at quasi-static gear compression.
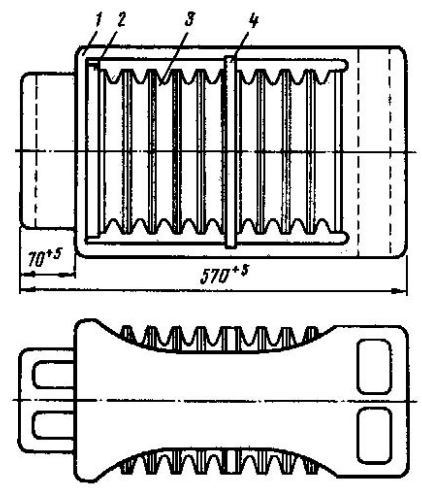

Figure 1.32. $\mathrm{P}-2 \Pi(\mathrm{R}-2 \mathrm{P})$ rubber- metal draft gear

Power characteristics of rubber-metal gears such as $\mathrm{P}-2 \mathrm{C}(\mathrm{R}-2 \mathrm{P})$ depend on the deformation rate $(v, \mathrm{~m} / \mathrm{sec}$.), which is determined by the phenomenon of stress dissipation in the material with time - the relaxation underlying such typical for rubber deformation processes as creep and hysteresis. Static - when loaded under press (curve $I$ ) - and dynamic - at the cars collision (curve $I I$ ) - characteristics of P-2П (R-2P) gear are shown in Figure 1.33.

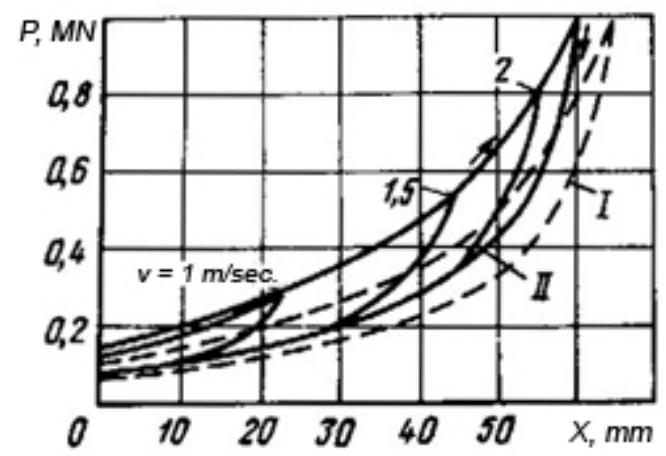

Figure 1.33. $\mathrm{P}-2 \Pi(\mathrm{R}-2 \mathrm{P})$ gear power characteristics 
The dependence of the longitudinal force (Figure 1.34) acting on the car on the passenger car collision rate subject to $\mathrm{P}-2 \Pi(\mathrm{R}-2 \mathrm{P})$ gears installation (curve $I$ ) was obtained experimentally.

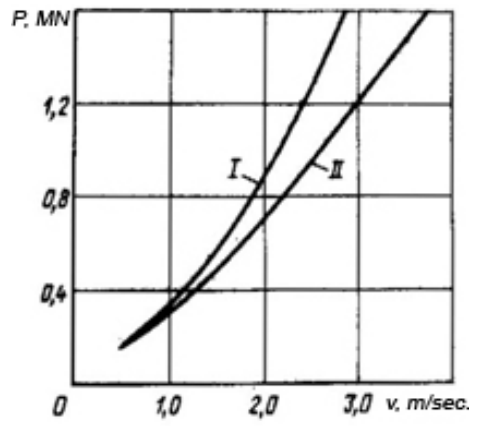

Figure 1.34. Draft gears forces as a function of the collision rate of passenger cars (curves $I$ and $I I$ ) equipped with $\mathrm{P}-2 \Pi(\mathrm{R}-2 \mathrm{P})$ and $\mathrm{P}-5 \Pi(\mathrm{R}-5 \mathrm{P})$ gears, respectively

At full stroke gear compression, the relative linear deformation of rubber members comprises 0.27 . The completeness factor of the rubber-metal gears power characteristic reaches 0.32 under static load and 0.4 under dynamic load. The irreversible energy absorption coefficient is 0.32 and 0.38 , respectively. At negative temperatures, stiffness (at initial compression stage) and power characteristic completeness factor increase. Meanwhile, the same energy capacity and final force values are realized at lesser gear compression stroke.

Such difference of rubber hardness values conditions the respective spread of the gear energy capacity that comprises $20 \ldots .25 \mathrm{~kJ}$ under static loads and $25 \ldots .29 \mathrm{~kJ}$ under dynamic loads. The characteristics of each individual gear are stable. The gear weight is $116 \mathrm{~kg}$.

P-5П (R-5P) rubber-metal draft gear (Figure 1.35) consists of the bowl housing 4 , stop 1 and intermediate 2 plates and a set of 16 rubber-metal members 3 . These members are similar to those of $\mathrm{P}-2 \Pi$ (R-2P) gear but they have lesser thickness, $33 \mathrm{~mm}$, and their transversal dimensions are increased to $310 \times 220 \mathrm{~mm}$. This was achieved by exclusion of a special housing used in P-2П (R-2P) gear, which limited transversal dimensions of rubber members in horizontal plane (in P-5П (R5P) gear this dimension is limited only by the distance between the center sill webs). The bowl housing the rubber members are directly located in differs from ordinary bowl in the presence of a platform supported by the rear stops and bigger wedge opening size.

The gear stroke is increased to $80 \mathrm{~mm}$, and, therefore, to achieve its complete realization, the gear has to be mounted in the car with shortened shock socket. The gear setting dimensions are the same.

With nominal dimensions of the gear parts (first of all the rubber-metal members thicknesses having tolerances within $\pm 2 \mathrm{~mm}$ ) and the space between the stops 
for its installation in the car, the initial tension is $34 \mathrm{~mm}$, but due to the fact that rubber-metal members are mostly fabricated with negative tolerances, the initial tension usually does not exceed $18 \mathrm{~mm}$, which corresponds to $115 \mathrm{kN}$ force.

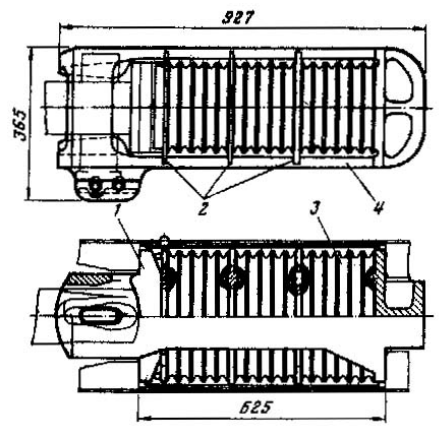

Figure 1.35. Р-5П (R-5P) rubber-metal draft gear

Thus, the increase of the number of rubber-metal members with parallel enlargement of tolerances for their fabrication requires at least rough members fitting by height when assembling. As this operation is not practically feasible, the gear construction development is in progress.

Static and dynamic power characteristics achieved by experiments with press compression (curve $I$ ) and cars collision (curve $I I$ ) are illustrated in Figure 1.36. As you can see from Figure 1.34 (curve $I I$ ), application of P-5П (R-5P) gear as compared with $\mathrm{P}-2 \Pi(\mathrm{R}-2 \mathrm{P})$ gear provides for the decrease of the longitudinal force by the value, which depends on the collision rate and reaches $20 . .25$ per cent at $3 \mathrm{~m} / \mathrm{sec}$. speed, thus significantly reducing the possibility of the car equipment damage due to violation of shunting rules.

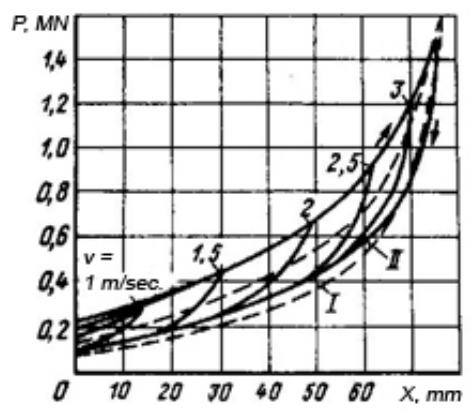

Figure 1.36. Power characteristics of $\mathrm{P}-5 \Pi(\mathrm{R}-5 \mathrm{P})$ gear 
When compressed to the full stroke, the relative deformation of rubber-metal members comprises 0.21 (instead of 0.27 in $\mathrm{P}-2 \Pi$ (R-2P) gear) taking into account their section area. Such decrease of maximum value of relative deformation contributes to increasing of the service life of rubber members, which limit the gear durability, and of the power characteristic completeness factor up to 0.35 under static loads and 0.42 under dynamic loads. At the same time, the energy absorption coefficient decreases insignificantly up to 0.31 and 0.36 , respectively.

Because of the decrease of the rubber-metal members thickness, the gear stability increased if compared with $\mathrm{P}-2 \Pi(\mathrm{R}-2 \mathrm{P})$ gear, which elements set demonstrates the lack of stability under big forces leading to the gear stiffness reduction.

The specific characteristic of $\mathrm{P}-5 \Pi$ (R-5P) gear operation determined by fact the rubber-metal members are located directly in the collet is described by the fact that under the compressive forces acting on the automatic coupling the collet does not move together with the coupling (like it happens with $\mathrm{P}-2 \mathrm{C}(\mathrm{R}-2 \mathrm{P})$ gears) because of the increased length of the collet key port and to the presence of the support platform bearing against the rear stops. Under the tensile forces acting on the automatic coupling, $\mathrm{P}-5 \Pi(\mathrm{R}-5 \mathrm{P})$ gear operation is analogous to that of $\mathrm{P}-2 \Pi(\mathrm{R}-$ 2P) gear. Thus, due to the reduction of the collet head and rear parts friction against the stops their wear is reduced.

The gear energy capacity is about $40 \mathrm{~kJ}$ under static load and $50 \mathrm{~kJ}$ under dynamic load and is also dependent on the actual hardness of rubber having a wide permissible range by this parameter (in the gear in question, 7-ИРП-1348 (7-IRР1348) grade rubber is used just as in $\mathrm{P}-2 \Pi(\mathrm{R}-2 \mathrm{P})$ gear).

The gear weight is $253 \mathrm{~kg}$ that is approximately equal to the total weight of $\mathrm{P}-2 \Pi(\mathrm{R}-2 \mathrm{P})$ gear with a yoke and a stop plate $\mathrm{P}-5 \Pi(\mathrm{R}-5 \mathrm{P})$ gear is completed with.

Miner company (the USA) together with European railways developed a structure of RF-4-31-CF friction rubber draft gear (Figure 1.37), which may be used with both automatic and ordinary coupling.

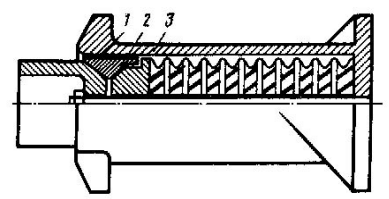

Figure 1.37. RF-4-31-CF draft gear by Miner (the USA)

The specific feature of RF-4-31-CF gear is the utilization of special asbestos gaskets 1 fixed on four gear wedges 2 between their main friction surfaces and housing 3 friction surfaces. The gear housing neck has cylindrical form. Special gaskets application contributed to stabilization of the parts friction interaction and significantly reduced the working surfaces wear. Figure 1.38 illustrates the com- 
pression effort $P$ as a function of stroke $X$ for static (curve 1 ) and dynamic (curve 2) modes of gear loading. Static and dynamic energy capacity of the gear is 73.5 and $78.4 \mathrm{~kJ}$, respectively.

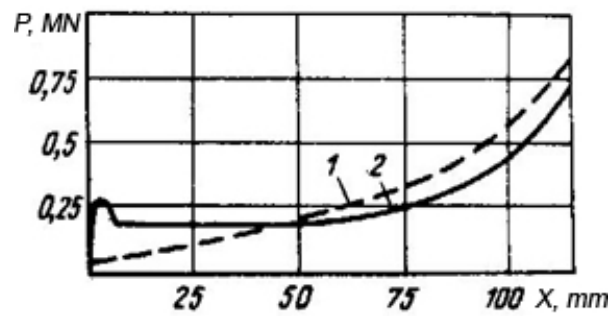

Figure 1.38. Power characteristics of RF-4-31-CF gear by Miner (the USA)

$L A F$ company (France) manufactures rubber-metal draft gears type 6012 for engines and type 6002 for freight cars. Application of a special Stenlaf rubber mix based on natural caoutchouc for the gear rubber members ensures effective and stable shock absorbers operation at temperatures between +20 and $-40^{\circ} \mathrm{C}$. The draft gears are operable even at $-50^{\circ} \mathrm{C}$ and still have satisfactory characteristics.

Hydraulic draft gears are the individual group. Let us consider GA-500 (ГA500) gear (Figure 1.39). Its operation is based on the principle of transformation of the kinetic energy of moving car weight into the heat energy by way of throttling the working liquid through the regulation units of the draft gear (see Section 6). GA-500 (ГA-500) gear consists of housing 2 and plunger 3 . The gear has five working chambers: $A$ and $B$ are the gas chambers, $C, D$ and $E$ are the hydraulic chambers. The gear housing is separated by intermediate bottom 4 , in which adjusting rod 5 with longitudinal profiled grooves is fixed. In the lower part of the gear, floating piston 3 separating low pressure gas chamber $A$ from hydraulic chamber $E$ is installed. High-pressure gas chamber $B$ is located in hollow plunger 8 and is separated from the hydraulic chamber $D$ with additional floating piston 7 . Hydraulic chambers $C$ and $D$ are separated with firmly fixed in the plunger diaphragm 6 , in which there is a central opening for adjusting rod 5 and additional throttle's ports 7 closed by a return valve. In addition, hydraulic chambers $C$ and $D$ are connected using throttle ports in intermediate bottom 4 . The gas chambers are filled with nitrogen through vertical pipes 1 equipped with direct valves. Filler gas pressure in chamber $A$ is $3.5 \mathrm{MPa}$, in chamber $B-9 \mathrm{MPa}$. AMG-10 (AMГ-10) oil is used as a working liquid in the gear.

GA-500 (ГА-500) draft gear has $120 \mathrm{~mm}$ stroke. It may be used both for eightand sixteen-wheel rolling stock. This type gears, just like rubber draft gears and in contrast to spring friction structures, do not require running-in and realize their maximum energy capacity from the very moment of their operation start. GA-500 
(ГA-500) gear (Figure 1.40) characteristics demonstrate that the gear energy capacity reaches $140 \mathrm{~kJ}$ at collision of the eighth-wheel cars with 83 tons gross weight under $2 \mathrm{MN}$ longitudinal force and the collision rate of $4.03 \mathrm{~m} / \mathrm{sec}$., and $170 \mathrm{~kJ}$ at collision of sixteen-wheel cars with 170 tons gross weight under $2.5 \mathrm{MN}$ longitudinal force; the safe collision rate in the latter case is $3.22 \mathrm{~m} / \mathrm{sec}$.

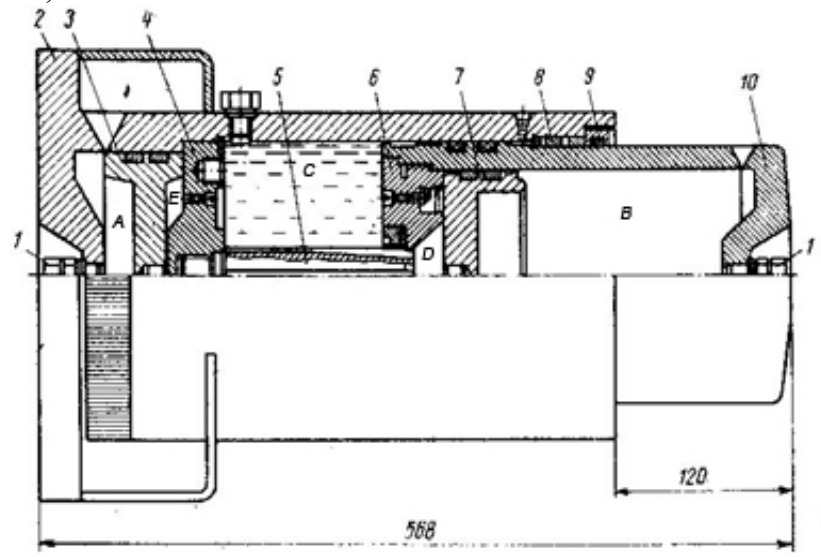

Figure 1.39. GA-500 (ГA-500) draft gear

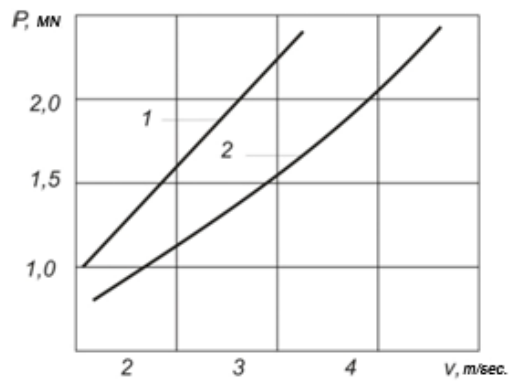

Figure 1.40. Compression effort of GA-500 (ГA-500) gears as a function of cars collision rate: 1 - sixteen-wheel; 2 - eight-wheel

The application of draft gears, in which silicon elastomers are used as a working medium, has significantly grown in recent years. These extenders have high resistance to natural and artificial aging factors. High stability of these substances allow for their successful application in temperature range of $-70 \ldots+250^{\circ} \mathrm{C}$. In addition to the elastic material properties, these substances possess high compression degree and demonstrate insignificant viscosity change under changing temperature that is they have the properties of liquids, but at the same time their viscosity is much higher than the viscosity of shock-absorbing oils. 
With equal dimensions, shock absorbers based on silicon elastomers have a simpler structure and high specific energy capacity per unit of their weight as compared with the other types of draft gears.

The type of power characteristic of this type of gears is determined by the parameters of their compression. Under quasi-static loading, the piston movement inside the cylinder results in the pressure increases due to the elastomer volume compression. The character of this relation change is determined by the elastomer volume, practically without any silicon elastomer hysteresis, and makes just 10 to 15 per cent.

Under shock loading, which is accompanied by high absorbing elastomer compression rate, additional resistance occurs on the piston due to the hydraulic processes of the silicon elastomer overflow through the gaps between the piston and the cylinder. This results in significant gear energy capacity increase and, consequently, its damping efficiency grows depending on the rate of loading.

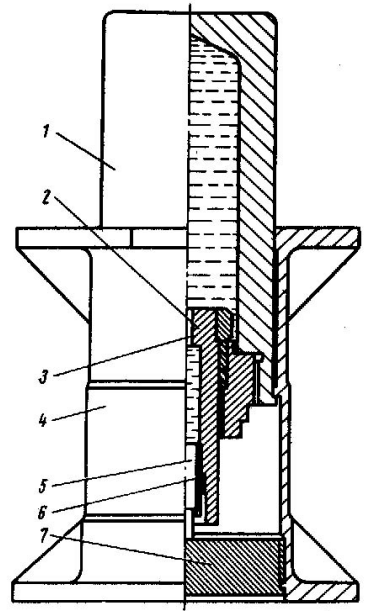

Figure 1.41. DC-12A draft gear by Domange-Jarret (France)

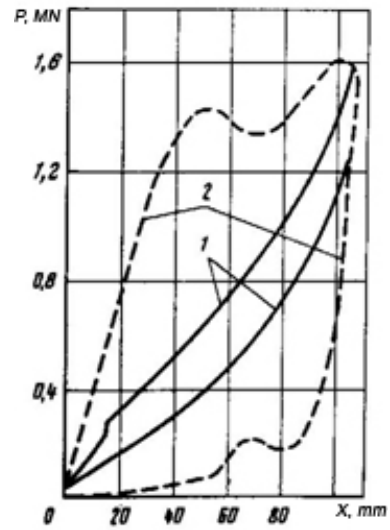

Figure 1.42. Power characteristic of DC12A draft gear by Domange-Jarret: 1 - static; 2 - dynamic

Figure 1.41 is the illustration of elastomeric draft gear type DC-12A. It consists of cylinder 7 where plunger 2 is located. The latter is, at the same time, the second cylinder interacting with plunger 5 , which bears against bottom 7 of housing 4 . Cavity of plunger 2 is connected with cylinder 1 cavity through calibrated port 3 . Plunger 2 interacting with cylinder 7 is sealed with gasket 6 . Inside cylinder 1 and plunder 2, there is the elsatomer. 
The gear has the installation dimensions fit for $625 \mathrm{~mm}$ magazine. The gear energy capacity under resistance force $P=1.6 \mathrm{MN}$ and stroke $X=110 \mathrm{~mm}$ is $120 \mathrm{~kJ}$ (Figure 1.42).

For critical carriages, the cars equipped with high-efficiency TZ (T3) class gears have to be used. Currently, by the total of economic and technical parameters the most promising are the gears, in which the working medium is volume compressed high viscosity polymer (elastomer). At the same time, this elastomer may function as resilient and damping member. The material compressibility in closed volume reaches 15 to 20 per cent under pressure of 250 to $500 \mathrm{MPa}$. This provides for its application as a hydraulic spring functioning at slow compression, and various types of throttling provide for significant increase of the shock absorber resistance force at high compression rates.

Thus, elastomeric draft gears ensure power characteristics close to hydraulic shock absorbers. If compared with other shock absorbers, the gears based on elastomers have higher specific energy capacity and relatively simple structure. At the same time, high pressure requires for high durability of working cylinders and sealed structure, which, together with the high cost of the elastomer, adds to significant product cost rise.

In TZ (T3) class, fully compliant with the standard are elastomeric gears APE120I (АПЭ-120И), ЕРА-120 (ЭПА-120) with 120 mm stroke developed by Russian production and research organizations [76]. EPA-120 (ЭПА-120) gear (Figure 1.43) has the housing connected with the yoke. This feature allowed for the utilization of the space between rear stops where an additional chamber filled with elastomer was allocated thus significantly reducing the working pressure (approximately by 1.5 to 2 times if compared with similar structures) and making it possible to use ordinary low-alloyed structural steel instead of aircraft steel thus reducing the total cost of the product.

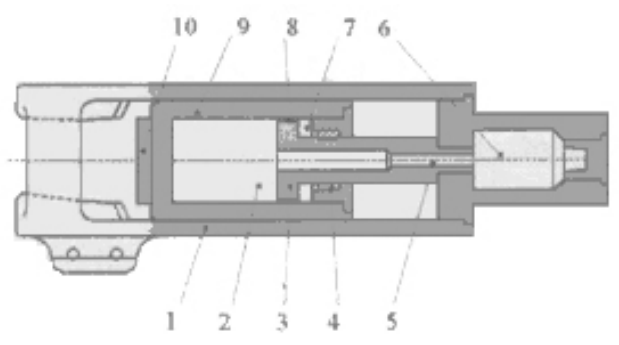

Figure 1.43. ЕРА-120 (ЭПА-120) draft gear

The draft gear consists of housing 1 integral with the automatic coupling yoke and of bottom 6 with the additional chamber located in the space between the rear automatic coupling stops. Piston 3 with a hollow rod and hollow plunger 9 with 
alternate size calibrated gap 8 between them, functioning as a throttling channel, are located in housing 1 . Cavities 2 and 7 inside plunger 9, cavity 5 inside piston rod 3 and additional bottom chamber 6 are filled with volume compressed working medium - the elastomeric mix. Seals 4 provide for the tightness of the sliding joint of the rod and plunger.

To determine the basic parameters of the gear structure, a set of theoretical and experimental researches was held [76]. Main dynamic parameters of EPA-120 (ЭПА-120) gear were obtained from the field tests. Sh-2-V (Ш-2-B) gear was installed on the colliding car and EРА-120 (ЭПА-120) gear was installed on the collided car. Nominal gear energy capacity comprised $152 \mathrm{~kJ}$, maximum energy capacity was $183 \mathrm{~kJ}$ under a closing force of $2.4 \mathrm{MN}$.

The endurance tests were carried out to assess the draft gear efficiency under multiple dynamic (shock) loading equivalent to the service life loading basing on the energy introduced into the gear. Figure 1.44 illustrates the static characteristics of the gear at different stages of the endurance tests. As you can see, the bigger the energy introduced into the gear the lower is the initial compression force (it drops from 0.29 to $0.06 \mathrm{MN}$ ) and the maximum compression force (it drops from 1.58 to $1.14 \mathrm{MN}$ ) of the gear. Static energy capacity of the gear decreased from $105 \mathrm{~kJ}$ in the beginning of the test to $60 \mathrm{~kJ}$ at the end of the test.

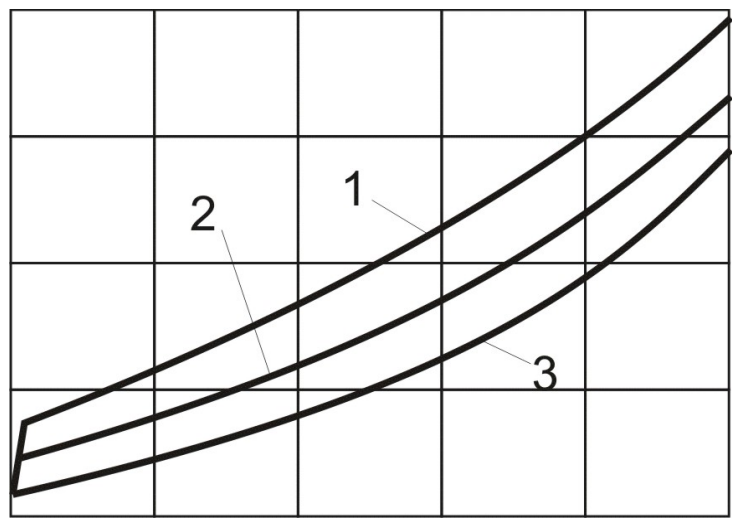

Figure 1.44. Static power characteristics of EPA-120 (ЭПА-120) draft gear: 1 - in the beginning of the test; 2 - after introduction of $100 \mathrm{MJ} ; 3$ - at the end of the test

The diagrams in Figure 1.45 illustrate the change of dynamic power characteristics of the gear during the endurance tests. Here you can see that with equal start collision rate the draft gear stroke grows together with the energy introduced into the gear, the maximum shock strength staying the same or slightly reducing. In the beginning of the test, the nominal energy capacity (under force $P_{\max } \approx 2 \mathrm{MN}$ ) was $164 \mathrm{~kJ}$, at the end of the endurance test it was $122 \mathrm{~kJ}$ (under a force of $1.87 \mathrm{MN}$ ). 
Such parameters reduction is within the limits permissible by standards. The inspection after the test demonstrated the absence of any failures or damages of the gear parts [76].

Elastomeric draft gear type SR-24 by Miner company (Figure 1.46) has the installation dimensions for $625 \mathrm{~mm}$ magazine and $82 \mathrm{~mm}$ stroke [75]. It ensures effective protection at collision of loaded cars moving at a speed of $3.12 \mathrm{~m} / \mathrm{sec}$. under a longitudinal force of $3.18 \mathrm{MN}$. The gear energy capacity under a longitudinal force of $2.25 \mathrm{MN}$ comprises $117 \mathrm{~kJ}$.

$73 \mathrm{ZW}$ elastomeric draft gear is meant for installation in standard automatic couplings of Russian freight cars and tank cars [77].

KAMAX draft gears type 73ZW are equipped with high efficiency elastomeric shock absorbers installed in a powerful housing. Thanks to smooth characteristic and big energy absorption, the force and acceleration acting on the car frame and the cargo are lower than in friction spring gears. As a result, the car and the cargo integrity, and the train's movement safety are significantly increased that is especially important for carrying of hazardous and highly hazardous cargos. KAMAXIL, the shock-absorbing substance used in the draft gears, retains its physical and chemical properties during decades under a wide range of temperatures; in addition, it is environmentally friendly. Starting from 1990 73ZW draft gears passed many bench and endurance tests in railway research organization of Poland and Russia. These tests proved the advantages of $73 \mathrm{ZW}$ as compared with previously applied gears.

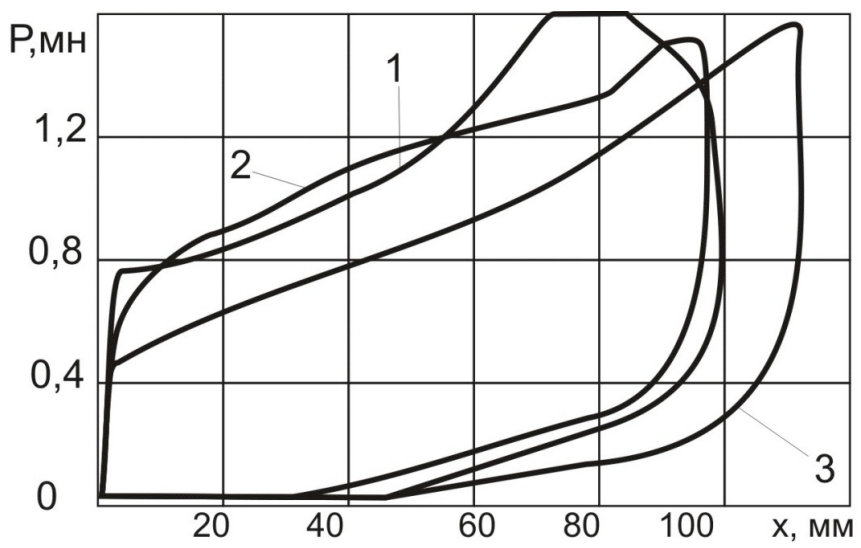

Figure 1.45. Power characteristics of EРА-120 (ЭПА-120) draft gear for the start collision rate of $2.6 \mathrm{~m} / \mathrm{sec} .: 1$ - in the beginning of the test; 2 - after introduction of $100 \mathrm{MJ} ; 3-$ at the end of the test 


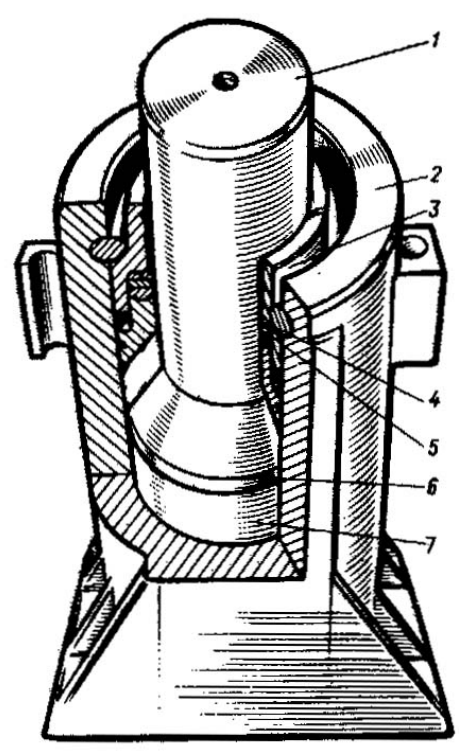

Figure 1.46. SR-24 draft gear by Miner company (the USA):

1 - plunger; 2 - housing; 3 - pilot bushing; 4 - stopper ring; 5 - sealing unit; 6 - piston; 7 - working medium, the silicon elastomer

73ZW parameters are: structural stroke $-90 \mathrm{~mm}$, dynamic capacity - $130 \mathrm{~kJ}$, starting tension force $-200 \mathrm{kN}$, static resistance force $-1,000 \mathrm{kN}$, nominal cars collision rate $-3 \mathrm{~m} / \mathrm{sec}$., working temperatures range --60 to $+50^{\circ} \mathrm{C}$, weight of the gear assembly $-214 \mathrm{~kg}$.

Not only dynamic and power characteristics of the gear are notable, but also the range of working temperature, which allows for the cars equipped with these gears operation in various geographic regions. In addition, the gear installation dimensions and structure guarantee its mounting (dismounting) under any carhouse conditions.

The gear consists of housing 2, stop plate with bolts 3, mounting bars 4 and elastomeric shock absorber 1 . To simplify the gear mounting on the car and to ensure the gear pre-tension, distance inserts 5 , which fall out at the first gear compression in the course of the railway cars shunting, are placed between mounting bars 4 and housing bosses (Figure 1.47).

Elastomeric shock absorber 1 type KZE-5-R2-1 has a cylindrical housing of high-strength steel filled with high-viscosity elastically compressed working medium (elsatomer), KAMAXIL. When the shock absorber is compressed, the rod comes into the housing and compresses the elastomer creating high internal pressure. At shock (dynamic) compression of the shock absorber the energy is ab- 
sorbed by overflow (throttling) of the working medium through the calibrated gap between the shock absorber housing and the piston installed on the rod. Figure 1.48 illustrates the installation diagram for $73 \mathrm{ZW}$ gear when mounted on a car.

$73 Z W$ gear is meant for 16-year operation without repair or parts replacement, or till the car capital repair. The manufacturer gives 4-year warranty for the gear subject to normal (emergency free) operation conditions.
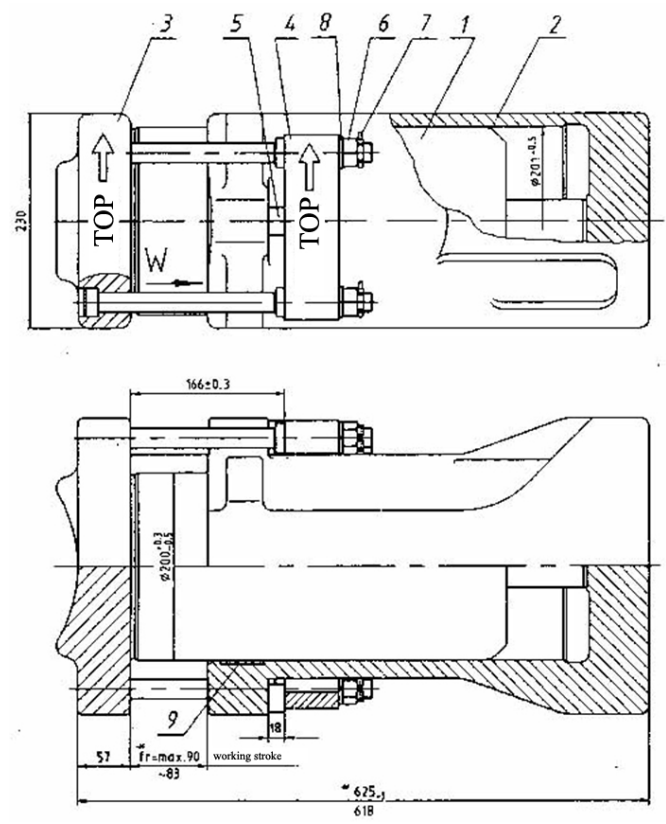

Figure 1.47. 73ZW draft gear general view:

1 - elastomeric shock absorber; 2 - draft gear housing; 3 - stop plate; 4 - mounting bar; 5 - distance insert; 6 - horned nut; 7 - keeper pin; 8 - spring collar; 9 - split collar

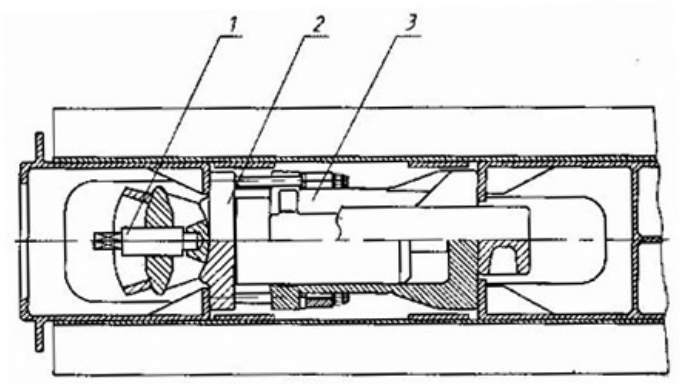

Figure 1.48. 73ZW draft gear installation on a car (top view):

1 - screw clamp, 2 - stop plate $73 \mathrm{ZW}, 3$ - draft gear 73ZW 
Hydraulic end draft gears type Freightmaster (Figure 1.49) are successfully used and proved well in the USA railways [75].

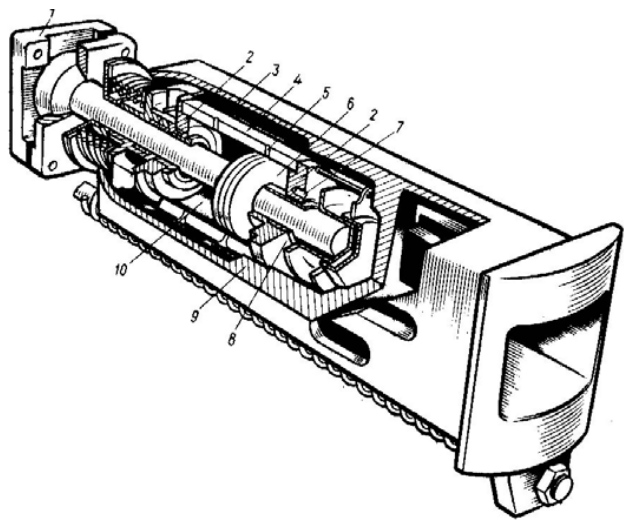

Figure 1.49. Freightamster type draft gear (the USA)

Freightmaster draft gears are made with 178, 254 and $381 \mathrm{~mm}$ stroke. Figure 1.50 illustrates the comparative characteristics of various types draft gears. As the test of these gears showed, if the longitudinal force in the automatic coupling was $2.23 \mathrm{MN}$, the collision rate for the cars with end friction draft gears was $1.6 \mathrm{~m} / \mathrm{sec}$.; for the cars with rubber draft gears it was $1.96 \mathrm{~m} / \mathrm{sec}$.; and for the cars equipped with $254 \mathrm{~mm}$ stroke Freightmaster hydraulic draft gears the rate was $4.73 \mathrm{~m} / \mathrm{sec}$., and $5.8 \mathrm{~m} / \mathrm{sec}$. for $381 \mathrm{~mm}$ stroke gears.

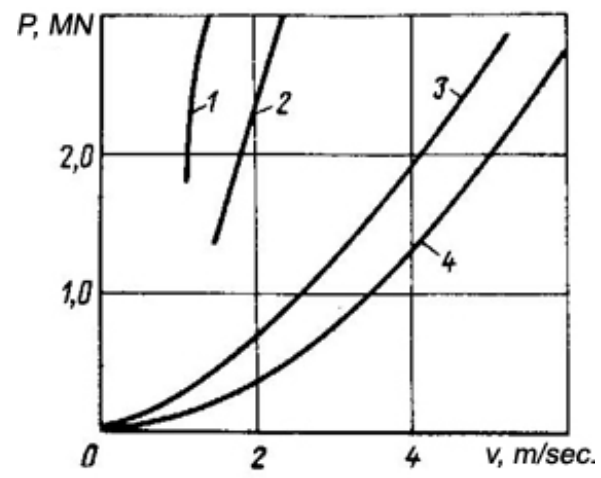

Figure 1.50. Various types draft gears compression force as a function of the cars collision rate: 1 - friction gears; 2 - rubber gears; 3 and 4 - Freightmaster type gears with 254 and $381 \mathrm{~mm}$ stroke, respectively 
Freightmaster hydraulic draft gear can be mounted both on new and old cars. It is located in the magazines at the ends of the center sill.

In the gear housing (see Figure 1.49), there is hydraulic cylinder 4, which, together with the housing, creates low pressure chamber 3 and, at the same time, serves as a cavity for high pressure chambers 10 that border with the compensation chamber 8 . The low and high-pressure chambers are communicated via calibrated ports 5 made in cylinder walls 4 and via return valves 7 installed in hydraulic cylinder covers 2 . If there is no load on the gear, piston 6 separating the hydraulic cylinder is in the middle position. The rod rigidly connected with the piston has a hinged connection with self-centering plate 1 at one its end; the plate is located between the stops in the center sill. Such structure provides for the gear self-centering and, at the same time, it is gear's housing 9 that moves at any load application direction (extension or compression) while the rod stays fixed. The gear is returned to its initial position by spiral springs. The absorption of shock loads occurs due to throttling of the working medium from the high-pressure chamber through calibrated ports 5 and through return valves 7 into low-pressure chamber 3 .

Central damping units in cars with flexible center sill. Despite the high cost of the equipment of cars with flexible center sill completed with damping unit (the cost of the sill comprises up to 20 per cent of the cost of the car) the operation of such cars for carrying precious and fragile cargos sensitive to longitudinal loads in the train is economically reasonable. The width of the application range of cars with floating center sill may be estimated by the following data: in 1978 in the USA more than 300 thousand of such cars were operated, currently 30 per cent of all the newly built cars are equipped with floating center sills with powerful central damping units [75].

Flexible center sill is located along the longitudinal axis in the car frame and is connected with it via the damping unit. Coupling units at the ends of the center sill usually include standard friction or rubber type draft gears.

At the car collision, its structure and the carried cargo accept significantly less dynamic efforts because due to the presence of the end draft gears and the powerful central shock absorber the shock energy is dissipated at relative longitudinal car frame and center sill movement. In a train, the central gear accepts only those dynamic forces, which cause the car body acceleration, as well as the stopping static forces acting on the car from the side of the wheel pairs. This unit does not transfer significant slow changing forces formed in the train during transitional movement modes created by the taking-off, draw changing, brakes work and the train motion cross the breaks in the track profile elevation.

Depending on the car type, car structure and the character of the cargo carried, the central damping units applied may have maximum stroke of 178, 254, 305, $457,508,610$ and $762 \mathrm{~mm}$.

There are the structures of car damping units with flexible center sills where rubber, friction or hydraulic types damping units are applied. 
The structures of car frames by Weight Equipment company type 32T, 40, 65 and 90 used for service, insulated and boxcars are equipped with floating center sill [75]. The longitudinal loads absorption is provided through the floating sill friction against the car body, the springs' resistance and various types shock absorbers operation.

In the US railways, there are cars with flexible center sill, which structure was developed together by the experts of Southern Pacific Railways and Stanford Research Institute (Figure 1.51) [75]. At the ends from the automatic coupling side, the flexible sill is equipped with standard draft gears 7 , and in the central part it is connected with the car frame through hydro-friction type shock absorber 4.

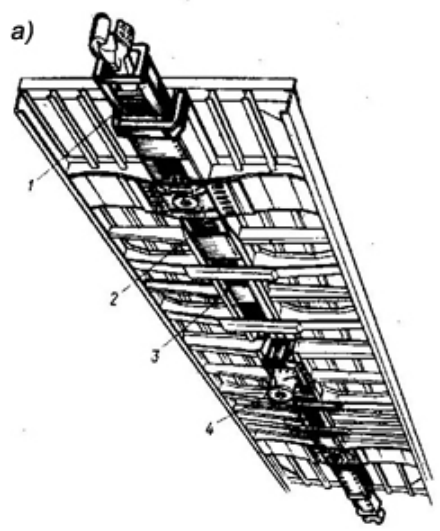

b)

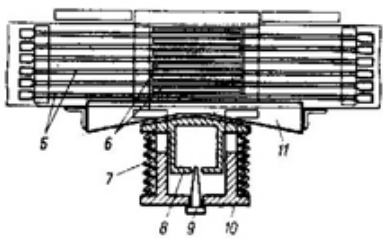

Figure 1.51. Car frame with flexible center sill $(a)$ and central hydro-friction type shock absorber $(b)$

The shock absorber structure includes a set of moving steel friction slats 5 , their ends tied with flexible sill 3 and located, in series, between bronze bars 6 of the shock absorber housing, which are firmly fixed on the car frame. Bars 6 and plate 11 are able to move vertically relative to the housing. The bottom fixed plate of the housing is made with inclined surfaces to ensure the interaction with hydraulic cylinder plunger head 8 , which contacts with plate 11 made with the matching inclined surfaces. Hydraulic cylinder 10, functioning, at the same time, as a housing part, is rigidly fixed in the middle part of the car frame. To return the flexible sill into the middle position, return coiled springs 2 are placed between the sill and frame stops.

The shock loads are absorbed by the central shock absorber at relative sill and car frame movement due to the forces of friction interaction of moving 5 and fixed 6 bars. The friction force between the specified bars changes due to spring 7 compression and to the resistance from the hydraulic shock absorber, the resistance of the latter being automatically regulated depending on the car collision rate. 
The operation of the hydraulic shock absorber in such structure is based on the principle of the liquid throttling from cylinder chamber 10 into plunger chamber 8 through the slot formed by regulating member 9 and the walls of the calibrated opening in the rod diaphragm. Central hydro-friction shock absorbers are used with flexible sill stroke of 254, 305 and $508 \mathrm{~mm}$. The later modification of this structure was called hydro-cushion.

The tests showed that the longitudinal force comprised $1.16 \mathrm{MN} \mathrm{[75]} \mathrm{at} 4 \mathrm{~m} / \mathrm{sec}$ collision rate of cars with gross weight of 77 tons equipped with flexible center sill with central hydro-friction shock absorber. The energy capacity of the damping units of flexible sill with central hydro-friction shock absorbers is equal to 274 to $338 \mathrm{~kJ}$ under a longitudinal force of 1.33 to $1.76 \mathrm{MN}$.

Starting from 1960 Pullman Standard company equips flexible center sill freight cars with hyd-frame type central hydraulic shock absorbers (Figure 1.52) [75]. Currently, more than 50 thousand of such units are in operation. These shock absorbers are made of two types: Hydroframe-40 with maximum sill movement of $508 \mathrm{~mm}$ each side and Hydroframe- 60 with the sill stroke of $762 \mathrm{~mm}$.

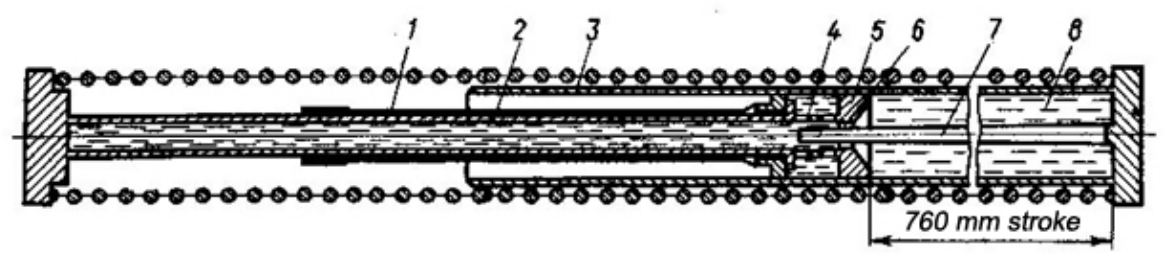

Puc 1.52. Single-action hydro-frame type central shock absorber

Structurally the unit has the form of cylinder 3 forming the high-pressure chamber, in the bottom which there is an adjustment member in form of rod 7, which free end goes thought calibrated port 6 in piston 5 of rod 2, and which is located in the cavity of the latter.

When the shock absorber is compressed the liquid, from cylinder chamber 8 through the slot between adjustment rod 7 and piston 5 and then through ring openings 4 , overflows into the compensation chamber formed by rubber-fabric tube shape bellows 1 and rod 2. One end of bellows 7 is fixed on rod 2, and the other its end is fixed on the cylinder bushing.

In European $1435 \mathrm{~mm}$ track railways, the application of drawbar couplings resulted in the necessity to create powerful buffer type damping units. Such units are equipped not only with resilient members in form of spiral springs, but also with the resilient members, which operation is based on the principles of shock energy absorption.

The buffer units (Figure 1.53,a) [75] made for Polish railways rolling stock have high damping qualities. They are built on the basis of KZE type car buffer 
and include replaceable insert made in form of serially connected coiled spring 5 and elastomeric shock absorber 2. Having high power intensity at quasi-static compression mode $(35 \mathrm{~kJ})$, this buffer unit is highly effective under dynamic loads $(70 \mathrm{~kJ})$, too. Figure $1.53, b$, illustrates the relation of the compression effort $(P)$ and the buffer stroke $(X)$ under static (curve 1 ) and dynamic (curve 2) loads.
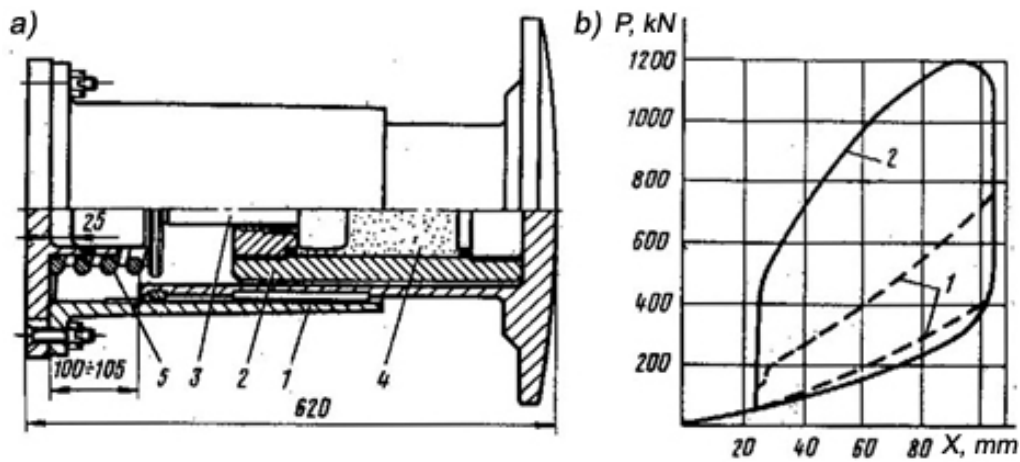

Figure 1.53. KZE type buffer with elastomeric shock absorber $(a)$ and its power characteristics $(b)$ :

1 - buffer housing; 2 - elastomeric shock absorber cylinder; 3 - rod with piston; 4 - working medium, the silicon elastomer; 5 - coiled spring

In European countries, the platforms with travelling deck floor or supports are used for carrying the cargos subject to damages under shock loads.

In British railways, buffer units with hydraulic OLEO series inserts (Figure 1.54) by OLEO Pnuematics are widely used [75]. The buffer unit operation is as follows. When plunger 4 moves slowly, the working medium from hydraulic chamber $A$ overflows to compensation chamber $B$ through ring gap 6 between the profiled pin 3 and diaphragm 8 ; the pressure drop between these chambers is insignificant and resistance to compression is determined by the pressure at the diaphragm.

At higher compression rates, the liquid throttling from chamber $A$ to chamber $B$ is accompanied by a significant pressure drop on the diaphragm, thus resulting in increased buffer compression resistance. OLEO Pneumatics offers also type 5C and 4EC-80 hydraulic inserts for buffers, which have maximum compression stroke of 105,110 and $135 \mathrm{~mm}$.

Figure 1.55 illustrates the power characteristics of buffers with hydraulic inserts at collision of single cars with gross weight of 80 tons.

The energy capacity of this type buffers at $105 \mathrm{~mm}$ stroke and under a longitudinal force of $1 \mathrm{MN}$ is $84 \mathrm{~kJ}$, and at $135 \mathrm{~mm}$ stroke and under a longitudinal force of $2 \mathrm{MN}$ it is $220 \mathrm{~kJ}$. 


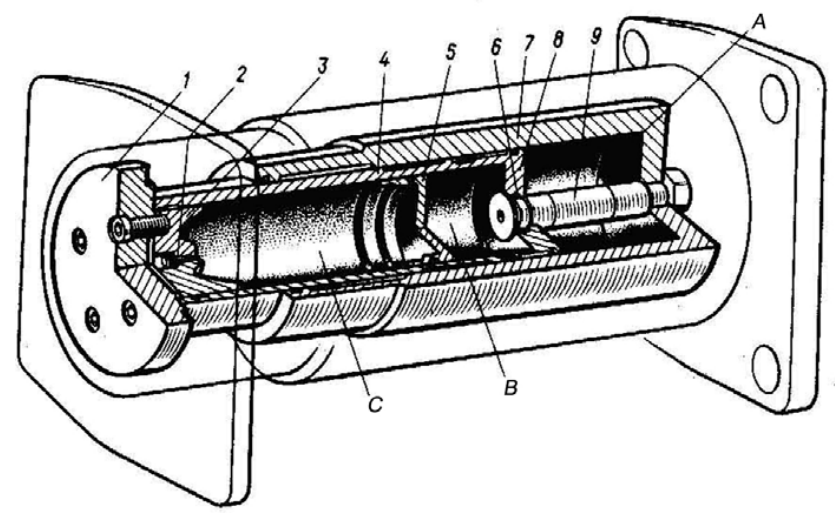

Figure 1.54. OLEO type buffer: 1 - stop plate; 2 - valve; 3 - end stop bushing; 4 - plunger; 5 - floating piston; 6 - ring gap; 7 - cylinder; 8 - diaphragm; 9 - profiled pin; $A, B, C$-hydraulic, compensation and gas chambers, respectively

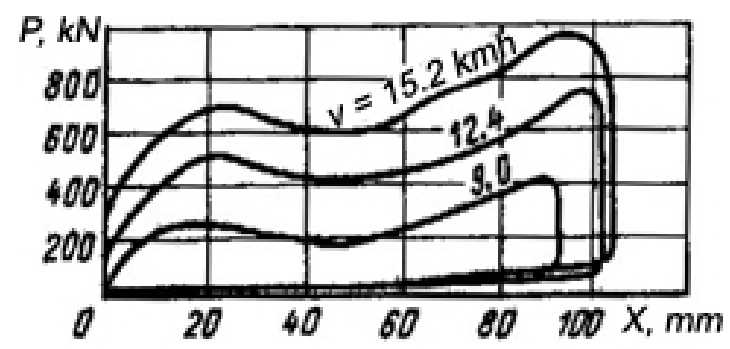

Figure 1.55. OLEO type buffer power characteristics

The family of damping units in cars with travelling deck floor may be enlarged with the platform structure developed by $S E A G$ company (Germany) (Figure 1.56) [75]. It includes the damping unit made in form of loading plate 1 , which bears against the car frame via rollers 2 moving along inclined surfaces 3 both ways in longitudinal direction depending on the external forces application direction. The rollers are equipped with braking mechanism. When the plate moves to the middle position, the braking mechanism is deactivated. The plate has the possibility to move both ways in longitudinal direction to a distance of $800 \mathrm{~mm}$, its elevation in vertical plane reaching up to $100 \mathrm{~mm}$. When the plate moves more than $700 \mathrm{~mm}$, the additional shock absorber is activated to decelerate its movement. This shock absorber is mounted between the loading plate and the car frame. The damping unit provides for the damping force change proportionally to the carried cargo weight. 


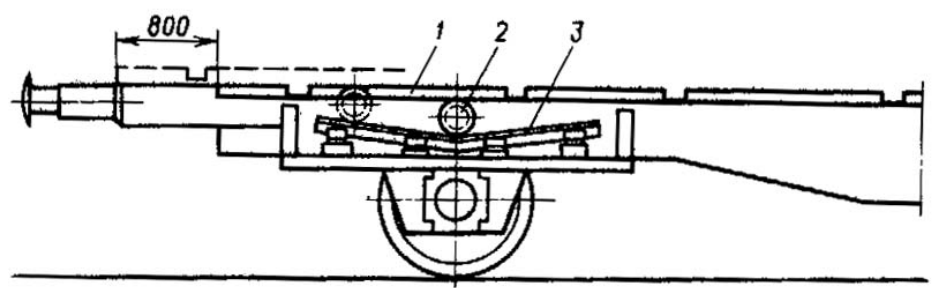

Figure 1.56. Platform with the damping unit in form of travelling deck floor

Specialized cars and platforms for containers carrying are equipped with travelling deck floors with the application of OLEO series hydraulic shock absorbers and long-stroke shock absorbers, which can be installed differently depending on the car type.

For example, doubled shock absorbers may be located in the central part of the platform center sill (Figure 1.57,a) [75]. The cargo or container may have special stop members or may be located on intermediate deck floors interacting with stop surfaces of the shock absorbers ends. The shock absorber stroke may be 500 to $760 \mathrm{~mm}$.
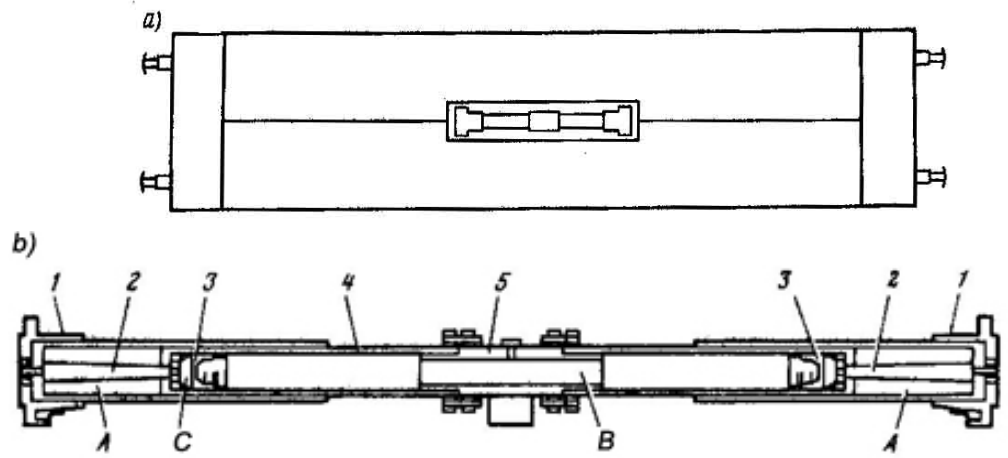

Figure 1.57. Layout ( $a$ ) and structure $(b)$ of OLEO type central shock absorber on cars with travelling deck floors

The shock absorber (Figure 1.57, $b$ ) is made in form of two equal cylinders 1 with high pressure chambers $A$, in the bottoms of which adjustment throttle needles 2 are mounted. Plungers 4 of two cylinders are interconnected with intermediate bushing 5 and form common gas chamber $B$. Each plunger has a floating piston 3 separating plunger $C$ hydraulic chamber from common gas chamber $B$.

The platforms equipped with OLEO Pneumatics damping units provide for acceleration not more than $2 \mathrm{~g}$ at collision rate of $4.17 \mathrm{~m} / \mathrm{sec}$. 


\subsection{Active Suspension Systems}

Detailed description of such systems is given in [34]. The most distinguishing characteristic of such systems is the fact that oscillation damping and the parameters of the oscillation damping systems are adjusted depending on the riding conditions.

So, article [79] analyzes the theory of active suspension systems. In addition to conventional resilient and damping members, such systems include a control feedback circuit with the acceleration meter, integrator, summing unit, and poweractuating element. The latter may have hydraulic, pneumatic, or electromagnetic drive, which realize alternating, phase-shifted relative to the oscillation amplitude, force. Depending on the chosen feedback circuit parameters, this system realizes a specific degree of oscillation damping; here the full damping is not recommended for practical systems as it results in increased forces in the actuating element. The specific features of vertical, transversal, and longitudinal oscillation damping, particularly in high-speed rolling stock, are also analyzed. It is indicated that there exist the possibility of significant improvement of the passengers' comfort by way of active suspension systems mounting. The sample calculations of active suspension for type TGV, ICE and ETR 500 electric trains and for high-speed passenger cars developed at Poznan Car Building Plant (Poland) are made.

Passenger car electromagnetic oscillation damper can also be categorized as the active oscillation damping system [80]. It consists of a coil, which is connected with alternate current generator and has a hinged connection with the bogie frame. Metal core is located in the coil center and is fixed on the car frame with one of its ends. When the alternate current is supplied to the coil block, the core is placed symmetrically relative to the transversal coil axis. This core positioning is possible when the car is in its normal position. Magnet field in the coil which force depends on the oscillation magnitude absorbs the car body oscillations at motion. This system has a forward-acting character, i.e. the damper characteristics may change depending on the vehicle motion conditions.

The authors of article [81] offer active suspension system for cars used in highspeed trains of Japanese railways. This system is based on the automatic regulation theory. Hydraulic actuator replaces the ordinary passive suspension side shock absorber between the bogie body and frame. It is proved that active suspension is an effective way to increase the travel comfort. Train with active suspension provides for comfort corresponding to 3-hour level of decreased comfort under ISO2631 international standard at $144 \mathrm{~km} / \mathrm{h}$ ride speed even with the low quality of local rail tracks.

WIN 3350 type electric trains passed line tests on the Japanese railways at $300 \mathrm{~km} / \mathrm{h}$ speed. The purpose of the tests was to optimize the active pneumatic suspension system with automatic air-spring stiffness regulation and the damping coefficient in oscillation parameters function [82]. To regulate the test conditions, the oscillation sensors were installed on the bogie in all three planes. Depending on the sensors readings, the working volume of the air-springs in the central suspension and the sections of calibrated ports determining the oscillation damping coef- 
ficient are changed automatically. The conclusion was made that, with active body suspension, the car riding comfort at high speeds was substantially increased. Some parameters of active suspension regulators were corrected. The tested system is recommended for installation on high-speed electric trains.

Patent [83] suggests to regulate the pressure in the locomotive or car air-springs installed inside the central suspension system using a microprocessor reacting to specific riding conditions in straight and curved track considering the train speed. When moving in the straight tack, the air springs are regulated by the criteria of maintaining the body in horizontal position, i. e. transversal and longitudinal car or locomotive lurching is minimized. When moving in the curved tack, a forced tilt of the body is created to compensate for transverse acceleration. Each air spring is regulated by its own electro-pneumatic valve controlled by a microprocessor. These valves control program performed by the microprocessor uses the readings of the geometrical body position sensors, air springs pressure sensors, train's speed sensors as the source data. To avoid the body vibration, mostly the transverse oscillation, the dynamic criteria of gradual pressure changing in air springs are met. This solution is recommended for application in trains planned for high-speed circulation in the existing Japanese railway lines where there is a big number of small radius curves requiring the speed decreasing.

The authors of patent [84] offer the car body support arranged of at least three controlled hydraulic cylinders, which one end is fixed to the body with a ball joint and the other end is hingedly fixed to the running gear. The hydraulic cylinders drive is controlled by electronic devices. One hydraulic cylinder is located horizontally across the riding direction, and the other two are located both sides of the longitudinal axis of the car. When operated, the hydraulic cylinders are moving tangentially to the circle with virtual center located on the car symmetry axis. This structure is simple, takes little space and has good compatibility with the secondary shock absorption stage in vertical and horizontal directions in the track curve.

Active suspension systems are the future of the high-speed rolling stock but currently the control algorithms of active power members used for smoothing the vibration in these systems are underdeveloped therefore they do not ensure good quality of oscillation damping. Such situation is proved by tests in trial bogies with active suspension and by the results of computer simulations. The authors of article [85] suggest to introduce a typical active suspension system including body 1 (Figure 1.58) affected by disturbances 2 , and control unit 3 . This unit operates basing on sensors 4 and 5 signals; the first sensor measures body 1 shifts and the second sensor measures the acceleration. In addition, acoustic noise signal $R$ comes to sensor 5 input because the level of this signal is determined by high frequency components of the body acceleration.

Sensor 4 output is arranged via threshold element 6 , and sensor 5 output signal comes directly to comparison element 7 . The latter output signal, through Kalman filter 8 , effects active power element (actuator) 9 , which generates effort $F$ smoothing the oscillation of body 1 . Several variations of control unit 3 are considered and tested using computer simulation techniques. 


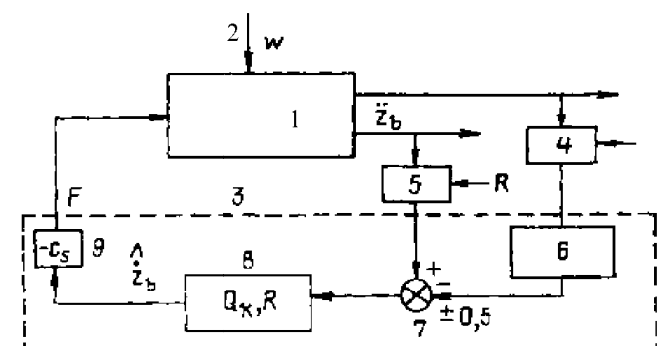

Figure 1.58. Active oscillation damping control system

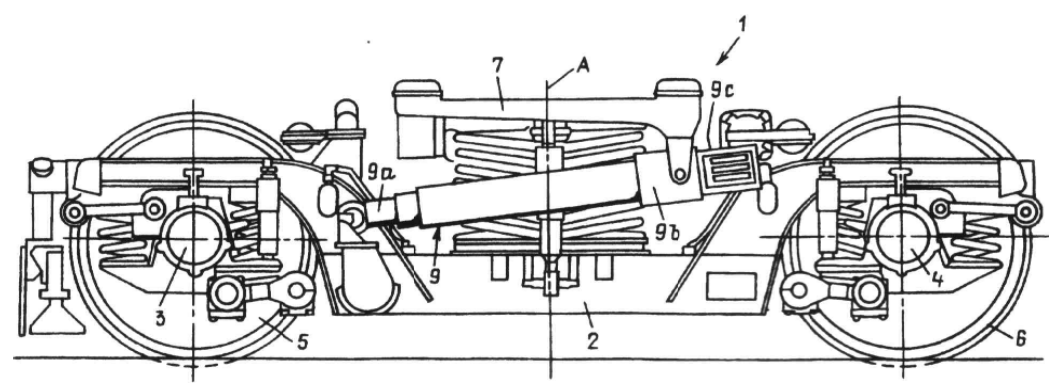

Figure 1.59. Passenger car bogie with active oscillation damping system by application [86]

Application [86] suggests active oscillation damping system for hunting of bogie 1 (Figure 1.59) with frame 2 and wheel pairs 3-4, which tyres 5-6, when rolling by rails, cause rotational oscillation of all the bogie 1 around vertical axis $A$. To damp this oscillation, controlled power member 9 is installed between frame 2 of bogie 1 and central suspension bogie bolster 7 (on both sides of the bogie). One end $9 a$ of this member is hingedly fixed on frame 2 and the other end $9 a$ is fixed on bogie bolster 7 also using the hinged connection. As members 9 , it is recommended to use hydraulic power cylinders controlled by electronic circuit including sensors 2 of the frame turn relative to car body. Application of the suggested unit helps to significantly smooth the transverse oscillation and to improve the bogie and the car riding comfort.

The authors of invention [87] offer a method of electronic control of pneumatic car air springs. Each of the four air springs is equipped with a pressure sensor, which signals come to a regulator. The regulator commands come to control solenoid, which connects the air springs with distribution air mains. The electronic units compare the values of pressure difference in air springs with the set difference value. When the absolute air-springs internal pressure difference in front and rear bogies exceeds the set value, the regulator generates the command for opening 
the solenoid thus removing the pressure difference in all the air-springs. Electronic air springs control provides for smooth ride in curves and prevents from the wheels oscillation.

In the unit offered by [88], the suspension characteristics are improved by way of response speed increasing and providing for the own suspension oscillation frequency in wide frequency range. Suspension system includes operability diagnostic gauge and suspension mechanical oscillation gauge connected with a friction transducer. Regulation units of each air spring are independently connected to functional transducer control block. The working medium of hydraulic damper is the magnetorheological liquid, and the hydraulic damper resistance is regulated by working medium viscosity electromagnet control.

The group of systems improving the dynamic qualities of railway vehicles and reducing their motion resistance includes the body tilting systems and bogie turning systems. Let us consider the structure of some of them.

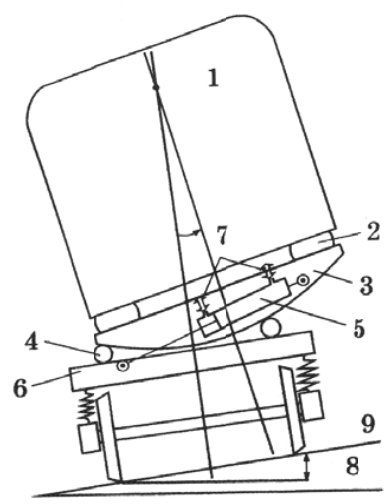

Figure1.60. Kinematic diagram of oscillation damping using the air springs

Article [89] suggests (Figure 1.60) central body 1 suspension for a passenger car consisting of air springs 2 and special transom 3 , which may move on rollers 4 under the force created by hydraulic drive 5 . The system ensures tilt angle 7 of $\pm 5^{\circ}$ relative to bogie frame 6 , which together with external track rail 9 elevation 8 provides for the necessary compensation of transverse acceleration effecting the passenger at the train movement along the curved line in plan. In the article, two options of the suspension structure are considered, the functional diagram of the tilt control system based on gyroscopic sensors is presented, the test results are reported and the respective oscillograms are analyzed.

The authors of patent [90] offer bogie hunting hydraulic stabilizer. For this, several torsion bars are fixed horizontally on the body across the longitudinal axis. Their ends through vertical levers are connected with hydraulic damping members. 
In such structure, the resultant forces of the hunting stabilization are not transferred to the body (no stabilizing moment is present around the vertical axis).

Application [91] suggests the hydraulic damper of the bogie sinuous movement oscillation with automatic regulation of the resistance force depending on the speed of the bogie frame movement relative to the body. The damper consists of the housing with end covers, inside which the piston and fixed head are located. The piston divides the working cavity of the housing into chambers $\mathrm{C} 1$ and $\mathrm{C} 2$ and the fixed head - into chambers C2 and C3. C3 chamber is connected with hydropneumatic accumulator using a pipeline. The structures of piston head and fixed head are identical and include channels with high hydraulic resistance, a channel with low hydraulic resistance equipped with return valve and a spool with a ball lock. When damping low frequency oscillations of the bogie sinuous movement, the spools take extreme left position providing for chambers $\mathrm{C} 1-\mathrm{C} 2$ and $\mathrm{C} 2-\mathrm{C} 3$ communication through the channels with high hydraulic resistance. In this case, the damper resistance force in increased proportionally to the speed of the piston movement in compliance with the hydraulic resistance characteristic of the channels throttles. At sudden piston movement speed growth when passing switches or cross-like intersections of tracks, the damper hydraulic resistance drops abruptly. In this case, the chambers communicate via the channel with low hydraulic pressure. At nominal piston movement speed, the spools take their initial position.

The improvement of horizontal engine dynamic in straight and curved track sections is achieved by the special tracer application [92] consisting of rods, which one end interacts, via rollers, with the curved surface of the body frame plates and the other end is fixed to the bogie bolster via springs. When moving along the curved line and at angle body and bogie movements, the plates move longitudinally transferring the movement to the rods and deforming the springs, in which the restoring forces occur.

The freight car bogie turn unit [93] consists of pneumatic cylinders, in which the turning moment relative to the bogie vertical axis is created at the car frame shifts in the curved track sections relative to the bogie frame.

To improve the dynamic qualities of the railway vehicles themselves and to improve the railway vehicles and track interaction conditions, various other units and structures for damping the efforts between the vehicles may be used, such as [94-96], as well as units for damping the elements of the track top structure [97; 98]. 


\section{FRICTION DRAFT GEARS}

Let us consider friction draft gears. Below are the models reflecting the basic properties of these units. These models are good for calculation of forces and simulation of the vehicle collisions during shunting operations and longitudinal oscillations in trains at transitional riding modes using modern computing devices.

Power characteristic of elastofriction draft gear (power $S$ as a function of phase state: extension $q_{\mathrm{f}}$ and extension speed $\left.\dot{q}_{\mathrm{f}}\right)$ is shown in Figure 2.1,a, where $S_{\mathrm{l}}\left(q_{\mathrm{f}}\right)$ is the power characteristic under loading when $\dot{q}_{\mathrm{f}}>0$ and $S_{\mathrm{u}}\left(q_{\mathrm{f}}\right)$ is the power characteristic under unloading $\left(\dot{q}_{\mathrm{f}}<0\right)$. The values of $S_{10}$ and $S_{\mathrm{u} 0}$ are the forces of the draft gear initial pressure under loading and unloading. The function shown in Figure 2.1, $a$ is described by following expression [3; 78]:

$$
|S|=\left\{\begin{array}{lll}
S_{1}\left(q_{\mathrm{f}}\right), & \text { if } \quad q_{\mathrm{f}} \dot{q}_{\mathrm{f}} \geq 0 ; \\
S_{\mathrm{u}}\left(q_{\mathrm{f}}\right), & \text { if } \quad q_{\mathrm{f}} \dot{q}_{\mathrm{f}}<0 ; \\
|S| \in\left[S_{\mathrm{u}}\left(q_{\mathrm{f}}\right), S_{1}\left(q_{\mathrm{f}}\right)\right], & \text { if } \quad \dot{q}_{\mathrm{f}}=0 .
\end{array}\right.
$$

The last row in expression (2.1) demonstrates that at $\dot{q}_{\mathrm{f}}=0$ force $S$ cannot be determined explicitly and may have any value in the specified interval, which is the "dead" zone for the shock absorber [99; 100].

a)

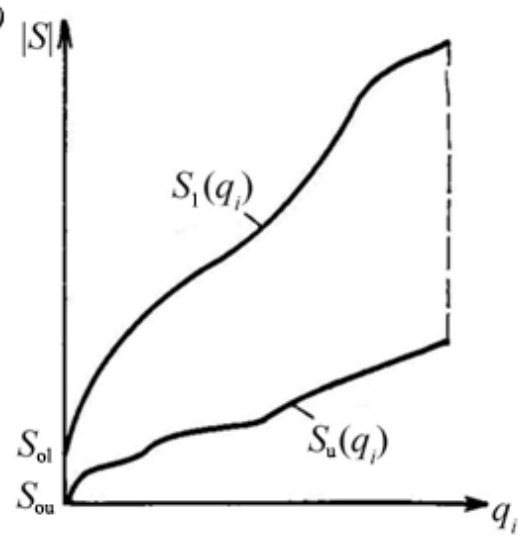

b)

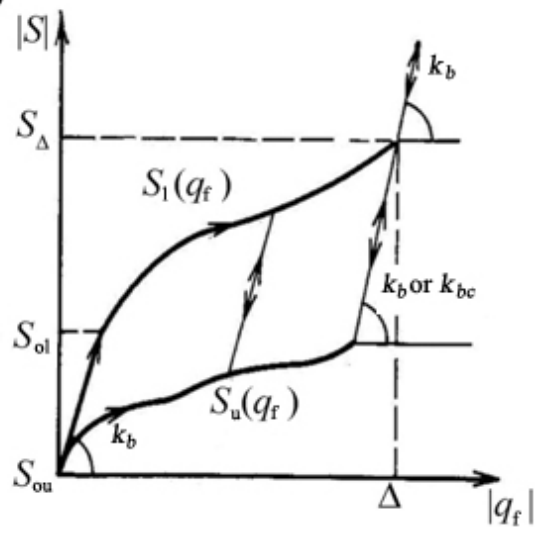

Figure 2.1. Power characteristics of elastofriction draft gear $(a)$ and equivalent connection member consisting of resilient and elastofriction parts $(b)$

For friction shock absorbers with big coefficient of irreversible energy absorption (about a unity), the power characteristic given above is idealized. In reality, such shock absorber compression is not monotonous but proceeds with stops and 
abrupt jerks. This is explained by the fact that due to high pressure transferred to the interacting surfaces they are "grasped" from time to time and then are released and slid [101]. The idealized power characteristic (Figure 2.1,a) may be considered as the result of energy averaging, which may be used only for the determination of the biggest force values acting on the railway vehicles at impacts [101; 102]. Occasionally occurring grasps and releases form alternating step-like varying force acting on the vehicle and causing intensive body and equipment oscillation. It is obvious that these phenomena should be taken into account when studying the vehicle and cargo elements acceleration. The detailed description of the model of the gear considering its separate parts movement and rheological friction properties on the interacting surfaces is given in work [78]. Phenomenological model of the gear, which compression is accompanied with alternating grasps and releases, will be given below.

The analysis of expressions (2.1) shows the force dependence on the resilient friction gear extension may be presented using an algebraic expression.

Integrate the element corresponding to the friction gear and element $\mathbf{k}$ into one element with total extension of $q_{\mathrm{f}}$. Dependence $S\left(q_{\mathrm{f}}, \dot{q}_{\mathrm{f}}\right)$ is shown graphically in Figure 2.1, $b$ and analytically (for application in numerical integration of motion equations) in form of the following expression [3]:

$$
S=\left\{\begin{array}{lll}
{\left[S_{\Delta}+k_{k}\left(\left|q_{\mathrm{f}}\right|-\Delta\right)\right] \operatorname{sign} q_{\mathrm{f}}+\beta_{k} \dot{q}_{\mathrm{f}},} & \text { if } \quad & q_{\mathrm{f}} \geq \Delta ; \\
\min \left\{S_{\mathrm{l}}\left(\left|q_{\mathrm{f}}\right|\right), S_{k p}\left(\left|q_{\mathrm{f}}\right|\right)\right\} \operatorname{sign} q_{\mathrm{f}}, & \text { if } & q_{\mathrm{f}} \dot{q}_{\mathrm{f}} \geq 0 ; \\
\max \left\{S_{\mathrm{u}}\left(\left|q_{\mathrm{f}}\right|\right), S_{k p}\left(\left|q_{\mathrm{f}}\right|\right)\right\} \operatorname{sign} q_{\mathrm{f}}, & \text { if } & q_{\mathrm{f}} \dot{q}_{\mathrm{f}}<0,
\end{array}\right.
$$

where $S_{\Delta}$ is the force corresponding to full extension of an integrated element;

$S_{\mathrm{l}}\left(\left|q_{\mathrm{f}}\right|\right)$ is the force as a function of the element extension under loading if $q_{\mathrm{f}}<\Delta ; \Delta$ is the stroke - full (maximum possible) extension of the integrated element;

$S_{b c}\left(\left|q_{\mathrm{f}}\right|\right)=\tilde{S}+k_{b}\left(\left|q_{\mathrm{f}}\right|-\tilde{q}_{\mathrm{f}}\right)+\beta_{k}\left(\dot{q}_{\mathrm{f}}-\dot{\tilde{q}}_{\mathrm{f}}\right) \operatorname{sign} q_{\mathrm{f}} ;$

$S_{\mathrm{u}}\left(\left|q_{\mathrm{f}}\right|\right)$ is the force as a function of extension under unloading;

$\tilde{S}=\left|S\left(t-h_{t}\right)\right| ; \tilde{q}_{\mathrm{f}}=\left|q_{\mathrm{f}}\left(t-h_{t}\right)\right| ; \dot{\tilde{q}}_{\mathrm{f}}=\dot{q}_{\mathrm{f}}\left(t-h_{t}\right) ;$

$h_{t}$ is the step of integration.

Let us consider some possible conditions [78] of railway vehicles connections.

Suppose there was the loading at moment $\left(t-h_{t}\right)$ and $\tilde{S}=S_{\mathrm{l}}\left(q_{\mathrm{f}}\right)$. Connection state corresponds to point 1 in Figure 2.2, $a$. At moment of time $t$, we determine $S_{b c}$ (point 3) and $S_{1}$ (point 2). As the draft gears operation conditions presuppose that inequality $S_{\mathrm{f}}<S_{\mathrm{l}}$ is met, point 3 does not correspond to possible connection states and the force is determined by point 2 . If at moment of time $\left(t-h_{t}\right)$ the connection state was determined by force $\tilde{S}=S_{\mathrm{f}}\left(t-h_{t}\right)=S_{b c}\left(q_{\mathrm{f}}\right)$ (point 1 in Figure 2.2,b) and $\dot{q}_{\mathrm{f}}>0$, this means that at moment of time $t$ point 3 corresponded to value $S_{b c}$ and point 2 corresponded to value $S_{1}$. As the force change at transition from point 1 into 
point 3 does not result in force overcoming friction in the draft gear, value $q_{\mathrm{f}}$ stays unchanged. Therefore, the connection state is described by point 3 not point 2, which would correspond to the connection state at the wedges sliding. Suppose in the course of the next step (by moment $\left(t+h_{t}\right)$ ) value $q_{\mathrm{f}}$ changes so that point 5 now corresponds to values $S_{b c}\left(q_{\mathrm{f}}\right)$. The force acting on the draft gear at $q_{\mathrm{f}}<\Delta$ cannot exceed value $S_{1}\left(q_{\mathrm{f}}\right)$. Therefore, in this case point 4 , not 5 , corresponds to the connection state. The analysis above reveals the sense of the second line in expression (2.2). Similarly, we can verify the correctness of the last line of the same expression.

a)

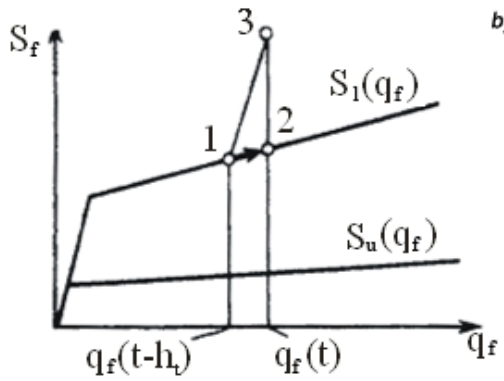

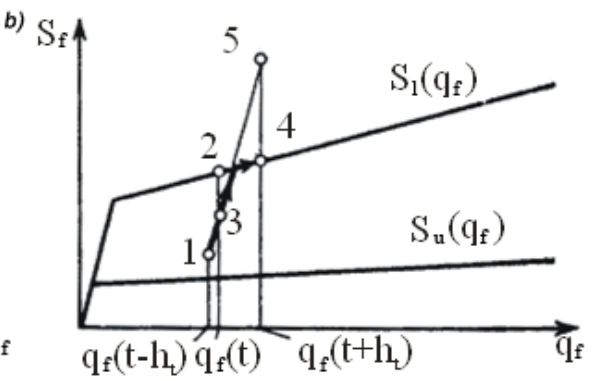

Figure 2.2. Logical relations determining $S_{\mathrm{l}}\left(q_{\mathrm{f}}\right)$ dependence under loading: $a$-at wedges $1-2$ sliding; $b$-at wedges $1-3$ equilibrium and wedges $3-4$ sliding

The work of force at full extension of the draft gear makes:

$$
A=\int_{0}^{\Delta} S_{1}\left(q_{\mathrm{f}}\right) d q_{\mathrm{f}} .
$$

At the same time, irreversibly absorbed work

$$
A_{\mathrm{abs}}=\int_{0}^{\Delta}\left[S_{\mathrm{l}}\left(q_{\mathrm{f}}\right)-S_{\mathrm{u}}\left(q_{\mathrm{f}}\right)\right] d q_{\mathrm{f}}
$$

is characterized by relative value

$$
\eta=A_{\mathrm{abs}} / A .
$$

Function $S_{\mathrm{u}}\left(q_{\mathrm{f}}\right)$ can be defined analytically. However, without any significant error, it can be defined as follows:

$$
S_{\mathrm{u}}=(1-\eta) S_{1}\left(q_{\mathrm{f}}\right) .
$$

Functions $S_{\mathrm{l}}\left(\left|q_{\mathrm{f}}\right|\right)$ and $S_{\mathrm{u}}\left(\left|q_{\mathrm{f}}\right|\right)$ are non-linear in general case. If applied to the description of the operation of friction draft gears in existing structure automatic couplings, it can be considered that: 


$$
S_{1}\left(\left|q_{\mathrm{f}}\right|\right)=S_{01}+k_{1}\left|q_{\mathrm{f}}\right|, \quad S_{\mathrm{u}}\left(\left|q_{\mathrm{f}}\right|\right)=(1-\eta) S_{1}\left(\left|q_{\mathrm{f}}\right|\right),
$$

where $k_{1}$ is the stiffness of an integrated element under loading. Value $k_{1}$ is determined by stiffness $k$ of all the serially connected resilient friction members and element k, i. e.

$$
k_{1}=k /\left(1+k / k_{k}\right) \text {. }
$$

In more general case, function $S_{\mathrm{l}}\left(\left|q_{\mathrm{f}}\right|\right)$ can be set out by piecewise linear dependence (Figure 2.3,a):

$$
S_{1}\left(\left|q_{\mathrm{f}}\right|\right)=\left\{\begin{array}{r}
S_{\mathrm{lj}}+\left[\left(S_{\mathrm{lj}+1}-S_{\mathrm{lj}}\right) /\left(q_{\mathrm{f} j+1}-q_{\mathrm{fj}}\right)\right]\left(\left|q_{\mathrm{f}}\right|-q_{\mathrm{fj}}\right), \\
\quad \text { if }\left(\left|q_{\mathrm{f}}\right| \in\left[q_{\mathrm{fj}}, q_{\mathrm{f} j+1}\right]\right) \cap\left(S_{\mathrm{lj}+1} \geq S_{\mathrm{lj}}\right) ; \\
S_{\mathrm{lj}+1}, \quad q_{\mathrm{f}}=q_{\mathrm{f} j+1}, \quad q=q+\left(q_{\mathrm{fj}+1}-q_{\mathrm{f} j}\right) \operatorname{sign} q, \\
\quad \text { if }\left(\left|q_{\mathrm{f}}\right| \in\left[q_{\mathrm{fj}}, q_{\mathrm{f} j+1}\right]\right) \cap\left(S_{\mathrm{lj}+1}<S_{\mathrm{lj}}\right),
\end{array}\right.
$$

where $q_{\mathrm{f} j}$ and $S_{\mathrm{l} j}$ are the junction points coordinates.

Formulae (2.9) allow for "grasping" and instant wedge sliding phenomena simulating (Figure $2.3, b$ ) that is described by the second condition. When applying formulae (2.9), function $S_{\mathrm{u}}\left(q_{\mathrm{f}}\right)$ is calculated using the second expression in formulae (2.7) or using the following expression

$$
S_{\mathrm{u}}\left(q_{\mathrm{f}}\right)=S_{0 \mathrm{u}}+k_{\mathrm{u}}\left|q_{\mathrm{f}}\right| \cdot
$$
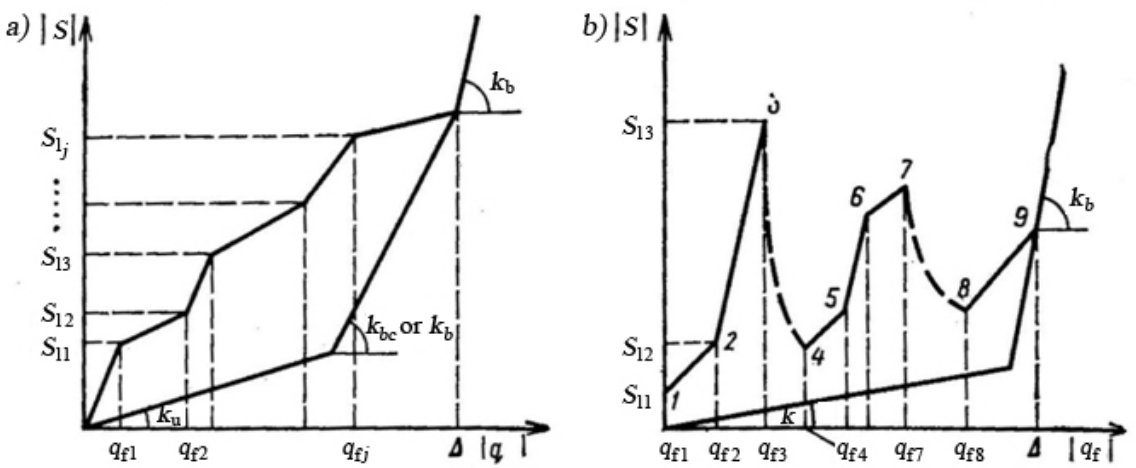

Figure 2.3. Piecewise linear defined power characteristics

When using the given above expressions in calculations, it is necessary to remember that their component parameters describing the existing draft gears are conditional and reflect static estimates found as a result of experimental researches of the draft gears or estimated a priori. 
Friction draft gears may operate almost without the alteration of grasps and releases of interacting surfaces. This may be implemented by application of specially selected materials, at the contact of which the friction force is realized [103], or by special grease lubrication used, for example, in draft gears type Mark by Westinghouse [2]. The characteristics of such draft gears may be estimated a priori at the stage of design and structure development.

The parameters of the expressions above should be determined taking into account the damped structure elasticity (mainly at the loading stage). This is not always practical, especially in the situations when non-linear systems are considered. More practical is mathematical model of connection, which requires only friction draft gear parameters. In such case the following relation should be met

$$
S_{1}\left(q_{\mathrm{f}}-q_{k}\right)=k_{k} q_{k},
$$

where $S_{\mathrm{u}}\left(q_{\mathrm{f}}-q_{k}\right)$ is the set dependence of the force on the friction draft gear stroke under loading $\left(q_{\mathrm{f}}\right.$ is the total extension of the friction draft gear and the equivalent spring with $k_{k}$ stiffness).

Then, in the course of numerical solution of non-linear equation (2.11) relative to $q_{k}$, we calculate force $S$ using expressions (I.4) - (I.8) [3].

The same task may be solved another way [104]. Suppose the draft gear extension is equal to $q_{a}=\left|q_{\mathrm{f}}\right|-\left|q_{k}\right|$ and values $q_{a}$ and $S$ are known at $\left(t-h_{t}\right)$ moment of time. Also, suppose that during the period starting from moment $\left(t-h_{t}\right)$ till moment $t$ value $\Delta q_{a}$ changes so that expansion of function $S\left(q_{a}\right)$ using Taylor formula by $\Delta q_{a}$ may be limited by summand with second-order small quantities, i. e.

$$
S_{1}(t)=S_{1}\left(t-h_{t}\right)+k_{1} \Delta q_{a}+0.5 k_{2} \Delta q_{a}^{2},
$$

where

$$
k_{v}=\partial^{v} S_{1} /\left.\partial q_{\vec{a}}^{v}\right|_{\dot{a}}(t-h), v=1.2
$$

At the same time,

$$
S_{1}(t)=S_{1}\left(t-h_{t}\right)+k_{k}\left(\Delta\left|q_{\mathrm{f}}\right|-\Delta q_{a}\right) .
$$

Equating force increments $\Delta S_{1}=S_{\mathrm{l}}(t)-S_{\mathrm{l}}\left(t-h_{t}\right)$ calculated using expressions (2.12) and (2.13), we receive quadratic equation solved as follows:

$$
\Delta q_{a}=b_{1}\left(\sqrt{1+b_{2} \Delta q_{\mathrm{f}}}-1\right)
$$

where $b_{1}=\left(k_{k}+k_{1}\right) k_{2}^{-1} ; b_{2}=2 k_{2} b_{1}^{-1}\left(k_{k}+k_{1}\right)^{-1}$.

Value $\Delta q_{1}=\left|q_{\mathrm{f}}(t)\right|-\left|q_{\mathrm{f}}\left(t-h_{t}\right)\right|$ is calculated using the data of interacting bodies movement equations integration performed using formulae (I.2) and (I.3). Then, basing on expressions (2.13) or (2.12), force $S$ is calculated. The integration interval $h_{t}$ should be chosen so that

$$
\left|\Delta q_{a}\right|>>\left(3 k_{2} / k_{3}\right) ; \quad k_{3}=\max \frac{\partial^{3} S_{1}}{\partial q_{a}^{3}}, \quad q_{a} \in[0, \Delta] .
$$


Simulation of rubber-metal draft gears is connected with solution of hereditarity integral equations [105]. Though, as is proved by experimental researches, these gears simulation may be similar to friction draft gears simulation using non-linear function $S_{1}\left(\left|q_{\mathrm{f}}\right|\right)$. This, to a great degree, is conditioned by the fact that time characteristics of stresses at cars collisions changes are not so important. A specific feature of such simulation is the replacement of value $k_{b}$ with value $k_{b c}$ characterizing the specificity of draft gears transition from loading to unloading in expression (2.2). 


\section{SPRING SUSPENSION AND FRICTION OSCILLATION DAMPERS IN FREIGHT CARS BOGIES}

\subsection{Plane Oscillation}

Let us consider spring suspension in three-member four-wheel freight car bogies with wedge-type friction draft gears model 18-100 (TsNII-Kh3 (ЦНИИ-Х3)). These draft gears should be simulated together with the analysis of spatial bogie loading as the stops at the springs compression during the time interval when the forces acting on the springs are less than the friction force also cause the stops of lateral movements of bogie bolsters. However, in some cases plane oscillations of vehicles are of special interest. Therefore, below we consider the simulation of spring suspension in vertical symmetry plane [106].

Introduce the following symbols: $R$ - vertical support reaction force; $\Delta-$ the value of the bogie bolster movement relative to the side frame; $\Delta_{T}-$ the value of $\Delta$ movement, upon exceeding of which the springs are no more compressed. The $\Delta$ values are calculated for each support using generalized coordinates determined in the process of the vehicle movement differential equations integration and are expressed as the sums of dynamic and static components under the movement forces of gravity.

Stiffness coefficients of the sets resistance to compression under loading and unloading are equal to $c_{\mathrm{l}}$ and $c_{\mathrm{u}}$, respectively. Now let us express the total side frame, bogie bolsters and wheelsets elasticity as the elasticity of equivalent spring with stiffness coefficient $c_{k T}$ located in series with springs and friction draft gears. Under the forces when the sets springs' deformations values do not change, only this spring is deformed.

The values of the supports reaction forces are calculated in the process of the vehicles movement equations integration using the following formulae:

$$
R=\left\{\begin{array}{lll}
0, & \text { if } \quad \Delta \leq 0 ; \\
\min \left\{c_{\text {load }} \Delta, R_{k T}\right\}, & \text { if } \quad(\Delta>0) \cap(\dot{\Delta} \geq 0) \cap\left(\Delta \leq \Delta_{\dot{O}}\right) ; \\
\max \left\{c_{\text {unload }} \Delta, R_{k T}\right\}, & \text { if } \quad(\Delta>0) \cap(\dot{\Delta}<0) \cap\left(\Delta \leq \Delta_{\dot{O}}\right) ; \\
R_{k T}, & \text { if } \quad \Delta>\Delta_{\dot{O}} .
\end{array}\right.
$$

Energy dissipation coefficient is calculated using the formulae similar to those given in the previous section.

In cases when the spring suspension sets do not work, the force is calculated

$$
R_{k T}=R\left(t-h_{t}\right)+\tilde{n}_{k T}\left[\Delta(t)-\Delta\left(t-h_{t}\right)\right]+\beta_{k T}\left[\dot{\Delta}(t)-\dot{\Delta}\left(t-h_{t}\right)\right],
$$

where $\beta_{k T}$ is the coefficient of viscous resistance to deforming determined experimentally.

The reaction forces calculated using expression (3.1) include static and dynamic components. To extract the dynamic component, the following formula is used: 


$$
R_{\mathrm{D}}=R-R_{\mathrm{ST}},
$$

where $R_{\mathrm{ST}}$ is the know static component of reaction forces.

In cases when the bogie structure allows for the bogie bolsters to turn relative to the side frames [107], moments $M_{T b}$ of forces restoring the normal position of the bogie bolster are calculated in compliance with the specified relation (equation of state):

$$
M_{T b}=c_{\varphi}\left(1+\beta_{\varphi} d / d t\right)\left(\varphi_{b}-\varphi_{\dot{O}}\right),
$$

where $c_{\varphi}$ is the coefficient of stiffness of spring resistance to the bogie bolster turning relative to the frame; $\beta_{\varphi}$ is the coefficient of viscous resistance to this turn; $\varphi_{b}$ and $\varphi_{T}$ are the angles of the bogie bolster and the bogie frame turning, respectively. In such simplest case, it can be considered that the members restoring the horizontal position of the bogie bolster are viscoelastic.

\subsection{Spatial or 3D-Models}

The specific feature of friction draft gears in model 18-100 (TsNII(КһЗЦНИИ-Х3)) bogies considered in the previous section is the fact that the friction force in vertical ( $z$ axis) and lateral ( $y$ axis) directions occurs at simultaneous vertical and lateral sliding of a spring wedge over the friction slat. In most works on the cars dynamics, such draft gears are simulated as independent mechanisms, i. e. their connections and works are not taken into account $[35 ; 108-114]$. These particulars show themselves as follows. First, friction forces both in vertical and lateral directions are proportional only to the vertical deformations of the bogie suspension springs. Second, in those intervals of time when the value of the force vector is within the limits of the suspension deformations dead zone as a whole and, at some moment, the deformation rate was equal to zero both vertical and lateral deformations of suspension cease. The mathematical model below reflects these particulars of suspension operation in the freight cars bogies specified above.

Usually, the forces in suspension and the suspension deformations are indexed with figures reflecting the bogie number in the car and the suspension number in the bogie. Here, these indices are not used, and it is supposed that $\Delta$ values of vertical and $\delta$ values of lateral deformations of the respective bogie suspension are determined previously basing on the known [108] algorithms for the given moment of time using the cars movement differential equations integration results as a whole.

The specific features of simulating the suspension with friction draft gears are immediately connected with the physical specificity of friction forces, which, at a standstill, balance all the acting forces until a specific value (force of static friction) is reached. During the motion, the friction force is directed oppositely to the speed vector, that is

$$
\vec{F}_{\mathrm{FR}}=-F \vec{v}_{\mathrm{SL}} / v_{\mathrm{SL}},
$$


Where $F$ is the value of the friction force and $v_{\mathrm{SL}}$ is the rate of the wedge sliding over the friction slat.

The value of the friction force in suspension is

$$
F=\mu c \Delta,
$$

Where $\mu$ is the reduced friction coefficient; $c$ is the spring set stiffness coefficient under compression; $\Delta>0$ is the value of the spring set compression equal to the static and dynamic compression components.

$y$ - and $z$-direction friction forces are equal to

$$
\begin{aligned}
& Y_{\mathrm{FR}}=-F \dot{\delta} /\left(\dot{\Delta}^{2}+\dot{\delta}^{2}\right)^{1 / 2}, \\
& Z_{\mathrm{FR}}=-F \dot{\Delta}\left(\dot{\Delta}^{2}+\dot{\delta}^{2}\right)^{1 / 2} ;
\end{aligned}
$$

where $\delta$ is the lateral movements of the respective spring sets of spring suspension; the dot above the symbol means time derivative of the respective value.

In those cases when only spring suspension sets are working, the supports reactions depend mostly on their deformations only. If the sets do not work, the reaction forces are determined by significantly lesser deformations of members located in series with spring sets (bogie bolster, side frames, wheel pairs, tracks). Taking this into account, $Y$ and $Z$ reaction forces may be calculated using the algorithm described by the following expressions:

$$
\begin{array}{r}
R^{y 0}(t)=Y\left(t-h_{t}\right)+c_{10}\left(1+\beta_{y} d / d t\right)\left[\delta(t)-\delta\left(t-h_{t}\right)\right] ; \\
R^{z 0}(t)=Z\left(t-h_{t}\right)+c_{0}\left(1+\beta_{z} d / d t\right)\left[\Delta(t)-\Delta\left(t-h_{t}\right)\right] ; \\
R^{y}(t)=c_{1} \delta(t)+Y^{\mathrm{FR}}(t) ; \\
Y(t)=\left\{\begin{array}{lll}
R^{y 0}(t), & \text { if } \quad\left(\mid \delta(t)+Z^{\mathrm{FR}}(t) ;\right. \\
\min \left[R^{y 0}(t), R^{y}(t)\right], & \text { if } \quad\left(|\delta(t)| \leq \delta_{\mathrm{M}}\right) \cap(\delta \dot{\delta} \geq 0), \\
\max \left[R^{y 0}(t), R^{y}(t)\right], & \text { if } \quad\left(|\delta(t)| \leq \delta_{\mathrm{M}}\right) \cap(\delta \dot{\delta}<0) ;
\end{array}\right. \\
Z(t)=\left\{\begin{array}{lll}
R^{z 0}(t), & \text { if } \quad\left(\Delta(t)>\Delta_{\mathrm{M}}\right), \\
\min \left[R^{z 0}(t), R^{z}(t)\right], & \text { if } \quad\left(|\Delta(t)| \leq \Delta_{\mathrm{M}}\right) \cap(\Delta \dot{\Delta} \geq 0), \\
\max \left[R^{z 0}(t), R^{z}(t)\right], & \text { if } \quad\left(|\Delta(t)| \leq \Delta_{\mathrm{M}}\right) \cap(\Delta \dot{\Delta}<0), \\
0 & \text { if } \quad \Delta \leq 0,
\end{array}\right.
\end{array}
$$

where $R^{y 0}$ and $R^{z 0}$ are the reaction forces projections in cases when the spring suspension sets do not work in the respective direction; and $R^{y}$ and $R^{z}$ are the reaction forces projections occurring when the car suspension and draft gears 
spring sets are working. In expressions (3.7) - (3.12), $t$ is time; $h_{t}$ is the interval of numerical time integration; $c_{0}$ and $c_{10}$ are the stiffness coefficients of all the deformed car structure and track elements located in series with spring sets in $z$ and $y$ axes directions, respectively; $\beta_{y}$ and $\beta_{z}$ are the coefficients of viscous energy dissipation in the structure elements determined so that the damping decrement of the respective free oscillation was equal to experimentally found [115] value $d=0.35$; $c_{1}$ are the spring sets stiffness coefficients at their bending; $\delta_{\mathrm{M}}$ and $\Delta_{\mathrm{M}}$ are structural limitations of springs bending and compression movements; $U$ and $\cap$ are logical operators "or finction" and "and function", respectively.

During the intervals of time, which are calculated by formulae (3.7) and (3.8) as is required by logical expressions of forces reaction (3.11) and (3.12), the suspensions sets do not work, and the reactions are determined by the bogie frame structure deformability and other listed earlier members.

Vertical reaction forces $Z$ calculated using expressions (3.12) include static and dynamic components. To extract the dynamic component the following formula is used:

$$
Z_{\mathrm{D}}=Z-Z_{\mathrm{ST}}
$$

where $Z_{\mathrm{ST}}$ is the known static component of the reaction forces.

Formulae (3.4), (3.8), (3.10) and (3.12) are applicable for simulation of axlebox oscillation dampers of KVZ-TsNII (КВ3-ЦНИИ) and KVZ-5 (КВ3-5) passenger cars bogies [116] and other similar structures.

When simulating disk oscillation dampers, similar expressions as (3.11) and (3.12) may be applied, but here friction force $F$ is a constant value, which is different for different types of oscillation [117]. 


\section{HYDRAULIC OSCILLATION DAMPERS}

Hydraulic oscillation dampers transform kinetic energy of separate vehicle parts or the whole vehicle motion both into potential energy of working liquid compression in the damper and the energy of the housing and its separate parts deformation and into the heat generated as a result of the liquid overflow overcoming local hydraulic resistances. At the same time, the main part of thus transformed kinetic energy is dissipated.

Extension and shortening of the hydraulic oscillation damper may be forced in the course of motion of the vehicle bodies, to which the ends of the oscillation damper are fixed. First, let us consider the generalized scheme of such damper without the units restoring the initial state.

When the liquid comes though the ports, the pressure drop $\Delta p$ occurs, which determines $Q^{v}$ (volume change) flow or $Q^{m}=\rho Q^{v}$ (weight change) flow of liquid per a unit of time. Volume flow may be calculated using the known correlation [118]

$$
Q^{v}=\mu f \sqrt{2|\Delta p| / \rho} \operatorname{sign} \Delta p,
$$

where $\mu$ is the flow coefficient; $f$ is the port section area; $\rho$ is the liquid density.

The flow coefficient depends on Reynolds number

$$
\operatorname{Re}=u d / v \text { or } \operatorname{Re}_{p}=(d / v) \sqrt{2|\Delta p| / \rho},
$$

Where $u$ the liquid flow rate though the throttling port; $d$ is the typical size; $v$ is the kinematic viscosity coefficient.

Flow coefficient $\mu$ also depends on the port contour configuration, the relation of the hydraulic diameter and the channel length, the channel finishing degree and the port edges shape, the concentration of gas dissolved in the liquid, the liquid temperature, the backpressure and on other factors. Usually, $\mu$ is determined experimentally for specific ports and conditions [118; 119].

Generalized diagram of hydraulic damper working in compression is given in Figure 4.1. However, the mathematical model description below stays unchanged when analyzing reversal loads.

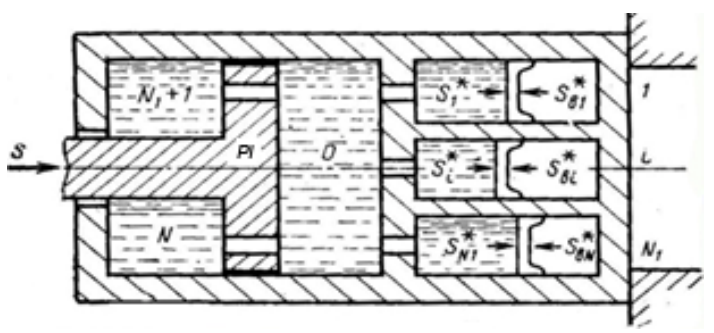

Figure 4.1. Generalized hydraulic damper calculation diagram 
The figure illustrates the housing with moving plunger pressing the viscous liquid out of the before-plunger chamber $O$ into $N$ of other auxiliary chambers and into $(N+1)$ chamber in the after-plunger cavity. In each of the auxiliary chambers, there are the units pressing the liquid out of them into the main chamber when reversing. Having overcome the friction resistance in the seal boots, force $S$ acting on plunger $P l$ creates pressure $p_{0}$ in liquid filled chamber $O$, which is equal to

$$
\left.\begin{array}{l}
p_{0}=S_{0} / F_{0}, \\
S_{0}=\left(S+S_{N+1}\right) /\left(1+\kappa_{0} \operatorname{sign} q_{0} \dot{q}_{0}\right),
\end{array}\right\}
$$

Where $S_{0}$ is the force acting on plunger $P l$ having area $F_{0}$ at chamber $O$ side; $S$ is the force compressing the oscillation damper or its compression resistance force; $S_{N+1}$ is the force acting on the piston at $N+1$ chamber side; $\kappa_{0}$ is the friction force coefficient at movement $q_{0}$ of plunger $P l$.

It is assumed that force $S$ is calculated using formulae

$$
S=k_{k} q_{k}+\beta_{k}\left|q_{k}\right| \dot{q}_{k}
$$

or

$$
S=k_{k} q_{k}+\beta_{k} \dot{q}_{k}
$$

Where $k_{k}$ is $\mathbf{k}$ member stiffness and $\beta_{k}$ is the coefficient of its viscous resistance to deforming. Usually, $\beta_{k}$ is a small value, and in a number of cases, the viscous component in expressions (4.4) and (4.5) can be neglected. Value

$$
q_{k}=q-\sum_{i=1}^{n_{a}} a_{i} q_{i} \operatorname{sign} q
$$

is equal to total deformation of viscoelastic members of the structure located in series with the oscillation damper; $q_{i}$ is the oscillation damper compression value conditioned by the liquid overflow from cavity $O$ into cavity numbered $i ; a_{i}$ is the number of cavities the liquid overflows to from cavity $O$.

Now let us assume that in each chamber, into which the liquid is forced from the before-piston chamber, there is a mechanism providing for creation of backpressure $p_{i}$ equal to force $S_{R i}^{*}$ divided by the area of chamber numbered $i$. Force $S_{R i}^{*}$ agrees with force $S_{R i}$ reduced to the plunger area and equal to

$$
S_{R i}=S_{R i}^{*} F_{0} / F_{i},
$$

where $F_{i}$ is the area of chamber numbered $i$.

Each channel of liquid overflow from one chamber to another may consist of serially located hydraulic resistances characterized by value $f_{i j}$ of the section area of throttling port and coefficient $\mu_{i j}$ of volume flow rate and related to the channels to chambers numbered $i$. Index $j$ corresponds to the serial number of hydraulic resistance in the given chamber. 
Volume flow rate $Q_{i}^{v}$ of liquid flowing from chamber $O$ into chamber numbered $i$ will comprise:

$$
Q_{i}^{v}=\left(\sum_{j} \mu_{i j} f_{i j}\right) \sqrt{2\left|p_{0}-p_{i}\right| / \rho_{i}} \cdot \operatorname{sign}\left(p_{0}-p_{i}\right) .
$$

In this expression, $\rho_{i}$ is the density of liquid in chamber numbered $i$ :

$$
\rho_{i}=\rho\left(1+\varepsilon_{i}\left(p_{i}, t^{\circ}\right)\right) \text {, }
$$

where $\rho$ is the liquid density at $p=0.1 \mathrm{MPa}$ and temperature $t^{\circ}=0^{\circ} \mathrm{C} ; \varepsilon_{i}\left(p_{i}, t^{\circ}\right)$ is relative change of initial liquid volume due to the pressure and initial temperature change before its compression; $p_{i}$ is the pressure excess over the atmospheric pressure; $t^{\circ}$ is the initial liquid temperature.

Relative change of liquid volume $\Delta V_{\mathrm{lq}} / V_{\mathrm{lq}}$ at possible changes of initial temperatures won't exceed 0.1 per cent [120]. Therefore, let us consider that $\varepsilon_{i}\left(p_{i}, t^{\circ}\right)$ is the relative change of volume due to the used liquid compression only [119] and retain the variable $t^{\circ}$ in expression (4.9) as the liquid compressibility modulus depends on pressure and temperature:

$$
E_{\mathrm{lq}}=d p / d \varepsilon \text {. }
$$

When calculating the shock absorbers, two values of liquid compressibility modulus should be considered: compressibility modulus $E_{\mathrm{lq} \text {.iso }}$ at isothermal process when the temperature at compression is constant (slow or static loading) and compressibility modulus $E_{\mathrm{lq} \text {.ad }}$ at adiabatic process when the compressed liquid temperature changes and the heat exchange in time internal in question $\Delta t$ may be neglected.

For example, work [120] gives the empirical dependence of compressibility coefficient $\gamma_{u}=1 / E_{\mathrm{lq} \text {.iso }}$ on the temperature and pressure at isothermal process for AMG-10 (АМГ-10) oil. This dependence suggests that

$$
E_{\text {lq.iso }}=\left(67+0.44 t^{\circ}-0.4 p\right)^{-1} \cdot 10^{5} \text {. }
$$

Basing on the information of [121], we can plot the empirical dependence $E_{\mathrm{lq} \text {.ad }}\left(p_{i}, t^{\circ}\right)$ for adiabatic process as

$$
E_{\text {lq.ad }}=18.4 \cdot 10^{2}\left(1-4.4 \cdot 10^{-3} t^{\circ}\right)\left(1+8.2 \cdot 10^{-3} p\right) .
$$

According to relation (4.10)

$$
\varepsilon_{\text {iso }}\left(p, t^{\circ}\right)=\int_{0}^{p} E_{\text {lq.iso }}^{-1}\left(p, t^{\circ}\right) d p .
$$

For AMG-10 (АМГ-10) oil, for example,

$$
\varepsilon_{a d}=\left(67+0.44 t^{\circ}-0.2 p\right) p \cdot 10^{-5} .
$$


Taking into account that $\varepsilon_{u}$ value is small, making approximate calculation we can assume

$$
\left.\begin{array}{l}
\varepsilon_{\text {iso }} \approx\left(67+0.44 t^{\circ}\right) p \cdot 10^{-5}=\left(p / E_{\text {lq.iso }}\right) \\
E_{\text {lq.iso }} \approx\left(67+0.44 t^{\circ}\right)^{-1} \cdot 10^{5} \mathrm{MPa} .
\end{array}\right\}
$$

Identically

$$
\varepsilon_{a d}=\left(82 E_{\mathrm{lq} . \mathrm{ad}}\right)^{-1} \cdot 10^{-4} \ln \left(1+8.2 \cdot 10^{-3} p\right)
$$

or approximately

$$
\left.\begin{array}{l}
\varepsilon_{a d} \approx p / E_{\mathrm{lq} . \mathrm{ad}} ; \\
E_{\mathrm{lq} . \text { ad }} \approx 18.4 \cdot 10^{2}\left(1-4.4 \cdot 10^{-3} t^{\circ}\right) .
\end{array}\right\}
$$

The calculation shows that application of formulae (4.15) and (4.17) results in less than 3 per cent error in determination of $\varepsilon$ under $p=100 \mathrm{MPa}$.

Thus, expression (4.9) may be set out as follows

$$
\rho_{i}=\rho\left(1+p_{i} / E_{\mathrm{lq}}\right) \text {. }
$$

Liquid flow by weight from chamber $O$ is

$$
Q_{0}^{m}=F_{0} \rho_{\hat{I}} v_{0}=\sum_{i=1}^{N} \rho_{i} Q_{i}^{v}=\sum_{i=1}^{N} F_{i} \rho_{i} v_{i}^{*},
$$

where $v_{i}^{*}$ is the rate of piston movements in $i$ chamber.

After integrating, we have

$$
F_{0} \rho_{\hat{I}} q_{\hat{I}}^{*}=\sum_{i=1}^{N} F_{i} \rho_{i} q_{i}^{*},
$$

where $q_{O}^{*}$ is the piston movement in chamber $O$ (plunger) evoked only by the liquid displacement from the chamber.

Full plunger movement will comprise

$$
q_{O}=q_{O}^{*}+\Delta q_{O},
$$

where $\Delta q_{O}$ is the additional movement due to the liquid volume compression in chamber $O$.

$$
\Delta q_{\hat{I}}=\left(m_{O} / \rho_{\hat{I}}^{0} F_{0}\right)-\left(m_{O} / \rho_{\hat{I}} F_{0}\right) ; m_{O}=\rho_{\hat{I}}^{0} F_{0}\left(\bar{l}-q_{\hat{I}}^{*}\right),
$$

where $m_{O}$ is the weight of the liquid in chamber $O ; \rho_{\hat{I}}^{0}$ is the density of the liquid in chamber $O$ at initial pressure $p_{O}^{0} ; \bar{l}$ is the distance between the plunger and fixed partition in the initial state. 
Considering expression (4.18), after simple transformation, we have

$$
\Delta q_{\hat{I}}=\left(p_{\hat{I}} E_{\mathrm{lq} 0}^{-1}-p_{\hat{I}}^{0} E_{\mathrm{lq} 00}^{-1}\right)\left(\bar{l}-q_{\hat{I}}^{*}\right) /\left(1+p_{\hat{I}} E_{\mathrm{lq} 0}^{-1}\right),
$$

where $E_{\mathrm{lq} 0}$ and $E_{\mathrm{lq} 00}$ are the values of the liquid compressibility moduli in chamber $O$ under pressures $p_{O}$ and $p_{O}^{0}$, respectively.

Let us insert this expression into equation (4.21) and replace the movements with reduced values

$$
q_{i}=F_{i} q_{i}^{*} / F_{0}
$$

Then

$$
q_{\hat{I}}=\sum_{i=1}^{N} \frac{\left(1+p_{\hat{I}}^{0} E_{\mathrm{lq} 00}^{-1}\right)\left(1+p_{i} E_{\mathrm{lq} i}^{-1}\right)}{\left(1+p_{\hat{I}} E_{\mathrm{lq} 0}^{-1}\right)^{2}} q_{i}+\frac{p_{\hat{I}} E_{\mathrm{lq} 0}^{-1}-p_{\hat{I}}^{0} E_{\mathrm{lq} 00}^{-1}}{1+p_{\hat{I}} E_{\mathrm{lq} 0}^{-1}} \bar{l} .
$$

At $q_{i}$ the coefficient in expression (4.24) is approximately equal to one. As the liquid compressibility is mostly expressed at values $p_{O}>>p_{O}^{0}$, let us replace expression (4.24) with more simple approximation

$$
q_{\hat{I}}=\sum_{i=1}^{N} q_{i}+p_{\hat{I}} \overline{l E}_{\mathrm{lq}}^{-1} ; \quad \bar{E}_{\mathrm{lq}}=\bar{E}_{\mathrm{lq}}+\bar{p}_{\hat{I}} ; \quad E_{\mathrm{lq}}=E_{\mathrm{lq}}\left(\bar{p}_{\hat{I}}, t^{o}\right),
$$

where $\bar{p}_{O}$ is the average expected value; $E_{\mathrm{lq}}$ is the liquid compressibility modulus corresponding to pressure $\bar{p}_{O}$ and initial temperature $t^{\circ}$ for isothermal or adiabatic processes depending on type of loading, slow or fast (impact), considered.

Instead of expression (4.25), it is more convenient to apply expressions

$$
q_{\hat{I}}=\sum_{i=1}^{N} q_{i}+S_{0} / k_{\mathrm{lq}}, \quad k_{\mathrm{lq}}=\bar{E}_{\mathrm{lq}} F_{0} / l .
$$

When arranging for the numerical integrating, it is convenient to consider the element with stiffness coefficient $k_{\mathrm{lq}}$ as the resilient member located in series with member $\mathbf{k}$ with stiffness coefficient $k_{k}$ in expressions (4.4) and (4.5), having replaced value $k_{k}$ with value $k_{k}^{*}=k_{k} k_{\mathrm{lq}} /\left(k_{k}+k_{\mathrm{lq}}\right)$. At the same time, instead of sum (4.26), sum $q_{O}=\sum_{i=1}^{N} q_{i}$ is used.

To calculate $q_{O}$, it is necessary to determine $q_{i}$ values. For this, taking into account the above assumptions, expression (4.8) is used.

After simple transformations and going into the reduced values, we have the following differential equations: 


$$
\left.\begin{array}{l}
\dot{q}_{i}=\sqrt{\beta_{i}^{-1}\left|S_{0}-S_{i}\right|} \operatorname{sign}\left(S_{0}-S_{i}\right), \quad S_{i}=S_{R i}\left(1+\kappa_{i} \operatorname{sign} q_{i} \dot{q}_{i}\right) \\
\text { if }\left(\left(0<q_{i}<\Delta_{i}\right) \cap\left(\left|S_{0}-S_{R i}\right|>\kappa_{i} S_{R i}\right)\right) \cup \\
\cup\left(\left(q_{i}=0\right) \cap\left(S_{0}>\left(1+\kappa_{i}\right) S_{R i}(0)\right)\right) \cup\left(\left(q_{i}=\Delta_{i}\right) \cap\left(S_{0}<\left(1-\kappa_{i}\right) S_{R i}\left(\Delta_{I}\right)\right)\right), \\
\text { otherwise } \dot{q}_{i}=0 ; \\
i=1, \ldots, N,
\end{array}\right\},
$$

where $S_{R i}$ is the reduced value of the restoring force; $\Delta_{i}$ is the limitation of the piston movement (their stroke); $\kappa_{i}$ is the friction coefficient in seal boots.

$$
\left.\begin{array}{l}
\beta_{i}=0,5 F_{0}^{3} \rho_{i}\left(\sum_{j} \mu_{i j} f_{i j}\right)^{-2} ; \\
\rho_{i}=\rho\left(1+\bar{p}_{i} E_{\mathrm{lq}}^{-1}\right) .
\end{array}\right\}
$$

In expression (4.28) value $\mu_{i j}$ is the reduced flow coefficient which depends on total pressure drop in the given hydraulic resistance member. The hydraulic resistance member comprises the set of serially acting local hydraulic resistances (these are the resistances conditioning the pressure drop due to the change of ports sections along the channel length, the presence of shutters and valves, etc.). The reduced flow coefficient or reduced resistance coefficient $\xi_{i j}=\mu_{i j}^{-2}$ of the member may be determined using the expression

$$
\xi_{i j}=\sum_{k=1}^{n_{j}}\left(f_{i j}^{m} / f_{i j}^{k}\right)^{2} \xi_{i j}^{k} \text { or } \xi_{i j}=l_{i j} \int_{0}^{l_{i j}}\left(f_{i j}^{m} / f_{i j}(x)\right)^{2} \xi_{i j}(\tilde{o}) d x,
$$

where $f_{i j}^{m}$ is the smallest area of the port along the member length; $f_{i j}^{k}$ and $f_{i j}(x)$ are the areas of the channel port in section numbered $k$ or having coordinate $x$ along the length of the given hydraulic resistance member; $\xi_{i j}^{k}$ or $\xi_{i j}(x)$ are the hydraulic resistance coefficients for these sections.

The ports creating the hydraulic resistances are categorized as nozzles and diaphragms (ports in a thin wall) [118]. For "nozzle" type ports $\left(\frac{l_{\text {port }}}{d_{\mathrm{H}}}>1\right.$ where $l_{\text {port }}$ is the port length; $d_{\mathrm{H}}=\frac{4 f}{P}$ is the hydraulic diameter, $f$ is the section area; $P$ is the perimeter) $\xi$ values are determined approximately using an empiric formula for $10^{2}<\operatorname{Re}_{p}<15 \cdot 10^{4}$ as

$$
\xi=\left[1.23+58 \mathrm{Re}_{p}^{-1} l_{\text {port }} / d_{\mathrm{H}}\right]^{2}+\lambda \cdot l_{\text {port }} / d_{\mathrm{H}},
$$

where $\lambda$ is the coefficient considering the liquid friction against the port walls. 
For "diaphragm" type ports $\left(\frac{l_{\text {port }}}{d_{\mathrm{H}}}<<1\right)$, it is recommended to determine $\xi$ coefficient using empiric formulae:

$$
\begin{aligned}
& \xi=\left(1.4+1.5 \operatorname{Re}_{p}^{-1}\right)^{2}, \quad \text { if } \quad 25<\operatorname{Re}_{p}<300 ; \\
& \xi=\left(0,592+0,27 \operatorname{Re}_{p}^{-1 / 6}\right)^{-2}, \quad \text { if } \quad 300<\operatorname{Re}_{p}<10^{4} ; \\
& \xi=\left(0.592+5.5 \operatorname{Re}_{p}^{-1 / 2}\right)^{-1}, \quad \text { if } \quad 10^{4}<\operatorname{Re}_{p} .
\end{aligned}
$$

When determining the hydraulic resistance force coefficients using formulae (4.30) - (4.33), it is necessary to remember that the determined values are only the approximate evaluations as these empiric formulae were received for stationary cavitation-free flows. If any cavitation occurs (especially under big backpressure), coefficients $\xi$ increase reaching values $\xi=2.6$ for nozzles [122; 123]. In work [124], it is theoretically and experimentally demonstrated that values $\xi$ for nozzles, in cases when outlet pressure is less than 0.42 of inlet pressure and in cases when the pressure is applied suddenly, may be the same as the pressure in ports in a thin wall, i. e. they may be calculated using formulae (4.31) - (4.33) and may reach values of 2...2.8. In addition, the liquid flow through the shock absorbers throttling members ports is not stationary as here comparatively fast flow rate changes and pressure drops may occur.

The shock absorbers structure may be so that coefficient $\beta_{i}$ of the member hydraulic resistance (see expression (4.29)) is the function of values $q_{O}, q_{i}, S_{0}, S_{R i}$ and the damped body movement acceleration.

Thus, having previously evaluated the parameters, we can solve equations (4.27) and calculate $q_{O}$ using expression (4.26). In these equations, value $S_{0}$ is determined using expressions (4.3) by force $S$ values previously calculated using formulae establishing the connection of force $S$ with values $q_{k}$ or $q_{\mathrm{f}}$ described above in the Introduction.

Values $S_{i}$ are calculated using expressions (4.7) by set functions $S_{R i}\left(q_{i}\right)$, which structure is determined by a specific type and structure of the applied return mechanism.

In chambers numbered $(N+1)$ in Figure 4.1 force $S_{R i}\left(q_{i}\right)$ occurs only when the liquid in this chamber is compressed. Therefore in these cases

$$
S_{R i} \approx E_{\mathrm{fl}} F_{0}\left(q_{i}^{*} / q_{0}-1\right) \sigma_{0}\left(q_{i}^{*}-q_{0}\right) ; \quad q_{i}^{*}=F_{0} q_{i} / F_{i},
$$

where $\sigma_{0}\left(q_{i}^{*}-q_{0}\right)$ is Heaviside unit function [125].

The described oscillation damper hydraulic member model is convenient for application when this member is in series with other resilient members or elastofriction members. Sometimes, the influence of these members on the damped structure oscillation is insignificant; they themselves are connected in parallel to 
the structure elements, which return the system into its initial state. In such cases, if we know the plunger movement rate $\dot{q}$ relative to the shock absorber housing, we can calculate force $S_{g}$ value, which overcomes the hydraulic damper resistance to movement:

$$
S_{g}=\beta \dot{q}^{2} .
$$

If the piston moves in the direction of some generalized coordinate, values $\dot{q}$ will be calculated by the difference of rates of the oscillation damper fixing points movements towards the bodies, between which the oscillation damper is located. However, in some cases, the hydraulic oscillation dampers are located so that to absorb the oscillation in two directions simultaneously. Let us assume that $\Delta$ and $\dot{\Delta}$ are, respectively, the relative movements and rate of relative movements of the damped body along $Z$ axis, and $\delta$ and $\dot{\delta}$ are, respectively, the relative movements and rate of relative movements along $Y$ axis.

Then

$$
S_{g}=-\beta \frac{\left[\left(h_{0}+\Delta\right) \dot{\Delta}+\left(d_{0}+\delta\right) \dot{\delta}\right]^{2}}{\left(h_{0}+\Delta\right)^{2}+\left(d_{0}+\delta\right)^{2}} \operatorname{sign}\left[\left(h_{0}+\Delta\right) \dot{\Delta}+\left(d_{0}+\delta\right) \dot{\delta}\right],
$$

and this force projection on the axes of coordinates will comprise

$$
\left.\begin{array}{l}
S_{g z}=S_{g} \frac{h_{0}+\Delta}{\sqrt{\left(h_{0}+\Delta\right)^{2}+\left(d_{0}+\delta\right)^{2}}}, \\
S_{g y}=S_{g} \frac{d_{0}+\delta}{\sqrt{\left(h_{0}+\Delta\right)^{2}+\left(d_{0}+\delta\right)^{2}}} .
\end{array}\right\}
$$

Here $h_{0}$ and $d_{0}$ are the distances between the oscillation damper fixing points at the initial moment of time along $Z$ and $Y$ axes, respectively.

The last formulae show that in case of inclined oscillation dampers, the oscillation interrelation, i. e. the generation of one oscillation by another, takes place together with the oscillation absorption.

The expressions and equations above used for calculation of the force deforming the damper are the equations of a shock absorber or a damper state. In cases when these equations parameters such as the hydraulic resistance coefficient may depend on the position of the control member (the valve, spool, etc.), which movement, in its turn, depends on the damper state (its pressure, temperature) or acceleration of the damped body movement, the equations of state have to be supplemented with the equations of control. Specific type of equations of state and control is determined by the analyzed unit structure. The damper equations of state and control supplement the equations of movement of the system in question (a single vehicle [111], system of vehicles [126], train [3]).

The formulae above show that coefficient $\beta$ of the damper inelastic resistance to deformation depends on the liquid temperature in the damper. Suppose the heat 
transfer process is quasi-stationary, i. e. the quantity of heat used to heat the housing and the damper elements may be neglected, or suppose these heat losses are significant, i. e. the heat transfer coefficient is increased, the liquid temperature in the oscillation damper may be assessed as follows.

The power of damper inelastic resistance forces is

$$
W=S_{g} \dot{q}=\beta \dot{q}^{3} .
$$

Having set it equal to the heat transfer rate of $\alpha \Delta t^{\circ}$ where $\alpha$ is the heat transfer coefficient and $\Delta t^{\circ}$ is the difference of temperatures $t^{\circ}$ lq of working liquid and $t^{\circ}$ ext of ambient environment, we receive the differential equation of the oscillation damper working liquid temperature change

$$
\Delta t^{\circ}=\frac{\beta}{\alpha}|\dot{q}|^{3} .
$$

This differential equation has to be integrated at the set initial temperature difference. For the case with stationary harmonic oscillations with amplitude $q_{a}$ and cyclic frequency $\omega$, we can easily receive

$$
\Delta t^{\circ}=\frac{4 \beta \omega^{3}}{3 \pi \alpha} q_{a}^{3} .
$$

When simulating single impacts, the heat losses due to the heat exchange may be neglected [142]. When simulating a series of impacts, such as in a train, the temperature change may be determined by way of integrating differential equation (4.39). Then the working liquid temperature is described by the following expression

$$
t^{\circ}{ }_{\mathrm{lq}}=t^{\circ}{ }_{\text {ext }}+\Delta t^{\circ} .
$$

Knowing the liquid temperature, we can determine the respective value of the oscillation damper hydraulic resistance coefficient.

The offered spatial mathematical models of friction and hydraulic oscillation dampers help to analyze the structural and specific conditions of their operation in railway vehicles bogies and may be used for simulating the oscillation dampers operation both on their own and as a part of mathematical models of spatial oscillation of single railway vehicles, coupled vehicles and trains as a whole [34; 128-137]. 


\section{PNEUMATIC RETURN MECHANISMS IN SHOCK ABSORBERS AND OSCILLATION DAMPERS}

The forces dissipating the impacts or oscillations mechanical energy cannot return the whole system to its initial state. For this, special return mechanisms exist. Their structure includes elements capable to accumulate the energy sufficient for the system restoration. In most cases, these are the gravitational energy, the energy of metal, liquid or gas elastic deformations and the energy of magnetic or electromagnetic fields. Simulation of elastic forces at metal or liquid deformation was described in the previous chapters. Magnetic or electromagnetic fields are applied in some specific cases, mostly in magnetic, electromagnetic or electrodynamic suspension systems. Here we consider only the issues of mathematic modeling of return mechanisms using the energy accumulated by compressed gas.

When considering the hydraulic oscillation dampers above, the assumption was made that they were included in parallel with the resilient suspension members or other members returning the whole system into its initial state. In cases when special pushers or rods move the pistons, parallel members inclusion should be considered with the force distribution between them according to their structural properties.

Restoring force $S_{R i}$ in cases when elstofriction or rubber-metal return mechanisms are used may be calculated using the mathematic dependences $S(q, \dot{q})$ described in the sections above.

Let us consider dependence $S_{R i}\left(q_{i}\right)$ for return mechanisms consisting of the chamber with compressed gas separated from liquid with a piston.

The dependence of $S_{R i}$ force of gas resistance to compression on plunger movement $q_{i}$ may be described using expressions (4.3):

$$
S_{R i}=F_{O} p_{i}
$$

where $F_{O}$ is chamber $O$ area; $p_{i}$ is the gas pressure in the chamber, which, under isothermal (static) compression, is determined using the relation

$$
\frac{p_{i}\left(1-r_{i} q_{i}\right)}{z\left(p_{i}, T_{i}\right) T_{i}}=\frac{p_{0 i}}{z\left(p_{0 i}, T_{0 i}\right) T_{0 i}}, \quad q_{i}<r_{i}^{-1},
$$

where $r_{i}$ is the constant coefficient equal to $F_{O}$ plunger area in liquid chamber $O$ and initial gas chamber $i$ volume $V_{i 0}$ ratio; $\mathrm{z}\left(p_{i}, T_{i}\right)$ is the gas compressibility coefficient experimentally determined for real gases; $T_{i}$ is the absolute temperature; $p_{0 i}$ is the initial pressure in $i$ chamber at $T_{0 i}$ temperature.

The values of nitrogen compressibility [138] given in Table 5.1 for different gas temperatures and pressures may be used in calculations and at the same time allow for a conclusion on the necessity of real gas state equations utilization in the analysis of pneumatic dampers operated in a wide range of pressures and temperatures. 
Nitrogen Compressibility Coefficient z Values

\begin{tabular}{|c|c|c|c|}
\hline \multirow{2}{*}{$p, \mathrm{MPa}$} & \multicolumn{3}{|c|}{$\mathrm{z}$ at temperature } \\
\cline { 2 - 4 } & $-50^{\circ} \mathrm{C}$ & $0^{\circ} \mathrm{C}$ & $+50^{\circ} \mathrm{C}$ \\
\hline 0 & 0.8173 & 1.0005 & 1.1836 \\
0.1 & 0.8162 & 1.0000 & 1.1836 \\
1 & 0.8062 & 0.9962 & 1.1837 \\
2 & 0.7958 & 0.9926 & 1.1843 \\
4 & 0.7769 & 0.9871 & 1.1868 \\
6 & 0.7610 & 0.9841 & 1.1912 \\
8 & 0.7489 & 0.9838 & 1.1960 \\
10 & 0.7407 & 0.9853 & 1.2031 \\
20 & 0.7820 & 1.0320 & 1.2650 \\
40 & 1.0160 & 1.2410 & 1.4880 \\
60 & 1.2890 & 1.4990 & 1.7160 \\
80 & 1.5580 & 1.7640 & 1.9750 \\
100 & 1.8150 & 2.0240 & 2.2330 \\
\hline
\end{tabular}

Expressions (5.1), (5.2) and the Table above are convenient for calculation of static piston movement resistance characteristics at the gas chamber volume change. But they are impractical for calculation of dynamic characteristics when both pressure and temperature vary. In addition, it is impossible to make equally simple calculation of the real gas pressure at adiabatic compression using adiabatic equation for the ideal gas and the empiric compressibility coefficient $z_{a}(p, T)$. Therefore, it is necessary to choose suitable for the given conditions equation out of the multitude of interpolatory gas state equations [139] and to determine the dependence of pressure on the plunger movement at adiabatic gas compression using this equation. To simplify the calculation, it is desired that the structure of the equation allows for exclusion of current value of temperature $T$ when deriving adiabatic equation in $p$ and $V$ coordinates. This group of equations include Van der Waals equation and some other derived on their basis. These equations may be set out as follows

$$
\left[p_{i}+a_{d}\left(\frac{v_{i}}{V_{i}}\right)^{d}\right]\left(V_{i}-b_{d} v_{i}\right)=\left[p_{0 T i}+a_{d}\left(\frac{v_{i}}{V_{i}}\right)^{d}\right]\left(V_{i 0}-b_{d} v_{i}\right),
$$

where $v_{i}$ is the number of moles in chamber $i ; V_{i}$ and $V_{i 0}$ are the volumes of chambers at current and initial plunger position, respectively; $d$ is the exponent (for Van der Waals equation $d=2$ and for the second Diterici equation $d=5 / 3$ ); $a_{d}$ and $b_{d}$ are the constant parameters corresponding to the first and the second (depending on $d$ value) equations of state (for nitrogen $a_{2}=1.35 \cdot 10^{5} \mathrm{MPa} \cdot \mathrm{cm}^{6} \cdot \mathrm{mole}^{-2}$, 
$\left.a_{5 / 3}=2,1 \cdot 10^{4} \mathrm{MPa} \cdot \mathrm{cm}^{5} \cdot \mathrm{mole}^{-5 / 3}, b_{2}=38.6 \mathrm{~cm}^{3} \cdot \mathrm{mole}^{-1}, a_{5 / 3}=20.6 \mathrm{~cm}^{3} \cdot \mathrm{mole}^{-1}[139]\right)$; $p_{0 T i}$ is the initial gas pressure at temperature $T$ determined using expression (5.2) at $q_{i}=0$.

Work [140] gives Van der Waals equation connecting values $p$ and $V$ under adiabatic gas compression. Similar expression may be obtained for Diterici equation. After generalization we have

$$
\left[p_{i}+a_{d}\left(\frac{v_{i}}{V_{i}}\right)^{d}\right]\left(V_{i}-b_{d} v_{i}\right)^{k}=\left[p_{0 T i}+a_{d}\left(\frac{v_{i}}{V_{i}}\right)^{d}\right]\left(V_{i 0}-b_{d} v_{i}\right)^{k},
$$

Where $k=\left(R+C_{v}\right) / C_{v}=1.4$ ( $R$ is the universal gas constant; $C_{v}$ is the gas grammolecules heat capacity at constant volume).

Having transformed expression (5.4), we obtain:

$$
\begin{gathered}
S_{R i}=\left(S_{0 T i} /\left(1-r_{1 d i} q_{i}\right)^{k}\right)\left[1+A_{d i}\left(1-\frac{\left(1-r_{1 d i} q_{i}\right)^{k}}{\left(1-r_{2 d i} q_{i}\right)^{d}}\right)\right] ; \\
S_{0 T i}=p_{0 T i} F_{0} ; \quad r_{1 d i}=F_{0} /\left(V_{i 0}-b_{d} v_{i}\right) ; \\
r_{2 i}=r_{i}=F_{0} / V_{i 0} ; \quad A_{d i}=a_{d} p_{0 T i}^{-1}\left(v_{i} / V_{i 0}\right)^{d} .
\end{gathered}
$$

Thus, expression (5.5) describes dependences $S_{R i}\left(q_{i}\right)$ for Van der Waals $(d=2)$ and Diterici $(d=5 / 3)$ gases under isothermal (static, $k=1)$ and adiabatic $(k=1.4)$ gas compression.

When the shock absorber is impact loaded, the compressed gas energy may be partially lost in form of heat released to the environment. Work [141] tries to assess theses energy losses. The evaluations obtained are greatly overstated as it was assumed that the gas chamber internal surface temperature matches the gas temperature. This assumption would be reasonable if the impact process were quite slow and the gas heat transfer coefficient approached infinity. In realty, the heat transfer coefficients for gases are small and the time of compression is short. The solution of the heat exchange non-stationary problem at the gas compression stage in the draft gear, when the heat exchange between the internal chamber surface and the gas is considered and it is assumed that the external surface of the gear maintains the ambient temperature due to close contact with the car metal, shows that at the first impact loading stage, not more than 1 per cent of energy acquired by gas during adiabatic compression is lost due to the heat exchange [142].

As in addition to the heat losses, the heat gains are also possible due to the piston cups against chamber walls friction forces and the heat exchange with the surface heated by damping liquid while throttling, we can assume (at a first approximation) that gas compression is developed adiabatically at impacts. Consequently, 
to determine the gas resistance force at impacts, it is necessary to apply expression (5.5) with $k=1.4$.

The values of the real gas resistance force $S_{R}(q)$ to isothermal compression at different ambient temperatures and charge nitrogen pressures in chamber $p_{0}=5 \mathrm{MPa}$ and $9 \mathrm{MPa}$ calculated using formulae (5.1) and (5.2) are given in Tables 5.2 and 5.3, respectively. To be certain, the gas compression in the highpressure chamber of GA-500 (ГA-500) draft gear [143] is considered (plunger stroke equal to $0.1 \mathrm{~m}$ corresponds to the maximum gas compression). Parameters in expressions $(5.1)-(5.5)$ are equal to $r=r_{2}=8.57 \mathrm{~m}^{-1}$, and $r_{1,2}=9.47 \mathrm{~m}^{-1}, r_{1.5 / 3}=$ $9.03 \mathrm{~m}^{-1}$ under initial pressure $p_{0}=5 \mathrm{MPa}$ and $r_{1,2}=10.18 \mathrm{~m}^{-1}, r_{1.5 / 3}=9.36 \mathrm{~m}^{-1}$ under $p_{0}=9 \mathrm{MPa}$. Values $A_{d}$ are given in Tables 5.2 and 5.3 [3]. $S_{R}^{(1)}, S_{R}^{(2)}, S_{R}^{(5 / 3)}$, values deviations $\delta_{1}, \delta_{2}$ and $\delta_{5 / 3}$, respectively, are given in the same work. The deviations were calculated using the ideal gas state equations, Van der Waals equations and the second Detirici equation basing on values of real gas resistance $S$ to isothermal compression determined in compliance with nitrogen compressibility coefficient $z$ table taken from work [138] and with expressions (5.1) and (5.2).

Comparison of $\delta_{1}, \delta_{2}$ and $\delta_{5 / 3}$ values together with the analysis of applied interpolatory equations of state allows for the conclusion that ideal gas equations are quite appropriate under relatively low pressures (up to $30 \mathrm{MPa}$ ). Under higher pressures, when the chamber volume significantly exceeds the "occupied volume" of gas molecules equal to $v_{i} b_{2}$ according to Van der Waals assumptions, the lesser error is attributed to calculations using equations with $d=2$. If this conditions is not met, but the chamber volume is bigger than the "occupied volume" of gas molecules $v_{i} b_{5 / 3}$ according to Detirici assumptions, equation (5.5) with $d=5 / 3$ should be preferred. Therefore, to choose the most appropriate for the given compression interpolatory equation of state, it is necessary to determine values $v_{i} b_{2}$ and $v_{i} b_{5 / 3}$ and compare them with $i$ chamber volume at the given moment of time.

In the example considered above, chamber volume $V_{i}=474 \mathrm{~cm}^{3}$ at $q_{i}=0.1 \mathrm{~m}$ and $V_{i}=758 \mathrm{~cm}^{3}$ at $q_{i}=0.09 \mathrm{~m}$. At the same time, under $p_{0 i}=5 \mathrm{MPa}$, values $v_{i} b_{2}=$ $318 \mathrm{~cm}^{3}$ and $v_{i} b_{5 / 3}=170 \mathrm{~cm}^{3}$ and under $p_{0 i}=9 \mathrm{MPa}$, values $v_{i} b_{2}=525 \mathrm{~cm}^{3}$ and $v_{i} b_{5 / 3}=280 \mathrm{~cm}^{3}$. Until value $v_{i} b_{2}$ is at least twice less than the rest of the chamber volume, Van der Waals equations should be applied. If value $v_{i} b_{2}$ approaches the chamber volume, Van der Waals equation is inapplicable and Detirici equation should be used (until $v_{i} b_{5 / 3}$ is less than the rest of the chamber volume). If this condition is not met either, it is necessary to use other equations of state (such as Van Laar equation [139]). This will significantly complicate the calculation of forces at adiabatic gas compression.

In the example considered, at $q_{i}=0.1 \mathrm{~m}$, the second Detirici equation is preferred. In this connection, Tables 5.1 and 5.2 give the values of adiabatic gas compression resistance force $S_{R}^{5 / 3, a}(q)$ derived using expression (5.5) with $k=1.4$ and $d=5 / 3$. 
Table 5.2

Restoring Force Calculation Results under Initial Pressure $p_{\mathbf{0}}=5 \mathrm{MPa}$

\begin{tabular}{|c|c|c|c|c|r|r|r|r|r|r|r|r|}
\hline $\begin{array}{c}T, \\
\mathrm{~K}\end{array}$ & $A_{2} \cdot 10^{3}$ & $A_{5 / 3} \cdot 10^{3}$ & $\begin{array}{c}q \\
\mathrm{~cm}\end{array}$ & $\begin{array}{c}S_{R} \cdot 10^{2}, \\
\mathrm{MN}\end{array}$ & $\begin{array}{c}\delta_{1}, \\
\%\end{array}$ & $\begin{array}{c}\delta_{2}, \\
\%\end{array}$ & $\begin{array}{c}\delta_{5 / 3}, \\
\%\end{array}$ & $n_{u}$ & $\begin{array}{c}\delta_{n}^{u}, \\
\%\end{array}$ & $\begin{array}{c}S_{R}^{5 / 3, a}, \\
\mathrm{MN}\end{array}$ & $n_{a}$ & $\begin{array}{c}\delta_{n}^{a}, \\
\%\end{array}$ \\
\hline 223 & 208 & 239 & 0 & 11.4 & 0 & 0 & 0 & 1.09 & 0 & 11.4 & 1.61 & 0 \\
& & & 4 & 16 & 8 & 4 & 3 & & 13 & 21 & & 7 \\
& & & 8 & 34 & 7 & -4 & -6 & & 18 & 66 & & 11 \\
& & & 9 & 48 & 4 & 0 & -9 & & 19 & 116 & & 6 \\
& & & 9.5 & 63 & -8 & 9 & -14 & & 13 & 172 & & 0 \\
& & & 10 & 95 & -16 & 54 & -20 & & 0 & 300 & & -13 \\
\hline 273 & 167 & 192 & 0 & 14 & 0 & 0 & 0 & 1.16 & 0 & 14 & 1.62 & 0 \\
& & & 4 & 23 & -2 & -9 & -9 & & 0 & 26 & & 8 \\
& & & 8 & 47 & -4 & -6 & -11 & & 16 & 83 & & 9 \\
& & & 9 & 69 & -10 & -3 & -14 & & 14 & 145 & & 7 \\
& & & 9.5 & 91 & -16 & 5 & -19 & & 10 & 215 & & 0 \\
& & & 10 & 136 & -27 & 45 & -23 & & 0 & - & & - \\
\hline 323 & 138 & 158 & 0 & 17.2 & 0 & 0 & 0 & 1.18 & 0 & 17.2 & 1.58 & 0 \\
& & & 4 & 27 & -3 & -4 & -5 & & 5 & 32 & & 4 \\
& & & 8 & 58 & -6 & 0 & -9 & & 16 & 101 & & 6 \\
& & & 9 & 86 & -13 & 1 & -13 & & 14 & 176 & & 0 \\
& & & 9.5 & 114 & -19 & 11 & -17 & & 10 & 261 & & -6 \\
& & & 10 & 170 & -29 & 49 & -20 & & 0 & - & & - \\
\hline
\end{tabular}

Таблица 5.3

Restoring Force Calculation Results under Initial Pressure $\boldsymbol{p}_{\mathbf{0}}=9 \mathrm{MPa}$

\begin{tabular}{|c|c|c|c|c|c|c|c|c|c|c|c|c|}
\hline$T, \mathrm{~K}$ & $A_{2} \cdot 10^{3}$ & $A_{5 / 3} \cdot 10^{3}$ & $\begin{array}{l}q \\
\mathrm{~cm}\end{array}$ & $\begin{array}{c}S_{R} \cdot 10^{2}, \\
\mathrm{MN}\end{array}$ & $\begin{array}{c}\delta_{1}, \\
\%\end{array}$ & $\begin{array}{c}\delta_{2}, \\
\%\end{array}$ & $\begin{array}{c}\delta_{5 / 3}, \\
\%\end{array}$ & $n_{u}$ & $\begin{array}{c}\delta_{n}^{u}, \\
\%\end{array}$ & $\begin{array}{c}S_{R}^{5 / 3, a}, \\
\mathrm{MN}\end{array}$ & $n_{a}$ & $\begin{array}{c}\delta_{n}^{a}, \\
\%\end{array}$ \\
\hline 223 & 229 & 319 & $\begin{array}{c}0 \\
4 \\
8 \\
9 \\
9.5 \\
10\end{array}$ & $\begin{array}{c}19.6 \\
29 \\
68 \\
114 \\
200 \\
-\end{array}$ & $\begin{array}{r}0 \\
3 \\
-9 \\
-25 \\
-47 \\
-\end{array}$ & $\begin{array}{r}0 \\
0 \\
10 \\
65 \\
202\end{array}$ & $\begin{array}{r}0 \\
0 \\
-12 \\
-20 \\
-35 \\
-\end{array}$ & 1.38 & $\begin{array}{r}0 \\
21 \\
42 \\
32 \\
0\end{array}$ & $\begin{array}{c}19.6 \\
37 \\
136 \\
270 \\
- \\
-\end{array}$ & 1.72 & $\begin{array}{r}0 \\
9 \\
5 \\
-8 \\
- \\
-\end{array}$ \\
\hline 273 & 252 & 244 & $\begin{array}{c}0 \\
4 \\
8 \\
9 \\
9.5 \\
10\end{array}$ & $\begin{array}{c}25.6 \\
37 \\
99 \\
168 \\
284 \\
-\end{array}$ & $\begin{array}{r}0 \\
5 \\
-18 \\
-33 \\
-51 \\
-\end{array}$ & $\begin{array}{r}0 \\
5 \\
9 \\
54\end{array}$ & $\begin{array}{r}0 \\
3 \\
-15 \\
-23 \\
-25 \\
-\end{array}$ & 1.32 & $\begin{array}{r}0 \\
0 \\
19 \\
7 \\
-17 \\
-\end{array}$ & $\begin{array}{l}25.6 \\
49 \\
177 \\
350 \\
- \\
-\end{array}$ & 1.71 & $\begin{array}{r}0 \\
7 \\
5 \\
-8 \\
- \\
-\end{array}$ \\
\hline 323 & 205 & 200 & $\begin{array}{c}0 \\
4 \\
8 \\
9 \\
9.5 \\
10\end{array}$ & $\begin{array}{c}31.4 \\
49 \\
129 \\
220 \\
- \\
-\end{array}$ & $\begin{array}{r}0 \\
-2 \\
-22 \\
-38 \\
- \\
-\end{array}$ & $\begin{array}{r}0 \\
0 \\
8 \\
49 \\
- \\
-\end{array}$ & $\begin{array}{r}0 \\
-2 \\
-17 \\
-25 \\
- \\
-\end{array}$ & 1.32 & $\begin{array}{r}0 \\
12 \\
12 \\
0 \\
- \\
-\end{array}$ & $\begin{array}{l}31.4 \\
60 \\
217 \\
- \\
- \\
-\end{array}$ & 1.67 & $\begin{array}{l}0 \\
5 \\
0\end{array}$ \\
\hline
\end{tabular}


In some cases (for analytical research, computer calculations of multi-mass mechanical systems with big number of hydraulic gas shock absorbers, etc.) approximating expression similar to polytropic equation may be used

$$
S_{R i}\left(q_{i}\right)=S_{0 m i}\left(1-r_{i} q_{i}\right)^{-n_{i}},
$$

where $n_{i}$ is the polytropy index.

As it is desirable that the approximation had the least errors at big $q_{i}$ and $S_{R i}$ values, value $n_{i}$ may be determined using expression

$$
n_{i}=\ln \left[S_{R i}^{*}\left(q_{i}^{*}\right) / S_{O m i}\right] / \ln \left(1-r_{i} q_{i}^{*}\right),
$$

where $q_{i}^{*}$ and $S_{R i}^{*}$ are the coordinates of the point where the line corresponding to (5.6) crosses the approximating dependence. This point is chosen at the edges of the area limited by permissible movement and permissible force.

In Tables 5.1 and 5.2, symbol $n_{u}$ stands for value $n_{i}$ in expression (5.6) approximating the dependence of the real gas resistance to isothermal (static) compression on $q_{i}$, and symbol $n_{a}$ stands for value $n_{i}$, at which expression (5.6) approximates the dependence of gas resistance to adiabatic compression on $q_{i}$ assumed for the purpose of calculation. Here, the approximation error values $\delta_{n}^{u}$ and $\delta_{n}^{a}$ are also shown. Value $n_{u}$ differs from unity, and value $n_{a}$ significantly exceeds the adiabatic index for an ideal diatomic gas.

Table 5.4.[3] gives the evaluation of approximating polytropy index derived from the analysis of the data of the experimental researches carried out by Dnipropetrovsk National Railway Transport University named after V. Lazaryan (DIIT) and Moscow State University of Communication Lines (MIIT). In course of these experiments, GA-500 (ГА-500) type draft gears with $120 \mathrm{~mm}$ full and $20 \mathrm{~mm}$ reduced piston stroke of low-pressure chamber were tested. Initial nitrogen pressure in the highpressure chamber with $100 \mathrm{~mm}$ reduced piston stroke was $5 \mathrm{MPa}$, i. e. the pretension force should be equal to $142 \mathrm{kN}$. In compliance with the drawings and technical specifications for the tested gears $r_{2}=8.57 \mathrm{~m}^{-1}$. For evaluation of $n_{2}$ values, the results of the tests with the gear stroke less than $90 \mathrm{~mm}$ were chosen. It was assumed that the low-pressure chamber piston reached the stops. Basing on this fact and in compliance with given above (see expression (4.12)) $E_{\mathrm{lq} . \mathrm{a}}(p)$ dependences the valuation was made using the following formula

$$
n_{2}=\ln \left[S_{R 2}\left(q_{m}\right) / S_{R 2}(0)\right] / \ln \left(1-r_{2} q_{m 2}\right)
$$

where $S_{R 2}\left(q_{m}\right)=\left|S\left(q_{m}\right)\right| /(1+\kappa)\left(S\left(q_{m}\right)\right.$ is the force compressing the draft gear at the moment of maximum compression; $\kappa=0.1$ is the friction coefficient in boots; $q_{m}$ is the maximum compression of the draft gear.

$$
q_{m 2}=q_{m}-\Delta_{1}-S_{R 2}\left(q_{m}\right) / k_{\text {lq.à }},
$$


where $\Delta_{1}=0.02 \mathrm{~m}$ is the reduced low pressure chamber piston stroke to the stops; $k_{\text {lq.a }}=2.5 \cdot 10^{2}\left[1+S_{R 2}\left(q_{m}\right)\right] \mathrm{MN} / \mathrm{m}$ is the adiabatic stiffness of the equivalent liquid column at $1 \mathrm{MN}<S_{R 2}<2 \mathrm{MN} / \mathrm{m}$ (it is assumed that AMG-10 (АМГ-10) oil is not mixed with gas).

Tables 5.2, 5.3 and 5.4 prove that polytropy index for approximating expression (5.6) derived both theoretically and experimentally are well correlated with each other and can significantly exceed adiabatic index value of ideal gas equal to 1.4.

Table 5.4

Experimental Evaluation of Approximating Polytropy Index

\begin{tabular}{|c|c|c|c|c|c|}
\hline Test conditions & Test number & $v_{0}, \mathrm{~km} / \mathrm{h}$ & $q_{m}, \mathrm{~mm}$ & $\begin{array}{c}S\left(q_{m}\right) \\
\mathrm{MN}\end{array}$ & $n_{a}$ \\
\hline \multirow[t]{3}{*}{ Collision of two eight-wheel cars } & 61 & 18.2 & 103 & 1.3 & 1.8 \\
\hline & 58 & 14.7 & 103 & 1.3 & 1.8 \\
\hline & 51 & 12 & 103 & 1.2 & 1.75 \\
\hline \multirow{3}{*}{$\begin{array}{l}\text { Collision of an eight-wheel car } \\
\text { with a coupling gear }\end{array}$} & 87 & 9.8 & 94 & 1.0 & 1.95 \\
\hline & 98 & 11.8 & 98 & 1.3 & 2.03 \\
\hline & 97 & 14.5 & 102 & 1.65 & 2.07 \\
\hline \multirow[t]{3}{*}{ Collision of two twelve-wheel cars } & 138 & 10.6 & 110 & 1.45 & 1.6 \\
\hline & 139 & 12.8 & 112 & 1.76 & 1.7 \\
\hline & 157 & 7.7 & 107 & 1.03 & 1.45 \\
\hline \multirow{3}{*}{$\begin{array}{l}\text { Collision of a twelve-wheel car } \\
\text { with a coupling gear }\end{array}$} & 173 & 8.4 & 116 & 1.5 & 1.44 \\
\hline & 176 & 9.7 & 119 & 1.02 & 1.44 \\
\hline & 178 & 11.2 & 119 & 2.26 & 1.53 \\
\hline Mean \pm standard & \multicolumn{5}{|c|}{$n_{2}=1.71 \pm 0.23$} \\
\hline
\end{tabular}

When the test results were processed, no information on a number of important test conditions was available: the gear temperature at its filling with gas during tests; gas content in oil (this parameter influences the modulus of volume elasticity of damping mix and the piston movement in the high pressure chamber); the gear housing deformation. Therefore, the experimentally derived $n_{2}$ values may serve as guess values only. However, provided the listed above parameters are known, experimentally derived $n_{2}$ values will be qualitative values. 


\section{HYDRO-GAS DRAFT GEAR MATHEMATICAL MODEL}

The next class of draft gears includes the gears using liquid or gas as a working medium. Let us consider an example of mathematical description of GA-500 (ГA500) hydro-gas draft gear operation [143].

The gear operates as follows (Figure 1.6). The force compressing the gear makes plunger 8 move inside housing 2. This forces AMG-10 (АМГ-10) working liquid to overflow from hydraulic chamber $C$, though the jet nozzles in fixed partition 4 , into the cavity between partition 4 and floating piston 3 , which moves and compresses the gas in low-pressure chamber $A$. With $20 \mathrm{~mm}$ movement of this piston, it stops at the gear bottom. As soon as the pressure in cavity $C$ between plunger 8 and partition exceeds the initial pressure in high-pressure chamber $B$, the liquid starts to overflow into the cavity between piston 6 of plunger 8 and floating piston 7 through the jet nozzles in piston 6 and profiled grooves in rod 5. The gas compresses in chamber $B$. When overflowing through the mentioned orifices, the liquid meets the resistance and creates the resistance to the gear compression proportional to the square of the rate of the plunger movement inside the gear housing.

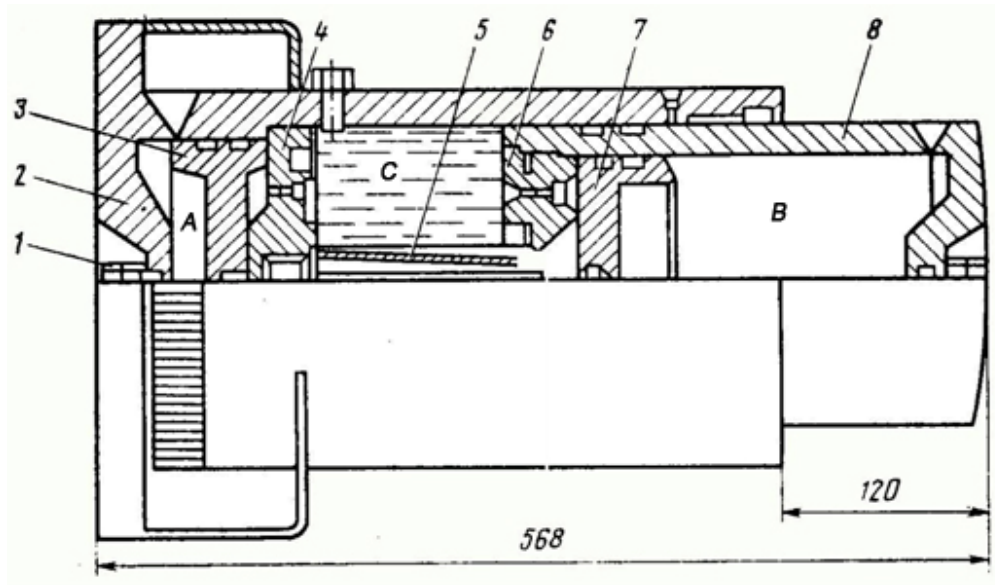

Figure 6.1. GA-500 (ГА-500) draft gear structural diagram

Thus, the force compressing the draft gear overcomes the force of the gas resistance to compression in chambers $A$ and $B$ and the force of the liquid hydrodynamic resistance to overflow from chamber $C$ into other chambers.

Plunger limits chamber $O$ and pistons 1 and 2 separate filled with gas chambers 1 and 2 from the rest of the space filled with AMG-10 (АМГ-10) liquid (Figure $6.2)$. 


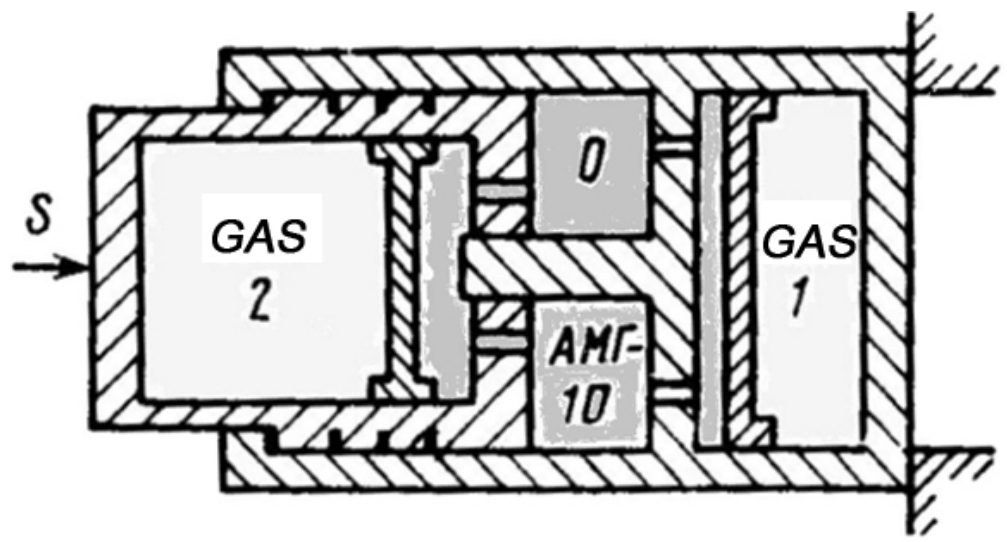

Figure 6.2. GA-500 (ГА-500) draft gear design model

In this case [3; 142]

$$
\left.\begin{array}{c}
S_{0}=\frac{|S|}{\left(1+\kappa_{0} \operatorname{sign} q_{0}\right)} ; \\
q_{0}=q_{1}+q_{2}+S_{0} / k_{\mathrm{lq}} .
\end{array}\right\}
$$

In compliance with formulae (4.27)

$$
\left.\begin{array}{c}
\dot{q}_{1}=\sqrt{\beta_{1}^{-1}\left|S_{0}-S_{1}\right|} \operatorname{sign}\left(S_{0}-S_{1}\right) ; \quad S_{1}=S_{R 1}\left(1+\kappa_{1} \operatorname{sign} \dot{q}_{1}\right) ; \\
\text { if }\left(\left(0<q_{1}<\Delta\right) \cap\left(\left|S_{0}-S_{1}\right|>\kappa_{R 1} S_{R 1}\right)\right) \cup\left(\left(q_{1}=0\right) \cap\left(S_{0}>S_{10}\left(1+\kappa_{1}\right)\right)\right) \cup \\
\cup\left(\left(q_{1}=\Delta_{1}\right) \cap\left(S_{0}<S_{R_{1}}\left(\Delta_{1}\right)\left(1-\kappa_{1}\right)\right)\right), \\
\text { otherwise } \quad \dot{q}_{1}=0 ;
\end{array}\right\}
$$

In expressions (6.2) and (6.3) 


$$
\left.\begin{array}{l}
S_{R i}=S_{i 0}\left(1-r_{i} q_{i}\right)^{-n_{i}} ; \\
r_{i}=F_{0} / V_{i 0} ; \quad i=1.2,
\end{array}\right\}
$$

where $n_{i}$ are the polytropy indices determined in advance as is described earlier; $\Delta_{1}$ is piston 1 movement limitation; $\Delta$ is the plunger movement. Coefficient $b_{2}\left(q_{0}\right)$ takes various values depending on $\dot{q}_{0}$ sign.

For the purpose of generalization differential equation in expressions (6.2) and (6.3) may be replaced with the following differential equations

$$
\dot{q}_{j}=\mu f_{j}\left(q_{j}^{*}\right) \sqrt{2\left(\rho F_{0}^{3}\right)^{-1}\left|S_{0}-S_{j}\right|} \operatorname{sign}\left(S_{0}-S_{j}\right), \quad j=1,2,
$$

where $f_{j}\left(q_{j}^{*}\right)$ is the dependence of the area of throttling orifices on movements $q^{*}$ governing the hydraulic resistance forces change.

The mathematical model of hydraulic draft gears described above was checked by comparing the results of electronic simulation using analog computer (AC) and numerical computer (NC) integration with experimental data obtained at cars collisions.

The experiments show the bigger the collision rate (starting from $v_{0}=$ $10 \ldots 12 \mathrm{~km} / \mathrm{h}$ ) the lesser backing coefficient $\lambda$ equal to the impact kinetic energy share necessary for the draft gear compression. This decrease reaches $20 \ldots 25$ per cent at the collision of eight-wheel gondola cars at a rate of $v_{0}=18.2 \mathrm{~km} / \mathrm{h}$ and corresponds to the decrease of the cargo weight firmly fixed to the car body. The rest of the cargo may shift. Neglecting the interacting force of the shifting part of the cargo with the rest of the cargo and the car body, we can consider that the collision occurs between the objects with reduced weight.

To compare the results of electronic simulation and the calculation with the experimental data, it was assumed that $S_{10}=35 \mathrm{kN} ; S_{20}=35 \mathrm{kN} ; r_{1}=37.6 \mathrm{~m}^{-1}$; $r_{2}=8.3 \mathrm{~m}^{-1} ; k_{f}=320 \mathrm{MN} / \mathrm{m} ; \kappa=0.1 ; \kappa_{1}=\kappa_{2}=0 ; n_{1}=1.4 ; n_{2}=1.5 ; \beta_{1}=$ $10 \mathrm{MNs}^{2} / \mathrm{m}$ and value $b_{2}\left(q_{0}\right) \mathrm{MNs}^{2} / \mathrm{m}^{2}$ was set as

$$
b_{2}\left(q_{0}\right)=\left\{\begin{array}{cc}
0.64+6.65 q_{0}+67.5 \cdot 10^{5} q_{0}^{7}, & \text { if } \dot{q}_{0} \geq 0 ; \\
0.1+1.1 q_{0}+760 \cdot 10^{5} q_{0}^{7}, & \text { if } \dot{q}_{0}<0 .
\end{array}\right.
$$

The draft gear power characteristics obtained experimentally at the collision of two eight-wheel cars at a rate of $v_{0}=18.2 \mathrm{~km} / \mathrm{h}$ using electronic simulation and a computer $[144 ; 145]$ are given in Figure 6.3, $a$.

In Figure $6.3, b$, lines 1 show the tests results and lines 2 show the results of electronic simulation obtained when analyzing the collisions of sixteen-wheel gondola cars in cases with the both cars equipped with hydro-gas draft gears (solid lines, $v_{0}=10 \mathrm{~km} / \mathrm{h}$ ) and with a jammed draft gear in one of the cars (broken lines, $\left.v_{0}=6 \mathrm{~km} / \mathrm{h}\right)$.

Theoretical and experimental researches of hydro-gas draft gears properties proved their advantages and helped to reveal their main weaknesses. 

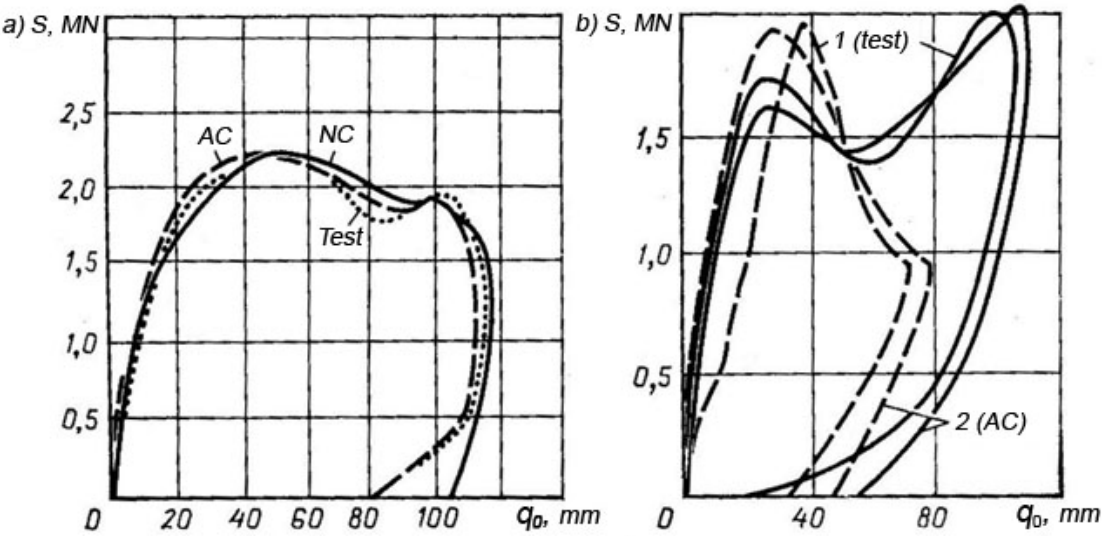

Figure 6.3. Power characteristics of GA-500 (ГА-500) draft gear obtained experimentally and by mathematic simulation

The first weakness is the difficulty to meet two requirements at the same time: to ensure effective shock absorption at shunting operations and to balance the significant quasi-constant force in trains. To meet the second requirement, it is necessary to increase the gas pressure in chambers. This results in impossibility to realize the possible stroke at forces exceeding the permissible level during the cars collision when the real gas is compressed almost adiabatically. This is especially true for the gears with increased stroke. In such cases, the dynamic stiffness of gas spring significantly exceeds the longitudinal stiffness of the car structure.

The second weakness is that the draft gear restores its initial state with some delay. This may lead to temporary formation or increase of gaps in connections.

The third weakness is connected with the fact that with increasing collision rate the steepness of the draft gear power characteristic also rises leading to significant vibratory acceleration at cars collision.

If the first two weaknesses may be eliminated by regulating the gas quantity in the gear working chamber, the third may be corrected only by way of serial connection of a deformed member limiting the steepness of the draft gear power characteristic increase to the hydro-gas draft gear. Structurally this may be realized, for instance, by serial introduction of a rubber-metal unit into the hydro-gas gear. This unit will limit the steepness of power characteristic increase at collisions and will be actuated in a train when the hydro-gas gear with optimal initial gas pressure in compliance with the impact conditions is deactivated. This unit is Fregat-Saver end draft gear with $381 \mathrm{~mm}$ stroke described in summary [146]. The relations described earlier may be used for mathematical simulation of this gear operation. 


\section{IMPROVED MATHEMATICAL MODEL OF PNEUMATIC RETURN MECHANISMS IN SHOCK ABSORBERS AND SUPPORT BEARINGS}

This Section considers the improved mathematical model of gas compressiondecompression processes in pneumatic return mechanisms of shock absorbers and pneumatic support bearings. This improved model is introduced because the model suggested in Section 5 is enough well appropriate only for single impacts occurring at car collisions during shunting operations when the impact time is quite short and the gas heat exchange with the environment may be neglected. However, the heat exchange with the environment cannot be neglected when modeling repeated impacts or prolonged non-stationary processes in pneumatic support bearings absorbing vibration. The processes occurring in the gas may be considered as isothermal only subject to stationary riding mode when the established gas temperature is determined using the same technique as for the oscillation damper working liquid temperature determination. When operated in stationary vibration mode, the pneumatic support bearings in vehicles do absorb individual impacts such as short-term surges, but the processes occurring in the gas cannot be considered isothermal in surge's time.

The attempt to solve this problem when simulating the processes in aircrafts landing gear gas was made in work [141]. The author applies the ideal gas polytropic expression to calculate the gas pressure. The polytropy index is derived from the differential equation using the heat-balance equation.

In this Section, the problem of modeling the pneumatic support bearings or pneumatic shock absorbers operation for the cases of stationary and non-stationary heat processes is solved using incremental methods of numerical integration of differential equations [145; 147].

As the models considered in this section are related to shock absorbers when the pressure in a liquid or a gas varies in a big range and reaches 100 and more megapascals, the equations of state used for the calculation purpose have the form of

$$
\frac{p V}{z(p, T)}=v R T
$$

or

$$
\left[p+a_{d}\left(\frac{v}{V}\right)^{d}\right]\left(V-v b_{d}\right)=v R T,
$$

Where $p$ and $V$ are the pressure in the cavity with gas and its value, respectively; $z(p, T)$ is determined experimentally [138] tabulated function characterizing the real gas compressibility; $v$ is the number of moles of gas in the cavity; $R$ and $T$ are the universal gas constant and absolute temperature in degrees by Kelvin, respectively, $R=8.31 \mathrm{~J}(\mathrm{~mole} \cdot \mathrm{K})^{-1}[127] ; d$ is the index and exponent making Van der Waals 
equation for real gas state (7.2) with $d=2$ and Diterici equation with $d=5 / 3$. Constants $a_{d}$ and $b_{d}$ are, respectively, equal to:

$$
\begin{array}{ll}
a_{d}=a_{2}=1.35 \cdot 10^{5} \mathrm{MPa} \cdot \mathrm{cm}^{6} \cdot \mathrm{mole}^{-2}, & b_{d}=b_{2}=38.6 \mathrm{~cm}^{3} \cdot \mathrm{mole}^{-1}, \\
a_{d}=a_{5 / 3}=2.1 \cdot 10^{4} \mathrm{MPa} \cdot \mathrm{cm}^{5} \cdot \mathrm{mole}^{-5 / 3}, & b_{d}=b_{5 / 3}=20.6 \mathrm{~cm}^{3} \cdot \mathrm{mole}^{-1}[139] .
\end{array}
$$

Value $v$ is calculated as $v=\rho_{0}\left(p_{0}, T_{0}\right) V_{0} / \mu$, where $\rho$ is the gas density, index 0 stands for the state at filling the chamber with initial volume $V_{0}$ with gas having temperature $T_{0}$ until the pressure reaches $p_{0} ; \mu$ is the weight of one mole of the gas.

When using incremental methods of numerical integration $[145 ; 147]$ of differential equations of movement it is assumed that in moment of time $t$ all the generalized coordinates and generalized velocities determining the dynamic system state as a whole are known. The mechanical system state is determined by velocities values $v$ and movements or deformations values $q$ with indices specifying the body or the body state. These generalized coordinates and velocities in a thermodynamic system (which includes the mechanical system) are supplemented with gas temperatures $T$ of all the members where the gas state supplements the determination of the system state as a whole. Thus, let us assume that in moment of time $t$ we know all the values $v(t), q(t)$ and $T(t)$. The chamber volume at this moment of time will be calculated as

$$
V(t)=V_{0}-F_{0} q(t),
$$

where $F_{0}$ is the area of the plunger or piston.

In most cases, the membranes deformations may be neglected. But, if a membrane is made of rubber or other elastomer with metal of glass core, its deformations may significantly change the working cavity volume. Then formula (7.3) used for the calculation of the occupied volume of gas is replaced with expression

$$
V(t)=V_{0}(1+\varepsilon)-F_{0} q(t),
$$

where $\varepsilon$ is the value of the membrane volumetric deformation calculated using the known techniques. In its final form it may be determined as

$$
\varepsilon=\frac{P}{k_{V}}
$$

where $k_{V}$ is the coefficient of the membrane volumetric stiffness reduced to force $P$ acting on the plunger or piston at the gas side.

The calculations at every next integration step for moment of time $t+\Delta t$ start from the determination of values of generalized coordinates, i. e. $q(t+\Delta t)$, including the chamber volume $V(t+\Delta t)$. After that, the gas temperature in the respective chamber is calculated.

Temperature calculation starts from the determination of its approximate value considering that during time $\Delta t$ the gas is compressed or decompressed isoentropically adiabatically.

Free energy $F_{e}$ of gas (as it is designated in work [140]) is equal to 


$$
F_{e}=F_{e i g}-v R T \ln \left(1-\frac{b_{d} v}{V}\right)-\frac{a_{d} v^{d}}{V^{d-1}} .
$$

Here $F_{\text {eig }}$ is the free energy of the ideal gas.

The real gas entropy $S_{\text {ent }}$ is determined as $S_{\text {ent }}=-\frac{\partial F_{e}}{\partial T}$. Then using expression (7.6), we have

$$
S_{\text {ent }}=S_{\text {entig }}+R \ln \left(1-\frac{b_{d} v}{V}\right),
$$

where $S_{\text {entig }}$ is the entropy of the ideal gas, which may be described by expression $S_{\text {entig }}=R \ln V+C_{V} \ln T$ [140] within the accuracy of a constant value. In this expression, $C_{V}$ is the heat capacity of one mole of gas at constant volume. Thus, for the isoentropic adiabatic process, gas entropy within the accuracy of a constant value may be described by expression

$$
S_{\text {ent }}=R \ln V+C_{V} \ln T+R \ln \left(1-\frac{b_{d} v}{V}\right)=\text { const. }
$$

This means

$$
T\left(V-b_{d} v\right)^{k-1}=\text { const. }
$$

Constant $b_{d}$ is chosen out of the values given above depending on the interpolatory equation of state used at the moment, $k=\left(C_{V}+R\right) / C_{V}$ is adiabatic index equal to 1.4 for the gas with biatomic molecules.

When choosing the interpolatory equation of gas state at the given moment of time, we base on one of the following considerations (assuming approximately 10 per cent error):

1) if pressure is less than $20 \mathrm{MPa}$ and temperature is about $0^{\circ} \mathrm{C}$ the ideal gas equation is used and the constants are $a_{d}=0, b_{d}=0$;

2) if the above conditions are not met the constants values are assumed in compliance with Van der Waals interpolatory equation until the chamber volume is at least 3 times bigger than the occupied volume of the gas molecules by Van der Waals, which is equal to $b_{d} v$;

3 ) if the last condition is not met the constants values are assumed in compliance with the second Diterici equation until chamber volume is at least 3 times bigger than the occupied volume of the gas molecules by Diterici, which is equal to $b_{d} v$.

The experience of calculations show these equations are sufficient for the analysis of forces complying such shock absorbers operation conditions. Otherwise, it is necessary to find other interpolatory equations of state such as Van-Laar equation [139].

Using expression (7.8) we can derive equality

$$
T(t)\left[V(t)-b_{d} v\right]^{k-1}=T_{a}(t+\Delta t)\left[V(t+\Delta t)-b_{d} v\right]^{k-1},
$$


which in turn is used as the first approximation for determination of temperature $T_{a}$ of the gas at moment of time $t+\Delta t$ :

$$
T_{a}(t+\Delta t)=T(t)\left[\frac{V(t)-b_{d} v}{V(t+\Delta t)-b_{d} v}\right]^{k-1} .
$$

Then it is assumed that external temperature is equal to $T_{\text {ext }}$ and the gas heat transfer coefficient is equal to $a_{g}$ and is determined experimentally for the specific shock absorber operation conditions (shock absorber housing material, specific fixing of the shock absorber to the damped structure, some features of this structure operation and the housing cooling, etc.). This means that during time $\Delta t$ the gas will lose a part of heat equal to

$$
\Delta Q_{R}=-\alpha_{g}\left[0,5 T_{a}(t+\Delta t)+0,5 T(t)-T_{e x t}\right] \Delta t .
$$

Simultaneously within the same interval of time, the gas will receive some quantity of heat from external sources. These sources are the heat emitted because of friction occurring between the plunger or piston boots and the chamber housing walls, and the heat transferred to the gas when the liquid in hydraulic dampers is heated while throttled through the local resistances. If rubber membranes are used for pneumatic support bearings, the gas may also be heated due to the deformation of the rubber membranes themselves.

The quantity of heat received by the gas from the plunger or piston boots friction within time $\Delta t$ will comprise, Kcal (slightly overstated)

$$
\Delta Q_{\mathrm{fr}}=0,24 \kappa S_{R}(t) \dot{q}(t) \Delta t,
$$

where $\kappa$ is the boots friction coefficient against the chamber walls, $S_{R}(t)$ is the force of the gas resistance to compression (in kiloneutons) at moment of time $t$. The boots friction coefficient against the chamber walls is usually assumed equal to 0.1 for rubber seals and 0.05 and less for fluoroplastic seals.

The quantity of heat received by the gas from the hydraulic oscillation damper integrated in the shock absorber in question will comprise, Kcal

$$
\Delta Q_{g}=0,24 S_{g} \dot{q} \Delta t=0,24 \beta|\dot{q}|^{3} \Delta t,
$$

where $S_{g}$ is the resistance force while throttling the liquid in the hydraulic oscillation damper; $\beta$ is the coefficient of hydraulic resistance.

When analyzing the information given in work [108], such membrane may be approximately considered as a non-linear elastoviscous member with coefficient of viscous resistance to deformation $\beta_{k}$. At the same time, the force of this member viscous resistance to deformation is evaluated as

$$
P_{v k}=\beta_{k}|\varepsilon| \dot{\varepsilon} .
$$

Approximate value $\dot{\varepsilon}$ may be calculated using difference method, for example, as 


$$
\dot{\varepsilon}=\frac{\varepsilon(t)-\varepsilon(t-\Delta t)}{\Delta t} .
$$

This force work during time $\Delta t$ is calculated using expression

$$
A_{v k}=\beta_{k}|\varepsilon| \dot{\varepsilon}^{2} \Delta t .
$$

One part of this work will be used for structural transformations in the elastomer, one more part will be used for heating the membrane itself and $\Delta Q_{v k}$ part, which we designate with coefficient $\psi$, will be used for additional gas heating. Thus

$$
\Delta Q_{v k}=\psi \beta_{k}|\varepsilon| \dot{\varepsilon}^{2} \Delta t .
$$

Using expressions (7.9)-(7.14), let us find total quantity of heat received by the gas during time $\Delta t$, i. e.

$$
\Delta Q=\Delta Q_{R}+\Delta Q_{\mathrm{fr}}+\Delta Q_{g}+\Delta Q_{v k} .
$$

In the absence of any of the listed above heat sources, the respective summand is equal to zero.

Expression (7.15) helps to find adjustment to the gas temperature determined using expression (7.10):

$$
\Delta T=\frac{\Delta Q}{C_{V} \rho\left(p_{0}, T_{0}\right) V_{0}}=\frac{\Delta Q}{C_{V} v \mu},
$$

then the gas temperature at the end of the integration step may be determined, viz at moment of time $t+\Delta t$ :

$$
T(t+\Delta t)=T_{a}(t+\Delta t)+\Delta T .
$$

Having found the gas temperature at moment of time $t+\Delta t$, we determine the pressure using equations of state (7.1) or (7.2)

$$
p(t+\Delta t)=z[p(t), T(t+\Delta t)] \frac{v R T(t+\Delta t)}{V(t+\Delta t)},
$$

or

$$
p(t+\Delta t)=\frac{v R T(t+\Delta t)}{V(t+\Delta t)-b_{d} v}-a_{d}\left[\frac{v}{V(t+\Delta t)}\right]^{d} .
$$

Exponent $d$ and the constants matching it are determined basing on the conditions described above.

Then the force of the gas resistance to compression $S_{R}(t+\Delta t)=F_{0} p(t+\Delta t)$, the bodies accelerations and velocities at moment of time $t+\Delta t$ are calculated in compliance with the differential equations of the system in question and with the chosen incremental method of numerical integration for the differential equations of movement. 
The program block diagram for numerical simulation of movement of a mechanical system with pneumatic members is given in Figure 7.1. This program is similar in its essence to that given in work [145]. The only difference is that before calculating the forces the values of temperature and gas pressure in the chambers has to be determined.

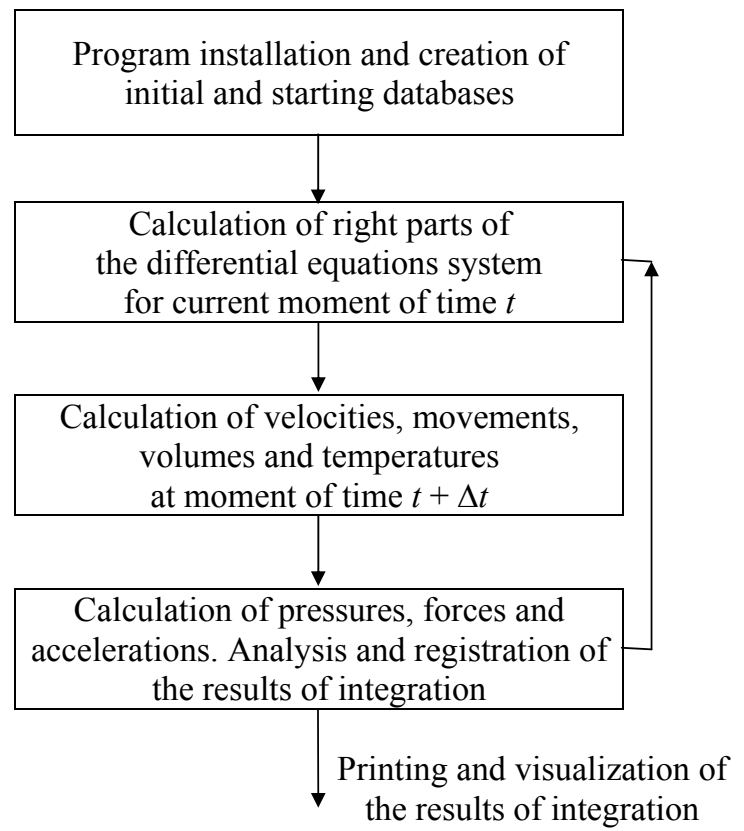

Figure 7.1. Program block diagram for numerical simulation 


\section{HYDRO-GAS DRAFT GEAR WITH VARIABLE MASS WORKING MEDIUM}

Actually, the hydro-gas draft gear considered in Section 6 is, at the same time, the variable mass working medium unit. The working medium is the liquid column between the plunger and the floating piston. The liquid mass in chamber $\mathrm{C}$, Figure 6.1 , or in chamber O, Figure 6.2, changes during the process of the draft gear compression. But, this mass change is connected only with the change of the length of space occupied by the liquid and influences only the liquid column stiffness coefficient, which is quite big and does not play significant role in the formation of the draft gear power characteristic. This stiffness together with other deformed structural members just limits the steepness of force increase at the draft gear impact compression. Invention [148] describes the structure of the hydro-gas draft gear with variable gas quantity in the working chamber.

The specific feature of gas shock absorbers or gas members with big stroke is that pre-tension force value rises at big gas quantity in the chamber, and the shock absorber works well at slow, quasi-isothermal processes, but does not realize its stroke at impact loads as during the adiabatic processes at big gear stokes its stiffness exceeds the stiffness of the damped structure. If the gas quantity in the working chamber is reduced, the draft gear with big stroke functions well at impacts, but at slow quasi-static loads it exhausts its stroke at relatively small forces. These conflicts are overcome in the draft gear with the variable gas quantity in the working chamber.

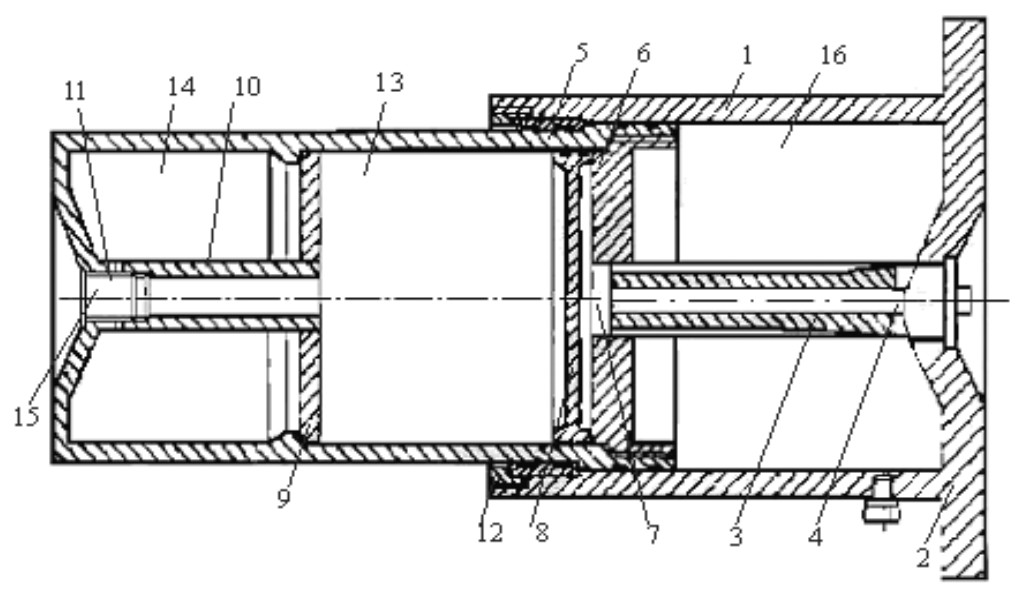

Figure 8.1. Section of a draft gear with the variable gas quantity in the working chamber

Figure 8.1 shows the section of the draft gear [148] with the variable gas quan- 
tity in the working chamber. The gear consists of cylindrical housing 1 with bottom 2 and the open throat. Along the longitudinal axis of the gear at bottom 2, the replaceable profiled rod 3 is mounted. In the channel of this rod, adjustable safety valve 4 is installed. Moving sleeve 5 is located in the housing throat. In the open end of the sleeve, power piston 6 is fixed. This piston has central orifice 7 for the profiled rod. Floating piston 8 and intermediate bottom 9 with channel 10 where double action valve 11 installed in the external bottom of the sleeve and comprising maximum and minimum pressure valves is located are placed inside the sleeve. The outward movement of the sleeve is limited by stop nut 12 . Low-pressure 13 and high-pressure 14 chambers are filled with industrial nitrogen through filler valve 15 . High-pressure chamber 14 may be located either after intermediate bottom 9 together with low-pressure chamber in the same sleeve or outside the sleeve. Hydraulic chamber 16 is filled with liquid (such as AMG-10 (АМГ-10) oil) through orifice 7 . To prevent from the liquid or gas leakage the floating piston, the external surface of the sleeve, the profiled rod and the valves are completed with seals.

The gear is operated as follows. In its initial state, the pressure in low-pressure working chamber 13 is equal to nominal - filling pressure and the pressure in chamber 14 (the receiver) is several times higher. At quasi-static compression during the fore stroke, sleeve 5 moves inside housing 1 and the liquid from chamber 16 is forced through orifice 7 into the after-piston zone. The floating piston moves and compresses the gas in the low-pressure chamber. As soon as the pressure in working chamber 13 exceeds the value set by the maximum pressure valve, which has to be higher than the pressure in chamber 14 , valve 11 opens and gas partially goes from chamber 13 into chamber 14 . This process is accompanied by limitation of the maximum force at gas compression and the gas energy dissipation due to its expansion while coming from chamber 13 into chamber 14 . Thus, the quantity of gas in working chamber 13 is changed during the draft gear operation. During the back stroke, the maximum pressure valve closes. The gas compressed in chamber 13 returns the floating piston into its initial state forcing the liquid from the afterpiston zone into chamber 16. When the pressure in chamber 13 drops below the nominal pressure the minimum pressure valve opens and the gas from chamber 14 returns into chamber 13 maintaining the nominal pressure level in the chamber. This ensures the constant level of force pushing the liquid and returning the gear into its initial state. At dynamic loading, the liquid resistance force occurring at the liquid overflow through the control port is added to the gas resistance force in chamber 13. If the force compressing the gear exceeds the permissible level, safety valve 4 is opened to reduce the hydraulic resistance of the gear and maintain the force at the constant level. This level is adjusted by valve 4 depending on the requirement.

The diagrams in Figure 8.2 show the qualitatively expected power characteristics of the gear at static (isothermal) loading (line 1), dynamic loading (line 2) and the dependence of the force of the gas resistance to compression at dynamic (adiabatic) loading on the gear stroke (line 3 ). Here, $S_{\text {in }}$ is the initial pressure force cor- 
responding to the nominal pressure in chamber $13, S_{\mathrm{GR}}$ is the gas resistance force limitation matching the actuation pressure of the adjustable maximum gas pressure valve, $q$ is the movement of gear power piston 6 having $\Delta$ stroke, $S_{g}$ is the level of force, at which the adjustable valve opens if the pressure in chamber 16 exceeds the set level.

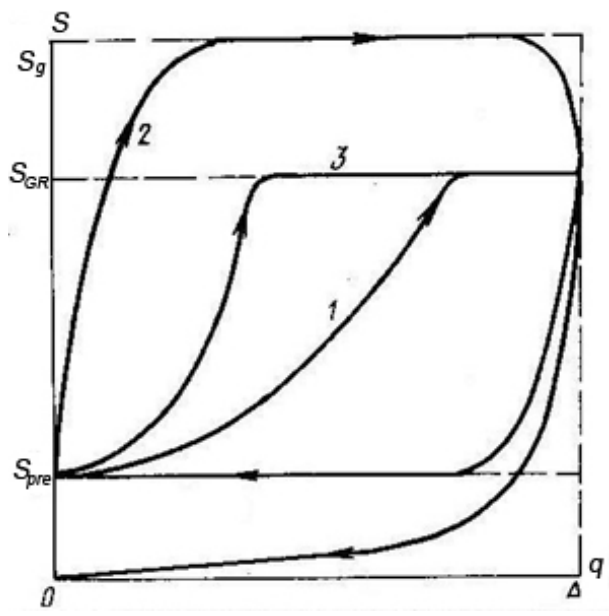

Figure 8.2. Power characteristics of the draft gear with variable gas quantity working chaber

The Figure shows the power characteristic of the gas part only of such gear may be quite energy-consuming with significant energy dissipation coefficient.

Let us consider the mathematical model of such damping unit [149].

As the gear in question is of hydro-gas type, we, in general, may apply the mathematical model described in Section 4 using the differential equation of type (4.27) or the mathematical model described in Section 6 by equation (6.5). In this case, the method of calculation of restoring force $S_{\mathrm{R}}$ at compression of the variable gas quantities makes the specificity of the mathematical model. The model is built using incremental algorithms of numerical integration of differential equations of systems with units using the variable gas quantity in their working chambers.

Just like in the previous sections, force $S_{\mathrm{R}}$ reduced to the piston area may be determined using expression

$$
S_{R}=F_{0} p_{1}
$$

where $F_{0}$ is the area of power piston 6 and $p_{1}$ is the pressure in working chamber 13 reduced to the gas pressure in chamber 16 .

Hereafter let us consider working chamber 13 in Figure 8.1 as the chamber indexed 1 . The gas state in this chamber at every moment of time $t$ is determined by its quantity expressed by number of moles $v_{1}$ and by temperature $T_{1}$, chamber vo- 
lume $V_{1}$ and pressure $p_{1}$. The parameters describing the gas state in chamber $14-$ the receiver - are designated similarly, but indexed 2 . To determine the gas pressure in chambers the equation of the real gas state is used:

$$
p_{i} V_{i}=z_{i}\left(p_{i}, T_{i}\right) v_{i} R T_{i}, i=1.2,
$$

where $z_{i}\left(p_{i}, T_{i}\right)$ is the compressibility coefficient for real gas determined experimentally and presented either in tables [138] or in diagrams [150;151].

First, let us determine the gas temperature due to the change of the working chamber volume, the gas overflow from one chamber to another, the heat exchange and heat transfer. To simplify the calculation let us neglect the chamber membrane deformation. The working chamber volume at any moment of time $t$ at power piston movement $q$ will comprise

$$
V_{1}(t)=V_{10}-F_{0} q(t), \quad V_{2}=V_{20}=\text { const },
$$

where $V_{10}$ is the initial volume of the working chamber, $V_{20}$ is the constant volume of receiver 14 . The volume change rate will make

$$
\dot{V}_{1}=-F_{0} \dot{q} .
$$

Values $q$ and $\dot{q}$ are determined during the process of integration of differential equations of movement of the system with the shock absorber in question, i. e. they are known for any moment of time $t$.

Gas enthalpy (heat content) $W$ is determined by expression $[140 ; 150 ; 151]$

$$
W=E+p V,
$$

where $E$ is the internal gas energy. Taking into account that $W=v C_{p} T$ and $E=v_{V} T$ and $C_{p}$ and $C_{V}$ are the heat capacities of one mole of gas at constant pressure and volume, let's derive the expression for the gas enthalpy in both chambers in form of

$$
v_{i} C_{p} T_{i}=v_{i} C_{V} T_{i}+p_{i} V_{i}, i=1.2 .
$$

We can be quite sure that $C_{p}-C_{V}=R$ where $R$ is the universal gas constant.

Derivatives with time will comprise

$$
\begin{aligned}
& v_{1} R \dot{T}_{1}=-\dot{v}_{1} R T_{1}+\dot{p}_{1} V_{1}+p_{1} \dot{V}_{1}, \\
& v_{2} R \dot{T}_{2}=-\dot{v}_{2} R T_{2}+\dot{p}_{2} V_{2} .
\end{aligned}
$$

Let us find the pressure derivatives with time using interpolatory equations of real gas state taken in form of Van der Waals equarion or the second Detirici equation expressed as

$$
\left[p_{i}+a_{d i}\left(\frac{v_{i}}{V_{i}}\right)^{d_{i}}\right]\left(V_{i}-v_{i} b_{d i}\right)=v_{i} R T_{i}, i=1.2 .
$$


where $p_{i}$ and $V_{i}$ are the gas pressure in the chambers and their volume, respectively; $R$ and $T_{i}$ are the univeral gas constant and absolute gas temperatures (in degrees Kelvin), respectivelly, $R=8.31 \mathrm{~J}$ (mole $\cdot \mathrm{K})^{-1}[127] ; d_{i}$ are the indecies and exponents for the equations of the gas state for each of the chambers, which make Van der Waals equation of the equation of the real gas state (8.9) at $d_{i}=2$ and the second Diterici equation at $d_{i}=5 / 3$. Constants $a_{d i}$ and $b_{d i}$ are equal, respectively, to [139]:

$$
\begin{aligned}
a_{d} & =a_{2}=1.35 \cdot 10^{5} \mathrm{MPa} \cdot \mathrm{cm}^{6} \cdot \mathrm{mole}^{-2}, & a_{d} & =a_{5 / 3}=2.1 \cdot 10^{4} \mathrm{MPa} \cdot \mathrm{cm}^{5} \cdot \mathrm{mole}^{-5 / 3} \\
b_{d} & =b_{2}=38.6 \mathrm{~cm}^{3} \cdot \mathrm{mole}^{-1}, & b_{d} & =b_{5 / 3}=20.6 \mathrm{~cm}^{3} \cdot \mathrm{mole}^{-1} .
\end{aligned}
$$

When choosing the interpolatory equation of gas state at the given moment of time we base on one of the following considerations (assuming approximately 10 per cent error):

- the constants values are assumed in compliance with Van der Waals interpolatory equation until the chamber volume is at least 3 times bigger than the occupied volume of the gas molecules by Van der Waals, which is equal to $b_{2 i} \nu_{i}$;

- if the last condition is not met the constants values are assumed in compliance with the second Diterici equation until chamber volume is at least 3 times bigger than the occupied volume of the gas molecules by Diterici, which is equal to $b_{\frac{5}{3}} v_{i}$.

Let us use symbol $G_{v}$ to designate the gas mass-flow rate in the number of moles per seconds at its overflow from chamber 1 into chamber 2 and back. Basing on the flow continuity conditions we derive

$$
G_{v}=-\dot{v}_{1}=\dot{v}_{2},
$$

that is the gas mass-flow rate is positive when gas overflows from the working chamber into the receiver and negative when it returns back during the back stroke of the draft gear.

After differentiating the equation of state, substitution of $\dot{p}_{1}$ and $\dot{p}_{2}$ values into expressions (8.7) and (8.8) and making a number of transformations, we obtain canonical differential equations for determination of the first approximation of gas temperatures $T_{a 1}$ and $T_{a 2}$ in chambers at the gas adiabatic compression or expansion during the draft gear operation:

$$
\begin{aligned}
& \dot{T}_{a 1}=-\left\{G_{v} \cdot\left[\frac{d_{1} V_{1}-b_{d 1} v_{1}}{b_{d 1} v_{1}}-\frac{V_{1}}{V_{1}-b_{d 1} v_{1}}-\frac{d_{1} p_{1} V_{1}\left(V_{1}-b_{d 1} v_{1}\right)}{R T_{1} b_{d 1} v_{1}^{2}}\right]+\right. \\
& \left.+\dot{V}_{1}\left[\frac{d_{1}}{b_{d 1}}-\frac{V_{1}}{b_{d 1}\left(V_{1}-b_{d 1} v_{1}\right)}-\frac{\left(d_{1}-1\right) p_{1}\left(V_{1}-b_{d 1} v_{1}\right)}{R T_{1} b_{d 1} v_{1}}\right]\right\} \frac{T_{1}}{v_{1}}, \\
& \dot{T}_{a 2}=-G_{v}\left[\frac{1-d_{2}\left(1-\beta_{d 2} v_{2}\right)}{1-\beta_{d 2} v_{2}}+\frac{d_{2}\left(1-\beta_{d 2} v_{2}\right) p_{2} V_{2}}{v_{2} R T_{2}}\right] \frac{T_{2}}{\beta_{d 2} v_{2}^{2}}, \quad \beta_{d 2}=\frac{b_{d 2}}{V_{2}} .
\end{aligned}
$$


The gas quantity in both chambers is determined by way of the equation integration

$$
\begin{aligned}
& \dot{v}_{1}=-\frac{G}{\mu}=-G_{v} \\
& \text { and } \dot{v}_{2}=\frac{G}{\mu}=G_{v}
\end{aligned}
$$

with known inintial conditions, $\mu$ is the weight of one mole of gas. The equation for determination of the gas mass-flow rate at its overflow from one chamber to another will be considered later.

We have mentioned above that values obtained at each step of equations (8.11) and (8.12) integration are just the first approximation. When building these equations the heat transferred by the gas itself, lost at the heat transfer, and received due to the boots friction against the gear housing was neglected. Therefore, hereafter we will assume that the temperatures obtained while integrating equations (8.11) and (8.12) are just the first approximation and should be specified by consideration of a number of physical processes.

Quantity of heat $\Delta Q_{12}$ transferred by the gas overflowing from chamber 1 into chamber 2 is determined by the difference of tempertures and the gas overflow rate during time $\Delta t$ matching the integration step. That is

$$
\Delta Q_{12}=\left\{\begin{array}{lll}
G C_{p}\left(T_{a 1}-T_{a 2}\right) \Delta t, & \text { if } & G>0, \\
0, & \text { if } & G \leq 0 .
\end{array}\right.
$$

Quantity of heat $\Delta Q_{21}$ transferred by the gas overflowing from chamber 2 into chamber 1 is determined by the difference of tempertures and the gas overflow rate during time $\Delta t$ matching the integration step. That is

$$
\Delta Q_{21}=\left\{\begin{array}{lll}
G C_{p}\left(T_{a 2}-T_{a 1}\right) \Delta t, & \text { if } & G<0, \\
0, & \text { if } & G \geq 0 .
\end{array}\right.
$$

The quantity of heat transferred by the gas from one chamber to another due to the heat exchange through the walls and partitions of the gear may be found using expression

$$
\Delta Q_{\mathrm{EX} 1}=-\Delta Q_{\mathrm{EX} 2}=-\alpha_{\mathrm{EX}}\left(T_{1}-T_{2}\right) \Delta t,
$$

where $\alpha_{\mathrm{EX}}$ is the heat exchange coefficient determined experimentally for the given draft gear structure.

Hereafter, it is assumed that the external temperature is equal to $T_{\text {ext }}$ and the coefficients of the gas heat transfer make $a_{g 1}$ and $a_{g 2}$ and are determined experimentally for the specific shock absorber operation conditions (the shock absorber housing material, the specific fixing of the shock asbsorber to the damped structure, the specific features of this structure operation and the housing cooling, 
etc.). This means that during time $\Delta t$ the gas in each of the chambers will lose the part of heat equal to

$$
\begin{aligned}
\Delta Q_{R 1} & =-\alpha_{g 1}\left[0,5 T_{a 1}(t+\Delta t)+0,5 T_{1}(t)-T_{e x t}\right] \Delta t, \\
\Delta Q_{R 2} & =-\alpha_{g 2}\left[0,5 T_{a 2}(t+\Delta t)+0,5 T_{2}(t)-T_{e x t}\right] \Delta t .
\end{aligned}
$$

Simultaneously within the same interval of time, the gas will receive some quantity of heat from external sources. These sources are the heat emitted because of friction occurring between the plunger or piston boots and the chamber housing walls, and the heat transferred to the gas when the liquid in hydraulic dampers is heated while throttled through the local resistances.

The quantity of heat received by the gas in chamber 1 due to the piston boots friction during time $\Delta t$ will comprise (slightly overstated)

$$
\Delta Q_{\mathrm{fr} 1}=0,24 \kappa S_{R}(t) \dot{q}(t) \Delta t,
$$

where $\kappa$ is the boots friction coefficient against the chamber walls; $S_{R}(t)$ is the force of the gas resistance to compression, $\mathrm{kN}$, at moment of time $t$. The boots friction coefficient against the chamber walls is usually assumed approximately equal to 0.1 for rubber seals and 0.05 and less for fluoroplastic seals.

The quantity of heat received by the gas from the hydraulic oscillation damper integrated into the shock absorber in question will comprise

$$
\Delta Q_{g 1}=0,24 S_{g} \dot{q} \Delta t=0,24 \beta|\dot{q}|^{3} \Delta t,
$$

where $S_{g}$ is the resistance force at the liquid throttling in the hydraulic oscillation damper; $\beta$ is the coefficient of hydraulic resistance.

Using the solutions of equations (8.11) and (8.12) for determination of values $T_{a 1}$ and $T_{a 2}$ at moment of time $t+\Delta t$ and expressions (8.15) - (8.21), let's find the resulting quantities of heat received by the gas in chambers 1 and 2 during time $\Delta t$ that is

$$
\begin{aligned}
& \Delta Q_{1}=\Delta Q_{21}+\Delta Q_{\mathrm{EX} 1}+\Delta Q_{R 1}+\Delta Q_{\mathrm{fr} 1}+\Delta Q_{g 1}, \\
& \Delta Q_{2}=\Delta Q_{12}+\Delta Q_{\mathrm{EX} 2}+\Delta Q_{R 2} .
\end{aligned}
$$

In the absence of any of the listed above heat sources or in case a heat source is neglected, the respective summand is assumed equal to zero.

Expressions (8.22) and (8.23) help to find adjustments $\Delta T_{1}$ and $\Delta T_{2}$ for the gas temperatures in chambers 1 and 2 :

$$
\Delta T_{1}=\frac{\Delta Q_{1}}{C_{V} \mu v_{1}}
$$

and

$$
\Delta T_{2}=\frac{\Delta Q_{2}}{C_{V} \mu v_{2}}
$$


then, the gas temperature at the end of the integration step may be determined, viz at moment of time $t+\Delta t$ :

$$
T_{1}(t+\Delta t)=T_{a 1}(t+\Delta t)+\Delta T_{1}
$$

and

$$
T_{2}(t+\Delta t)=T_{a 2}(t+\Delta t)+\Delta T_{2} .
$$

Having found the gas temperature at moment of time $t+\Delta t$, we determine the gas pressure in the chambers using equation of state (8.2):

$$
\begin{gathered}
p_{1}(t+\Delta t)=z\left[p_{1}(t), T_{1}(t+\Delta t)\right] \frac{v_{1} R T_{1}(t+\Delta t)}{V_{1}(t+\Delta t)}, \\
p_{2}(t+\Delta t)=z\left[p_{2}(t), T_{2}(t+\Delta t)\right] \frac{v_{2} R T_{2}(t+\Delta t)}{V_{2}(t+\Delta t)} .
\end{gathered}
$$

To make the calculations using the formulae above, it is necessary to determine the real gas mass-flow rate $G(t)$ at its overflowing from one chamber to another. Works $[151 ; 152]$ suggest such formulae derived for the ideal gas flow. However, the pressure and temperature in the chambers at the draft gear operation have such values, at which the state of the gas significantly differs from the ideal gas state. Hereafter, when simulating the gas flow from chamber 1 into chamber 2 and back, let us assume an approximate formula of state in form of

$$
p_{i}\left(V_{i}-b_{i} v_{i}\right)=v_{i} R T_{i}, \quad i=1.2,
$$

where coefficient $b_{i}$ value is determined at each moment of time using expression

$$
b_{i}=\frac{\bar{z}_{i}-1}{\bar{p}_{i}} R T_{i}, \quad i=1.2,
$$

where $\bar{z}_{i}$ is known $[138 ; 150 ; 151]$ experimentally found value of the gas compressibility coefficient for its state determined by temperature $T_{i}$ at the given moment of time and by average value of pressure $\bar{p}_{i}$ within interval $\left[p_{i}, p_{i}(t)\right]$ - hereinafter $i=1.2$ - respectively at the gas flow from chamber 1 into chamber 2 and back from chamber 2 into chamber 1 .

For determination of the gas flow through the channels connecting chambers 1 and 2 with one another, let us use Bernoulli equation for the case of the constant potential volume forces [151]

$$
\frac{v_{i}^{2}}{2}+P\left(p_{i}(t)\right)=\text { const }
$$

In this Bernoulli equation, $P\left(p_{i}\right)$ is the pressure function (barotropic motion) and 


$$
P\left(p_{i}\right)=\int_{p_{i}}^{p_{i}(t)} \frac{d p}{\rho_{i}(p)},
$$

where $\rho_{i}(p)$ is the dependence of the gas density on pressure. The process in question determines this dependence. Hereafter, just like in works [152; 153], let us assume that short-term process of the gas overflow from one chamber to another occurs adiabatically. It can be demonstrated [140] that the following equality is true at adiabatic process:

$$
p_{i}(t)\left(\frac{\mu}{\rho_{i}(t)}-b_{i}\right)^{k}=p_{i}\left(\frac{\mu}{\rho_{i}}-b_{i}\right)^{k},
$$

where $k=1.4$ and $p_{i}$ and $\rho_{i}$ are the fixed for some initial moment gas pressure and density values in the chamber matching the index number. It is then derived

$$
\rho_{i}(t)=\frac{\mu \rho_{i}\left(\frac{p_{i}(t)}{p_{i}}\right)^{\frac{1}{k}}}{\mu-b_{i} \rho_{i}\left[1-\left(\frac{p_{i}(t)}{p_{i}}\right)^{\frac{1}{k}}\right]},
$$

where $\mu$ is the weight of one mole of gas.

Having substituted the last expression into (8.33) and then, after integration, into (8.32), we arrive at

$$
\frac{v_{j}^{2}}{2}-\frac{k}{k-1} \frac{p_{i}}{\rho_{i}}\left(1-\frac{b_{i} \rho_{i}}{\mu}\right)\left(1-\sigma_{i}^{\frac{k-1}{k}}\right)-\frac{b_{i} p_{i}}{\mu}\left(1-\sigma_{i}\right)=\mathrm{const}=\frac{v_{i}^{2}}{2},
$$

where $j=1.2$ and $j \neq i, v_{j}$ is the gas inflow rate into the chamber numbered $j$, and $\sigma_{i}$ makes $\sigma_{1}=\frac{p_{2}}{p_{1}}, \sigma_{2}=\frac{p_{1}}{p_{2}}$. Initial gas flow in the chamber, from which it outflows, may be considered equal to zero that is $v_{i}=0$. Thus

$$
v_{j}=\left[\frac{2 k}{k-1} \frac{p_{i}}{\rho_{i}}\left(1-\frac{b_{i} \rho_{i}}{\mu}\right)\left(1-\sigma_{i}^{\frac{k-1}{k}}\right)-\frac{b_{i} p_{i}}{\mu}\left(1-\sigma_{i}\right)\right]^{\frac{1}{2}} .
$$

In case with the ideal gas when $b_{i}=0$, expression (8.37) is reduced to known Saint-Venant - Wantzel equality [152; 153].

Having determined the gas overflow rate, let us find mass-flow rate $G(t)$ using formula 


$$
G(t)= \begin{cases}\xi^{-\frac{1}{2}} f_{2} \rho_{2} v_{2}, & \text { if } p_{2}<p_{1}, \\ \xi^{-\frac{1}{2}} f_{1} \rho_{1} v_{1}, & \text { if } p_{1}<p_{2},\end{cases}
$$

where $\xi$ is the coefficient of the channel resistance to the gas overflow determined experimentally and depending on the channel shape and the gas resistance to the movement in the channel (accelerating channels such as de Laval nozzles [152] are not considered here); $f_{i}$ is the section area of the channel, in which the gas overflows from one chamber to another. The gas densities in the chambers are determined in the process of differential equations integration using expression

$$
\rho_{i}=\frac{\mu v_{i}}{V_{i}}, i=1.2
$$

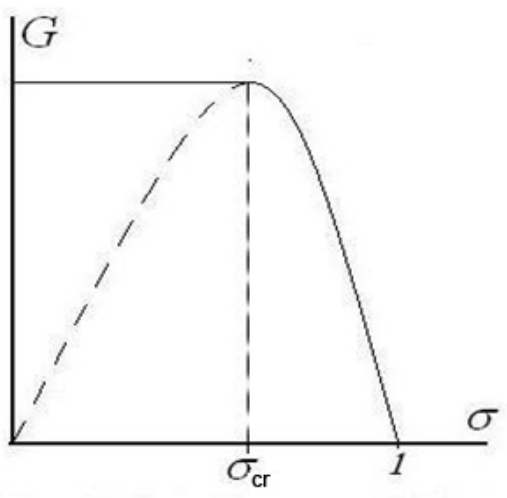

Figure 8.3. Dependence $G(\sigma)$

The analysis of gas mass-flow rate $G$ change depending on value $\sigma_{i}$ reduction conducted in works $[152 ; 153]$ for the case with the ideal gas shows that at some critical value $\sigma_{\mathrm{cr}}=0.538$, value $G$ reaches its maximum. From physics point of view this is explained by the fact that at such correlation of inlet and outlet gas pressures the flow rate equal to the sound velocity establishes. With such velocity any pressure reduction at $\sigma_{i}<\sigma_{\mathrm{cr}}=0.538$ cannot distribute against the flow but are carried towards the flow without changing its velocity. That is with $\sigma_{i}<\sigma_{\mathrm{cr}}=$ 0.538 the gas flow will be constant and equal to the maximum value. Similar phenomena are typical for the real gas flow under consideration. At the same time, remember the sound velocity is greatly dependent on the gas pressure and temperature. Therefore, when building the model basing on the formulae above the flow calculation algorithm should include the numerical analysis of maximum flow rate values $G$ under the conditions at the specific moment of time. Figure 8.3 shows the 
quality dependence $G(\sigma)$ diagram. Dashed part of the curve corresponding to $\mathrm{G}$ values at $\sigma_{i}<\sigma_{\text {cr }}$ is replaced with horizontal interval $G=G_{\text {max }}$.

Let us consider function $G(t)$ calculation algorithm. It is assumed that for the given moment all the values in formulae $(8.37)-(8.39)$ are known, i. e. for the given moment we know the values of pressures $p_{i}$ and $\bar{p}=0.5\left(p_{1}+p_{2}\right)$, respective value $\bar{z}$, value $\sigma$ and matching it value $G$. Let us use symbol $G_{0}$ for this value. Then we increase value $\sigma$ for a small amount $\Delta \sigma$, i. e. we calculate new value $\sigma+\Delta \sigma$ and matching it value $G$ using expressions (8.37) - (8.39). This new $G$ value is designated $G_{1}$. If it turns out that $G_{1}<G_{0}$, we assume that $G(t)=G_{0}$. If otherwise $G_{1}>G_{0}$, we again increase the previous $\sigma$ value by amount $\Delta \sigma$, calculate $G$ using expressions $(8.37)-(8.39)$ and make it equal to $G_{1}$. Then we compare the two thus obtained values until value $G(t)$ corresponding to the solid lines in Figure 8.3 is found. Figure 8.4 shows the calculation program block diagram using the described value $G(t)=G(\sigma(t))$ algorithm.

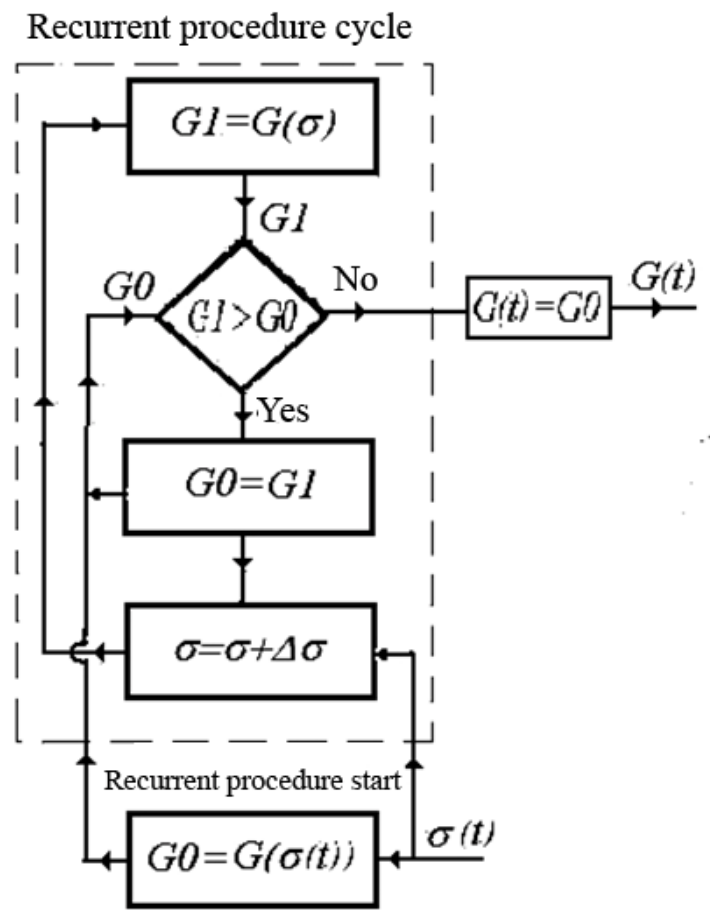

Figure 8.4. Program block diagram for calculation of mass-flow rate $G(t)$ 
The most accurate calculation of pressure may be made using expression (8.2) if the gas compression coefficients are known. The same information is necessary for determination $b_{i}$ parameters in expressions (8.30) and (8.31) used for calculation of the gas flow rate $G(t)$. Works $[150 ; 151]$ give generalized curves of gases compressibility coefficients as a function of pressure values at different temperatures. Using these curves the experimentally determined numerical values of gas compressibility coefficient $z\left(p_{r}, T_{r}\right)$ were obtained and tabulated for a number of reduced pressure $p_{r}=\frac{p}{p_{c}}$ and reduced temperature $T_{r}=\frac{T}{T_{c}}$ values. Thus, reduced pressure and temperature are equal to the ratios of pressure and temperature values to their critical values $T_{c}$ and $p_{c} ; T_{c}$ is the critical temperature, above which no pressure can transform the gas into liquid; $p_{c}$ is the critical pressure. For nitrogen $T_{c}=126 \mathrm{~K}, p_{c}=3.39 \mathrm{MPa}[139 ; 151]$. The nitrogen pressure and temperature values corresponding to the chosen generalized parameters are given in brackets.

Experimental diagrams for practical technical calculation of pneumatic shock absorbers may be approximated quite accurately using expression

$$
\begin{aligned}
& z\left(p_{r}, T_{r}\right)=1-1,16 e^{-0,7 T_{r}}+\left(0,012+0,16 e^{-0,7 T_{r}}\right) p_{r}+ \\
& +\left[0,27+0,057\left(p_{r}-4\right)^{2}\right] e^{-0,7 T_{r}} \sigma_{0}\left(5,0-p_{r}\right),
\end{aligned}
$$

where $\sigma_{0}\left(5.0-p_{r}\right)$ is Heaviside operator equal to unity at $p_{r} \leq 5.0$ and to zero at $p_{r}>5.0$.

Table 8.1 gives values $z_{a p p r}\left(p_{r}, T_{r}\right)$ and determination errors using approximating formula (8.40) of gas compressibility coefficient. These values demonstrate that within intervals of $0 \leq p_{r} \leq 40$ and $1.8 \leq T_{r} \leq 6.0$ (for nitrogen $-50^{\circ} \mathrm{C}$ to $+483^{\circ} \mathrm{C}$ ) the gas compressibility coefficient calculation accuracy using approximating expression (8.40) is sufficient for technical calculations. At the same time, it should be kept in mind that the gas compressibility determination error occurring when the experimentally plotted diagrams are used is comparable with the approximation error.

It should be noted that approximating expression (8.40) is built formally mathematically and is not based on any physical factors.

Thus, above we have the mathematical model of gas draft gear, loaded pneumatic support bearing, shock absorber with variable gas quantity working chamber.

Dashed line in Figure 8.5 highlights the program block diagram for a shock absorber with variable gas quantity working chamber. This diagram is a component of the program used for mathematical simulation of the mechanical system as a whole. Figures 1-14 stand for the program blocks. The parts of the program not related to the simulation of the shock absorber in question are figured 1, 12-14.

In these parts the initial conditions are formed, the forces and the right parts of differential equations are calculated, the chosen method of numerical integration is realized with increment $\Delta t_{\text {reg }}$ multiple of integration increment $\Delta t$, the problem analysis results are stored and displayed as is described in work [145]. 
Table 8.1

Gas Compressibility Coefficients [150; 151]

\begin{tabular}{|c|c|c|c|c|}
\hline$T_{r}\left(t^{\circ} \mathrm{C}\right)$ & $p_{r}(p, \mathrm{MPa})$ & $z\left(p_{r}, T_{r}\right)$ & $z_{\text {appr }}\left(p_{r}, T_{r}\right)$ & $\delta \%$ \\
\hline \multirow{8}{*}{$\begin{array}{c}1.8 \\
(-50)\end{array}$} & $2(6.78)$ & 0.94 & 0.93 & -1.1 \\
\hline & $4(13.56)$ & 0.92 & 0.98 & +6.5 \\
\hline & $6(20.34)$ & 0.96 & 1.02 & +6.3 \\
\hline & $8(27.12)$ & 1.06 & 1.13 & +6.6 \\
\hline & $10(33.9)$ & 1.17 & 1.24 & +6.0 \\
\hline & $20(67.8)$ & 1.73 & 1.82 & +5.2 \\
\hline & $30(101.7)$ & 2.28 & 2.39 & +4.8 \\
\hline & 40 (145.6) & 2.81 & 2.96 & +5.3 \\
\hline \multirow{10}{*}{$\begin{array}{c}2.0 \\
(-21)\end{array}$} & $0(0)$ & 1.00 & 1.01 & +1.0 \\
\hline & $1(3.39)$ & 0.98 & 0.96 & -2.0 \\
\hline & $2(6.78)$ & 0.97 & 0.94 & -3.1 \\
\hline & $4(13.56)$ & 0.96 & 0.99 & +3.1 \\
\hline & $6(20.34)$ & 1.01 & 1.02 & +1.0 \\
\hline & $8(27.12)$ & 1.08 & 1.13 & +4.6 \\
\hline & $10(33.9)$ & 1.17 & 1.23 & +5.1 \\
\hline & $20(67.8)$ & 1.67 & 1.74 & +4.2 \\
\hline & $30(101.7)$ & 2.16 & 2.26 & +4.6 \\
\hline & $40(145.6)$ & 2.63 & 2.77 & +5.3 \\
\hline \multirow{9}{*}{$\begin{array}{c}2.5 \\
(+42)\end{array}$} & $1(3.39)$ & 1.00 & 0.97 & -3.0 \\
\hline & $2(6.78)$ & 1.01 & 0.97 & -4.0 \\
\hline & $4(13.56)$ & 1.03 & 0.96 & -6.8 \\
\hline & $6(20.34)$ & 1.07 & 1.04 & -2.8 \\
\hline & $8(27.12)$ & 1.13 & 1.12 & -0.9 \\
\hline & $10(33.9)$ & 1.17 & 1.20 & +2.6 \\
\hline & $20(67.8)$ & 1.57 & 1.59 & +1.2 \\
\hline & $30(101.7)$ & 1.96 & 1.99 & +1.5 \\
\hline & $40(145.6)$ & 2.32 & 2.23 & -3.9 \\
\hline \multirow{6}{*}{$\begin{array}{c}3.5 \\
(+168)\end{array}$} & $0(0)$ & 1.00 & 1.00 & 0.0 \\
\hline & $1(3.39)$ & 1.03 & 0.99 & -3.9 \\
\hline & $2(6.78)$ & 1.03 & 0.99 & -4.0 \\
\hline & $4(13.56)$ & 1.06 & 1.03 & -3.0 \\
\hline & $6(20.34)$ & 1.11 & 1.08 & -2.7 \\
\hline & $8(27.12)$ & 1.15 & 1.13 & -1.7 \\
\hline \multirow{4}{*}{$4.0(+231)$} & $10(33.9)$ & 1.19 & 1.15 & -3.4 \\
\hline & $20(67.8)$ & 1.41 & 1.36 & -3.5 \\
\hline & $30(101.7)$ & 1.64 & 1.58 & -3.7 \\
\hline & $40(145.6)$ & 1.87 & 1.80 & -3.7 \\
\hline \multirow{4}{*}{$6.0(+483)$} & $10(33.9)$ & 1.18 & 1.13 & -4.2 \\
\hline & $20(67.8)$ & 1.32 & 1.27 & -3.8 \\
\hline & $30(101.7)$ & 1.48 & 1.41 & -4.7 \\
\hline & $40(145.6)$ & 1.5 & 1.64 & +9.3 \\
\hline
\end{tabular}




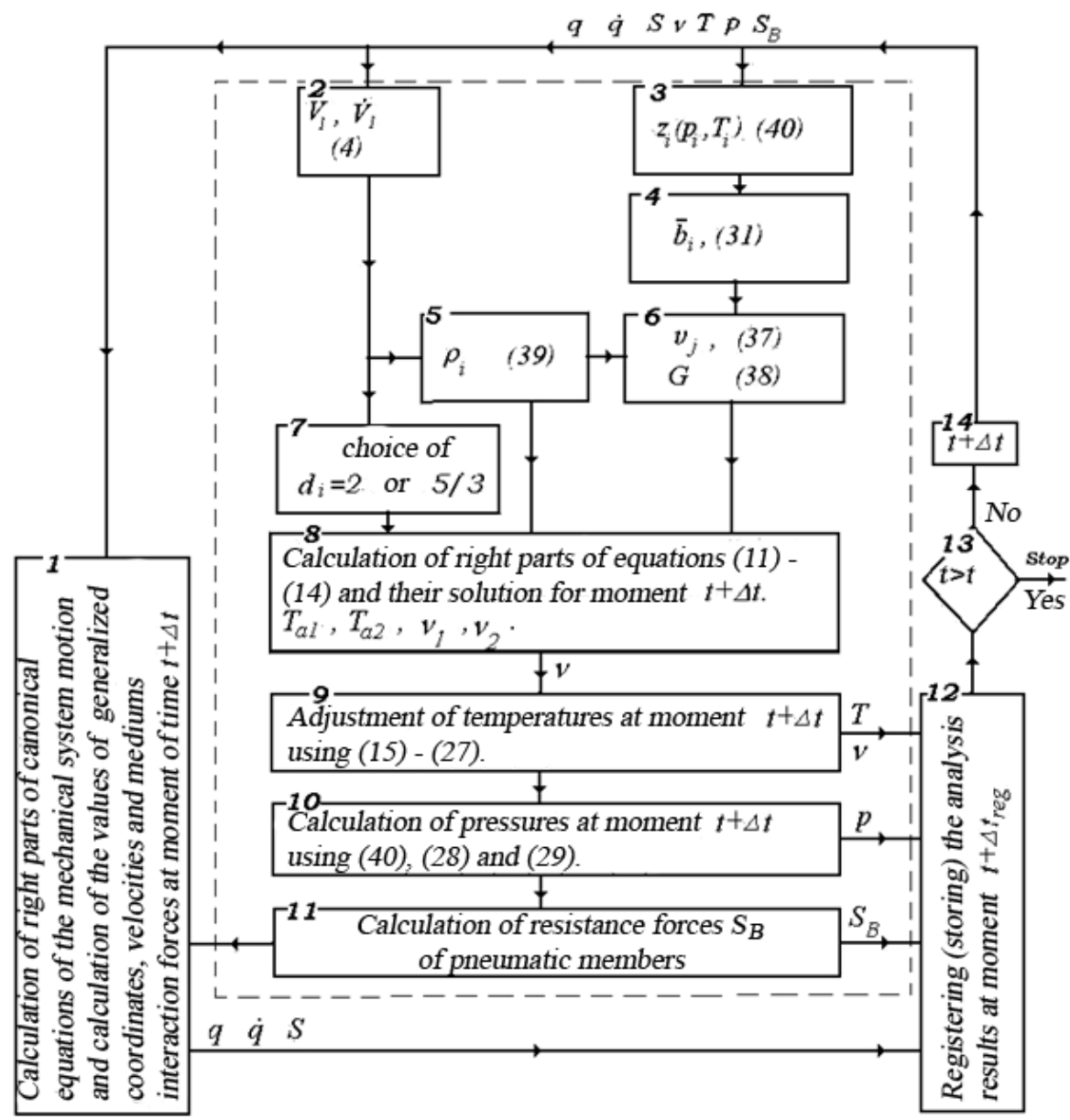

Figure 8.5. Program block diagram including programmable realization of mathematical model of a member with variable gas quantity working chamber

The part highlighted with the dashed line realizes calculations in compliance with the mathematical model described above. Inside this part, the calculated parameters are indicated in each block, and the numbers of the formulae used for the calculation of the indicated parameters are given in brackets.

The mathematical model of a gas draft gear offered above and the program algorithms of this model realization may be used both when simulating the spatial oscillation of railway vehicles in a train $[124 ; 137]$ and independently for the analysis of the respective draft gear structures operation. 


\section{APPROXIMATED MODEL OF SHOCK ABSORBERS. OPTIMAL PARAMETERS OF AUTOMATIC COUPLING DRAFT GEARS}

The mathematical models analyzed above describe the physical processes influencing the main damper characteristics quite fully. Their application is justified, first of all, by the utilization of modern computers. In a number of cases, the analysis may be carried out applying the approximated description of processes connected with the dampers operation, but such description still should allow for analytical assessment of the dampers main specificities. Now, let us analyze the shock absorbers.

Let us assume power characteristic $S(q, v)$ of a shock absorber in form of:

$$
S(q, v)=S_{R}(q)(1+\varphi(v) \operatorname{sign} q), \quad v=\dot{q} .
$$

Differential equation of relative movement of two colliding solid bodies separated with a shock absorber may be set out as

$$
m v \dot{v}+S_{R}(q)(1+\varphi(v) \operatorname{sign} q)=0,
$$

where $m=\frac{m_{1} m_{2}}{\left(m_{1}+m_{2}\right)}\left(m_{1}\right.$ and $m_{2}$ are the masses of colliding bodies); $v$ is the shock absorber compression speed; $\varphi(v)$ is some function characterizing the energy dissipation by the shock absorber. The initial conditions specifying the whole system movement comprise $v(0)=v_{0}, q(0)=0, v_{0}$ is the bodies collision rate. By a number of simple transformations [99] we can arrive at the following equation:

$$
m \Phi\left(v_{0}\right)=\Pi\left(q_{m}\right)
$$

used for determination of $q_{m}$ value of the maximum shock absorber compression where

$$
\left.\begin{array}{l}
\Phi(v)=\int_{0}^{v}(\varphi(v)+1)^{-1} v d v, \\
\Pi(q)=\int_{0}^{q} S_{R}(q) d q .
\end{array}\right\}
$$

The biggest rate $v_{1}$ of the back shock and coefficient $\eta$ of the energy dissipation are determined using expressions

$$
\left.\begin{array}{l}
\Phi\left(v_{0}\right)=\Phi\left(v_{1}\right), \\
\eta=1-v_{1}^{2} / v_{0}^{2} .
\end{array}\right\} .
$$

The maximum force $S_{m}$ in the process of a shock will occur either at the maximum compression, or at the moment when the compression is equal to $q_{s}$ and the compression rate is $v_{s}$. The value of the maximum force will be calculated using expression 


$$
S_{m}=S_{R}\left(q_{s}\right)\left(1+\varphi\left(v_{s}\right)\right),
$$

where values $q_{s}$ and $v_{s}$ are determined by solution of algebraic equations

$$
\left.\begin{array}{l}
m\left[\hat{\mathrm{O}}\left(v_{0}\right)-\hat{\mathrm{O}}\left(v_{s}\right)\right]=\ddot{I}\left(q_{s}\right), \\
\frac{d S_{R}}{d q}=\frac{S_{R}^{2}}{m v} \cdot \frac{d \varphi}{d v} .
\end{array}\right\}
$$

Further, let us analyze hydraulic draft gears only. In this case, $\varphi(v)=p_{2} v^{2} \operatorname{sign} v$, i. e. the resistance force is proportional to the square of the connection deformation rate. Basing on expression (9.4) we have

$$
\hat{\mathrm{O}}(v)=\frac{1}{2 p_{2}} \ln (1+\varphi(v)) \operatorname{sign} v .
$$

The analysis of equations (9.7) solution for the case under consideration implies that value $q_{s}$ of the shock absorber compression, at which the maximum force at the bodies collision occurs, stays constant and independent from the collision rate starting from some specific value.

The power characteristics of GA-100 (ГА-100) and GA-500 (ГА-500) draft gears obtained experimentally [154] demonstrate that, starting from some specific collision rate value, the biggest forces occur at the gears plungers movements lesser than the maximum values of such movements. At the same time, the movements the maximum forces are observed at are insignificantly dependent on the cars collision rate. Therefore, we can consider $q_{s}=$ const and assume the following formula as an approximated mathematical model of hydro-gas draft gears connection:

$$
\left.\begin{array}{c}
S=S_{0}(1-r|q|)^{-n}\left(1+\varphi_{1} \operatorname{sign} q\right) \operatorname{sign} q ; \\
\varphi_{1}=p_{2} v_{1}^{2} \operatorname{sign} v ; \quad v_{1}=0,5 v .
\end{array}\right\}
$$

Hereinafter, let us consider $q>0$ and additionally multiply coefficient $p_{2}$ by positive coefficient $\xi$ if $\operatorname{sign}(q v)=-1$. After the transformations made in compliance with the formulae and equations above, we arrive at

$$
\begin{aligned}
& q_{m}=r^{-1}\left\{1-\left[1+\alpha_{1} \ln \left(1+\varphi_{10}\right)\right]^{\frac{1}{1-n}}\right\} ; \\
& q_{s}=r^{-1}\left(1-\alpha_{2}\right),
\end{aligned}
$$

where

$$
\alpha_{1}=\frac{m r(n-1)}{2 p_{2} S_{0}} ; \quad \alpha_{2}=\left(\frac{2 p_{2} S_{0}}{m n r}\right)^{\frac{1}{n-1}} ; \quad \varphi_{10}=p_{2} v_{10}^{2} .
$$

The maximum force at collision, if $q_{s} \geq q_{m}$, will be equal to 


$$
S_{m}=S_{0}\left[1+\alpha_{1} \ln \left(1+\varphi_{10}\right)\right]^{\frac{n}{n-1}}
$$

and if $q_{s}<q_{m}$

$$
S_{m}=S_{0} \alpha_{2}^{-n} e^{\gamma}\left(1+\varphi_{10}\right) ; \quad \gamma=\frac{n}{n-1}\left(1-\alpha_{2}^{n-1}\right) .
$$

If it turns out that $q_{s}<0$,

$$
S_{m}=S_{0}\left(1+\varphi_{10}\right) .
$$

In the latter case, the force evaluation using formula (9.13) will be greatly overstated as the level of forces, under these conditions, is determined mostly by the liquid compressibility in the draft gear and the damped structure elements deformations.

Power characteristic in form of function $S(q v)=S^{*}\left(q v_{10}\right)$ in the movement interval $\left(0, q_{m}\right)$ may be determined using expression

$$
S=S_{0}(1-r|q|)^{-n}\left(1+\varphi_{10}\right)^{\xi_{1}} \exp \left[\xi_{1} \alpha_{1}^{-1}\left(1-(1-r|q|)^{1-n}\right)\right],
$$

where $\xi_{1}=(-\xi)^{0,5(1-\operatorname{sign}(q v))}$.

Function (9.14) was derived subject to the condition that the liquid compressibility is not taken into account. We can find the additional gear plunger displacement due to the liquid compressibility using the following expression:

$$
q_{\mathrm{lq}}=k_{\mathrm{lq}}^{-1}\left\{S-\Delta^{-1}|q|\left[S-S_{0}(1-r|q|)^{-n}\right]\right\} ; \quad k_{\mathrm{lq}}=E_{\mathrm{lq}} F \Delta^{-1},
$$

in which $\Delta$ и $F$ are the full plunger displacement and the area, respectively; $E_{\mathrm{lq}}$ is the liquid compressibility modulus.

Ignoring force $S$ operation on the liquid compression, we can evaluate the plunger displacement as

$$
q^{*}=q+q_{\mathrm{lq}}
$$

$S_{0}, r, n$ and $p_{2}$ parameters may be identified if static and dynamic power characteristics of a draft gear are known. Using the static characteristic and evaluating the gas pressure in the chambers, the values of $S_{0}, r$ and $n$ are selected to best fit the given static characteristic. Then, the value of polytropic coefficient $n$ is adjusted for the impact loads using the forces values under the maximum gear compression, and $q_{s}$ compression values are determined under the maximum forces for the power characteristics realized at various impact rates. These values are averaged and $p_{2}$ value is found basing on average $q_{s}$ value and using expression (9.10). $S_{m}$ and $q_{m}$ values are used for verification of the accuracy of the approximated mathematical description of the gear dynamic power characteristic.

Estimated $S_{0}, r, n$ and $p_{2}$ values for GA-100 (ГА-100) (with initial gas pressure in the chambers of 0.8 and $6.5 \mathrm{MPa}$ ) and GA-500 (ГА-500) (with initial gas pressure in the chambers of 1.2 and $12.5 \mathrm{MPa}$ ) draft gears derived from the experiments results $[3 ; 148]$ are given in Table 9.1 [3]. The value recommended for ap- 
plication when the deformability of the structure or other damped system and the liquid compressibility should be taken into consideration is given in brackets.

Table 9.1

\section{Results of Identification of Power Characteristics Parameters for Hydro-Gas Draft Gears [3]}

\begin{tabular}{|c|c|c|c|c|}
\hline Gear & $S_{0}, \mathrm{MN}$ & $r, \mathrm{~m}^{-1}$ & $n$ & $p_{2}, \mathrm{sec}^{2} \mathrm{~m}^{-1}$ \\
\hline $\begin{array}{c}\text { GA-100 } \\
\text { (ГА-100) }\end{array}$ & 0.1 & 12.5 & 1.5 & $6.5(7.2)$ \\
\hline $\begin{array}{c}\text { GA-500 } \\
(\text { ГA-500) }\end{array}$ & 0.1 & 8.0 & 1.7 & 3.7 \\
\hline
\end{tabular}

The maximum plunger displacements in GA-100 (ГА-100) and GA-500 (ГА-500) draft gears computed using formulae (9.10)-(9.13), (9.15) and (9.16) and the maximum forces expected at the cars collisions are given in Tables 9.2 and 9.3 [3]. The experimental results obtained when testing these gears are given ibidem $[3 ; 148]$.

Figure 9.1 illustrates the power characteristics of GA-500 (ГА-500) draft gears obtained experimentally (solid lines) and plotted basing on the approximated calculations using expression (9.14) with $\xi=3$ (dashed lines). The comparison of the approximated calculation results with the test results proves the suggested approximation is quite good for description of real processes and may be applied in other cases, which will be analyzed below.

Provided function (9.12) minimum conditions are met, we can find the optimal value of coefficient $p_{2}$ for the cars collision case which is equal to

$$
p_{2}^{y}=0,5 m r S_{0}^{-1} .
$$

Basing on the information of Table 9.1, we find that for fully loaded eightwheel gondola cars, optimal $p_{2}^{y}$ value is $5.4 \mathrm{sec}^{2} / \mathrm{m}^{2}$ for GA-100 (ГА-100) draft gears and $3.4 \mathrm{sec} .{ }^{2} / \mathrm{m}^{2}$ for GA-500 (ГA-500) draft gears. The same table shows the identified coefficient $p_{2}$ values are close to the optimal values. However, it can be derived from expression (9.17) that the power characteristic optimum depends on the colliding bodies weights. This deficiency may be overcome using feedback units, an example of which will be described later.

Table 9.2

Estimated and Test Values of GA-100 (ГA-100) Draft Gear Maximum Forces and Compressions at Collisions of Loaded Eight-Wheel Gondola Cars [3; 148]

\begin{tabular}{|c|c|c|c|c|}
\hline \multirow{2}{*}{$\begin{array}{c}v_{0}, \\
\mathrm{kmh}\end{array}$} & \multicolumn{2}{|c|}{$q_{m}, \mathrm{~mm}$} & \multicolumn{2}{c|}{$S_{m}, \mathrm{MN}$} \\
\hline 4 & Estimated & Test & Estimated & Test \\
\hline 6 & 42 & $24-48$ & 0.32 & $0.29-0.55$ \\
\hline 8 & 53 & $31-57$ & 0.58 & $0.47-0.70$ \\
\hline 10 & 59 & $37-64$ & 0.95 & $0.73-1.19$ \\
\hline 12 & 62 & $43-70$ & 1.42 & $1.00-1.45$ \\
\hline
\end{tabular}


Table 9.3

Estimated and Test Values of GA-500 (ГA-500) Draft Gear Maximum Forces and Compressions at Collisions of Loaded Eight-Wheel Gondola Cars [3; 148]

\begin{tabular}{|c|c|c|c|c|}
\hline \multirow{2}{*}{$\begin{array}{r}v_{0}, \\
\mathrm{kmh}\end{array}$} & \multicolumn{2}{|c|}{$q_{m}, \mathrm{~mm}$} & \multicolumn{2}{c|}{$S_{m}, \mathrm{MN}$} \\
\hline \multicolumn{5}{|c|}{ Eight-wheel gondola cars } \\
\hline 4.2 & 58 & 58 & 0.28 & 0.34 \\
\hline 7.2 & 81 & 84 & 0.59 & 0.69 \\
\hline 9.0 & 88 & 93 & 0.85 & 0.93 \\
\hline 10.8 & 93 & 101 & 1.17 & 1.13 \\
\hline 12.8 & 99 & 101 & 1.58 & 1.50 \\
\hline 16.2 & 102 & 106 & 2.47 & 2.16 \\
\hline \multicolumn{5}{|c|}{ Twelve-wheel gondola cars } \\
\hline 4 & 70 & $55-80$ & 0.38 & $0.25-0.43$ \\
\hline 6 & 87 & $80-100$ & 0.70 & $0.50-0.75$ \\
\hline 8 & 97 & $95-110$ & 1.11 & $0.85-1.20$ \\
\hline 10 & 105 & $105-115$ & 1.62 & $1.20-1.70$ \\
\hline 12 & 110 & $110-120$ & 2.24 & $1.60-2.30$ \\
\hline
\end{tabular}

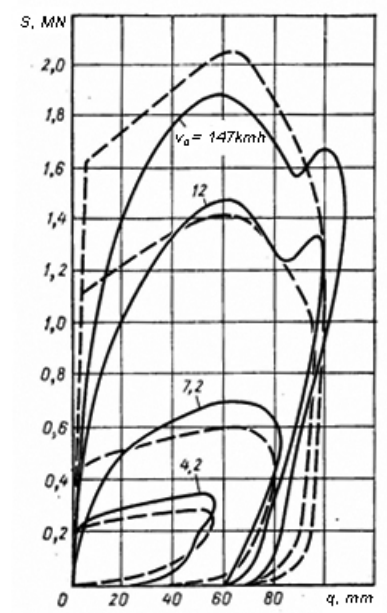

Figure 9.1. Power characteristics of GA-500 (ГА-500) draft gear obtained experimentally (solid lines) and theoretically (dashed lines)

Let us consider a more general case [155] of mathematical description of a hydraulic shock absorber. Suppose

$$
S=S_{R}\left(q_{1}\right)+\beta\left(q_{1}\right) v_{1}\left|v_{1}\right|,
$$


where $\beta\left(q_{1}\right)$ is the coefficient of hydraulic resistance depending on the draft gear stroke $q_{1}$.

The equitation of motion of a car weighing $m$ at its collision with another similar car at a rate of $v_{0}=2 v_{10}$ may be presented as follows

$$
m \dot{v}_{1}+\beta\left(q_{1}\right) v_{1}\left|v_{1}\right|+S_{R}\left(q_{1}\right)=0 ; \quad \dot{q}_{1}=v_{1} .
$$

Now let us substitute $v_{1}^{2}=V$ and consider the collision stage when $q_{1}>0$. Equation (9.19) may be transformed as follows

$$
\left.\begin{array}{l}
0,5 m V^{\prime}+\beta\left(q_{1}\right) V+S_{R}\left(q_{1}\right)=0 \\
V^{\prime}=\frac{d V}{d q_{1}} ; V(0)=v_{10}^{2} .
\end{array}\right\} .
$$

Now let us find dependence $\beta\left(q_{1}\right)$, at which maximum force $S_{m}$ occurring at the cars collision at a rate corresponding to maximum compression rate $v_{10}=\bar{v}_{0}$ of the draft gear (i. e. $V(0)=\bar{V}$ ) is minimal and does not exceed the specified value of $\bar{S}$, other factors being equal. At the same time, suppose the draft gear stroke is $q_{1 m}=\bar{q}(\bar{q}$ is the maximum possible draft gear stroke permitted by its structure) and $S_{R}(\bar{q}) \leq \bar{S}$. The energy relations make it obvious that the smallest vale of maximum force is achievable if at any $q_{1}$ during the impact with the mentioned rate, the following is true

$$
\beta\left(q_{1}\right) V+S_{R}\left(q_{1}\right)=\bar{S}=\text { const } .
$$

Having inserted expression (9.21) into expression (9.20), we have

$$
V^{\prime}=-2 \bar{S} / m
$$

whence it follows that

$$
V\left(q_{1}\right)=\bar{V}-\frac{2 \bar{S}}{m} q_{1}=\frac{2 \bar{S}}{m}\left(\bar{q}-q_{1}\right),
$$

as $0.5 m \bar{V}=\bar{S} \bar{q}$.

Therefore, $S_{R}\left(q_{1}\right)+\beta_{\text {opt }}\left(q_{1}\right) \frac{2 \bar{S}}{m}\left(\bar{q}-q_{1}\right)=\bar{S} ; \quad 0 \leq q_{1} \leq \bar{q}$.

whence it follows that

$$
\beta_{\text {opt }}\left(q_{1}\right)=0.5 m\left[1-\bar{S}^{-1} S_{R}\left(q_{1}\right)\right]\left(\bar{q}-q_{1}\right)^{-1} .
$$

Expression (9.24) suggests that at $S_{R}(\bar{q}) \leq \bar{S}$ values $\beta_{\text {opt }}(\bar{q}) \rightarrow \infty$. If the draft gear parameters are chosen so that $S_{R}(\bar{q})=\bar{S}$, it becomes necessary to evaluate an indeterminate form $\frac{0}{0}$ in order to find $\beta_{\text {opt }}(\bar{q})$ and then, using L'Hopital's rule, 


$$
\beta_{\mathrm{opt}}(\bar{q})=\frac{m}{2 \bar{S}} S_{R}^{\prime}(\bar{q})
$$

Automatic coupling draft gears are the same shock absorbers. However, their main specificity is that, in addition to all other forces, they transfer comparatively slow changing traction and braking forces realized in a train. At the same time, the draft gears have to damp the longitudinal oscillations of a train generated by its transitional modes as well as the impacts and the impact series spread along the train or formed in the train $[3 ; 108 ; 156 ; 157]$. The existing experience, experimental and theoretical studies of dynamic processes in trains $[3 ; 101 ; 108 ; 112 ; 145$; $154 ; 156 ; 157]$ demonstrate that these units manifest somehow different character in trains if used in quite a big aggregate. Therefore, we will analyze the optimal for hydro-gas draft gears characteristics conditions at their operation in a train when their properties are manifested in the aggregate [3]. Here, the minimum forces in train automatic couplings and minimum train cars accelerations have to occur under respective conditions.

Hereinafter, we will analyze the hydro-gas draft gears only as the process in trains with such draft gears may lead to deterioration of longitudinal dynamics if the hydraulic resistance in them is selected improperly. At the same time, if the draft gears hydraulic resistance to compression is well selected, good results may be obtained [3; 157]. In this relation, friction draft gears are not so promising because it is practically impossible to avoid the impacts in a train with gaps in the draft.

It is quite easy to verify [3] that the equations of motion of a train as a onedimensional system of solid bodies are analogous to the differential-difference equations of motion of some solid one-dimensional system (such as a rod or an air in a tube) derived using direct or integral relations method [158]. Work [159] demonstrates that the solution of differential-difference equations reduces to the solution of respective boundary value problem provided this solution is, in turn, smooth.

Power characteristics of gas restoring mechanisms of draft gears are consave down, i. e. $\frac{\partial^{2} S_{R}}{\partial q^{2}}>0$. If force $F_{0}$ smoothly increasing from zero to its maximum value is applied to one of the ends of the respective onedimensional continuous system with consave down function $\mathrm{S}_{\mathrm{R}}(\mathrm{q})$ and without hydraulic resistance(here, $F_{0}$ has to be significantly greater than value of the draft gear pre-tension $S_{0}$ ), it will be cteated a blast wave in quite a long system, at the front of which the jump from 0 to $F_{0}$ value will occur [4].. This means the solution of the respective boundary value problem is discontinuous. That is why the train motion equations solution cannot be reduced to it, and the forces in the train will significantly exceed $F_{0}$ value [3]. Due to introduction of non-elastic forces of the respective continuous onedimensional system resistance to deforming and the forces of the draft gear hydraulic resistance to their compression, it becomes possible to achieve smooth transition from one state to another, and the train motion equations solution may be 
reduced to the solution of the boundary value problem. The forces so developed in a train will not exceed $F_{0}$, i. e. they will be minimal.

Following work [159], let us now analyze the compression blast wave front structure. For this, let us consider the train motion may be described as the motion of equivalent by mass and rheology rod. Suppose close to the end $x=L$ of a uniform rod, smoothly increasing from zero to its maximum value force $F(t)$ $\left(\max F(t)=F_{0}\right)$ is applied, and suppose the rod end $x=0$ is free. In Lagrangean coordinates, the differential equations corresponding to the law of conservation of mass, pulse and energy [159] may have the form

$$
\begin{gathered}
\frac{\partial \varepsilon}{\partial t}=(1+\varepsilon) \frac{\partial v}{\partial x}, \\
\rho \frac{\partial v}{\partial t}=\frac{\partial S}{\partial x}+f(x, t), \\
\frac{\partial}{\partial t}\left(E+0,5 \rho v^{2}\right)=\frac{\partial}{\partial x}(S v)+f v,
\end{gathered}
$$

where $\varepsilon$ and $v$ are the deformation and the motion rate of the rod, respectively; $x$ and $t$ are the section coordinate and time, respectively; $\rho$ is the rod mass density; $E$ is the rod internal energy.

$$
S=S_{R}(\varepsilon)+S_{g}(\varepsilon, \dot{\varepsilon}),
$$

where $S_{R}=S_{0}\left(1-r_{\varepsilon}|\varepsilon|\right)^{-n} \operatorname{sign} \varepsilon$ is the restoring force $\left(S_{0}\right.$ is the force corresponding to the draft gears preinterference ; $r_{\varepsilon}$ is the constant as applied to the rod); $S_{g}(\varepsilon, \dot{\varepsilon})$ is the force of non-elsatic ressitance to the rod deformation. Function $f(x, t)$ describes the force intensity; when solving the problem of the train motion start, this force is equal to zero.

To make the considerations and computations mores simple, let us analyze only the train start mode, i. e. let us consider the motion of an equivalent rod under the following limit and initial conditions:

$$
\begin{aligned}
& \left.\begin{array}{l}
S(L, t)=F(t)+F_{1}, \\
S(0, t)=-F_{1}, \quad F_{1}>S_{0},
\end{array}\right\}, \\
& \left.\begin{array}{l}
\varepsilon(x, 0)=\varepsilon_{1}, \\
v(x, 0)=0, \\
E(x, 0)=E_{1} .
\end{array}\right\} .
\end{aligned}
$$

Here $S\left(\varepsilon_{1}\right)=S_{1}=F_{1}$.

Let us also consider that the solution is automodel to [159] at the stage of force $S$ propagation along the $\operatorname{rod}$ from $x=L$ to $x=0$, i. e. 


$$
\left.\begin{array}{l}
\varepsilon(x, t)=\varepsilon(z), v(x, t)=v(z), \\
z=D t+x-L,
\end{array}\right\},
$$

where $D$ is the rate of agitation propagation.

After the agitation wave comes, the transition from one state to another takes place, i. e. subject to $z<0$ in points sufficiently remote from end $x=L$, the initial state is retained, which characteristics are indexed 1: $\varepsilon=\varepsilon_{1}, S=S_{1}=F_{1}$ and $v_{1}=0$; and subject to $z>0$, a new state is reached, which characteristics are indexed 2: $\varepsilon=\varepsilon_{2}, S=S_{2}=S\left(\varepsilon_{2}\right)=F_{0}+F_{1}$ and $v=v_{2}$ corresponding to the rod motion under force $F(t)$.

Substituting expressions (9.31) to equations (9.25) - (9.27) and integrating them, we have the relations determining the compression blast wave front structure

$$
\begin{aligned}
& v=D\left(\varepsilon-\varepsilon_{1}\right), \\
& S=S_{1}+\rho_{0} D^{2} \frac{\left(\varepsilon-\varepsilon_{1}\right)}{(1-\varepsilon)\left(1-\varepsilon_{1}\right)}, \\
& D\left(E-E_{1}+\frac{\rho_{0} v^{2}}{2(1+\varepsilon)}\right)=S v,
\end{aligned}
$$

where $\rho_{0}$ is the rod density at $\varepsilon=0$. As for the rod

$$
E-E_{1}=\int_{\varepsilon_{1}}^{\varepsilon} S_{R}(\varepsilon) d \varepsilon,
$$

at $\varepsilon>0$, the following is true

$$
E-E_{1}=\frac{S_{R}(\varepsilon)\left(1-r_{\varepsilon} \varepsilon\right)-S_{1}\left(1-r_{\varepsilon} \varepsilon_{1}\right)}{r_{\varepsilon}(n-1)} .
$$

Taking into account expressions (9.28), (9.32) - (9.34) and assuming $\varepsilon_{1}<\varepsilon<<1$, we have

$$
S_{g}(\varepsilon, \dot{\varepsilon})=0,5 \rho_{0} D^{2} r_{\varepsilon}(n+1) \frac{\left(\varepsilon-\varepsilon_{1}\right)\left(\varepsilon_{2}-\varepsilon\right)}{\left(1-r_{\varepsilon} \varepsilon\right)},
$$

where

$$
\varepsilon_{2}=\frac{2}{r_{\varepsilon}(n+1)}+\frac{n-1}{n+1} \varepsilon_{1}-\frac{2 n S_{1}}{(n+1) \rho_{0} D^{2}} .
$$

First, let us analyze the wave motion along the completely elastic rod with the defined dependence $S_{R}(\varepsilon)$, i. e. in situation when $S_{g}=0$. Then, using expression (9.36), we come to the conclusion that two rod states are possible and are determined by either $\varepsilon_{1}$ value or $\varepsilon_{2}$ value, which may be obtained from Hugoniot correlation [159].

Suppose 


$$
\left.\begin{array}{l}
S_{g}=p_{0} g(\varepsilon) \operatorname{sign} \dot{\varepsilon}, \\
\frac{\partial g(\varepsilon)}{\partial \varepsilon} \geq 0, \quad g(\varepsilon)>0,
\end{array}\right\},
$$

where $p_{0}$ is the coefficient of unlubricated friction. Having substituted (9.38) into (9.36), considering sign $\dot{\varepsilon}=1$, and taking into account relations (9.32)-(9.34), we derive algebraic equations, which demonstrate that two $\varepsilon$ values are also possible in this case, the transition from one to another being abrupt. Therefore, in case of friction draft gears with consave down characteristics, there will be an abrupt change at the compression blast wave front under loading. This means the solution of the respective train boundary value problem is discontinuous and does not coincide with the solutions of the train motion equations. In this case, the time change of forces $S$ acting on the trains is a series of spikes significantly exceeding traction force $F_{0}$, just as it takes place at a compressed train start when the gaps in the cars couplings show up.

Let us consider the case when

$$
\left.\begin{array}{l}
S_{g}=p_{2 \varepsilon} g(\varepsilon) \dot{\varepsilon}|\dot{\varepsilon}|=p_{2 \varepsilon} D^{2} g(\varepsilon)\left(\frac{d \varepsilon}{d z}\right)^{2}, \\
p_{2 \varepsilon}>0, \dot{\varepsilon}>0, g(\varepsilon)>0 .
\end{array}\right\} .
$$

Having substituted this expression into expression (9.36) and supposing $g(\varepsilon)=S_{0}\left(1-r_{\varepsilon} \varepsilon\right)^{-1}$ and $n=1$, we have

$$
\frac{d \varepsilon}{d z}=b_{2} \sqrt{\left(\varepsilon-\varepsilon_{1}\right)\left(\varepsilon_{2}-\varepsilon\right)} .
$$

Subject to $\varepsilon(0)=0.5\left(\varepsilon_{1}+\varepsilon_{2}\right)$ the solution of equation (9.40) will be expression

$$
\varepsilon=0,5\left(\varepsilon_{1}+\varepsilon_{2}\right)+0,5\left(\varepsilon_{2}-\varepsilon_{1}\right) \sin b_{2} z,
$$

which corresponds to physical sense only in the section of $b_{2} z$ change from $-0.5 \pi$ to $+0.5 \pi$. The blast wave front width will make

$$
\Delta=\pi b_{2}^{-1}=\pi \sqrt{\frac{S_{0} p_{2 \varepsilon}}{\rho r_{\varepsilon}}} .
$$

Having substituted $p_{2 \varepsilon}=0,25 p_{2} l^{2}, r_{\varepsilon}=0,5 r l, \rho_{0}=m l^{-1}$ (here $l$ is the length of a single car), we can derive the value of $p_{2}$ coefficient of the hydro-gas draft gear hydraulic resistance:

$$
p_{2}=\frac{2 m r}{\pi^{2} S_{0}} n_{\mathrm{f}}^{2},
$$


where $n_{\mathrm{f}}=\frac{\Delta}{l}$ is the number of cars making the train section, along the length of which the transition from state 1 to state 2 occurs.

The analysis of expressions (9.42) and (9.43) shows that the width of the blast wave front depends only on the system parameters (the draft gears characteristics and the cars masses) and does not depend on the loading conditions (in the analyzed situation, on the traction force increase law).

Comparing expression (9.17) used for computation of coefficient $p_{2}^{y}$ optimal value for shunting with expression (9.43), we can make the conclusion that this optimal value of $p_{2}^{y}$ in a train corresponds to the width of the blast wave (or shocks) front equal to $n_{\mathrm{f}} \approx 1.6$. The calculations show that at $n_{\mathrm{f}}=3 \div 4$ and more value $S_{m}=\max S \approx F_{0}$, and at $n_{\mathrm{f}}=2 \div 3$ the value of the biggest force in automatic couplings exceeds insignificantly the biggest value of the applied traction force. Thus for trains, $p_{2}^{n}$ is the optimal value of the draft gear hydraulic resistance to compression, which should be $2.5 \div 4$ times more than $p_{2}^{y}$ value.

Calculation of forces for different modes of train motion (following the program described in work [145]) and the results of experimental research [157] prove the conclusions made. Therefore, when designing hydro-gas draft gears (this is applied to any type hydraulic draft gears), it is necessary to engineer the hydraulic resistance unit self-adjusting to the mode close to optimal under various loading conditions. The example of such draft gear is the hydro-pneumatic shock absorber described in invention [160], which longitudinal section is illustrated in Figure 9.2.

The shock absorber consists of cylindrical housing 1 with bottom 2, hollow plunger 3 with piston 4 , and floating piston 5 dividing the plunger cavity into gas 6 and hydraulic 7 chambers.

In bottom 2 of housing 1 , hollow cylinder 8 with ports 9 is fixed. In this cylinder, spool 10 with bottom 11 and holed wall 12 with ports 13 is located. Extended spring 14 presses spool 10 to stop 15 in its initial position. Stop 16 made in form of a nut limits spool 10 movements.

The force of spring 14 is regulated by adjustment screw 17 connected with spring 14 via foot 18 and screw 19 .

Cavity 20 of hollow cylinder 8 is communicated with cavity 21 of housing 1 and hydraulic chamber 7 via calibrated ports 22 and 23 .

The shock absorber operates as follows.

Using adjustment screw 17 , spring 14 pre-tension is created to press spool 10 to stop 15 , the flow section of ports 9 and 13 of hollow cylinder 8 and spool 10 being minimal.

Under compression force, plunger 3 moves inside housing 1 , the liquid from cavity 21 of housing 1 overflows into hydraulic chamber 7 through the flow section of ports 9 and 13 and calibrated ports 22 and 23 causing the displacement of piston 5 and the gas compression in gas chamber 6 . 


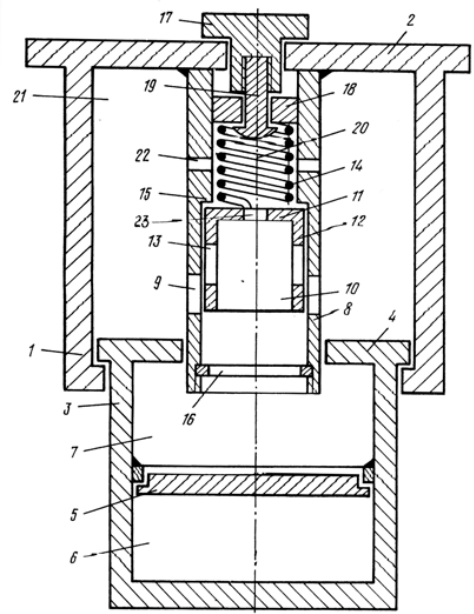

Figure 9.2. Longitudinal section of hydro-pneumatic shock absorber

Due to liquid throttling through the flow section of ports 9 and 13 and calibrated ports 22 and 23 , which area is significantly less than the flow section of ports 9 and 13 , liquid pressure in chamber 21 increases thus providing for the energy absorption by the shock absorber.

Spring 14 pre-tension force is chosen so that spool 10 remains in its initial position at low rates of liquid overflow subject to the train vibration. The sections of the ports the liquid overflows through remain minimal ensuring the optimal for the shock absorber operation in a train coefficient of the force of hydraulic resistance to the shock absorber compression.

When absorbing intensive impact loads occurring at the cars collisions, the difference of pressure loads on spool 10 in cavity 20 and chamber 7 and inertia forces, acting on the spool, become bigger than spring 14 pre-tension force, spool 10 is shifted, the flow section of ports 9 and 13 is increased until the required power characteristic at the cars collision is achieved. Ports 9 and 13 may be made variable section.

When throttling the liquid through calibrated ports 22 and 23, the pressure in cavity 20 becomes less than in cavity 21 of the housing. This allows making spring 14 with small size and low stiffness and provides for the improvement of power characteristic of the shock absorber and its operation stability enhancement.

In contrast to the earlier described hydro-pneumatic shock absorbers, the mathematical model of such absorber is supplemented with control equations, which part in the given structure is played by the spool motion equations.

The differential equation of $q_{a}$ movement of the draft gear plunger may be set out in form analogues to equations (6.5), namely 


$$
\dot{q}_{a}=\mu f\left(q_{a}, q_{\text {spool }}\right) \sqrt{2\left(\rho F_{0}^{3}\right)^{-1}\left|S_{0}-S_{R}\right|} \operatorname{sign}\left(S_{0}-S_{R}\right),
$$

where the same designations as for differential equation (6.5) are used, and $f\left(q_{a}, q_{\text {spool }}\right)$ is the dependence of the throttling ports area on the plunger movement relative to the shock absorber housing and the spool movement relative to the cylinder or the housing of the shock absorber. The change of this area governs the change of the hydraulic resistance forces. The spool movement equation may be written as

$$
m_{\text {spool }} \ddot{q}_{\text {spool }}=\left\{\begin{array}{lll}
0, & \text { if } & \left(S_{\mathrm{y}}-\psi_{R} S_{R}\right) \leq S_{0 \text { çspool }}, \\
\text { otherwise } & S_{\mathrm{y}}-\psi_{R} S_{R}-S_{0 \text { spool }}-k_{\text {spool }} q_{\text {spool }},
\end{array}\right.
$$

where $m_{\text {spool }}$ is spool 12 mass; $S_{y}$ is the control force; $\psi_{R}$ is the coefficient of the restoring force transfer equal to spool 12 and floating piston 5 areas ratio; $S_{0 \text { spool }}$ and $k_{\text {spool }}$ are the pre-tension force and spring 14 of spool 12 stiffness coefficient, respectively.

$$
S_{\mathrm{y}}=m_{\mathrm{spool}} \grave{a}_{\mathrm{car}}+\psi_{y}\left(S_{0}-\beta_{k} \dot{q}_{a}^{2}\right),
$$

where $a_{\text {car }}$ is the car acceleration; $\psi_{y}$ is the coefficient of force transfer equal to spool 12 and piston 4 areas ratio; $S_{0}$ is the force acting on piston 4 and depent on force $S$ acting on the draft gear according to relation (6.1); $\beta_{k}$ is the coefficient of the hydraulic resistance force determined by calibrated ports $22 ; \dot{q}_{a}$ is the draft gear compression rate.

Expression (9.46) supposes that the control force depends on both the car acceleration and the force acting on the car. The section of calibrated ports 22 may be chosen so small that the main governing factor will be the car acceleration. This allows applying such shock absorber for effective damping of lightweight damagesensitive cargos. If the calibrated ports sections are chosen quite big, the draft gear characteristic will be controlled mostly by the force acting on the gear.

It should be noted that analogues units may be used in hydraulic oscillation dampers of the railway vehicles spring suspensions. The structure of such units should include the member reducing the hydraulic resistance at slow, low frequency processes in order to ensure the enhancement of the railway vehicles dynamic performance.

It is reasonable to analyze the spring suspension oscillation dampers and shock absorbers altogether with the mechanical system of a railway vehicle, i. e. to consider them under longitudinal loading in a train $[3 ; 134]$ or under spatial loading taking into account vertical and horizontal irregularities of the rails in inertia elastoviscous track $[34 ; 137,161 ; 162]$. To analyze the dynamic loading of railway vehicles, there are many mathematical models presented in respective computer software. The authors offer their own original software allowing not only for the railway vehicles dynamics analysis $[117 ; 128-131 ; 135 ; 163-167]$, but also for setting the optimal parameters of the oscillation damping systems $[34 ; 137 ; 168-170]$. 


\section{EXPERIMENTAL RESEARCH}

Both theoretical and experimental researches are conducted to analyze the shock absorbers and oscillation dampers performance. The experiments results are compared with the calculation results. This ensures the reliable determination of main characteristics of the damping units themselves together with the dynamic and strength parameters of the railway vehicles as a whole subject to application of the shock absorbers and oscillation dampers in question.

By their characteristic features, the tests may be categorized as follows:

by method of the test carrying out

- laboratory (bench) tests;

- field tests;

by purpose

- functional tests;

- determinative tests;

- endurance tests;

by method of loading

- static tests;

- dynamic tests;

by function

- typical tests;

- periodic tests;

- acceptance tests;

- certification tests.

All the test types are usually regulated by respective normative documents, primarily the test method procedures, which are the part of special standards or are specifically approved by the customer.

\subsection{Test Methods}

The test methods should include definite description of an object and the purpose of the test, the test procedure for specific products, the requirements to the personnel of the test laboratory and the equipment applied, the list of test equipment and the methods of the measurements analysis. The most important are the measurements methods and techniques for various parameters characterizing the damping units performance. They may be established directly by way of the damping unit testing and indirectly by way of testing the whole railway vehicle equipped with the damping unit in question.

Let us consider the test methods for the rolling stock hydraulic dampers and draft gears together with some methods of measuring the values while testing the rolling stock and the measurement results analysis. The test procedures and main standard values are given in compliance with the effective Certification Standards for Federal Railway Transport of Russian Federation that is the governing document for products certification for CIS railways. 
10.1.1. Test Method for Rolling Stock Hydraulic Dampers. This test method is used for testing the dampers installed in the axle-box suspension stage (the first stage) and between the body and the bogies (in the second, central stage) in any type of railway rolling stock. This method is not applied to the dampers structures installed in the rolling stock in longitudinal direction to damp the bogies hunting oscillations. The dampers of one and the same dimension type group having the regulated power characteristic are tested using two samples realizing the maximum resistance force at control rates.

The dampers are tested in two steps:

- control tests;

- endurance tests.

The main parameters checked when testing the hydraulic dampers are [171; 172]

1) damper overall and coupling size:

- length when compressed;

- piston stroke;

- maximum outer diameter;

- fixtures sizes;

- damper weight;

2) damping performance:

- power characteristic;

- damper working diagram;

- control resistance forces at regulated rate and piston movement values;

3) resistance force at increased positive temperatures of the damper operation corresponding to its climatic construction;

4) resistance force at the damper cooling to minimum temperature corresponding to its climatic construction;

5) damper reliability parameters during the bench endurance testing, mln. cycles;

6) the damping liquid safety requirements compliance:

- inflammation resistance;

- non-toxicity;

- absence of irritating smell.

Standard [172] describes the methods and conditions of determination of rated parameters used for the evaluation of the hydraulic dampers efficiency and reliability.

The overall and coupling dimensions of dampers are controlled instrumentally according to OST 24.153.01-87 [173]. The linear damper dimensions are measured not less than three times.

The damping performance of the tested damper is determined experimentally. The damper is tested completed with fixing heads, the damper piston being close to the middle position relative to its full stroke. The damper should be fixed to the test bench in the position of its installation in the rolling stock. The tests are carried out 
on a bench with a drive providing the damper fixing heads point movement by harmonic law.

The power characteristic $P(V)$ ( $V$ is the damper extension or compression rate) and working diagrams $P(S)$ ( $S$ is the damper extension or shortening value) are measured at the rates of the damper fixing heads points movements, which values are given in Table 10.1. The real rates may differ from the control rates not more than by \pm 5 per cent. Here and below the designations complying with the Certification Standard are used.

Table 10.1

Control Rates for Dampers Tests

\begin{tabular}{|l|c|c|c|c|}
\hline \multirow{2}{*}{ Damper type } & \multicolumn{4}{|c|}{ Control rates, $\mathrm{m} / \mathrm{sec}}$. \\
\cline { 2 - 5 } & $V_{1}$ & $V_{2}$ & $V_{3}$ & $V_{4}$ \\
\hline Second suspension stage dampers & & & & - \\
\cline { 1 - 2 } $\begin{array}{l}\text { First suspension stage (axle-box) dam- } \\
\text { pers }\end{array}$ & 0.075 & 0.15 & 0.3 & 0.6 \\
\hline
\end{tabular}

The power characteristic and working diagrams are measured at the extension and compression strokes after preliminary bleeding of the tested damper for 30 seconds. The power characteristic and working diagrams may be measured using two methods.

When the first method is used, the power characteristic is measured (using the set algorithm) by registering the current rates and respective damper resistance forces at compression and extension strokes within the range from zero rate values to the maximum control values and from the maximum control values to zero rate values. This method gives the power characteristic in form of a continuous curve plotted basing on the arithmetic means of the resistance forces in the piston stroke acceleration and deceleration zones.

When the second method is used (if no computer processing is possible), the curve is plotted in form of a dot diagram, in which resistance force values $P(V)$ are indicated for each control rate of relative movements of the damper fixing heads. For each control rate, the working diagram $P(S)$ with the indication of their areas is made.

The change of control resistance forces at increased temperatures is evaluated using the measured power characteristic and the working diagrams for control rate $V_{2}=0.15 \mathrm{~m} / \mathrm{sec}$. subject to achievement of the damper housing heating temperature of $80^{\circ} \mathrm{C}$.

The damper working liquid heating temperature is measured in the lower part of the damper housing.

For evaluation of the changes of the control damper resistance forces at its cooling, the following procedure is used: 
- the damper is cooled to the minimum temperature corresponding to its climatic construction according to the approved design documents and kept for two hours in a climatic chamber located close to the test bench;

- thus cooled damper is placed on the test bench.

The change of the control resistance forces in the cooled damper is evaluated using the measured working diagram $P(S)$ at control rate $V_{2}=0.15 \mathrm{~m} / \mathrm{sec}$.

The reliability indices are checked during the bench endurance tests. The tests are carried out using two test specimens. The tested damper is placed on the test bench for endurance testing in the position corresponding to its allocation in the rolling stock imitating the permissible oblique setting of the fixing heads. The tests are carried out until the base number of loadings is reached, which is equal to 2 million cycles subject to single-frequency loading of the tested damper or 1 million cycles subject to double-frequency loading determined by the lowest frequency. When testing the damper, 2 million cycle frequency mode is set basing on the damper fixing heads movement amplitude equal to $25 \mathrm{~mm}$. The stability of the frequency mode is maintained by cooling the working liquid, which temperature should not exceed $80^{\circ} \mathrm{C}$.

For 1 million cycles double frequency mode testing with the lowest frequency of $1.6 \mathrm{~Hz}$ and the highest frequency of $4.8 \mathrm{~Hz}$, the total rate of relative movements of the damper fixing heads is provided at $0.3 \mathrm{~m} / \mathrm{sec}$. with equal components of $0.15 \mathrm{~m} / \mathrm{sec}$. at each frequency. The temperature is controlled on the lower parts of the damper housing where it should not exceed $80^{\circ} \mathrm{C}$.

The power characteristic or the working diagrams under loading in singlefrequency mode are controlled every 500 thousand cycles and under doublefrequency mode - every 250 thousand cycles of loading by the lowest frequency.

The damping liquid volume reduction is controlled instrumentally. The volume is measured after the endurance tests by draining all the working liquid from the tested damper into the volumetric glassware and fixing its volume by the filling marks.

The damping liquid volume reduction may be controlled without the damper disassembling by weighing. The damper is weighed before and after the endurance test, and the volume is calculated by the resultant specific weight.

The working liquid compliance with the safety requirements is checked for the given damping liquid type by the respective certificates.

During the endurance tests, it is also necessary to control the changes in the main damper units dimensions and the damping liquid contamination with the wear products of the friction members for the purpose of further development of the recommendations as for the preventive measures and the unit serviceability monitoring during its operation.

10.1.2. Test Methods for Rolling Stock Automatic Coupling Draft Gears. All the types and modifications of the automatic coupling draft gears are subject to testing. For determination of the draft gears parameters and characteristics, the following types of tests are used: 
- static tests;

- hardness drop tests (including the energy capacity analysis as delivered and testing for the wear resistance, etc.);

- endurance tests;

- cars collision tests;

- train dynamic tests;

- train performance tests.

Below, we will consider the methods for carrying out the listed above tests.

Static Test Method. When carrying out these tests the following parameters are measured [174]:

- initial pressure force $P_{0}$ - the minimum force required to be applied to the gear for it to start compressing;

- maximum force required for the draft gear compression to the value of its structural stroke (closing force) $P_{\text {st max }}$;

- static energy capacity $W_{\text {st }}$ - the energy accepted by the gear under quasi-static load application;

- stroke change $\varepsilon$ under constant force of 1,200 $\mathrm{kN}$ application during $30 \mathrm{mi}-$ nutes;

- irreversible energy absorption coefficient $\eta$;

- closing force change range under extreme operational conditions;

- irreversible energy absorption coefficient under extreme temperatures.

The tests are carried out in the hydraulic press or test machine with the maximum force of not less than 2.5 MN. For the force and movement measuring and registering, the force gage and linear movement gage, the amplifier and the Hardware and Software Complex (HSC) based on a personal computer are used.

The gears are tested by way of quasi-static loading and compression for the full stroke at any small deformation rate not exceeding $0.05 \mathrm{~m} / \mathrm{sec}$. The specific deformation rate is determined considering the applied equipment characteristics.

Each specimen is subject to three-stage loading until compressed to the full stroke with the afterwards unloading. The controlled parameters are measured by the results of the third loading. The stroke stability under constant force is controlled under additional forth loading. While testing, the force and movement (the draft gear stroke) are constantly registered.

The tests at extreme temperatures of minus $60 \pm 5^{\circ} \mathrm{C}$ to plus $50 \pm 5^{\circ} \mathrm{C}$ are carried out after the tests at normal temperature. The necessity of testing at extreme temperatures is determined by the test center (the laboratory) depending on the type of the tested draft gear and the materials used in its structure.

The results of the registered force and the computer processing of movement change processes are used for plotting and printing the static power characteristics (the dependence of the force on deformation - stroke $X$ ) of the draft gear including the loading line (when the stroke is increased from $X_{0}=0$ to $X_{\max }$ ) and the unloading line (when the stroke is decreased from $X_{\max }$ to $X_{0}=0$ ). The pre-tension force and the closing force are determined using the power characteristic diagram; static 
energy capacity $W_{\text {st }}$ equal to the absorbed energy $W_{a}$ is determined using software as the area between the loading line and axis $X$ in the power characteristic diagram. The same procedure is used for determining back stroke energy $W_{\mathrm{B}}$, which as calculated as the area between the unloading line and axis $X$. Then irreversible energy absorption coefficient is computed using expression

$$
\eta=\left[\left(W_{a}-W_{\mathrm{B}}\right) / W_{a}\right] \cdot 100 .
$$

The test results at extreme temperatures are used for determination of the closing force as the percentage of the closing force at normal temperature and of the absorption coefficient.

Hardness Drop Test Method. When carrying out these tests the following parameters are measured [175]:

- energy capacity as delivered $E_{0}$ - the energy absorbed by the draft gear under the resistance force not exceeding the rated values level;

- nominal energy capacity after running-in $E_{k n}$ - the energy capacity under typical test conditions under resistance force not exceeding the nominal rated force of $2 \mathrm{MN}$;

- maximum energy capacity of the run-in gear $E_{k m}$ - the energy capacity under typical conditions of the draft gear testing under the resistance force equal to the maximum rated force of $3 \mathrm{MN}$ or at the maximum stroke equal to the full stroke whatever the parameter is reached first;

- energy capacity reduction after the introduction of $50 \mathrm{MJ}$ of energy;

- energy capacity reduction after testing under maximum load. When testing under maximum load, it is also necessary to control the absence of the draft gear damages causing its functional failures.

The tests are carried out in the impact machine with the drop-weight of 12.8 tons under laboratory conditions at a temperature of $20 \pm 5^{\circ} \mathrm{C}$.

It should be born in mind that, with equal impact energy, the power characteristics of the drop tested units derived experimentally in impact machines will be significantly different from the operational characteristics of these units provided their power characteristics depend on the compression or extension rates. Such tests may be carried out in control cases for checking these units for compliance with their technical requirements at hardness drop test with the set characteristics of impact machines.

When determining the energy capacity as delivered, the tested draft gear is placed on the bottom (anvil) of the impact machine in the test "pocket", which inner size and configuration provide for the draft gear allocation inside the dimensions corresponding to its installation dimensions in a car.

The initial height of the weight drop $H_{0}$ is chosen out of the requirement of ensuring the impact energy equal to $60 \ldots 80$ per cent of the minimum permissible value:

$$
H_{0}=(0.6 \ldots 0.8) E_{0} / G-S t_{k},
$$

where $E_{0}$ is the energy capacity of the gear as delivered rated at $30 \mathrm{~kJ} ; G=126.2$ is the dropping weight; $S t_{k}$ is the full (structural) stroke of the draft gear. 
The gear stroke $S t$ has to be less than its structural stroke $S t_{k}$.

Then, the drop height is gradually increased until the next impact causes full gear closure $\left(S t=S t_{k}\right)$. The weight drop height increment is chosen considering the gear stroke at every next impact so that to reach the height with the minimum number of impacts necessary for the gear closing (desirably not more than 5). Maximum drop height $H$ is used for determination of the draft gear energy capacity as delivered $E_{0}=\left(H+S t_{k}\right) G$.

To the test results of six specimens, the typical statistical analysis methods are applied to find out the mean value, the standard deviation and minimum energy capacity value of the draft gear as delivered with a probability of 0.85 , which is used as the given draft gear parameter.

Wearing tests include the following stages:

- draft gear running-in;

- determination of the nominal and maximum energy capacity of the gear when run in;

- introduction of rated energy of $50 \mathrm{MJ}$;

- determination of the nominal and maximum energy capacity after the introduction of the rated energy.

To avoid the draft gears overheating, the quantity of energy introduced into the tested specimen during 30 minutes should not exceed $600 \mathrm{~kJ}$ irrespective of the stage of the hardness drop test. To meet these requirements, if necessary, the testing procedure is interrupted for the gear cooling.

The draft gear running-in and the introduction of the rated energy are realized through repeated typical (basic) test cycles that includes a series of a dropping weight impacts over the draft gear installed in the bottom of the impact machine. The weight dropping height is increased with a constant increment from some minimum initial height to the maximum height, at which the gear stroke equals to the structural stroke and the force reaches $3.5 \mathrm{MN}$. The initial dropping height and the increment are assumed equal to $0.02 \mathrm{~m}$.

Dropping height $H$, gear stroke $S t$ and the introduced energy computed using formula $E=(H+S t) G$ are registered in the primary protocol for each of the impacts. The energy introduced with the last impact of the cycle (with the gear closing) is considered to be the draft gear energy capacity at the given test cycle.

The gear running-in criterion is the stabilization of the energy capacity that is controlled by the closing energy during three successive cycles realized within one and the same working shift: the closing energy value in each of the cycles should not differ from the average value for these cycles for more than 5 per cent.

The wearing tests are carried out by way of repetition of the basic test cycle until the total introduced energy (considering the energy introduced while running in) reaches $50 \mathrm{MJ}$. Then, the nominal and maximum energy capacity is computed again.

The nominal and maximum energy capacity are determined by registering the force and stroke of the gear during its shock compression in a reduced test cycle, for which the initial weight dropping height is defined basing on the gear runningin data at its stroke equal to the half of the structural stroke $S t=0.5 S t_{k}$. The regis- 
tration system should provide for the processes recording within the frequency range of 0 to $200 \mathrm{~Hz}$.

Housing resistance to ultimate load is tested using two draft gears, for which the nominal and maximum energy capacity values have been already determined in the impact machine.

During the test, the impact force is registered. The working frequency range of the registration system should provide for the possibility of recording the processes with frequencies of 0 to $300 \mathrm{~Hz}$.

The initial dropping height is set $10 \mathrm{~mm}$ more than the dropping height the gear closing occurs at $\left(S t=S t_{k}\right)$.

If it is necessary, the dropping height is increased with the increment of $10 \mathrm{~mm}$ until the impact force reaches 3.3...3.5 MN. Then, the weight is dropped 20 times from thus chosen constant height.

Upon finishing the test for the housing resistance to ultimate load, the mean values of the nominal and maximum energy capacity in the impact machines are computed again.

For draft gears, which resistance force under compression is significantly dependent on the compression rate (hydraulic, elastomeric or combined with hydraulic member), the tests for the housing resistance to ultimate load are carried out in the impact machine only in case when the gear resistance force at closing does not exceed $5 \mathrm{MN}$. To reduce the hydraulic resistance force of the draft gears when carrying out such tests in the impact machine, it is possible to replace the regulating elements of the gear hydraulic system.

To compute the nominal and maximum energy capacity using computer processing, the draft gear power characteristics (the force dependence on the deformation - stroke $S t)$ are plotted and printed. Such power characteristics include the loading line (when the stroke is increased from $S t_{0}=0$ to $S t_{\max }$ ) and the unloading line (when the stroke is decreased from $S t_{\max }$ to $S t_{0}=0$ ) of each of the registered impacts (tests). The energy $W_{a}$ absorbed at each test is calculated using special program as the area between the loading line and $X$ axis in the power characteristic diagram. The diagram of absorbed energy $W_{a}$ dependence on maximum force $P_{\max }$ is used for determination of nominal, under force $P=2 \mathrm{MN}$, and maximum, under force $P=3 \mathrm{MN}$ or at the gear closing, energy capacity.

The error permissible for the certification tests control should be not more than 5 per cent.

Endurance Test Method for Automatic Coupling Draft Gears. The test method is applied to all the types and modifications of draft gears having a stable resistance force - compression (stroke) dependence along the whole length of the structural stroke under quasi-static loading. The test is carried out with, minimum, two test draft gear specimens that have already passed static tests [176].

The test results are used for determination of the static closing force change after the gear absorbs $250 \mathrm{MJ}$ of energy. This change should not exceed 20 per cent of the initial value. 
The test is carried out using the method of repeated quasi-static or dynamic loading under laboratory conditions at an ambient temperature of $20 \pm 5^{\circ} \mathrm{C}$. For the test, the hydraulic pulsator with effort of not less than $1.5 \mathrm{MN}$ is used. For registration of the force, movement and the number of cycles, the standard test machine registration system is used.

The endurance tests consist of three cycles including the following draft gear loading each:

$-3,000$ loadings with the absorbed energy equal to 25 per cent of the nominal draft gear energy capacity each $(W e=0.25 E n)$;

$-1,200$ loadings with the absorbed energy equal to 50 per cent of the nominal draft gear energy capacity each $(W e=0.50 E n)$;

-200 loadings with the absorbed energy equal to 85 per cent of the nominal draft gear energy capacity each $(W e=0.85 E n)$;

Upon completion of the endurance tests, the total energy absorbed by the draft gear should be not less than $250 \mathrm{MJ}$ [176].

When carrying out the pulsator endurance tests for the draft gears, which resistance force mostly depends on the compression rate (hydraulic, elastomeric, etc.), the loading modes may be determined by the draft gear stroke value equal to the draft gear stroke when tested in a car, at which the gear absorbs the respective energy ( 25,50 and 85 per cent of the nominal energy capacity). When testing in the impact machine, the regulating elements of the draft gear determining the resistance force value should be set up or adjusted so that the energy equal to 25,50 and 85 per cent of the nominal energy capacity is absorbed, approximately, at the same stroke of the draft gear as in the cars collision tests.

When endurance testing in the cars, it is possible to place the collided car backed up by a group of loaded decelerated cars and to block its draft gear and the draft gears of the backing up cars. In such case, the draft gear should be installed only in the running on car.

Before the endurance tests under the accepted test conditions (in the cars, pulsator or impact machine), the initial mean values of the nominal and maximum gear energy capacity are determined for the given conditions.

During the fine tuning of the endurance test modes, the draft gear resistance force and the stroke together with the cars collision rate, the pulsator operation mode or the weight dropping height in the impact machine are registered if the required loading modes cannot be chosen basing on the previous test stages results.

When endurance testing, it is necessary to prevent from the draft gear members overheating as it may influence on the members service life or cause their damaging. To do this, the temperature in critical points should be, where possible, monitored, and the quantity of energy introduced into the gear during the uninterrupted working cycle should be limited. It is recommended that the energy absorbed by the gear during one hour do not exceed $800 \mathrm{~kJ}$.

The results of the computer processing of the registered parameters are used for plotting and printing the initial and reference static power characteristics (the dependence of the force on deformation - the stroke $S t$ ) of the draft gear including 
the loading line (when the stroke is increased from $S t_{0}=0$ to $S t_{\max }$ ) and the unloading line (when the stroke is decreased from $S t_{\max }$ to $S t_{0}=0$ ). Closing force $P_{\text {st max }}$ is determined by the power characteristic diagram. The closing force determined during control static testing upon finishing the endurance testing is compared with the initial draft gear closing force before the endurance testing.

Cars Collision Test Method for Automatic Coupling Draft Gears. The test method is used for draft gears, which installation dimensions correspond to GOST 3475-81 [177]. Spring-friction draft gears should be first run in by way of introduction of not less than $0.5 \mathrm{MJ}$ of energy directly in a car of in the impact machine [178].

The test is applied to not less than two test specimens of draft gears with stable power characteristics, for which the parameters values, determined for the two specimens, differ from their mean value for not more than 5 per cent. Otherwise, five specimens are tested.

The parameters obtained during the impact testing are the main performance parameters for the given draft gear in the rolling stock under the conditions of the shunting operations. The test results are used for computing:

- the nominal energy capacity $E_{n}$ for the standard size range;

- maximum energy capacity $E_{m}$ for the standard size range;

- nominal collision rate $V_{n}$ for the standard size range of the draft gears;

- maximum (permissible) collision rate $V_{m}$ for the standard size range of the draft gears;

- dynamic closing force $P_{k d}$ for the standard size range of the draft gears;

- permissible, with the probability of not more than 0.05 , excess of $2 \mathrm{MN}$ force at nominal energy capacity for the standard size range of the draft gears.

The test is carried out under natural climatic conditions. The draft gears are tested be way of colliding of a run on car (hammer car) and a free standing nonbraked test car (collided car) in a straight horizontal track.

For the test car, two gondola cars are used, one of which is equipped with a mass produced draft gear with earlier defined characteristics (known dependence of absorbed energy $W_{e}$ on maximum force $P_{\max }$, nominal $E_{n}$ and maximum $E_{m}$ energy capacity) and with the nominal energy capacity of $40 \ldots 60 \mathrm{~kJ}$, and the second is equipped with the tested draft gear.

For registering the car run on rate, the impact force and the draft gear stroke, the dynamometer automatic coupling, the linear movement sensor, the amplifier and the PC hardware-software complex are used.

When determining the parameters, both cars should be loaded with crashed stone up to gross weight of $100 \pm 5$ tons, and the car equipped with the mass produced draft gear (Sh-2-V (Ш-2-B) type) should be used as a hammer car.

The following parameters should be registered during the test:

- the hammer car speed before collision;

- the collision force over the dynamometer automatic coupling; 
- the stroke of the test and mass produced draft gears;

- the acceleration of the body frame of the car equipped with the test draft gear (if additionally required).

The test is carried out in a bench hill or using a locomotive. The range of the registered frequencies should be from 0 to $125 \mathrm{~Hz}$.

The collision rate is set at $0.83 \mathrm{~m} / \mathrm{sec}$. $(3 \mathrm{kmh})$ to the maximum rate, at which the maximum force equals to $3.0 \ldots 3.5 \mathrm{MN}$, with the increment of $0.27 \ldots 0.55$ $\mathrm{m} / \mathrm{sec}$. $(1 \ldots 2 \mathrm{kmh})$ depending on the expected maximum. In each of the rate intervals: 0.83 (3) to $1.66(6), 0.66(6)$ to 2.5 (9), 2.5 (9) to 3.33 (12) and over 3.33 $\mathrm{m} / \mathrm{sec} .(12 \mathrm{kmh})$, at least five collisions are required.

For each test, the absorption coefficient and absorbed energy are computed using the special software. The nominal and maximum rates and energy capacity parameters, as well as the acceleration level at the set collision rates are computed basing on the statistic processing of $P(V), P(E)$ and $J(V)$ dependences.

Train Dynamic Test Method for Automatic Coupling Draft Gears. For testing, not less than four specimens are used. The test gears are installed in fully loaded gondola cars [179].

The test results are used for computing:

- the nominal energy capacity in train mode for the standard size range;

- irreversible energy absorption coefficient $\eta$ for the standard size range of draft gears.

The test is carried out by way of loading in a heavy-weight train at starting and backing under real operating conditions of the railway network.

The test is carried out in a train weighing not less than 7 thousand tons and composed of fully loaded freight cars.

Total head end locomotives power shouldprovide for the realization of traction force applied to the head car automatic coupling of not less than $0.9 \mathrm{MN}$ at starting.

The group of test cars should consist of not less than 10 cars, two of which should be equipped with tested draft gears loaded to gross weight, which is not less than the gross weight the given draft gears are designed for. This group should be located between the middle and the last third of the train.

The test procedure includes the backing of elongated and starting of compressed train under various modes starting from light mode when traction is developed slowly to the heaviest modes when the longitudinal force in the automatic coupling of the tested group of cars is not less than 2.0 MN. Total number of tests should be not less than 60 including 10 tests with the longitudinal forces in the tested group of cars weighing not less than 180 tons $(1.8 \mathrm{MN})$ and more.

During the tests, the dynamometer automatic coupling readings and the draft gears strokes values are registered at least in one control section located in the middle of the test cars group. It is allowed to include the laboratory car into the group of the test cars, but not closer than three cars from the control section. 
The criterion for the test results analysis is the value of the energy absorbed by the draft gear under longitudinal force of not more than $2.0 \mathrm{MN}$.

The computer processing results are used for plotting and printing the dynamic power characteristics (the dependence of the force on deformation - the stroke $S t$ ) of the draft gear including the loading line (when the stroke is increased from $S t_{0}=0$ to $S t_{\max }$ ) and the unloading line (when the stroke is decreased from $S t_{\max }$ to $S t_{0}=0$ ). The energy capacity equal to absorbed energy $W_{a}$ is computed using special software as the area between the loading line and $X$ axis in the power characteristic diagram. The same procedure is used for computing back stroke energy $W_{\mathrm{B}}$ as the area between the unloading line and $X$ axis, and then, the irreversible energy absorption coefficient is calculated using expression $\eta=\left[\left(W_{a}=W_{\mathrm{B}}\right) / W_{a}\right] \cdot 100$.

Such limitation of the train tests scope is allowed if the draft gears in question are not serial (mass produced), i. e. they are not installed in all or the most of the operating rolling stock cars. In case of train tests of mass produced draft gears, they shouldbe installed in all the cars of the train as, in such a system, the specific features of the draft gears behavior in multitude may be revealed. These features are, for example, the processes of formation and damping of blast wave fronts in a train, the reaction of such a train to deceleration using pneumatic brakes.

Train Performance Test Method for Automatic Coupling Draft Gears. The test checks the changes of the gear power characteristic parameters (closing force and energy capacity) after one year of operation and after two years of operation [180].

The test is carried out under the real conditions of the gears operation in railway network.

The test is applied to not less than 20 draft gears of the same batch, from which 6 (4) gears were chosen for the bench tests.

Shunting mode tests are carried out by way of the automatic shunting of cars equipped with the tested draft gears and loaded to full capacity. The cars are detached on a gravity hump with automatic registration system for car starting speed at the last decelerator position.

Average cars collision rate should be equal to nominal collision rate determined for the given draft gear during the impact tests. Each draft gear should accept at least 200 collisions with single car and not less than 20 collisions with groups of 2 to 3 cars.At the end of the shunting mode test, the commission inspection of the cars and tested gears condition is held together with the railway representatives. The results of the inspection are documented with the inspection report and the findings as for the possibility of further testing in a train.

Train performance tests are carried out in cars, for which the given draft gears are designed, under conditions of controlled operation in main tracker trains or in cars belonging to or rented by the enterprises that are regularly controlled and have a specific limited circulation ground.

During the train tests, the following parameters are registered:

- car mileage; 
- draft gears defects and failures detected and the remarks as for their operation, inspection process and condition monitoring.

At least once every two quarters, commission inspections are held together with the Test Center representatives, the applicant and transport enterprises and organizations operating the cars equipped with the tested draft gears. Subject to an agreement between the Test Center and the applicant, the representatives of other organizations may be present at the commission inspections. The results of periodic inspections are documented with special reports.

The duration of train performance tests should comprise 2 years, the mileage of each car equipped with tested draft gear being not less than 100 thousand kilometers.

Upon expiration of the set period of performance tests, at least two of the draft gears that underwent these tests should be re-tested for static parameters and, if the Test Center representatives consider reasonable, for cars collision to determine their nominal and maximum dynamic energy capacity.

By the applicant's request, intermediate control test may be carried out after one year of operation with mileage less than 80 thousand kilometers. Basing on the control test results, the decision is made on the fabrication of the development batch of draft gears.

The draft gears failure (service outrage) during the performance test is inacceptable and considered the basis for the test termination.

Except for the direct draft gear tests, there are other types of tests that help to evaluate their performance efficiency. These are, for example, cars dynamic ride tests evaluating the dynamic parameters of the railway vehicle as a whole. The conclusion on the correctness of individually chosen elastoviscous characteristics of spring suspension and individual damping units may be made through measuring individual dynamic indices. An example of measurement of vertical forces in side frames of fright cars bogies is given below.

\subsection{Test Method for Measuring Vertical Forces Acting on Freight Cars Bogies at Wheelset Side}

The measurement of vertical forces acting on the wheelsets is the prerequisite of experimental determination of safe riding conditions of freight cars. These measurements are usually made indirectly by deformations of the bogies sides under the vertical forces at the wheelsets side. Figures 10.1, $a$ and 10.1,b illustrate two most frequently used positions of sensors for measuring the vertical forces [145; 181]. Unfortunately, both these positions are sensitive to the action of longitudinal forces at the wheelset axle-boxes to the bogie. In 1991-1992, L. Manashkin together with A. Zhakovskiy and V. Kolbun carried out an experiment studying the influence of longitudinal forces acting on the side frame at the axle-box side on the vertical forces sensors readings. The experiments were carried out at the Car Chair bench of Dnipropetrovsk Transport Engineers Institute. The tests demonstrated that sensor positioning illustrated in Figure $10.1, b$ is very sensitive to the action of lon- 
gitudinal forces. The analysis shows that the positioning in Figure 10.1, $a$ also gives the error when measuring the vertical forces. These restrictions are well known to the freight cars investigators. Therefore, when analyzing the cars riding stability from the wheel flange mounting on a rail, the information taken during the cars braking were excluded from the consideration or the braking system was deactivated in the tested cars.
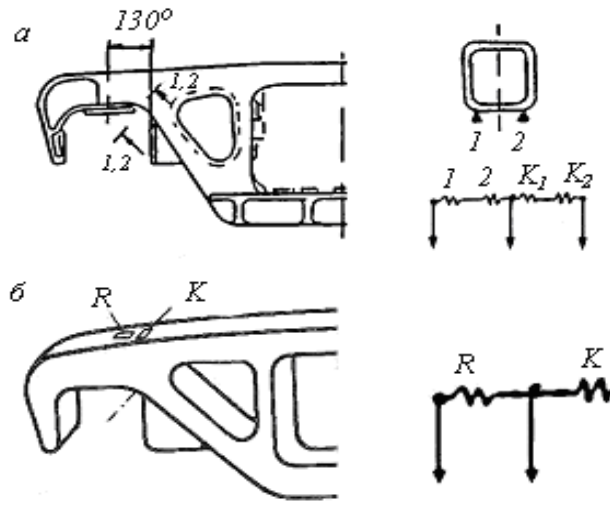

Figure 10.1. Typical positioning of sensors for measuring the vertical forces

It should be noted that longitudinal forces are present constantly at cars testing, even at slow-down riding. These are the forces components at impact interaction of wheels with rails in splice-joints, the longitudinal forces occurring at wheelsets negotiation with curved track sections, the components of longitudinal inertia forces of wheelsets at longitudinal cars interaction, the components of motion resistance forces. Moreover, when analyzing the cars riding safety, the determination of the wheel flange mounting on a rail stability factor at cars braking is interesting on its own as the wheelsets coming-offs frequently result from braking modes. Therefore, the exclusion of the influence of longitudinal forces acting on the bogies side frames at the axle-box side is quite an important task.

In 1992, L. Manashkn together with N. Garkavi made a series of attempts to exclude the longitudinal forces from the sensors readings, but these attempts were of no effect.

The problem of longitudinal forces compensation when measuring the vertical forces was discussed by the specialists, and after such discussions, the suggestions as for the compensation of bogie side frame complex loading negative effect on the results of vertical forces measurements were made [182; 183].

However, the statement by the authors of work [182] that the problem may be solved by "sticking the tensoresistors in four points of side frame upper zone to 
compensate for the effect of side and longitudinal forces" is inacceptable. The fact is that, first, this method helps to compensate only for the horizontal side forces influence on the vertical forces measurement results. Second, the longitudinal forces affecting the vertical forces sensors readings act through the frame horn or along the plane of the bogie bearing against the axle-box through friction forces and produce different effect on the vertical forces sensors deformations. Third, longitudinal forces, if ideally applied (uniformly along the horn width or the width of the plane of bogie bearing against the axle-box), cause not only the extensioncompression deformations in the side frame upper zone, but also its bending deflection in the same plane as the vertical forces. Therefore, the sensors measuring the bending moment conditioned by the effect only of the longitudinal forces resulting from the axle-box interaction with the side frame chute, and the sensors measuring the fibers deformations demonstrating the greatest deformations resulted from the longitudinal forces applied to the bogie in the plane of the axle-box bearing should be used.

It is also known that friction forces occurring both at vertical oscillations of a freight car and at its horizontal oscillations depend on the vertical forces. Therefore, we can suppose that in cases of almost constant lateral forces during motion along a curved line, the variable (due to the vertical oscillations) friction force will contribute to parametrical non-linear excitation of side oscillations with the frequencies of vertical oscillations. At the same time, if the movements in suspension at vertical oscillations occur with stops (due to dry friction forces), the stops at side oscillations will also be expected with all that the situation implies. And it implies the occurrence of vibrations with greater frequencies (conditioned by the elastic characteristics of the side frame) at these moments of time. Perhaps, the effects detected during the described experiments are connected not only with the measurement defects influences, but also with the parametrical excitation of side oscillations by vertical oscillations.

Longitudinal forces acting at the axle-box side on the bogie side frame and accepted by the measuring sensor are applied with friction forces (in the given case, it is correct to call them traction forces) tangential to the horizontal surface of the axle-box horngap and to the side frame horn at moments of the axle-box interaction with them.

This work offers one of the possible diagrams (Figure 10.2,a) of measuring the vertical forces acting on the bogie side frame at the axle-box side, which, as the authors believe, will help to significantly reduce the effect of longitudinal components of forces on the measurement results $[183 ; 184]$. Here $R$ is the working tensometer that measures the fiber deformations in the middle symmetry plane of the side frame occurring both under the vertical forces and the longitudinal forces acting on the bogie side frame; $K_{1}$ is the tensometer located at the intersection of the middle surface of the side frame and the external surface of its horn at its root section; $K_{21}$ and $K_{22}$ are the tensometers located at the middle line of the side surfaces of the upper zone of the side frame in the same section with the sensor marked with $R$ symbol. $K_{21}$ and $K_{22}$ sensors are connected serially forming resistance $K_{2}=$ 
$K_{21}+K_{22}$ illustrated in Figure10.2,b. It is desirable that the values of resistances $K_{1}$ and $K_{2}$ were equal and the resistance $R$ value equaled to the sum of these resistances. Resistors $R_{\mathrm{SH} 1}$ and $R_{\mathrm{SH} 2}$, shunting sensors $K_{21}$ and $K_{22}$ are installed basing on the assumption that sensors $K_{1}$ and $K_{2}$ sensitivity to longitudinal forces is higher than the sensitivity of the working sensor to the same forces. Otherwise, it is necessary to add to the diagram in Figure 10.2, $b$ another resistor shunting the working sensor and to exclude one of the resistors shunting the force-balance sensors.
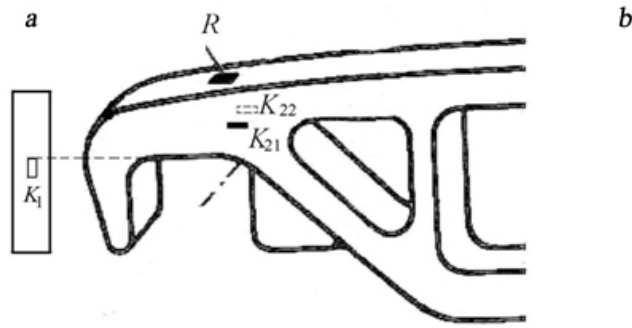

Figure10.2. New sensors positioning on the side frame

When analyzing the diagram functioning, it was assumed that $2 \mathrm{U}$ voltage of measuring bridge power was applied to points $A$ and $B$ in the diagram (Figure 10.2,b). Point $\mathrm{C}$ is one of the apexes of the measuring bridge diagonal. To simplify the mathematical calculation, let us assume that $K_{1}=K_{2}=0.5 R=R_{0}$ in the initial position. Let us call the longitudinal force acting on the side frame horn longitudinal force one and index it with "It1", and the longitudinal force acting tangentially to the horizontal surface of the horngap - longitudinal force two indexed "lt2". Deformations of sensor $K_{1}$ fiber are determined by force one only. Deformations of sensors $R$ and $K_{2}$ are determined by the vertical force (indexed V) with different transfer ratios, by longitudinal force one, and by longitudinal force two. Therefore, the tensometers resistances increments under dynamic load in general case of motion are presented as follows:

$$
\begin{gathered}
\Delta R=\Delta R_{v}+\Delta R_{\mathrm{lt} 1}+\Delta R_{\mathrm{lt} 2}, \\
\Delta K_{1}=\Delta K_{1 \mathrm{lt} 1}, \\
\Delta K_{2}=\Delta K_{2 v}+\Delta K_{2 \mathrm{lt} 1}+\Delta K_{2 \mathrm{lt} 2} .
\end{gathered}
$$

Having completed the necessary calculations and ignoring the second and higher order smalls, we will receive the following expression for the voltage in the diagonal of prebalanced bridge under the mentioned forces:

$$
\begin{gathered}
\Delta U \approx \frac{U}{2 b R_{0}} \times \\
\times\left[-\Delta R_{V}\left(a-a_{2} z_{V}\right)-\Delta R_{\mathrm{lt} 1}\left(a-a_{1} z_{1}-a_{2} z_{12}\right)-\Delta R_{\mathrm{lt} 2}\left(a-a_{2} z_{2}\right)\right],
\end{gathered}
$$


where

$$
\begin{aligned}
& \left.\begin{array}{l}
a=1+\frac{R_{0}}{R_{\mathrm{SH} 1}}+\frac{R_{0}}{R_{\mathrm{SH} 2}}, \\
a_{1}=1+\frac{R_{0}}{R_{\mathrm{SH} 2}}, \\
a_{2}=1+\frac{R_{0}}{R_{\mathrm{SH} 1}}, \\
b=1+a .
\end{array}\right\} \\
& z_{V}=\frac{\Delta K_{2 V}}{\Delta R_{V}}, \\
& z_{1}=\frac{\Delta K_{1 \mathrm{lt} 1}}{\Delta R_{\mathrm{lt} 1}}, \\
& z_{2}=\frac{\Delta K_{2 \mathrm{lt} 2}}{\Delta R_{\mathrm{lt} 2}}, \\
& z_{12}=\frac{\Delta K_{2 \mathrm{lt} 1}}{\Delta R_{\mathrm{lt} 1}} .
\end{aligned}
$$

Values (10.6) are constant for the specific measuring diagram as they characterize the relation of deformation values in specific points of the side frame under the definite force.

Expression (10.4) supposes that the influence of longitudinal forces one and two on the vertical force measurement results will be balanced if the differences in the second and third brackets in this expression are equal to zero. At the same time, the diagram sensitivity to the measurement of the vertical force itself will decrease, but this may be balanced by the increase of the gain.

Having expressed variable $a$ as $a_{1}$ and $a_{2}$ and having equaled the expressions in the second and third brackets in expression (10.4) to zero, we receive the equation for computing coefficients $a, a_{1}, a_{2}$ :

$$
\left\{\begin{array}{l}
a-a_{1}-a_{2}=-1, \\
a-z_{1} a_{1}-z_{12} a_{2}=0, \\
a-\quad z_{2} a_{2}=0 .
\end{array}\right.
$$

Equation (10.7) determinant is not equal to zero in general case. Consequently, this equation is soluble. It can be used to find values $a_{1}$ and $a_{2}$ and then the values of shunting resistances.

In practice, the offered diagram should be adjusted experimentally during the measuring paths preparation and calibration. To do this, first, the measuring bridge is balanced using balancing devices of tensometric amplifier. Then, force two is applied to the axle-box located in the middle part of horngap so that it does not 
touch the horn. The force value shouldbe so that it does not evoke the axle-box sliding against the side frame. Then the bridge is balanced using shunting resistor $R_{\mathrm{SH} 1}$. Thus, the working sensor resistance changes due to the action of longitudinal force two are balanced. In such case, no force one and the working sensor deformations caused by it are present. After these operations, force one is applied to the side frame horn using a jack as if the force is applied by the axle-box. In this case, not force two and working sensor $R$ and force-balancing sensor $K_{2}$ deformations are present. This means only the deformations caused by force one will take place. The bridge is balanced using the variable resistor $R_{\mathrm{SH} 2}$ and force one effect on the working sensor and sensor $K_{2}$ is compensated.

Thus, the described above method for measuring the vertical forces acting on the side frame at the axle-box side allows for balancing the longitudinal forces effect on the vertical forces measurement results and for making quite accurate measurement of vertical forces and analysis of the car motion stability during the longitudinal forces action.

\subsection{Test Method for Determination of Frequency Characteristics of Railway Vehicles}

Railway vehicles have quite a wide spectrum of own oscillation frequencies. When moving, the vehicle is exposed to various excitations including the excitations connected with the rail track irregularity. The frequency of such excitations depends on the vehicle speed. If, at some speed, the excitations frequencies coincide with the own vehicle oscillation frequencies, the resonances take place, at which the dynamic quality parameters of the vehicle (such as dynamic coefficients, overtopping and wheels mounting on a rail stability factor, riding comfort indices) may take critical values. It shouldbe noted that resonance speed [185] may be significantly lower than the designed speed (i. e. the maximum speed for the given vehicle). The tests on the line should either confirm the possibility of the rolling stock operation within the range of its limit speeds or restrict the operating speeds if the standard documents requirements $[181 ; 186]$ are not met at some speed. It is assumed that the rolling stock considered passed the tests successfully was checked in trips, during which all the possible in operation resonance properties of the tested object were detected.

To determine the frequency characteristics in compliance with document [181], it is recommended to test the railway rolling stock for "dropping from wedges", which height does not exceed the splice-joints irregularities. Though, neither the test method nor the test results analysis are standardized. Below, you can find one of the methods of testing and test results analysis at "dropping from wedges" developed by Professor Ye. P. Blokhin, Professor M. L. Korotenko, Candidate of Technical Science R. B. Granovskiy, Engineer N. Ya. Garkavi and others [187]. This method is used in the Industry Research and Development Laboratory for Rolling Stock Dynamics and Stability under Dnipropetrovsk National University of Railway Transport named after Academician V. Lazaryan. 
When testing, the force, movement, speed and acceleration sensors are installed on the railway vehicle. The realizations of all the processes $\underset{k}{\forall} x_{k}(t)$ registered by these sensors at "dropping from wedges" starting from moment of time $t_{0}$ (Figure 10.3) may be considered the linear combinations of transition functions of mechanical system described by the linear differential equations $£\{\vec{x}(t)\}=0$. Hereinafter, it is assumed that process $x_{k}(t)$ persisting for time $T$ is registered by sensor $k, \underset{k}{\forall} x_{k}(t)$ are the components of vector $\vec{x}(t)$, and their derivatives $\underset{k}{\forall} \dot{x}_{k}(t)$ are the components of vector $\overrightarrow{\dot{x}}(t)$; vector $\vec{X}(2 \pi f i)$ components are Fourier transformations of variables $\underset{k}{\forall} x_{k}(t)$. It is obvious that if

$$
\underset{k}{\forall}\left[\left[x_{k}\left(t_{0}\right)=0\right] \wedge\left[x_{k}(t \rightarrow \infty) \rightarrow 0\right]\right] \wedge \underset{k}{\exists} \dot{x}_{k}\left(t_{0}\right) \neq 0,
$$

then

$$
£\{\vec{x}(t)\}=0 \leftarrow L[\vec{X}(2 \pi f i)]-\vec{H}=0 \rightarrow £\left\{\vec{x}\left(t-t_{0}\right)\right\}=\vec{H} \delta\left(t-t_{0}\right) .
$$

Here $L[\vec{X}(2 \pi f i)]$ is Fourier transformation of differential operator $£\{\vec{x}(t)\}$; $\vec{H}=\vec{H}\left(\overrightarrow{\dot{x}}\left(t_{0}\right)\right)$ is the constant vector depending on the values of the components of vector $\overrightarrow{\dot{x}}\left(t_{0}\right) ; \delta\left(t-t_{0}\right)$ is Dirac delta-function; $i=\sqrt{-1}$.

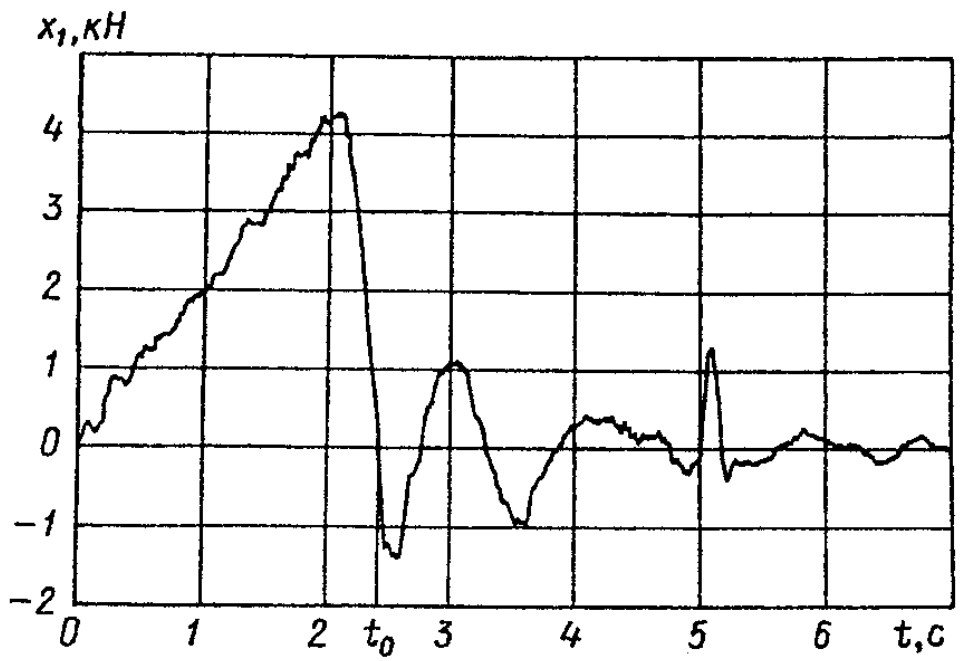

Figure 10.3. Realization of vertical force in axle-box spring suspension of DE1 electric locomotive 
When "dropping from wedge" installed under one wheel (it is technologically more convenient if this wheel is the last in the wheelset motion direction), Fourier transformation $Z_{k, j}(f)=F\left\{h_{k, j}(t)\right\}$ of transition function $h_{k, j}(t)=x_{k}\left(t-t_{0}\right)$ will be non-normalized transfer function of $j$ wheel to $k$ sensor [188]. This, most likely, will excite the oscillations corresponding to all forms except for longitudinal. The longitudinal oscillations may be excited when running on a hammer car on a free standing tested object within the frames of railway vehicles impact testing [181].

It should be noted that requirements of $x_{k}\left(t_{0}\right) \approx 0$ and $x_{k}(t>T) \approx 0$ are surely met for speed sensors when "dropping from wedges" and impact testing; after dropping, the movements of individual structure units may be shifted relative to their position at $t_{0}$; sometimes, at $t \rightarrow \infty$, acceleration sensors still register high frequency oscillations [189] even after the low frequency oscillation die out.

When applying fast Fourier transformation [190], realization $h_{k, j}(t)$ should be supplemented with function $x_{k}(t>T)=0$ till $N=2^{n}$ points length (where $n$ is a whole number). For identification of the damping coefficient it is preferred that $N=16,384$. Quantization frequency is usually chosen according to dependence $f_{\mathrm{qu}}=(10 \div 20) f_{a x}$ where $f_{a x}$ is the lowest frequency, at which

$$
\left|Z_{k, j}\left(f>f_{a x}\right)\right| \leq 0,05 \max _{0<f<\infty}\left|Z_{k, j}(f)\right| .
$$

At railway vehicles testing, the movement, speed and force sensors usually register the oscillations with frequencies up to $10 \mathrm{~Hz}$. Therefore, $f_{\mathrm{qu}}=100 \div 200 \mathrm{~Hz}$ frequency is usually sufficient for quantization. Moment of time $T$ when the registering apparatuses are switched off is determined by expression $\max _{t>T}\left|h_{k, j}(t)\right| \leq 0,05 \max _{0 \leq t \leq T}\left|h_{k, j}(t)\right|$.

For linear mechanical system with one degree of freedom, the damping coefficient near the resonance frequency $f_{\mathrm{r}}$ may be determined by three points of amplitude-frequency characteristic (AFC) $A(f)[191]$ :

$$
k_{a}=\pi \sqrt{\frac{\left(\left(f_{a}^{2}-f_{2}^{2}\right) \alpha\right)^{2}-\left(f_{a}^{2}-f_{1}^{2}\right)}{f_{1}^{2}-\left(f_{2} \alpha\right)^{2}}},
$$

where

$$
\begin{gathered}
f_{a}=\sqrt[4]{\frac{\frac{f_{1}^{4}-f_{2}^{4} \alpha^{2}}{f_{2}^{2} \alpha^{2}-f_{1}^{2}}-\frac{f_{3}^{4}-f_{2}^{4} \beta^{2}}{f_{2}^{2} \beta^{2}-f_{3}^{2}}}{\frac{1-\beta^{2}}{f_{2}^{2} \beta^{2}-f_{3}^{2}}-\frac{1-a^{2}}{f_{2}^{2} \alpha^{2}-f_{1}^{2}}} ; \quad \beta=\frac{A\left(f_{2}\right)}{A\left(f_{3}\right)}} \\
\alpha=\frac{A\left(f_{2}\right)}{A\left(f_{1}\right)} ; \quad
\end{gathered}
$$


or by three points of imaginary frequency characteristic (IFC) $I(f)$ [192]:

$$
k_{\mathrm{im}}=\pi \sqrt{\frac{f_{\mathrm{im}}^{4}(\psi-1)-2 f_{\mathrm{im}}^{2}\left(\psi f_{2}^{2}-f_{1}^{2}\right)+\left(\psi f_{2}^{4}-f_{1}^{4}\right)}{f_{1}^{2}-\psi f_{2}^{2}}},
$$

where

$$
\begin{aligned}
f_{\mathrm{im}} & =\sqrt[4]{\frac{\left(\varphi f_{2}^{4}-f_{3}^{4}\right) \theta-\left(\varphi f_{2}^{4}-f_{1}^{4}\right) \tau}{(\psi-1) \tau-(\varphi-1) \theta}} ; \\
\psi=\frac{f_{1} I\left(f_{2}\right)}{f_{2} I\left(f_{1}\right)} ; \quad \varphi & =\frac{f_{3} I\left(f_{2}\right)}{f_{2} I\left(f_{3}\right)} ; \quad \theta=\psi f_{2}^{2}-f_{1}^{2} ; \quad \tau=\varphi f_{2}^{2}-f_{3}^{2} .
\end{aligned}
$$

Here $A(f)=\sqrt{\left[\operatorname{Re}\left(Z_{k, j}(f)\right)\right]^{2}+\left[\operatorname{Im}\left(Z_{k, j}(f)\right)\right]^{2}}, I(f)=\operatorname{Im}\left(Z_{k, j}(f)\right)$; resonance frequency $f_{\mathrm{r}}$ corresponds to local AFC maximum, i. e. out of three subsequent $\mathrm{AFC}$ abscissa values $f_{1}, f_{2}, f_{3}, f_{\mathrm{r}}=f_{2}$ if

$$
A\left(f_{1}\right) \leq A\left(f_{2}\right)>A\left(f_{3}\right) \text { or } A\left(f_{1}\right)<A\left(f_{2}\right) \geq A\left(f_{3}\right) ;
$$

$f_{a}, f_{\text {im }}$ and $k_{a}, k_{\text {im }}$ are the own frequencies and damping coefficients of the system with one degree of freedom identified by three points of AFC and IFC, respectively.

The indirect criterion of the correctness of mechanical system identification near the resonance frequency as the system with one degree of freedom is the proximity of $k_{a}$ and $k_{\mathrm{im}}$ values.

According to work [193], the damping coefficient of linear system with one degree of freedom may be determined by the difference of frequencies corresponding to AFC values at the level of 0.7 of maximum:

$$
h=\pi\left(f_{a}-f_{b}\right)
$$

where $\quad f_{\grave{a}}=\max f:\left[A(f)=0.7 A\left(f_{\mathrm{r}}\right)\right] ; \quad f_{b}=\min f:\left[A(f)=0.7 A\left(f_{\mathrm{r}}\right)\right]$; $f_{\mathrm{r}}:\left[A\left(f_{\mathrm{r}}\right)=\max _{0 \leq f \leq \infty} A(f)\right]$.

It is obvious that, when testing on the line, speed $v, \mathrm{kmh}$, of the tested train, length $L_{\mathrm{cr}}, \mathrm{m}$, of continuous rail and frequency $f_{\mathrm{r}}, \mathrm{Hz}$, are connected by dependence $v=3.6 L_{\text {cr }} f_{\mathrm{r}} / K$ where the values of coefficient $K \in\{1 / 3 ; 1 / 2 ; 1 ; 2 ; 3\}$ correspond to the oscillation excitation by splice joints irregularities at resonance frequencies $\frac{v}{3 \cdot 3.6 \cdot L_{\mathrm{cr}}} ; \frac{v}{2 \cdot 3.6 \cdot L_{\mathrm{cr}}} ; \frac{v}{3.6 \cdot L_{\mathrm{cr}}} ; \frac{2 v}{3.6 \cdot L_{\mathrm{cr}}} ; \frac{3 v}{3.6 \cdot L_{\mathrm{cr}}}$.

Values of $K=1 / 3$ and $1 / 2$ correspond to resonance oscillations excitation by not every splice joint but every third or second passed spliced-joint . Such effect is possible only in very short continuous rails or subject to vary high quality factor of the rolling stock structure. Usually, such resonances are not observed in the rolling stock. Values of $K=2$ and 3 correspond to the resonances of the second and the 
third frequency tone exited by the irregularities of splices passed by the train. Resonance increase of the oscillation amplitudes may result in structure elements collisions, increase of the dynamic coefficients, and decrease of the wheel mounting on the rail stability coefficients of the tested object $[181 ; 186]$. When testing on the line, the resonance of transversal oscillations is more frequently observed in curved line, and the resonance of vertical oscillations is observed both in curved and straight line. Dangerous operating regimes are expected at speeds that the resonances at maximum $\mathrm{AFC}$ frequencies correspond to.

Figure 10.3 illustrates the realization of vertical force in axle-box suspension registered by the tensometer $x_{1}$ when "dropping from wedge" of DE1 electric locomotive. The wedge was installed under the left wheel of the first center shaft of the electric locomotive.

Table 10.2 lists the values of $f_{\mathrm{r}}, f_{a}, f_{\mathrm{im}}, k_{a}, k_{\mathrm{im}}$ obtained from dependencies (10.8)-(10.12) and $A\left(f_{\mathrm{r}}\right)$. Resonance frequencies $f_{\mathrm{r}}>f_{y}$, at which $A\left(f_{y}\right)<<\max _{f} A(f)$, were not listed in the Table. Asterisk is used to indicate $k_{\text {im }}$ values that are impossible to be determined using formula (10.10).

Table 10.2

Own Frequencies, Damping Coefficients and AFC of a System with One Degree of Freedom

\begin{tabular}{|c|c|c|c|c|c|}
\hline$f_{\mathrm{p}}$ & $f_{a}$ & $f_{\mathrm{M}}$ & $-k_{a}$ & $-k_{\mathrm{M}}$ & $A\left(f_{\mathrm{p}}\right)$ \\
\hline 0.635 & 0.648 & 0.612 & 0.698 & 0.631 & 0.067 \\
\hline 0.757 & 0.768 & 0.738 & 0.658 & 0.169 & 0.086 \\
\hline 0.879 & 0.896 & 0.896 & 0.962 & 0.123 & 0.083 \\
\hline 1.001 & 1.014 & 1.034 & 0.892 & 0.457 & 0.097 \\
\hline 1.343 & 1.334 & 1.334 & 0.555 & 0.489 & 0.053 \\
\hline 1.440 & 1.436 & 1.425 & 0.583 & 0.372 & 0.042 \\
\hline 1.758 & 1.759 & 1.761 & 0.571 & 0.433 & 0.036 \\
\hline 1.855 & 1.848 & 1.839 & 0.684 & 0.240 & 0.028 \\
\hline 2.100 & 2.111 & 2.111 & 0.555 & 0.457 & 0.025 \\
\hline 2.222 & 2.219 & 2.198 & 0.849 & 0.351 & 0.027 \\
\hline 2.515 & 2.523 & 2.524 & 0.711 & 0.438 & 0.027 \\
\hline 2.905 & 2.913 & 2.902 & 0.575 & 0.443 & 0.023 \\
\hline 3.027 & 3.024 & 3.019 & 0.587 & $*$ & 0.023 \\
\hline 3.320 & 3.330 & 3.304 & 0.660 & 0.342 & 0.016 \\
\hline 3.442 & 3.447 & 3.455 & 0.729 & $*$ & 0.011 \\
\hline 3.662 & 3.672 & 3.660 & 0.475 & 0.347 & 0.020 \\
\hline 4.102 & 4.095 & 4.092 & 0.475 & $*$ & 0.017 \\
\hline 4.224 & 4.227 & 4.236 & 0.647 & 0.278 & 0.010 \\
\hline 4.443 & 4.448 & 4.420 & 0.817 & 0.299 & 0.013 \\
\hline 4.858 & 4.860 & 4.862 & 0.657 & $*$ & 0.011 \\
\hline
\end{tabular}



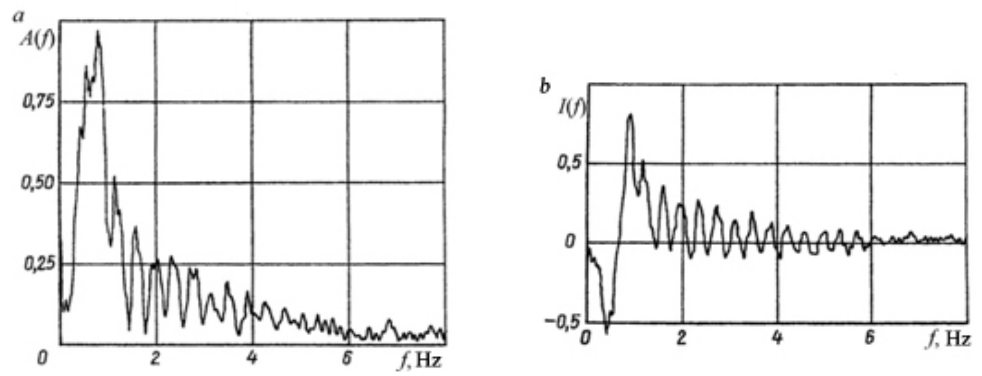

Figure 10.4. Non-standardized $\operatorname{AFC}(a)$ and IFC $(b)$ of a freight electric locomotive
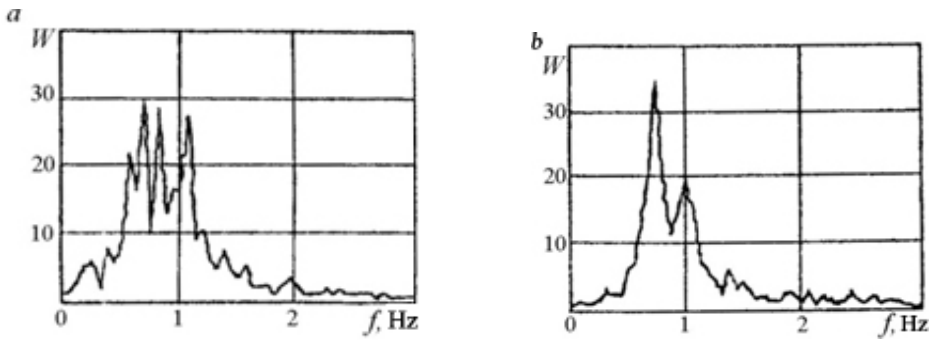

Figure 10.5. Spectral densities $\mathrm{W}$ (in relative units) of realizations at a speed of $v=$ $70 \mathrm{kmh}(a)$ and $v=90 \mathrm{kmh}(b)$

Figure 10.4 illustrates non-standardized AFC $(a)$ and IFC $(b)$ of a freight electric locomotive plotted by realization $x_{1}(t)$ illustrated in Figure 10.3. Figure 10.5 illustrates spectral densities $W$ of the realization (in relative units) registered by tensometer $x_{1}$ at various electric locomotive motion regimes: when the tested locomotive moves at a speed of $v=70 \mathrm{kmh}(a)$ and $90 \mathrm{kmh}(b)$. In Figure 10.5, $a$, the oscillations with frequencies $f_{\mathrm{r} 1} \approx 0.60 \mathrm{~Hz}, f_{\mathrm{r} 2} \approx 0.74 \mathrm{~Hz}, f_{\mathrm{r} 3} \approx 0.87 \mathrm{~Hz}$ and $f_{\mathrm{r} 4} \approx 1.07 \mathrm{~Hz}$ are observed at a speed of $v=70 \mathrm{kmh}$. At a speed of $v=90 \mathrm{kmh}$, the oscillations with frequencies $f_{\mathrm{r} 2} \approx 0.76 \mathrm{~Hz}$ and $f_{\mathrm{r} 4} \approx 1 \mathrm{~Hz}$ are observed. These frequencies match the own oscillation frequencies determined experimentally by "dropping from wedges".

The comparison of the data in Table 10.2 and Figure 10.5 demonstrates that oscillation at own frequencies found by the results of "dropping from wedges" may be excited at different motion regimes and not always simultaneously.

Thus the offered method of the railway vehicles frequency characteristics determination may be used for their preliminary assessment when testing any railway 
vehicles and rolling stock provided the form and height of the wedge ensure the excitation of own frequencies when "dropping from wedges". This method allows for the assessment of the efficiency of some oscillation damping systems and shock absorbers before the dynamic testing on the line.

\subsection{Method for Analyzing the Results of Railway Vehicles Testing on the Line}

Under the requirements of standard documents that are in effect in Russia [181; $194]$ and Ukraine $[195 ; 196]$, the following parameters are determined and rated at dynamic testing of the railway vehicles on the line: coefficients of horizontal $\left(K_{\mathrm{DH}}\right)$ and vertical dynamics $\left(K_{\mathrm{DVR}}\right.$ - right to the motion direction, $K_{\mathrm{DVL}}-$ left to the motion direction), overtopping stability factor $\left(K_{\mathrm{SO}}\right)$ and wheels coming off the rails stability factor $\left(K_{\mathrm{S}}\right)$. This subsection offers the method for analyzing the results of the dynamic testing of the railway vehicles on the line that systemizes the requirements of various standard documents [197].

In compliance with standard documents $[181 ; 194 ; 196]$, the initial information for defining the target values that are related to an unsprung bogie frame of the railway vehicle is the time realizations of the dynamic increments of vertical forces $x_{1}(t), x_{2}(t)$ acting on the right and left axle-box of one and the same wheelset, respectively, and the realization of the horizontal transversal (frame) force $x_{3}(t)$ acting on the same wheelset. Under $[181 ; 194 ; 196]$, the mentioned above dynamic coefficients are defined for a spring bogie frame, too, if the bogie has spring suspension. In this case, the initial information for analysis is the dynamic increments of horizontal and vertical forces acting on the bogie bolster at the wheels side. Using the rule of signs that is assumed in documents [181; 196] for $x_{1}(t)$ and $x_{2}(t)$, additional loading to the wheel corresponds to "minus" sign, while unloading corresponds to "plus" sign; the force acting on the wheelset from the right to the left in the direction of the railway vehicle motion is assumed positive.

When digitizing three input signals $\underset{i=1}{\forall} x_{i}(t)$ using the analog-digital converter (ADC) [198], the quantization frequency of $f_{\text {qu }}=100 \mathrm{~Hz}$ is usually sufficient. In general case, frequency $f_{\text {qu }}=f_{x}$ is considered sufficient for quantization of realizations $\underset{i=1}{\forall} x_{i}(t)$ if, when quantizing [197] with frequency $f_{x}$, the target quantiles of confidence probabilities of dynamic coefficients moduli are not lower, and the stability factors moduli are not higher than they are when quantizing with frequency $2 f_{x}$. The above corresponds to expression

$$
f_{\text {qu }}=f_{x} \Leftarrow \mathfrak{I}_{\mathrm{D}} \wedge \mathfrak{I}_{\mathrm{S}},
$$

where

$$
\mathfrak{I}_{\mathrm{D}}=\left[\underset{\Omega \in\left\{K_{\mathrm{DVR}}, K_{\mathrm{DVL}}, K_{\mathrm{DH}}\right\}}{\forall} \max _{f_{x}}|\Omega| \geq \max _{2 f_{x}}|\Omega|\right],
$$




$$
\mathfrak{I}_{\mathrm{S}}=\left[\left.\underset{\Omega \in\left\{K_{\mathrm{S}}, K_{\mathrm{SO}}\right\}}{\forall} \Omega\right|_{f_{x}} \leq\left.\Omega\right|_{2 f_{x}}\right]
$$

The rules of obtaining the quantiles of confidence probabilities of the target values of $K_{\mathrm{DVR}}, K_{\mathrm{DVL}}, K_{\mathrm{DH}}, K_{\mathrm{S}}, K_{\mathrm{SO}}$ are described below. When digitizing, the timing error between any two channels should not exceed values $\Delta t_{2}$ determined by expression $\sin \left(2 \pi f_{\max } \Delta t_{2}\right)<0.05$. It is obvious that, if the frequency range of input signals is limited by $f_{\max } \approx 4 \mathrm{~Hz}$ frequency, $\Delta t_{2} \approx 0.002$ seconds. For digitizing purposes, it is reasonable (but not mandatory!) to reject a fortiori erratic results that occur due to the instrumentation failures. To do this, the test manager sets the "reasonable boundaries" for the entered values $\underset{i=1}{\forall} X_{i} \geq \sup _{0<t<\infty} x_{i}(t)$. If, at moment of measurement $t_{i}$, any one of the entered processes goes out of its "reasonable boundaries", the measurement results at this moment of time are ignored in all the three processes. It is obvious that all the points of the digitized processes realizations correspond to expression

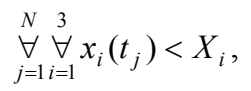

where the number of points in realization $N \leq T f_{\text {qu }}, T$ is the realization duration. When the tested railway vehicle moves in straight sections of the track, all the entered realizations should be centered [197] so that their arithmetic means equale to zero. When the tested railway vehicle moves in curved sections of the track or by switches to the side track, every entered realization should be centered so that its directrix matches the arithmetic mean of the realization registered by the same sensor in the straight section of the track preceding the given curved section or following it.

Arithmetic means in each realization $\underset{j=1}{\forall} x_{i}\left(t_{j}\right)$ are defined by expression [199]

$$
\underset{i=1}{\forall} M\left[x_{i}\right]=\frac{1}{N} \sum_{j=1}^{N} x_{i}\left(t_{j}\right) .
$$

Here $i$ is the number of the sensor $(i \in[1,2,3]), j$ is the ordinal number of the element in the realization.

At every moment of time $t_{j}$, the coefficients of vertical dynamics $K_{\mathrm{DVR}}\left(t_{j}\right)$ on the right and $K_{\mathrm{DVL}}\left(t_{i}\right)$ on the left to the direction of the railway vehicle motion are determined by dependencies $[181 ; 196]$

$$
\underset{j=1}{\forall} K_{\mathrm{DVR}}\left(t_{j}\right)=x_{1}\left(t_{j}\right) / Q_{\mathrm{J}}, \quad \underset{j=1}{\forall} K_{\mathrm{DVL}}\left(t_{j}\right)=x_{2}\left(t_{j}\right) / Q_{\mathrm{J}},
$$

and the coefficient of horizontal dynamics is determined by dependence [194] 


$$
\underset{j=1}{\forall} K_{\mathrm{DH}}\left(t_{j}\right)=x_{3}\left(t_{j}\right) / \bigoplus_{\mathrm{ST}}
$$

where $Q_{\mathrm{J}}$ is the load applied to the wheelset axle journal; $P_{\mathrm{ST}}$ is the static load applied to the rails by the wheelset.

The coefficients of vertical dynamic on running-on $K_{\mathrm{R}}$ and non-running-on $K_{\mathrm{NR}}$ wheel (Figure 10.6 illustrates the back view relative to the direction of motion) are defined as follows: with $H_{\mathrm{H}}$ acting right to left, $K_{\mathrm{R}}=K_{\mathrm{DVL}}$ and $K_{\mathrm{NR}}=K_{\mathrm{DVR}}$; with $H_{\mathrm{H}}$ acting left to right, $K_{\mathrm{R}}=K_{\mathrm{DVR}}$ and $K_{\mathrm{NR}}=K_{\mathrm{DVL}}$. Here $H_{\mathrm{H}}=\left|x_{3}\left(t_{j}\right)\right|$. For every moment of time $t_{j}$ according to $[181 ; 196]$

$$
K_{\text {Ó }}=\frac{\operatorname{tg} \beta-\mu}{1+\mu \operatorname{tg} \beta} \frac{G_{\dot{\dot{\tau}}}}{G_{\mathrm{c}}},
$$

where $\beta$ is the tilting angle of the wheel flange generatrix to the horizontal axis; $\mu=0.25$ is the friction coefficient; $G_{\mathrm{c}}$ and $G_{\mathrm{z}}$ are conditional values having the same units of measurement as forces:

$$
\begin{gathered}
G_{\mathrm{c}}=Q_{\mathrm{N}}\left[\frac{2\left(b-a_{2}\right)}{L}-\frac{K_{\mathrm{R}}\left(2 b-a_{2}\right)}{L}+\frac{K_{\mathrm{NR}} a_{2}}{L}\right]+q \frac{b-a_{2}}{L}+\frac{r}{L} H_{\mathrm{p}}, \\
G_{\mathrm{z}}=\mu Q_{\mathrm{N}}\left[\frac{2\left(b-a_{1}\right)}{L}-\frac{K_{\mathrm{NR}}\left(2 b-a_{1}\right)}{L}+\frac{K_{\mathrm{R}} a_{1}}{L}\right]+\mu q \frac{b-a_{1}}{L}+\left(1-\frac{r}{L} \mu\right) H_{\mathrm{p}}
\end{gathered}
$$

Here $2 b$ is the distance between the wheelset axles journals middles, $\mathrm{m} ; a_{1}$ and $a_{2}$ are the distances from the contact points of wheels and rails to the wheelset axles journals middles of the running-on and non-running-on wheel, $\mathrm{m} ; L$ is the distance between the contact points of the wheels and rails, $\mathrm{m}$; $q$ is the weight of unsprung parts applied to the wheelset, $\mathrm{kN}$ (it is obvious that $P_{\mathrm{ST}}=2 Q_{\mathrm{J}}+q$ ); $r$ is the radius of the taping line, $\mathrm{m}$.

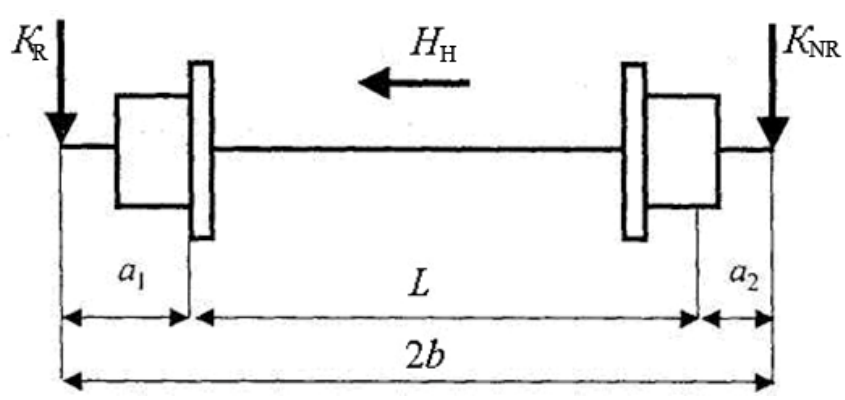

Figure 10.6. Wheelset of the tested railway vehicle. Back view 
Values $H_{\mathrm{H}}$ and $Q_{\mathrm{J}}$ in expressions (10.19) and (10.20) are measured in kilonewtons. Under $[181 ; 196]$, for typical wheelsets, the values of $2 b, a_{1}, a_{2}, L, r$ are preset. It should be noted that, according to document [196] that is in effect in Ukraine, $r=0.475 \mathrm{~m}, b=1.018 \mathrm{~m}, a_{1}=0.264 \mathrm{~m}, a_{2}=0.217 \mathrm{~m}, L=1.555 \mathrm{~m}$, i. e. $a_{1}+a_{2}+L=2 b$, and according to document [181] that is in effect in Russia, $r=0.45 \mathrm{~m}, b=1.018 \mathrm{~m}, a_{1}=0.264 \mathrm{~m}, a_{2}=0.217 \mathrm{~m}, L=1.555 \mathrm{~m}$, though with this values $a_{1}+a_{2}+L \neq 2 b$. The weight of unspung parts applied to the wheelset is $q / g=2.02$ ton for three-member bogie of model 18-100 (TsNII-Kh3 (ЦНИИ-Х3)) freight car, and $q / g \approx 1.65 \ldots 1.78$ ton for the real bogie of KVZ-TsNII passenger car depending on the bogie modification.

At every moment of time $t_{j}$, the overtopping stability factor for one wheelset may be determined using expression

$$
K_{\mathrm{SO}}=\frac{2-K_{\mathrm{R}}-K_{\mathrm{NR}}}{K_{\mathrm{R}}-K_{\mathrm{NR}}},
$$

that does not contradict the standard documents [181; 196]. It should be noted that quantile of confidence probability of overtopping stability factor of the railway vehicle usually slightly exceeds the quantile of coefficient $K_{\text {SO }}$ computed using formula (10.21).

To make a decision on the tested car serviceability, the information on the digitized realizations should be classified by a fuzzy set of criteria. The results of analysis of thus classified information may be used for setting the restrictions for the tested car circulation (in such case, the car is actually considered as partially serviceable).

One of the classification criteria is the track plan (TP). Following the recommendation of [200], let us consider the straight sections of the track as matching condition ( $\mathrm{TP}=\mathrm{str})$, the curved sections to the right to the direction of motion (right curved section) - as matching to condition $(\mathrm{TP}=\mathrm{r})$, left curved sections - to condition $(\mathrm{TP}=1)$, switches - to condition $(\mathrm{TP}=\mathrm{sw})$. The curved sections are usually divided into small radius curved sections $\left(R \leq R_{\mathrm{SM}}\right)$, medium radius curved sections $\left(R_{\mathrm{SM}}<R \leq R_{\mathrm{L}}\right)$ and large radius curved sections $\left(R>R_{\mathrm{L}}\right)$. For all the cars (except for the special purpose cars [201] and industrial transport cars [202; 203]), the following values are usually assumed: $R_{\mathrm{SM}}=350 \mathrm{~m}, R_{\mathrm{L}}=650 \mathrm{~m}$. Sometimes the realizations collected during the tested car riding in switches are necessary to be classified into the realizations passed in straight switches and in switches to the side track. Sometimes, such track sections as elevations, slopes, bridges and highway crossings are also classified into separate groups. It is obvious that the multitude of values of TP criterion may be described by expression:

$$
\begin{aligned}
& \mathrm{TP} \in\left[\operatorname{str}, \mathrm{r} \wedge\left(R \leq R_{\mathrm{SM}}\right), \mathrm{r} \wedge\left(R_{\mathrm{SM}}<R \leq R_{\mathrm{L}}\right), \mathrm{r} \wedge\left(R>R_{\mathrm{L}}\right),\right. \\
& \left.1 \wedge\left(R \leq R_{\mathrm{SM}}\right), 1 \wedge\left(R_{\mathrm{SM}}<R \leq R_{\mathrm{L}}\right), 1 \wedge\left(R>R_{\mathrm{L}}\right), \tilde{n}, \ldots\right] .
\end{aligned}
$$


Usually, by the track arrangement (TA) parameter, the test sections are divided into spliced track $(\mathrm{TA}=\mathrm{spl})$ and continuously welded track $(\mathrm{TA}=\mathrm{cw})$. Sometimes, such division is unnecessary $(\mathrm{TA}=0)$. The multitude of values of TA may be written as:

$$
\mathrm{TA} \in\{[\mathrm{spl}, \mathrm{cw}] \vee 0\} .
$$

By the condition of motion $(\mathrm{CM})$, the digitized realizations may be classified as matching the traction $(\mathrm{CM}=\mathrm{t})$, slowing-down $(\mathrm{CM}=\mathrm{s})$, pushing $(\mathrm{CM}=\mathrm{p})$, braking of the train with locomotive $(\mathrm{CM}=1)$ or braking with the locomotive and the train of cars $(\mathrm{CM}=\mathrm{c})$. One of the examples of the train braking with the locomotive is the regeneration braking, and the example of the braking with the locomotive and the train of cars is the electropneumatic braking. Sometimes, classification by $\mathrm{CM}$ criterion is unnecessary $(\mathrm{CM}=0)$. It is obvious that

$$
\mathrm{CM} \in\{[\mathrm{t}, \mathrm{s}, \mathrm{p}, 1, \mathrm{c}] \vee 0\} .
$$

It should be noted that sometimes the classification by the condition of motion is applied to incomplete multitude of $\mathrm{CM}$ values, for example, for $\mathrm{CM} \in[\mathrm{t}, 1]$.

Test trips are most frequently arranged as "shuttle" trips, with the motion in one direction considered as forward trip and the back motion considered as backward trip. For the backward trip, the tested car is not turned around. The wheelset that was the rear one at the forward trip becomes the first at the backward trip. When the test results of the backward trip, the rule of defining $K_{\mathrm{R}}$ and $K_{\mathrm{NR}}$ by $x_{3}(t)$ value sign may stay unchanged. Then, at the backward trip, the right curve should be considered as left and the left curve - as right. There are two types of classifications by leadership (L):

1) the information for the first wheelset of the car when this wheelset is leading $\left(\mathrm{L}_{\mathrm{f}}=1 \wedge \mathrm{f}\right)$ makes one separate data pool, another pool includes the information on the same wheelset when it is the rear one in the motion direction $\left(L_{r}=1 \wedge r\right)$; irrespective of the first wheelset the data pool, for instance, for the fourth wheelset of the same car when this wheelset is leading $\left(\hat{L}_{\mathrm{f}}=4 \wedge \mathrm{f}\right)$ may be collected, with separate data pool including the information on this wheelset when it is in the rear position $\left(\hat{\mathrm{L}}_{\mathrm{r}}=4 \wedge \mathrm{r}\right)$; in other words, the digitized information on two wheelsets is classified by four criteria: $\mathrm{L} \in\left[\mathrm{L}_{\mathrm{f}}, \mathrm{L}_{\mathrm{r}}, \hat{\mathrm{L}}_{\mathrm{f}}, \hat{\mathrm{L}}_{\mathrm{r}}\right]$;

2) the information on the leading (first) and rear (last) wheelsets in the direction of the motion is collected irrespective of the current position of the wheelset, i. e. whether it is the first wheelset of the railway vehicle or the fourth wheelset (the last wheelset of the eight-wheel railway vehicle).

In other words, the digitized information is classified by two criteria: $\mathrm{L} \in\left[\mathrm{L}_{\mathrm{f}}, \mathrm{L}_{\mathrm{r}}\right]$ where $\mathrm{L}_{\mathrm{f}}=(1 \wedge \mathrm{f}) \vee(4 \wedge \mathrm{f}), \mathrm{L}_{\mathrm{r}}=(1 \wedge \mathrm{r}) \vee(4 \wedge \mathrm{r})$.

By the customer's request, it may be necessary to classify the entered information by the track condition $\mathrm{C} \in\{[\mathrm{excl}$, good, sat, unsat $] \vee 0\}$ where "excellent", 
"good", "satisfactory" and "unsatisfactory" are the evaluations of the track condition and $\mathrm{C}=0$ stands for the absence of any classification by the track condition. Sometimes, it is necessary to classify the entered information by the type of the cross-ties in the test section of the track - concrete $(\mathrm{CT}=$ con) or wooden $(\mathrm{CT}=$ wood $)$. Expression $\mathrm{CT}=0$ is used in case the classification by the cross-ties type is unnecessary.

Standard documents $[181 ; 196]$ require for classification of the entered information by speed. Under the standard document that is in effect in Russia [181], the whole range of the test speeds is divided into intervals of $\Delta V=10 \ldots 15 \mathrm{kmh}$; under the Ukrainian standard document [196], this range is divided into intervals of $\Delta V=15 \ldots 20 \mathrm{kmh}$. The range of speeds $\left[V_{\min }, V_{\max }\right]$ is defined by the Test Program $[181 ; 196]$. For every realization lasting $T$ and matching requirement $(10.14)$, the average speed $v=\frac{1}{N} \sum_{j=1}^{N} v\left(t_{j}\right)$ is calculated. Then the realization is matched with the speed interval numbered $k$ if $V_{\min }+(k-1) \Delta V \leq \bar{v}<V_{\min }+k \Delta V$. The same speed interval is matched with speed $V_{k}=V_{\min }+(k-0,5) \Delta V$. It is obvious that the number of the intervals is $K=\operatorname{int}\left(\left(V_{\max }-V_{\min }\right) / \Delta V\right)$ where int $(z)$ is the smallest whole number not less than $z$.

The realizations corresponding to each of the combinations of the classification criteria comprise the assembly. The strength (size) of the assembly $N_{\mathrm{a}}$ is determined by total length (total quantity of points) of all the realizations registered by the sensor numbered $i(i \in[1,2,3])$ included into the assembly:

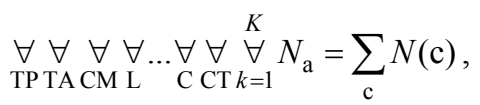

where $\mathrm{c}$ is the ordinal number of the realization in the given assembly, $N(\mathrm{c})$ is the length of the realization numbered c. Let us determine the integral law of distribution of separately positive $\left(K_{\mathrm{DVR}}:\left[K_{\mathrm{DVR}} \geq 0\right], K_{\mathrm{DVL}}:\left[K_{\mathrm{DVL}} \geq 0\right], K_{\mathrm{DH}}:\left[K_{\mathrm{DH}} \geq 0\right]\right)$ and separately negative $\left(K_{\mathrm{DVR}}:\left[K_{\mathrm{DVR}}<0\right], K_{\mathrm{DVL}}:\left[K_{\mathrm{DVL}}<0\right], K_{\mathrm{DH}}:\left[K_{\mathrm{DH}}<0\right]\right)$ dynamic coefficients and all (positive and negative) values of the wheels coming off the rails stability factors $\left(K_{\mathrm{S}}\right)$ and overtopping stability factors $\left(K_{\mathrm{SO}}\right)$. To define the distribution laws, the area of the dynamic coefficients moduli is divided into intervals. The interval numbered $q$ is defined by its boundaries $\left[\xi_{q}, \xi_{q+1}\right)$ where under $[181 ; 196]$

$$
\begin{gathered}
\underset{q}{\forall} \xi_{q} \in[0 ; 0.05 ; 0.10 ; 0.15 ; 0.20 ; 0.24 ; 0.25 ; 0.30 ; 0.35 ; 0.38 ; 0.40 ; \\
0.45 ; 0.50 ; 0.55 ; 0.60 ; 0.70 ; 0.80 ; 0.90 ; 1.00 ; \infty] .
\end{gathered}
$$

The area for defining the wheels coming off the rails stability factors is also divided into intervals. For this area, under the Russian standard document [181] 


$$
\begin{gathered}
\underset{q}{\forall} \xi_{q} \in[-\infty ; 0.8 ; 0.9 ; 1.0 ; 1.15 ; 1.25 ; 1.3 ; 1.45 ; 1.5 ; 1.6 ; 1.7 ; 1.8 ; 1.9 ; \\
2.0 ; 2.1 ; 2.3 ; 2.5 ; 2.7 ; 2.9 ; 3.0 ; \infty]
\end{gathered}
$$

and under the Ukrainian standard document [196]

$$
\begin{gathered}
\underset{q}{\forall} \xi_{q} \in[-\infty ; 0.8 ; 0.9 ; 1.0 ; 1.1 ; 1.2 ; 1.3 ; 1.4 ; 1.5 ; 1.6 ; 1.7 ; 1.8 ; 1.9 ; \\
2.0 ; 2.1 ; 2.3 ; 2.5 ; 2.7 ; 2.9 ; 3.0 ; \infty] .
\end{gathered}
$$

For the overtopping stability factor, under $[181 ; 196]$

$$
\underset{q}{\forall} \xi_{q} \in[-\infty ; 1.1 ; 1.2 ; 1.3 ; 1.4 ; 1.5 ; 1.6 ; 1.7 ; 1.8 ; 1.9 ; 2.0 ; 2.1 ; 2.2 ; \infty] .
$$

The probability of the measured values getting into [199] interval $\left(-\infty, \xi_{q}\right.$ ] is

$$
P\left\{\Psi \leq \xi_{q}\right\}=n_{q} / N_{q},
$$

where $n_{q}$ is the number of points, for which $\Psi \leq \xi_{q}$ in the given characteristic assembly. Here $\Psi \in\left\{K_{\mathrm{DVR}}:\left[K_{\mathrm{DVR}} \geq 0\right] ; K_{\mathrm{DVR}}:\left[K_{\mathrm{DVR}}<0\right] ; K_{\mathrm{DVL}}:\left[K_{\mathrm{DVL}} \geq 0\right]\right.$; $\left.K_{\mathrm{DVL}}:\left[K_{\mathrm{DVL}}<0\right] ; K_{\mathrm{DH}}:\left[K_{\mathrm{DH}} \geq 0\right] ; K_{\mathrm{DH}}:\left[K_{\mathrm{DH}}<0\right] ; K_{\mathrm{S}} ; K_{\mathrm{SO}}\right\}$.

The unknown values for the dynamic coefficient and overtopping stability factor are the quantiles of probabilities $P_{\mathrm{c}}=0.95$ under the Ukrainian standard documents [195; 196] or $P_{\mathrm{c}}=0.999$ under the Russian standard document [181]. If the sensors for measuring $x_{1}(t), x_{2}(t)$ and $x_{3}(t)$ are installed as is specified in [181; 196], the requirements of $[181 ; 194-196]$ are considered met when the quantile values for the dynamic coefficients are lower than the criterial values:

$$
\left[K_{\mathrm{DV}}\right]=\left\{\begin{aligned}
& 0.75 \text { for spring bogie frame of empty freight cars } \quad \text { for axle-box spring bogies) }[181 ; 196], \\
& 0.95 \text { for unsprung bogie frame of empty freight cars }[181 ; 196], \\
& 0.70 \text { for spring bogie frame of loaded freight cars } \\
& \quad \text { (for axle-box spring bogies) }[181 ; 196], \\
& 0.80 \text { for unsprung bogie frame of loaded freight cars }[181 ; 196], \\
& 0.40 \text { for empty passenger cars }[181 ; 196], \\
& 0.38 \text { for loaded passenger cars under }[196], \\
& 0.35 \text { for loaded passenger cars under [181], } \\
& 0.40 \text { for empty freight cars }[181 ; 196], \\
& 0.38 \text { for loaded freight cars }[181 ; 196]
\end{aligned}\right.
$$




$$
\left[K_{\mathrm{DH}}\right]=\left\{\begin{array}{l}
0.40 \text { for empty freight cars }[181 ; 196], \\
0.38 \text { for loaded freight cars }[181 ; 196] \\
0.25 \text { for empty passenger cars }[181 ; 196] \\
0.24 \text { for loaded passenger cars }[181 ; 196],
\end{array}\right.
$$

and the quantile values for the overtopping stability factor are higher than the criterial values:

$$
\left[K_{\mathrm{SO}}\right]=\left\{\begin{array}{l}
1.8 \text { for freight cars }[181 ; 196] \\
1.4 \text { for passenger cars }[181 ; 196] \\
1.5 \text { for service cars on passenger bogies }[181 ; 196] \\
1.6 \text { for service cars on freight bogies }[181]
\end{array}\right.
$$

For the wheels coming off the rails stability factors, in each assembly, it is reasonable to search not for the quantiles of threshold $[181 ; 196]$ probabilities $P_{\mathrm{YI}} \in[0.00001 ; 0.0001 ; 0.001 ; 0.01]$, but for the frequencies (probabilities) 4

$\forall P\left\{K_{\mathrm{S}} \leq K_{(\mathrm{YA}, \mathrm{YI})}\right\}$ of $K_{\mathrm{S}}$ values that turned to be lower than the threshold values $\beta=1$

of the stability factor $K_{(\mathrm{YA}, \mathrm{YI})}$. If it turns out that $P\left\{K_{\mathrm{S}} \leq K_{(\mathrm{YA}, \mathrm{YI})}\right\}>\mathrm{P}_{\mathrm{YI}}$, it is necessary to calculate the biggest interval of time $T_{\mathrm{YA}, \mathrm{YI}}$, during which this condition was met uninterruptedly. Index YA defines the type of the railway vehicle and the document standardizing $K_{(\mathrm{YA}, \mathrm{YI})}$ values. Under $[181] K_{(\mathrm{YA}=1, \mathrm{YI})} \in[1.15 ; 1.25 ; 1.45$; $1.6]$ for a freight car and $K_{(\mathrm{YA}=2, \mathrm{YI})} \in[1.3 ; 1.5 ; 1.8 ; 2.0]$ for a passenger, mail, luggage or refrigerator car. Under $[196] K_{(\mathrm{YA}=3, \mathrm{YI})} \in[1.1 ; 1.2 ; 1.5 ; 1.6]$ for a freight and $K_{(\mathrm{YA}=4, \mathrm{YI})} \in[1.2 ; 1.5 ; 1.7 ; 2.0]$ for a passenger, mail, luggage or refrigerator car. Here, YI is the ordinal number of the specified values $\mathrm{YI} \in[1,2,3,4]$, YA $\in$ $[1,2]$ correspond to Russian standard document [181] and values $Y A \in[3,4]$ correspond to Ukrainian standard document [196].

During the tests, before each test train trip, it is necessary to forecast the values of the dynamic characteristics of the tested railway vehicle in order to make a decision on the increase of the speed of passage of any specific section of the test track basing on the previously collected trip information. When forecasting the values of the wheels coming off the rails stability factors for those speeds that haven't been tested yet, it is necessary to extrapolate the quantiles of [204] identical probabilities (do not confuse with the probabilities of identical quantiles!!!) found for those speeds that have been already tested.

As the standard documents $[181 ; 194-196]$ recommend to carry out the tests on the line as comparative tests of new (modernized) and mass produced well-proven railway vehicles, it is necessary to provide for the possibility of development of comparative tables and diagrams for two types of cars (test car $(\mathrm{F}=$ test $)$ and reference car $(\mathrm{F}=\mathrm{ref})$ ) when making report forms. At the same time, there should be the possibility of making the reports for the test railway vehicle $(\mathrm{F}=$ test $)$ only. 
The assemblies of the classified realizations of the registered processes should possess the property of universality - the probability estimates of the dynamic coefficients and stability factors should not vary greatly if any two samples or realizations are excluded of the assembly. Naturally, the probability estimates obtained by the analysis are meaningful only if the probability of the instrumentation [198] failure $\left(P_{\text {fail }}\right)$ is significantly (at least by an order) less than probability $P_{\mathrm{bl}=1}=$ 0.00001 for $K_{\mathrm{S}}$ and less than probability $\left(1-P_{\mathrm{d}}\right)$ for $K_{\mathrm{DVR}}, K_{\mathrm{DVL}}, K_{\mathrm{DH}}, K_{\mathrm{SO}}$. One of the metrological characteristics for each instrumentation channel is the probability of the failure in the "sensor-computer" channel $\left(P_{\text {failure }}\right)$ determined by the relation to the full scope of the test realization of the number of measurements where the reading error for the measured value is bigger than the claimed permissible instrumentation error. It should be taken into account that the probability of failure when defining $K_{\mathrm{S}}$ is three times $\left(P_{\text {fail }}=3 P_{\text {failure }}\right)$ and when defining $K_{\mathrm{DVR}}$ is two times $\left(P_{\text {fail }}=2 P_{\text {failure }}\right)$ more than the probability of failure in one (every) channel.

Thus, for making the decision on acceptance or partial (i. e. with some limitations) acceptance of the railway vehicle for operation, the computer system used for the analysis of the results of dynamic testing on the line should allow for several series of classification of the collected information by a fuzzy set of criteria. When analyzing the results of dynamic testing of the railway vehicles on the line, it is necessary that the assembly of realizations have the property of universality for any criteria combination used for the registered processes classification.

\subsection{Method for Digitizing the Sensors Information When Testing Railway Vehicles}

Various processes registered by the sensors when testing the railway vehicles may be transferred to photo paper using a light-beam oscillograph $[205 ; 206]$, to magnetic tape of a magnetograph $[145 ; 207]$ or entered directly into a computer through analog-digital converter (ADC) [198]. The latter method is the most advanced as the information registered in the oscillograms and magnetograms, most frequently, should be anyway digitized for further analysis $[145 ; 198 ; 205 ; 206$; 208].

This section offers the method for digitizing the information of sensors located on the test railway vehicle (object) when testing the dynamic performance of the railway rolling stock [209]. This method is developed in collaboration with the employees of the R\&D Laboratory of the Rolling Stock Dynamics and Stability (RSDS) under Dnipropetrovsk National Railway Transport University named after V. Lazaryan (DIIT) Professor Ye. P. Blokhin, Candidate of Technical Science R. B. Granovskiy, Candidate of Technical Science V. L. Gorobets, Candidate of Technical Science V. V. Glukhov, Engineers N. Ya. Garkavi and Ye. F. Fedorov. The offered method has passed multiple approvals during the field tests of railway vehicles carried out at RSDS R\&D Laboratory of DIIT.

When entering the sensors information into the computer, the task of quantization of the digitized processes in time is inevitably solved. The frequency $f_{\text {qu }}$ of 
quantization with amplitude spectrum $A(f)$ of entered process $x(t)$ is usually related with dependence $f_{\text {qu }} \geq k f_{\max }$ where $k \approx 10 \ldots 20$ and the frequency is

$$
f_{\max } \geq \max _{f_{0}>0}\left(f_{0}:\left[A\left(f_{0}\right)>0,05 \cdot \max _{0<f<\infty} A(f)\right]\right) .
$$

It should be noted that sometimes $f_{\max }$ may be calculated basing on the frequency characteristic of the sensors or the frequency filters pass band in "sensorcomputer" chain [198]; sometimes $f_{\text {qu }}$ is determined experimentally:

$$
f_{\mathrm{qu}}=f_{1} \Leftarrow \underset{0<f<\infty}{\forall}\left|A(f)_{f_{1}}-A(f)_{2 f_{1}}\right|<0,05 \max _{0<f<\infty} A(f) .
$$

Here $A(f)_{f_{1}}$ and $A(f)_{2 f_{1}}$ are the amplitude spectrums of $x(t)$ process at sufficient its duration $T$ and quantization frequencies $f_{1}, 2 f_{1}$, respectively; process duration $T \gg 1 / f_{\min }$ where $f_{\min }$ is the smallest frequency in $x(t)$ process spectrum that is interesting for the investigator. If, while testing, the processes are recorded by the magnetograph at one speed of the magnetic tape rewinding $\left(W_{1}, \mathrm{rpm}\right)$, and the tape is played back to the computer at another, lower, speed $\left(W_{2}, \mathrm{rpm}\right)$, the actual quantization frequency of the initial process $f_{\text {qu.ac }}=f_{\text {qu }} W_{1} / W_{2}$ turns to be bigger than quantization frequency $f_{\text {qu }}$ of the information digitized from the magnetograph as $f_{\text {qu.ac }} / f_{\text {qu }}=W_{1} / W_{2}>1$. Let us remind that finite Fourier transformation used for calculation of amplitude spectrum $A(f)$ of $x(t)$ process is, in its essence, the expanding of $x(t)$ realization with $T$ duration into Fourier series by frequencies $i / T$ at $i \in[0 ; 1$; $2 ; 3 ; \ldots]$. Such expanding will be accurate for polyharmonics

$$
x(t)=\sum_{j=1}^{J} A_{j} \sin \left(2 \pi f_{j} t+\varphi_{j}\right)
$$

at

$$
T=\frac{n}{\varepsilon \cdot G C D\left(\underset{j=1}{\forall}\left[\frac{f_{j}}{\varepsilon}\right]\right)},
$$

where $G C D(d, b)$ is the greatest common divisor of the integral positive numbers $d$ and $b ; \varepsilon$ is the accuracy of the polyharmonics frequencies setting; $n$ is the integral positive number. In order to reduce the error of determination of amplitude spectrum $A(f)$ before the finite Fourier transformation of the polyharmonics in case when $n$ is nonintegral number and before the finite Fourier transformation of wideband random signal, it is recommended [210] that "conditional" process $x(t) \eta\left(t, T, f_{\mathrm{qu}}\right)$ realization with $T$ duration was expanded into Fourier series rather than initial process $x(t)$ realization. Function $\eta\left(t, T, f_{\mathrm{qu}}\right)$ is called the time window. The variants of function $\eta\left(t, T, f_{\mathrm{qu}}\right)$ setting up are listed in [210].

Usually, the analysis of the results of dynamic testing of the railway vehicles on the line includes the analysis of the ride performance including the tested object 
stability for the wheels coming off the rails [181; 194-196]; the analysis of vibration protection of the locomotive crew, the passengers and the cargo $[181 ; 194$; 211-213]; the determination of the fatigue strength of the load bearing structures of the rolling stock $[181 ; 186 ; 214]$; the determination of the distribution laws and the spectral composition of the processes registered by the sensors of movement, acceleration, force and stress [198] in different points of the structure. Sometimes, during the tests on the line, the information for identification of the track irregularities and determination of causes of the wheels, rails and parts of the tested structure wear is collected. The results of collision strength [78; 181] and dropping from wedges [181] testing are analyzed using the computer. It should be noted that, when studying the movement stability, it is allowed [194] to filter the initial information using filters with the cutoff frequency of not higher than $20 \mathrm{~Hz}$; when studying the vibration protection, the requirements of [211] limit the range of the vibratory acceleration measurements with frequencies of $0.5 \ldots 20 \mathrm{~Hz}$, the requirements of [213] - with frequencies of $0.9 \ldots 90 \mathrm{~Hz}$, the requirements of [212] - with frequencies of $0.9 \ldots 44.9 \mathrm{~Hz}$; to assess the vibration safety of the rolling stock under the requirements of [194], it is necessary to analyze the vibratory accelerations passed through the band filter of $0 \ldots 4 \mathrm{~Hz}$. When analyzing the collision tests [78] and "dropping from wedges" tests [181] results, the quantization frequencies over $800 \mathrm{~Hz}$ are usually not necessary. When analyzing the results of the tests for identification of the track irregularities and tests for determination of causes of the wheels wear, the entered processes quantization frequency lower than $200 \mathrm{~Hz}$ turned to be sufficient. To determine the fatigue strength of the load bearing structures of the rolling stock during the tests on the line, the information with the frequencies of not higher than $60 \mathrm{~Hz}$ is collected. This is explained by the fact that, when operating the railway vehicles at speed $v, \mathrm{kmh}$, maximum force excitation frequency at the wheels side $f_{\text {force }}, \mathrm{Hz}$, is determined by bogie base $L_{\text {bogie }}, \mathrm{m}$ :

$$
f_{\text {force }}=(v \cdot 1,000 \mathrm{~m} / \mathrm{km}) /\left(L_{\text {bogie }} \cdot 3,600 \mathrm{sec} . / \mathrm{h}\right)=v /\left(L_{\text {bogie }} \cdot 3.6\right),
$$

at speed $v \leq 180 \mathrm{kmh}$ and $L_{\text {bogie }} \geq 1 \mathrm{~m}$, it is obvious that $f_{\text {force }}<60 \mathrm{~Hz}$; frequency $f_{\text {exc }}$ of force excitation conditioned by the eccentric rotation of the engine and auxiliary machines of self-propelled railway vehicles with the rotation speed of $w[\mathrm{rpm}]$ is connected by the dependence $w=60 f_{\text {exc }}$, i. e. at $w<3,600 \mathrm{rpm}$ the excitation of force with frequency $f_{\mathrm{exc}}=60 \mathrm{~Hz}$ is non-realizable in principle (surely, the force excitation value conditions by the eccentric engine rotation cannot be compared with the force excitation value at the wheels side). Basing on the above said, quantization frequency of all the registered processes equal to $f_{\text {qu }}=800 \mathrm{~Hz}$ may be considered sufficient for analyzing the results of all the tests. This quantization frequency should be sufficient for the analysis of the test results according to international standard [215].

Simultaneity of three sensors measurements is required for the analysis of the results of dynamic testing on the line for the wheels coming off the rails stability $[211 ; 213]$ and for the determination of the fatigue strength of the load bearing structures using the deformation rose [216]; simultaneity of several sensors measurements is required for the determination of the forms of oscillations of different 
rolling stock parts and for defining the causes of the railway wheels flanges wear. To provide for such simultaneity, the time shift between the information received by two ADC channels $\Delta t_{2}$, hereinafter referred to as the simultaneity error, should comply with condition

$$
0.05>\sin \left(2 \pi f_{\max } \Delta t_{2}\right) \approx 2 \pi f_{\max } \Delta t_{2},
$$

where $f_{\max }$ is the frequency corresponding to expression (10.31) for more highfrequency of the processes entered using these two ADC channels. It is obvious that $\Delta t_{2}<0.05 /\left(2 \pi f_{\max }\right)$, i. e. for any two of those three channels that are used for entering the information from the deformation rose, the permissible simultaneity error at quantization is $\Delta t_{2}<0.05 /(2 \pi \cdot 60)=0.133 \cdot 10^{-3} \mathrm{sec}$. If, for entering the analog signals into the computer (for digitization), 32 channel ADC with a switchboard [198] is used (such as L-264), it is possible that three channels used for digitizing the information from the rose sensors have sequential numbers (this is called "to fix the sensors to sequential ADC channels"), or that the sensors inputs are allowed to any of the channels, for example, into the $1^{\text {st }}, 12^{\text {th }}$ and $32^{\text {nd }}$ channel. In order not to fix the rose sensors to specific ADC channels, it is necessary that the simultaneity error between the $1^{\text {st }}$ and $32^{\text {nd }}$ channels is not more than $\Delta t_{32}=0.133$. $10^{-3} / 31=4.3 \cdot 10^{-6} \mathrm{sec}$. This means that, in absence of the boxcar detector [198] in "sensor-ADC" channel, the ADC capable to provide for quantization frequency not less than $f_{\text {qu max }}=1 / \Delta t_{32} \approx 232 \mathrm{kHz}$ should be used (note that quantization frequency $f_{\text {qu }}$ of $x(t)$ process has almost no interrelation with $f_{\text {qu max }}$ value). Naturally, the requirements to the digitization of the entered processes may be lower depending on the purpose of the analysis. So, in case of the wheels coming off the rails stability studying, condition $\Delta t_{32}<0.05 /(2 \pi \cdot 20 \cdot 31)=12.9 \cdot 10^{-6} \mathrm{sec}$. should be met. It also should be noted that, when determining the fatigue strength of the load bearing structures using the deformation rose, but with the sensors fixation to three sequentially scanned ADC channels, the permissible simultaneity error between the first and the third in scanning queue channels comprise $\Delta t_{32} \leq 0.133 \cdot 10^{-3} / 2=$ $66.5 \cdot 10^{-6} \mathrm{sec}$. Also note that, with parallel operation of two ADC cells, the requirements to simultaneity almost do not rise (despite the fact that now there are 64 input channels). If no frequency analysis of the digitized processes is expected, the time quantization interval increment variability is possible when quantizing the digitized processes by time. However, it is necessary that, at any three sequential moments of time of digitizing the information of one and the same ADC channel $\left(t_{j}, t_{j+1}, t_{j+2}\right)$, the following condition is met

$$
\left(t_{j+1}-t_{j} \leq \delta\right) \wedge\left(t_{j+2}-t_{j+1} \leq \delta\right) \Leftarrow \delta \approx 1 / f_{\text {qu }} .
$$

This means that the intervals between the sequential scanning of one and the same ADC channel can be less (but cannot be significantly more!) than $1 / f_{\text {qu }}$ value. For Fourier analysis of the time processes, the requirements to the quantization interval increment stability are significantly higher [210]: 


$$
\underset{j=1}{T \cdot f_{\mathrm{qu}} T \cdot f_{\mathrm{qu}}} \underset{k=1}{\forall}(k \neq j) \Rightarrow t_{k}-t_{j}=(k-j) / f_{\mathrm{qu}} \pm \Delta_{\mathrm{qu}},
$$

where $\Delta_{\text {qu }} \leq 0.01 f_{\text {qu }}$.

When developing the digitizing system without the utilization of any intermediate carrier (oscillograph or magnetograph), it is necessary to limit the permissible duration of the entered realizations by four to five minutes. Usually, it is unreasonable to increase the time of continuous digitizing as, in case of any emergency in the laboratory car (such as the computer power supply failure), the loss of any four minute information hardly can lead to serious errors when making the conclusion basing on the test results; the losses of longer information may cause big delays in the test procedure as the additional trips of the test train may be necessary to restore the lost data. To achieve maximum 20 per cent time loss of information on the dynamic tests on the line, the computer recovery time upon completion of the receipt of every next assembly of realizations should not exceed 1 minute.

When using the ADC, the following methods of digitizing the analogue information exist [198].

1. Channel by channel conversion. The computer initiates the analog-to-digital conversion in a specific ADC channel, waits for the signal of the ADC readiness (for example, repeatedly addressing the port until the availability bit is not reset), reads the information at the computer port, and then initiates the conversion in the same or the next channel.

2. Step-frame conversion. The computer initiates the ADC functioning. The ADC itself switches the conversion channels, and generates the readiness signal when all the channels finish their operations. At the same time, it is necessary to get the information on all the channels from the computer port assigned to the ADC. This can be achieved, for example, by repeatedly addressing the computer port. Naturally, to function this way, the ADC should have internal memory.

In both cases, the computer can use the timer [198] to start the quantization of the first channel (method 1) or the quantization of the first frame (method 2).

3. Asynchronous operation of the ADC and computer. The computer sets the quantization frequency, the queue of conversion channels scanning and length of the realization in one (each) channel for the ADC. Upon finishing its operation and having accumulated the information in its internal memory, the ADC initiates the breakup to the computer. Then the information from the internal memory of the ADC is transmitted to the computer random access memory (RAM) or directly to the disk via the direct access channel.

With 4 minutes (240 seconds) realization time and $800 \mathrm{~Hz}$ quantization frequency, 32-channel ADC operating by the third method will require the internal memory for $240 \cdot 800 \cdot 32 \approx 6.14 \cdot 10^{6}$ words $(\approx 12.3 \mathrm{MB}$ for 12 - or 16-digit ADC). Currently, it is reasonable to have this volume RAM in the computer, but not in the ADC cell. It is undesirable to store the information in half the volume of the small internal memory of the ADC (for instance, $128 \mathrm{kB}$ ) and then transmit this information to the computer disk while the information is asynchronously collected in the 
second half of the internal memory of the ADC as this may cause the delay in the information receipt via the ADC due to failures and multiple repeated recordings to disk (multiple repetition of failed recordings is one of the functions of disk drivers). Such delays are unacceptable for the Fourier analysis of the digitized realizations. With the asynchronous operation of the ADC and computer, it is somehow problematic to interrupt the information digitizing after the time interval significantly less than 4 minutes if requested by the test manager. Basing on the above said, the asynchronous operation of the ADC and computer has to be considered inapplicable.

The starting point for the information frame (or the first channel in the frame) quantization can be set using the computer timer, the computer clock (for computers with IBM 286 and higher processor), the external generator or the set of satellite commands. Application of the satellite commands implies the uniform set of commands between the signal quantization moments in one and the same channel of the ADC. This means that the digitizing programs become machine-specific that makes the operation problematic. The list of the equipment necessary for normal operation of the laboratory car is given in [145]. Signal generator that could be used for sampling the beginning of the information frame quantization with the multi-channel ADC has no functional application in the laboratory car. It is usually undesirable to introduce excessive additional equipment to the laboratory car. Utilization of the timer and clock is almost of equal worth. The described software uses the timer.

When using the IBM compatible computers, the most convenient for the test data digitizing operating system is MS-DOS provided it operates in protected mode. The advantages of MS-DOS are its simplicity, the simplicity of the operating system restoration from an external carrier (diskette), and the absence of the initiative to self-preventing (it should be noted that Windows operating system versions 95,98 and 2000 gives rather high priority to self-preventing programs, and thus may destroy the continuous character of acceptance of big volumes of analog information via the ADC). The most appropriate programming language for the development of analog information digitizing programs is TMT-Pascal.

The software developers recommend to display the oscillograms of digitized processes parallel to the analog information digitizing. Most frequently, for this purpose, the digitizing process is interrupted for some time, but, at the asynchronous operation of the ADC and computer, there is a fundamental possibility to accurately align these computation processes. Let us remind that, during the tests, the information is entered into the computer using sometimes 20 and sometimes 64 channels. It is impossible to display all the digitized information at the same time, as even 20 oscillograms are almost indistinguishable on a screen. Actually, there's no sense in duplicating the digitized information on the screen because almost all the processes that are entered into the computer are displayed on the laboratory car monitors [145]. However, the possibility of viewing the already digitized information (displaying three to five processes at a time) is, by no means, necessary. The modern personal computers provide no possibility for processing the digitized in- 
formation on-line with the input or in intervals between the sequential inputs of the realization assemblies because their structure does not have additional processors operating in parallel with the main processor of the computer and with each other.

When digitizing the sensors information, it is convenient to use special board, which can be used for entering the track plan and the benchmarks of the mileposts passing. This information is radiographed to the laboratory car by the observer in the locomotive cabin [145]. The settings in the ADC channel used for the profile entering are as follows: $u(t) \approx 0 \mathrm{~V}$ voltage corresponds to the straight section of the track, $u(t) \geq+1 \mathrm{~V}$ (but $u(t)<1.5 \mathrm{~V}$ !) corresponds to the right curved section of the track, $u(t) \leq-1 \mathrm{~V}-$ to the left curved section of the track and $u(t)>+2 \mathrm{~V}-$ to switches. The train coming pass the milepost is registered in another channel of the ADC by switching the voltage level from $u(t) \approx 0 \mathrm{~V}$ to $u(t) \geq 1 \mathrm{~V}$ or from $u(t) \geq 1 \mathrm{~V}$ to $u(t) \approx 0 \mathrm{~V}$. The voltage level of $u(t) \leq-1 \mathrm{~V}$ in the same channel corresponds to the command "end of realization assembly input". The information on the train location may also be entered using the satellite navigation system. The speed of the test train should be digitized via separate ADC channel. For the information decoding when processing, the records of the bogie side frame movements relative to the car body in the bolster section are very useful [196; 201-203]. These processes allow for the determination of the car entering (exiting) the curved section and the switches and for assessing the curved line radius. It should be noted that the message about the train entering the curved line sent by the observer in the locomotive serves only as a signal of the motion condition change, but cannot be considered the reference point because of the big error. Therefore, the time difference between the changes of plan and track profile for the locomotive and the test car can be computed by the software. In principle, there is the possibility to store the plan and profile of the track into the computer memory before the beginning of the trip and then to watch the car position in the plan considering the speedometer during the software data processing (without the interference by the operator). However, the laboratory car power supply failures, sensors failures, and information input termination by the request of the test manager are possible during the tests. For classification while processing, the additional information is usually necessary: staking out of the test section of the track; elevation of the external rail in the curved line; train handling regime (traction, slowing-down, braking); weather conditions (dry, rain, snow); rails condition (dry, wet); passage of bridges, crossings; track structure (spliced or continuous welded track, wooden or reinforced concrete cross-ties); the bed and ballast section type; emergencies during the tests; other information. That is why the program for watching the test train position in the track plan should mandatory have the branched dialog graphic interface with the operator.

If the program for digitizing the sensors information via the ADC have included the test number (the test train trip number) and the test entry number into the original realization file name and the file extension [198], all the necessary information can be entered into the computer while preparing the digitized information for processing basing on the entries in the test $\log [145 ; 181]$. It should be 
noted that the mandatory part of preparation is the generation of the master file, in which each entry fragment is matched with the respective test number, plan and average speed in the given section of the track.

The operator should have the possibility to correct the entries sizes not only at the stage of the analog information digitizing, but also at the stage of this information processing. This requirement is connected with the fact that it may be necessary to calibrate the sensors after the test in addition to their calibration (adjustment) $[78 ; 145 ; 207]$ before the test.

Let us note that uninterrupted continuous information registration may be arranged using two computers. In this case, the information receipt by the second computer should be started at the moment when the first computer goes into recording on its disk (or slightly in advance of this moment).

The described method of the sensors information digitizing may be used for dynamic tests on the line and strength tests of the railway vehicles aimed at determination of their respective characteristics, and for studying the performance of new or modernized oscillation damping and shock absorbing systems. 


\section{REFERENCES:}

1. Biderman V. L., Dynamic Oscillations Damper // Mechanical Oscillations Theory. - Moscow: High School, 1980. - p.123-126 (in Russian).

2. Kolimiychenko V. V., Bespalov N. G., Semin N. A., Automatic Coupling Unit in Rolling Stock. - Moscow: Transport, 1980. - 185 p (in Russian).

3. Blokhin Ye. P., Manashkin L. A., Train Dynamics (Non-Stationary Longitudinal Oscillations). - Moscow: Transport, 1982. - $222 \mathrm{p}$ (in Russian).

4. Rakhmatulin Kh. A., Demyanov Yu. A., Strength under Intensive ShortTerm Loads. - Moscow: Fizmatiz, 1961. - 400 p (in Russian).

5. Danovich V. D., Myamlin S. V., Neduzhaya L. A., Summary of Technical Solutions of Running Gear Structures in Some Types of Locomotives // Technical Mechanics. - 2000. - No. 2. - p. 111-119 (in Russian).

6. Donchenko A. V., Development Trends for Rolling Stock Running Gears // Ukrainian Railway Transport. - 2002. - No. 6. - p. 41-43(in Russian).

7. New Car Bogies // World Railway Transport. - 1994- No.3. - p. 3-9(in Russian).

8. Voronovich V. P., Radzikhovskiy A. A., Demin Yu. V., Development of Bogies for Domestic High-Speed Passenger Cars // Ukrainian Railway Transport. 2002. - No. 5. - p. 12-15(in Russian).

9. Demin Yu. V., Kochmala G. D., Improvement of Technical Characteristics of Freight Cars // Ukrainian Railway Transport. - 1999. - No. 3. - p. 26-29(in Russian).

10. Lvov A. A., Pevzner V. O., Romen Yu. S., Requirements to Freight Cars in High-Speed Lines // Railway Transport. - 1998. - No. 1. - p. 37-39(in Russian).

11. Frederich F., Passenger Car Bogie for German Railways // World Railway Transport. - 1990. - No. 7. - p. 8-9.

12. Panagin R., FIAT Passenger Car Bogie // World Railway Transport. 1990. - No. 7. - p. 10-11.

13. Smith B., Harding A., Freight Cars Bogies // World Railway Transport. 1990. - No. 7. - P. 11-12.

14. Steinman F., New Locomotive Bogie // World Railway Transport. - 1990. No. 7. - P. 12-13.

15. Meinke P., Mauer L., Support Bogie for High Speeds of Motion // World Railway Transport . - 1990. - No. 7. - P. 13-17.

16. Improvement of Freight Car Bogie Structures // World Railway Transport. - 1993. - No. 10. - P. 69-72.

17. Yefimov V. P., Pranov A. A., Pavlyukov A. E., Bogies for Prospective Freight Cars // Railway Transport. - 2002. - No. 4. - P. 46-49(in Russian).

18. Changes in Y25 Bogie Structure // World Railway Transport. - 1985. No. 8. - P. 32-35.

19. Tsygankov P. Yu., Belyaev A. I., Prospective Bogie for Traction Rolling Stock // Railway Transport. - 2002. - No. 1. - P. 22-25(in Russian). 
20. New Structures of Freight Cars Bogies (USA) // Railway Transport Abroad. - 1996. - No. 1. - P. 14-18(in Russian).

21. Prospective Structures of Bogies for Freight Cars (USA) // Railway Transport Abroad. - 1996. - No. 3. - P. 28-33(in Russian).

22. Modern Structures of Passenger Car Bogies by ALSTOM (France) // Railway Transport Abroad. - 1991. - No. 4. -P. 15-19(in Russian).

23. Prototypes of High-Speed Bogies for Passenger Cars // Railway Transport Abroad. - 1991. - No. 1. - P. 10-12(in Russian).

24. High-Speed Passenger Car Bogie (Austria) // Railway Transport Abroad. 1991. - No. 5. - P. 6-9(in Russian).

25. Improvement of Car Structure and Equipment in Some European Countries // Railway Transport Abroad. - 1981. - No. 6. - P. 39-51(in Russian).

26. Main Line Electric Locomotive with 120 Series Three-Phase Traction Drive in State German Railways // Railway Transport Abroad. - 1986. - No. 4. - P. 19(in Russian).

27. Beisler L., High-Speed Freight Carriages in New Lines // World Railway Transport. - 1991. -No. 1. - P. 5-6.

28. Improvement of Freight Car Structure // World Railway Transport. - 2000. - No. 9. - P. 20-22.

29. Improvement of Freight Cars in US Railways // World Railway Transport. - 2001. - No. 1. - P. 34-35.

30. Prospective US Passenger Rolling Stock // World Railway Transport. 2000. - No. 10. - P. 21-23.

31. Tsyurenko V. N., Silin V. S., Kornikova T. I., Requirements to Freight Cars in West-East Communication Lines // Railway Transport. - 2000. - No. 8. - P. 34-37(in Russian).

32. Up-to-Date Requirements to Rolling Stock// World Railway Transport. 2001. - No. 1. - P. 18-21.

33. Tsyurenko V., East-West Freight Car. What It Should Be // Bulletin of OSZhD. - 2000. - No. 4-5. - P.3-9(in Russian).

34. Myamlin S. V., Improvement of Railway Vehicles Dynamic Characteristics by Improvement of Spring Suspension Characteristics: Thesis Paper for Doctor of Technical Science Degree: 05.22.07. - Luhansk, 2004. - 455 p(in Russian).

35. Verigo M. F., Kogan A. Ya., Interaction of the Track and the Rolling Stock. - Moscow: Transport, 1986. - 559 p(in Russian).

36. Aufhängung für einen Wagenkasten an einem Fahrgestell, insbesondere an einem Drehgestell eines schienengebundenen Fahrzeugs: Application 4243886 Germany, MKI5 B 62 D 24/04 / Dappa Ewald; Mannesmann Rexroth GmbH. No. 42438861; Applied on 23.12.92; Published on 30.6.94.

37. Longitudinal Effort Transmitting Mechanism from Locomotive Bogie Frame to Locomotive Body Frame: A.p. 1708680 CCCP, MKI5 B 61 F 5/00 / A. V. Razepin, I. P. Demchenko (USSR). No. 4704035/11; Applied on 12.06.89; Published on 30.01.92; Bulletin No. 4(in Russian).

38. Transversal Forces Transmitting Mechanism from Vehicle Body to Bogies: 
A.p. 1687487 CCCP, MKI5 B 61 F 5/02 / I. V. Astakhov (USSR). No.4633584/11; Applied on 09.01.89; Published on 30.10.91; Bulletin No. 40(in Russian).

39. Method for Fixing the Unit for Damping the Oscillations of Car Body Flexure: Application 3204369 Japan, MKI5 B 61 D 17/00 / Sato Yosi; Sumitomo Kindzoku Koge k. k. - No. 2-1960 ; Applied on 8.1.90 ; Published on 5.09.91.

40. Side Frame-Bolster Interface for Railcar Truck Assembly: Patent 6173655 USA, MPK7 B 61 F 3/00 / Hawthorne V. Terrey; AMSTED Ind. Inc. No. 09/136911; Applied on 20.08.1998; Published on 16.01.2001; НПК 105/182.1.

41. Berger H. A good ride at $200 \mathrm{~km} / \mathrm{h} / /$ Railway Gazette Int. - 1983. - No. 11. - P. 843-847.

42. Sekundärfederung für ein Drehgestell eines Schienenfahrzeuges: Patent 396096 Austria, MKM5 B 61 F 5/14 / Haigermoser Andreas, Haas Herbert, Kaserer Cerhard, Zöscher Karl, Stephanides Johannes; SGP Verkehrslechnik G.M.B.H. No. 415/90; Applied on 22.02.90; Published on 25.05.93.

43. Querfederung von schienengebundenen Fahrzeugen: Application 4216727 Germany, MKI5 B 61 F 5/24 / Fröhlich Udo, Schäfer Wolfgang; Mannesmann Rexroth GmbH. No. 4216727.2; Applied on 20.5.92; Published on 25.11.93.

44. Active bump-stop boosts ride quality // Railway Gazette Int. - 1994 . - 150, No. 12 . - C. 818.

45. Pneumatic Spring: Application 3148345 Japan, MKI5 B 60 R 21/18 / Khamada Sindzi; Ikeda Bussan k. k. No. 1286392; Applied on 02.11.89; Published on 25.06.91; Kokai tokke koho. Series 2(5). -2 p.

46. Railway truck side bearing: Patent 634036 Australia, MKI5 B 61 F 005/14 / Wright James F.; Hansen Inc. No. 72946/91; Applied on 15.03.91; Published on 11.02.93.

47. Pommereit Gustav, Völkening Wilhelm. Elastomeriedern für Schienenfahrzeuge (Teil II) // Nahverkehr Prax. - 1991. -39, No. 9-10. - C. 366-370.

48. Dergachev E. P., Dergachev E. E., Increased Reliability of Passenger Car Bogie // Railway Transport. - 2002. - No. 10. - P.29-32(in Russian).

49. Mulyukin O. ., Kovtunov A. V., Chegodayev D. Ye., Parovoy F. V., Vibration Insulation of Carried Cargoes by Elastoinertial Members with Regulated Stiffness // Samara State Aerospace University Bulletin: Problems and Perspectives of Engine Building Development. - 2000. - No. 4. - P. 232-341(in Russian).

50. Truck pedestal design: Patent 5450799 USA, MKI6 B 61 F 5/26 / Coding David J.; Arasted Ind Inc. No.180026; Applied on 11.1.94; Published on 19.9.95; NKI 105/222.

51. Axle box suspension with resilient elements adhered to the movable components such that all relative movement between the components occurs by deformation of the resilient elements: Patent 5189962 USA, MKI5 861 F 5/30 / Iwamura A., Akashi S.; Kawasaki Jukogyo K.K. No. 892713; Applied on 29.5.92; Published on 2.5.93; Priority 1.9.88, No. 63-216220 (Japan); NKI 105/218.2.

52. A vehicle suspension arrangement: Application 2271747 Great Britain, MKI6 B 62 D 61/12 / Bennett Lan Robert, Smart David Anthony, Young Donald Walter Steel, Okada Takeru, Azakami Masayoshi, Takizawa Hidsyuki; Dowty 
Aerospace Gloucester Ltd; Nabco Ltd; Railway Technical Research Institute. No. 9321519.2; Applied on 19.10.93; Published on 27.4.94; NKI B7D.

53. Multi friction side bearing for a railcar truck: Patent 5046866 USA, MKI5 F 16 C 17/04 / Mulcahy Harry W.; AMSTED Ind. Inc. No. 582422; Applied on 14.09.90; Published on 10.09.91; NKI 384/423.

54. Side bearing: Patent 5046865 USA, MKI5 F 16 C 25/04 / Gantnarek Bruce; A. Stucki Co. No. 405416; Applied on 11.09.89; Published on 10.09.91; NKI 284/423.

55. Mechanical Part of Traction Rolling Stock: Text Book for Railway Transport Institutes. / I. V. Biryukov, A. N. Savoskin, G. P. Burchak and others; Edited by I. V. Biryukov. - Moscow: Transport, 1992. - 440 p(in Russian).

56. Galiev I. P., Nekhayev V. A., Nikolayev V. A., Enhancement of Dynamic Characteristics of Locomotive Spring Suspension Based on Invariability Principle // Materials of $3^{\text {rd }}$ International Conference on Current State and Development Perspectives of Electric Rolling Stock. - Novocherkassk: South-Russia State Technical University, 2000. - P. 98-100(in Russian).

57. Ford R., Series 60 Diesel Locomotive (Great Britain) Axle-Box Suspension // Railway Transport Abroad. - 1992. - No. 12. - P. 2-5(in Russian).

58. Unité ferroviaire, telle que wagon ou bogie, à essieux stabilisés par traction: Application 2634713 France, MKI5 B 61 F 5/52 / Haesebrouck Francis; Usines et Acieries de Sombre et Meuse . No. 8810135; Applied on 27.07.88; Published on 02.02.90.

59. Achslenker für die Führung von Eisenbahnachsen: Application 2634713 France, MKI5 B 61 F 5/52 / Zander Carl-Peter; Krauss-Maffei AG. No. 40108244; Applied on 04.04.90; Published on 10.10.91.

60. Chelnokov I. I., Analysis and Classification of Freight Car Oscillation Dampers / I. I. Chelnokov, V. M. Garbuz, M. M. Sokolov, A. A. Maltsev // Rolling Stock Dynamics. - Л., 1968. - Issue 281. - P.26-46(in Russian).

61. Boronenko Yu. P., Varava V. I., Levit T. M., Unified Hydraulic Damper for Railway Rolling Stock // Materials of Research and Practice Conference "Scientists Solve the Problems of Railway Transport". - St.-Petersburg: PGUPS Publishing House, 1995. - P. 69. (in Russian).

62. Railway truck friction shoe with resilient pads: Patent 1322301 Canada, MKI5 B 61 F 005/24 / Spencer Charles P.; AMSTED Ind. Inc. No. 590122; Applied on 3.2.89; Published on 21.9.93.

63. Friction Assembly: A.p. 1707346 CCCP, MKI5 F 16 D 55/16 / O. V. Kravchenko, A. P. Kucherenko. No.4701635/27; Applied on 06.06.89; Published on 23.01.92; Bulletin No. 3(in Russian).

64. Dämpfungseinrichtung für Schienenfahrzeuge: Patent 295324 Germany, MKI5 B 61 F 5/14 / Hellmich Bernd, Meinken Jörg, Höher Manfred, Neumann Jürgen, Landwehr Michael; VEB Schwermaschinenbau S. M. Kirow. No. 3418435; Applied on 20.06.90; Published on 31.10.91.

65. Shock Absorber: A.p. 1684240 USSR, MKI5 F 16 F 3/02 / V. N. Starchenko, V. V. Avgust, N. V. Starchenko. No. 4756604/28; Applied on 09.11.89; Pub- 
lished on 23.10.91; Bulletin No. 39(in Russian).

66. Shock Absorbers: A.p. 1677403 USSR, MKI5 F 16 F 7/08 / V. I. Alferov, G. V. Boytsov, K. P. Budko, N. G. Gromov, S. P. Pakhilko, N. A. Sabadash, V. Ye. Spiro, A. V. Karpyuk. No. 4133644/25-28; Applied on 15.06.86; Published on 15.09.91; Bulletin No. 34.

67. Horizontaldämpfung an Laufwerken von Etsenbahngüterwagen: Patent 296253 Germany, MKI5 B 61 F 5/24 / Rode Walter, Berndt Werner, Lange Rüdiger, Lubosch Klaus, Wenke Siegbert; Waggonbau Niesky GmbH. No.3422013; Applied on 28.06.90; Published on 28.11.91.

68. Dämpfungseinrichtung für Laufwerken von Schienenfahrzeugen: Patent 296254 Germany, MKI5 B 61 F 5/24 / Hellmich Bernd, Neumann Jürgen, Meinkol Jörg, Landwehr Michael; VEB Schwermaschinenbau S.M.Kirow. No. 3422175; Applied on 28.06.90; Published on 28.11.91.

69. Oscillation Damper of Railway Vehicle Bogie: A.p. 1708691 USSR, MKI5 B 61 F 5/12/ Ye. P. Blokhin, N. I. Granovskaya, A. D. Zhakovskiy, L. A. Manashkin, N. A. Pasternak, O. M. Savchuk. No. 4765111/11; Applied on 05.12.89; Published on 30.01.92; Bulletin No. 4(in Russian).

70. Shapshal A. S., Kupriyanov A. G., Enhancement of Dynamic and Weight Characteristics of Shunting Diesel Locomotives due to Optimization of Resilient and Dissipative Members of Spring Suspension // Materials of $3^{\text {rd }}$ International Conference on Current State and Development Perspectives of Electric Rolling Stock. - Novocherkassk: SRSTU, 2000. - P. 104-106(in Russian).

71. Oscillation Dampers: A.p. 1778381 USSR, MKI5 F 16 F 6/00 / A. A. Pranov. No.4901137/28; Applied on 09.01.91; Published on 30.11.92; Bulletin No. 44(in Russian).

72. Friction shoe for railcar truck: Patent 5095823 USA, MKI5 B $61 \mathrm{~F} 5 / 06$ / Mckeown Franklin S.; Amsted Ind. Inc. No. 628380; Applied on 17.12.90; Published on 17.03.92; NKI 105/198.2.

73. Friction Oscillation Damper: Declaration Patent 50420 Ukraine, MPK6 B61F 5/12 / Ye. O. Andryeyev, M. M. Gryshchenko, V. F. Ivin, V. V. Kozak, S. V. Myamlin, B. M. Smirnov, I. D. Stetsenko; Dnipropetrovsk State Railway Transport Engineers Institute. No.20022010144; Applied on 03.01.2002; Published on 15.10.2002; Bulletin No. 10, 2002(in Russian).

74. Elastomer Based Shock Absorber. Railcar cushioning device with internal elastomeric spring: Patent 6199708 USA, MPK7 B 61 G 9/00 / ASF-Keystone, Inc., Monaco Jay P. No.09/263256; Applied on 05.03.1999; Published on 13.03.2001; NPK 213/43.

75. Automatic Coupling Unit for Railway Rolling Stock/V. V. Kolomiychenko, N. A. Kostina, V. D. Prokhorenkov, V. I. Belaev. - Moscow: Transport, 1991. $232 \mathrm{p}$.

76. Prospective Structures of Automatic Coupling Draft Gears // www.tmholding.ru

77. ЭПА-120 (ЕPA-120) Draft Gear // www.epa.kpyt.ru

78. Freight Cars Impact Strength Calculation: Text Book for Railway Trans- 
port Institutes / Ye. P. Blokhin, I. G. Barbas, L. A. Manashkin, O. M. Savchuk. Moscow: Transport, 1989. - $230 \mathrm{p}$ (in Russian).

79. Gasowski W., Marciniak Z., Sobaś J. Zawieszenie aktywne f moźliwośii jego zastosowania w taborze dla krajowych linii szybkiego ruchu // Probl. kolej.1994. - No. 117. - C. 5-32, 115-118.

80. Electromagnetic Passenger Car Oscillation Damper: Declarative Patent 50393 Ukraine, MPK7 F16G 15/00 / S. V. Myamlin, Ye. M. Gerasimenko; Dnipropetrovsk State Railway Transport Engineers Institute. No.2002010019; Applied on 03.01.2002; Published on15.10.2002; Bulletin No. 10, 2002(in Russian).

81. Shimura Akihiko, Yoshida Kazuo. Ho vibration control of active suspension for high-speed train // J. Rob. and Mechatron.- 1995.- No. 4.- C. 319-323.

82. Active and semi-active suspensions smooth $300 \mathrm{~km} / \mathrm{h}$ ride // Railway Gazette Int. -1997. - 153, No. 4. - P. 241-242.

83. Adjustment of Pneumatic Springs in Rolling Stock: Application 3295758 Japan, MKI5 B 61 F 5/10 / Isikhara Koitiro, Isikava Tatsutaro, Kondzumi Satosi, Khamamoto Syudzi; Sumitomo Kindzoku Koge k. k. No. 297210; Applied on 12.4.90; Published on 26.12.91.

84. Einrichtung zur Abstützung eines Wagenkastens auf einem Laufwerk, insbesondere für ein Schienenfahrzeug: Patent 401913 Austria, MKI6 B 61 F 5/22 / Stribersky Anton, Schäfer Wolfgang; SGP Verkehrstechnik G.M.B.H.; Mannesmarm Rexroth G.M.B.H. No. 1617/91; Applied on 16.8.91; Published on 27.12.96.

85. Mei T. X., Li H., Goodall R. M. Kalman filters applied to actively controlled railway vehicle suspensions // Trans. Inst. Meas. and Contr. - 2001. - 23, No. 3. - P. 163-181.

86. Active anti-hunting device for railway vehicles: Application 1138568 EПВ, MPK7 B 61 F 5/24 / Diana Giorgio, Galcione Ferdinando; FIAT FERROVIARIA S. p. A. No. 00830469.3; Applied on 04.07.2000; Published on 04.10.2001.

87. Method for Electronic Control of Pneumatic Springs in Railway Rolling Stock: Application 3164366 Japan, MKI5 B 61 F 5/10 / Kondzumi Noriyuki, Isikava Ryutaro, Isikhara Koitiro, Yamamoto Mituyuki; Sumitomo Kindzoku Koge k. k. No. 1-304476; Applied on 21.11.89; Published on 16.07.91; Kokai Tokke Koho. Series 2(5). - C 475-482.

88. Suspension System for Multi-Support Vehicle Running Gear: A.p. 1705162 USSR, MKI5 B 61 F 5/12 / V. A. Grebnev, V. V. Konovalov. No. 4761951/11; Applied on 25.09.89; Published on 15.01.92(in Russian).

89. Okamoto Isao, Control of Forced Car Body Tilt in Curved Track Sections // Nihon Kikai gakkaishi=J.Jap.Soc.Mech.Eng. - 2001. -104, No. 992. - P. 463-467.

90. Hydraulische Drehstabilisierung für Schienenfahrzeuge: Application 4329299 Germany, MKI6 B 61 F 5/24 / Hachmann Ulrich, Lang Hans-Peter, Richter Wolfgang-Dieter, Schüller Uwe; AEG Schienenfahrzeuge Nahverkehr und Wagen GmbH. No. 4329299.2; Applied on 31.8.93; Published on 2.3.95.

91. Controlling damper characteristics: Application 2288218 Great Britain, MKI6 F 16 F 9/50 / Street Robin Michael, Taylor George John Michael; Air-Log 
Ltd. No. 9406334.4; Applied on 30.3.94; Published on 11.10.95; NKI F2S.

92. Communication Device for Railway Vehicle and Bogie: A.p. 1344662 USSR, MKI B 61 F 5/16 / V. P. Gundar, N. I. Gorbunov, V. S. Titarenko, A. N. Konyayev, M. L. Burka. No.3986451/25-11; Applied on 09.12.85; Published on 15.10.87; Bulletin No. 38(in Russian).

93. Turning Unit for Freight Car Bogie: Declarative Patent 51189 Ukraine, MPK6 B61F 5/38 / S. V. Myamlin, Ye. M. Gerasimenko; Dnipropetrovsk State Railway Transport Engineers Institute. No.2002010716; Applied on 29.01.2002; Published on 15.11.2002; Bulletin No. 11, 2002(in Russian).

94. Shock Absorbing Unit for Freight car Automatic Coupling: Declarative Patent 39530 Ukraine, MPK7 B61G 7/12 / S. V. Myamlin, Ye. M. Gerasimenko; Dnipropetrovsk State Railway Transport Engineers Institute. No.2000105592; Applied on 02.10.2000; Published on 15.06.2001; Bulletin No. 5, 2001(in Russian).

95. Coupling Units Draft Gear: Declarative Patent 41674 Ukraine, MPK7 B61G 7/00 / S. V. Myamlin, Ye. M. Gerasimenko; Dnipropetrovsk State Railway Transport Engineers Institute. No.2001010301; Applied on 15.01.2001; Published on 17.09.2001; Bulletin No. 8, 2001(in Russian).

96. Shock Absorbing Draft Gear for Coupling Units: Declarative Patent 45204 Ukraine, MPK7 B61G 7/12 / S. V. Myamlin, Ye. M. Gerasimenko; Dnipropetrovsk State Railway Transport Engineers Institute. No.2001064191; Applied on 18.06.2001; Published on 15.03.2002; Bulletin No. 3, 2002(in Russian).

97. Rail Bond: Declarative Patent 41859 Ukraine, MPK7 E01B 9/00 / S. V. Myamlin, Ye. M. Gerasimenko; Dnipropetrovsk State Railway Transport Engineers Institute. No.2001010277; Applied on 15.01.2001; Published on 17.09.2001; Bulletin No. 8, 2001(in Russian).

98. Spring Rail Bond for Switches: Declarative Patent 50154 Ukraine, MPK6 E01B 9/02 / S. V. Myamlin, V. P. Gnatenko, Ye. M. Gerasimenko; Dnipropetrovsk State Railway Transport Engineers Institute. No.2001107267; Applied on 25.10.2001; Published on 15.10.2002; Bulletin No. 10, 2002(in Russian).

99. Lazaryan V. A., Manashkin L. A., About Shock Absorbing // Applied Mechanics. - 1964. - Issue 10, No. 4. - P. 349-359(in Russian).

100. Lazaryan V. A., Manashkin L. A., Shock Absorbers Operation at Impacts Accompanied by Constant Value Longitudinal Force // DRTEI Materials. - Dnipropetrovsk, 1965. - Issue 55. - P. 97-104(in Russian).

101. Integral Bonds Evaluation in a Train and Determination of Their Parameters Basing on the Field Test Results / V. A. Lazaryan, Ye. P. Blokhin, L. A. Manashkin, L. S. Badikova // DRTEI Materials. - Dnipropetrovsk, 1971. - Issue 103. - P. 3-17(in Russian).

102. Manashkin L. A., Determination of Coupling Stiffness When Analyzing Transitional Regimes of Freight Cars Motion Subject to the Cars Equipping with Friction Draft Gears // Higher Education Journal: Machine Building. - 1972. No. 1. - P.105-108(in Russian).

103. Nikolskiy L. N., Keglin B. G., Shock Absorbers in Rolling Stock. - Moscow: Machine Building, 1986. - 144 p(in Russian). 
104. Manashkin L. A., Knyshenko V. S., Effect of Energy Dissipation in NonLinear Couplings with Rigid Characteristics on Longitudinal Oscillations of OneDimensional Multi-Mass Systems When Started // Problems of Dynamics and Strength of Railway Rolling Stock. - Dnipropetrovsk: DRTEI, 1980. - P. 35-42(in Russian).

105. Poturayev V. N., Dyrda V. I., Krush I. I., Applied Rubber Mechanics. Kyiv: Naukova Dumka, 1980. - 260 p(in Russian).

106. Manashkin L. A., Granovskaya N. I., Zhakovskiy A. D., Kalinichenko Ye. A., Mathematical Model for Investigation of Freight Car Center Plate Arrangement Loading at Oscillations in Vertical Plane // Dynamic Loading of Railway Rolling Stock. - Dnipropetrovsk: DRTEI, 1988. - P. 59-69(in Russian).

107. Railway Vehicle Oscillation Damper: A.p. 1337298 USSR / Ye. P. Blokhin, A. D. Zhakovskiy, L. A. Manashkin, N. A. Pasteknak, O. M. Savchuk. No.4004763; Applied on 8.01.86; Bulletin No. 34, 1987(in Russian).

108. Lazaryan V. A. Railway Train Oscillations // Vibration in Mechanics: Reference Book. 3 vol. - Moscow, 1980. - Vol. 3. - P. 398-434(in Russian).

109. Sokolov M. M., Khusidov V. D., Minkin Yu. G., Dynamic Car Loading. Moscow: Transport, 1981. - 208 p(in Russian).

110. Railway Vehicles Autooscillations and Riding Stability / Yu. V. Demin, L. A. Dlugach, M. L. Korotenko, O. M. Markova. - Kyiv: Naukova Dumka, 1984. -160 p(in Russian).

111. Blokhin Ye. P., Danovich V. D., Morozov N. I., Mathematical Model of Spatial Oscillations of Eight-Wheel Railway Vehicle / Dnipropetrovsk Railway Transport Engineers Institute. - Dnipropetrovsk, 1986. - 39 p. - Rur. - TsNIITEI MCL 29.09.86, No.7252 zh.d(in Russian).

112. Garg V. K., Dukkipatti R. V., Rolling Stock Dynamics. - Moscow: Transport, 1988. - $391 \mathrm{p}$ (in Russian); Translation from "Dynamics of railway Vehicle Systems. - Academic Press, Toronto, 1984”.

113. Mathematical Simulation of Railway Vehicles Oscillations / V. F. Ushkalov, L. M. Reznikov, V. S. Ikkol and other; Edited by . F. Ushkalov. - Kyiv: Naukova Dumka, 1989. - 240 p(in Russian).

114. Vershinskiy R. V., Danilov V. N., Khusidov V. D., Railway Car Dynamics. -Moscow: Transport, 1991. -360 p.

115. Manashkin L. A., Yurchenko A. V., Ratner B. S., Khanin M. S., About Mathematical Modeling of Planar Oscillations of All-Steel Freight Cars Bodies at Longitudinal Impacts // Investigation of Rolling Stock Oscillations. - Dnipropetrovsk: DRTEI. - Issue 158. - 1975. - P. 44-56(in Russian).

116. Sokolov M. M., Varava V. I., Levit G. M., Railway Rolling Stock Oscillation Dampers. - Moscow: Transport, 1985. - 216 p(in Russian).

117. Manashkin L. A., Myamlin S. V. Spatial Models of Car Bogies Oscillation Dampers // Ukrainian Railway Transport. - 2005. - No. 2. - P. 20-24(in Russian).

118. Alstul A. D., Hydraulic Resistances. - Moscow: Nedra, 1970. - 216 p(in Russian). 
119. Bashta T. Moscow, Machine Building Hydraulics. - Moscow: Machine Building, 1971. $-672 \mathrm{p}$ (in Russian).

120. Dmitriyev V. M., Dmitriyeva M. V., Stepanova N. G., Analysis of Temperature Effect on Operation of Truck Damper Strut with Oil-Pneumatic Shock Absorber // Materials of Central Aerohydrodynamics Institute. - 1971. - Issue 1334. - P. 3-24(in Russian).

121. Luzava I. A., Prokofyev V. N., Experimental Determination of Adiabatic Modulus of Liquid Volume Elasticity // Problems of Hydroautomatics. - Moscow: Nauka, 1969. - P. 25-30(in Russian).

122. Dimensionless Hydraulic Characteristics of Cylindrical Extensions Considering Cavitation and Reynolds Number / V. M. Fomichev, O. M. Olenin, O. Ya. Biryukov and others// Machine Building Bulletin. - 1975. - No. 11. - P. 7-11(in Russian).

123. Turygin L. N., Glinin L. V., To the Problem of Liquid Flow through Openings into the Mediums with Back-Pressure // Machine Building Bulletin. 1976. -No. 11. - P. 8-11(in Russian).

124. Siov B. N., Liquid Flow through Nozzles into Mediums with BackPressure. - Moscow: Machine Building, 1968. - 140 p(in Russian).

125. Lazaryan V. A., Konashenko S. I., Generalized Functions in Mechanics Problems. - Kyiv: Naukova Dumka, 1974. - 191 p(in Russian).

126. Manashkin L. A., Granovskaya N. I., Mathematical Model of Train for Car Loading Analysis // Problems of Dynamics and Strength of Rolling Stock. Dnipropetrovsk: DRTEI, 1984. - P.24-28(in Russian).

127. Physics Encyclopedic Dictionary. - Moscow: Soviet Encyclopedia, 1983. - 928 p(in Russian).

128. Pshinko A. N., Myamlin S. V., Pismennyy Ye. A., Yalovoy A. I., Railway Vehicles Spatial Oscillation Modeling Program // East-Ukrainian National Dal Institute Bulletin. - Luhansk: Dal ENI Publishing House. - 2004. - No. 8. - P. 1113(in Russian).

129. Pshin'ko O., Blokhin Y., Myamlin S. Simulation of vehicle dynamic loading by means of object-oriented programming // Archives of transport. Polish academy of sciences. Committee of transport. -2002 . - Vol. 14, iss. 1. - P. 6775(in Russian).

130. Blokhin Y.P., Myamlin S.V., Pshin'ko O.M. Mathematical modeling of body braces in a railway vehicle // Problemy eksploatacji: Kwartalnik. - Radom: Wyd. Instytutu Technologii Eksploatacji, 2002. - No. 1. - P. 269-276(in Russian).

131. Blokhin Y. P., Pshin'ko A. N., Myamlin S. V. Spatial train oscillations and wear of the wheels // Proc. $5^{\text {th }}$ Intern. Scientific Conf. for Middle and Eastern European Countries. - Katowice. - 2002. - CD.

132. Copyright Registration Certificate for Investigation No. 7305. Dynamics of Rail Vehicles (DYNRAIL) Sortware Program / Myamlin S. V.; Registered on 20.03.2003(in Russian).

133. Myamlin S. V., Rolling Stock Spatial Oscillations Modeling Program // Ukrainian Railway Transport. - 2000. - No. 3. - P. 52-54(in Russian). 
134. Blokhin Ye. P., Pshinko A. N., Myamlin S. V., About Longitudinal Accelerations in Passenger Trains // Ukrainian Railway Transport. - 2002. - No. 1. P. 7-11(in Russian).

135. Myamlin S. V., Modeling of rail line irregularities in determination of wagon dynamic loading // Problemy eksploatacji: Kwartalnik. - Radom: Wyd. Instytutu Technologii Eksploatacji, 1999. - No. 3. -P. 293-301(in Russian).

136. Pshinko A. N., Myamlin S. V., Effect of Freight Trains Forming Diagrams on Empty Cars Riding Safety // East-Ukrainian National Dal Institute Bulletin. - 2002. - No. 6 (52). - P. 113-119(in Russian).

137. Myamlin S. V., Railway Vehicles Dynamics Modeling. - Dnipropetrovsk: Novaya Ideologiya, 2002. $-240 \mathrm{p}$ (in Russian).

138. Vargaftik N. B., Reference Book on Thermophysical Properties of Gases and Liquids. - Moscow: Fizmatiz, 1963. - 708 p(in Russian).

139. Vulkanovich M. P., Novikov I. I., Real Gases State Equation. - Moscow: GEI, 1948. - 340 p(in Russian).

140. Landau L., Lifshits Ye., Static Physics. - Moscow; Leningrad: GITTL, 1951. - 479 p(in Russian); Statistical physics, Pergamon Press, Oxford, New York, 1980 Chap. 2, 4, 7.141. Wahi Mahinder K. Oil Compressibility and Polytropic Air Compression Analysis for Oleopneumatic Shock Struts // J. Aircraft. - 1976. - No. 3. - P. 527-530.

142. Manashkin L. A., Some Issues of Methematical Modeling of Hydraulic and Hydrogas Shock Absorbers / Dnipropetrovsk Railway Transport Engineers Institute. - Dnipropetrovsk, 1977. - 36 p. TsNIITEI MCL 1977, No. 568 - Uk VNIITI, 1977, No. 11, p. 233(in Russian).

143. Increased Energy Capacity Hydrogas Unit for Automatic Coupling / Z. O. Karkashyan, M. M. Bolotin, B. Ya. Pershin and others // Materials of Moscow Railway Transport Engineers Institute. - 1975. - Issue 451. - P. 161-16(in Russian) 4 .

144. Manashkin L. A., Yurchenko A. V., Investigation of Hydro-Pneumatic Shock Absorbers Using Electronic Simulation // Machine Building Bulletin. 1977. - No. 6. - P.7-11(in Russian).

145. Heavy-Weight Trains Calculations and Testing / Ye. P. Blokhin, L. A. Manashkin, Ye. L. Stambler and others. - Moscow: Transport, 1986. - 236 p(in Russian).

146. Kost Ye. L., Samsonova S. A., Draft Gears in Foreign Freight Cars. Moscow: NIIINFORMTYAZHMASH, TM, 1975. - 22 p(in Russian).

147. Babushka I., Vitasek E., Prager M., Numerical Processes for Differential Equations Solving. - Moscow: Mir, 1969. - 275 p(in Russian); Numerical processes in differential equations, SNTL, Interscience Publishers, Prague, New York, 1966.- 351p.

148. Hydrogas Draft Gear: A.p. 744044 USSR, MKI2 B 61 G 9/08 / V. A. Lazaryan, L. A. Manashkin, A. V. Yurchenko, I. A. Krutikov, L. D. Novikov, B. S. Ratner, G. B. Krayzgur, L. D. Kuzmich. No. 2493493/27-11; Applied on 08.06.1977; Published on 15.05.1980; Bulletin No. 18(in Russian). 
149. Manashkin L. A., Myamlin S. V., Varied Working Body Weight Draft Gear // Dnipropetrovsk National Railway Transport University Bulletin. - Dnipropetrovsk: DNRTU Publishing House. - 2005. - No. 8. - P. 70-78(in Russian).

150. Obert E. F. Concepts of Thermodynamics. - N.-Y.: McGRAW-HILL BOOK COMPANY, 1960. -528 p.

151. Moran M. J., Shapiro H. N. Fundamentals of Engineering Thermodynamics. - N.-Y.: John Wiley \& Sons, 2000. - 918 p.

152. Loytsyanskiy L. G., Liquid and Gas Mechanics. - Moscow: Nauka, 1987. -840 p(in Russian).

153. Gerts Ye. V., Dynamics of Machines Pneumatic Systems. - Moscow: Machine Building, 1985. - $256 \mathrm{p}$ (in Russian).

154. GA-100 (ГA-100)M Type Hydrogas Draft Gears Operation Analysis at Impacts / V. A. Lazaryan, Ye. P. Blokhin, Z. O. Karakaxhyan and others. // Tp. DRTEI. - Dnipropetrovsk, 1975. - Issue 158. - P. 34-44(in Russian).

155. Manashkin L. A., Determination of Optimum Coefficient of Forces of Inelastic Resistance to Compression // Higher Education Bulletin: Machine Building. - 1979. - Issue 6. - P. 94-98(in Russian).

156. Pankin N. A., Strong Excitation Spreading in a Train // Scientists' Notes of VZIIT. - 1961. - Issue 7. - P. 105-166(in Russian).

157. About Transitional Riding Regimes of a Train Equipped with Hydrogas Draft Gears / Ye. P. Blokhin, T. F. Grebenyuk, Z. O. Karakashyan and others. // Dynamics and Strength of High-Speed Land Transport. - Kyiv: Naukova Dumka. - 1976. - P. 54-64(in Russian).

158. Budak B. M., Gorbunov F. V., Straight Lines Method for One Non-Linear Boundary Value Problem Solving in Curved Boundary Area // Report for the Academy of Sciences of the USSR. - 1958. - Vol. 118, No. 5.

159. Samarskiy A. A., Popov Yu. P., Gas Dynamics Difference Diagrams. Moscow: Nauka, 1975(in Russian).

160. Hydropneumatic Shock Absorber: A.p. 1190112 USSR, MKI4 F 16 F 9/34 / Ye. P. Blokhin, L. A. Manashkin, A. V. Yurchenko, V. N. Timchenko, R. P. Ivanitskiy. No.3668705/25-28; Applied on 21.11.1983; Published on 07.11.1985; Bulletin No. 41(in Russian).

161. Danovich V. D., Spatial Cars Oscillations in Inertia Track: Thesis for Doctor of Technical Science Degree: 05.22.07. - Dnipropetrovsk, 1981. - 465 p(in Russian).

162. Myamlin S. V., Choice of Structural Diagram and Parameters of Freight Car Bogie for Prospective Operation Conditions: Thesis for Candidate of Technical Science Degree: 05.22.07. - Dnipropetrovsk, 1995. - 142 p(in Russian).

163. Pshin'ko O. M., Blokhin Y. P., Myamlin S. V. The influence of the length of horizontal and vertical irregularities of railway track on dynamic loading of an open wagon // Proc. of the 7th mini conf. on vehicle system dynamics, identification and anomalies. Budapest (Hungary). - 2000. - P. 247-254(in Russian).

164. Pshin'ko O., Blokhin E., Myamlin S. Effect of lengths of rail line horizontal and vertical irregularities on dynamic loading conditions of open wagon // $\mathrm{Ab}-$ 
stracts of the 7th mini conf. on vehicle system dynamics, identification and anomalies. Budapest (Hungary). - 2000. - P. 14(in Russian).

165. Myamlin S., Pshin'ko O. Modeling of rail line irregularities using estimation of their correlation functions // 14 Konf. Naukowa Pojazdy Szynowe na przelomie wiekow. - Krakow, 2000. - P. 101-108(in Russian).

166. Myamlin S. V., Neduzhaya L. A., Pismennyy Ye. A., Yalovoy A. I., Effect of Central and Axle-Box Suspension Parameters on Dynamic Loading of a Gondola Car // Materials of the $2^{\text {nd }}$ Scientific and Technical Conference "Rolling Stock of $21^{\text {st }}$ Century - Ideas, Requirements, Projects". - St.-Petersburg: PGUPS, 2001. P. 40-41(in Russian).

167. Myamlin S. V., Pismennyy Ye. A., Yalovoy A. I., Manashkin L. A., Mathematical Modeling of Shock Absorbers // Dnipropetrovsk National Railway Transport University Bulletin. - Dnipropetrovsk: DNRTU Publishing House. 2004. - No. 4. - P. 119-121(in Russian).

168. Blokhin Y. P., Pshin'ko O. M., Myamlin S. V. Optimization of parameters of spring suspension of the freight car three-piece bogie // Proc. 5th intern. conf. on railway bogies and running gears. - Budapest, 2001. - P. 263-271(in Russian).

169. Bubnov V. M., Manashkin L. A., Myamlin S. V., Adaptation of MARK Series Draft Gears for Domestic Railways // Abstracts from the Report for the $11^{\text {th }}$ International Conference on Railway Transport Mechanics Problems: Rolling Stock Dynamics, Strength and Riding Safety. - Dnipropetrovsk: Full Computer Service, 2004. - P. 54(in Russian).

170. Myamlin S. V., Pshinko A. N., Optimization of Railway Vehicles Spring Suspension Parameters // East-Ukrainian National Dal Institute Bulletin. - Luhansk: 2003. - No. 9 (67). - P.79-85(in Russian).

171. Railway Rolling Stock Hydraulic Dampers. Certification Requirements: NB ZhT TsT-TsL-TsV 012-99: Approved by the Ministry of Communication Lines of Russia on 01.02.1999. -Moscow, 1999. - 10 p(in Russian).

172. ST SSFZhT TsT-TsL-TsV 111-2001. Railway Rolling Stock Hydraulic Dampers. Typical Test Methods. - Introduced on 10.07.2001. - Moscow, 2001. 19 p(in Russian).

173. OST 24.153.01-87. Railway Rolling Stock Hydraulic Dampers. General Technical Specifications. - Introduced in 1987. - Moscow: Mintyazhmash, 1987(in Russian).

174. ST SSFZhT TsV-TsL 09.04-99. Static Test Method for Automatic Coupling Draft Gears. - Instead of TM 14-001-91; Introduced on 20.08.1999. - Moscow: MCL of Russia, 1999. - 5 p(in Russian).

175. ST SSFZhT TsV-TsL 09.05-99. Hardness Drop Test Method for Automatic Coupling Draft Gears. - Instead of TM 14-001-91; Introduced on 20.08.1999. Moscow: MCL of Russia, 1999. - 8 p(in Russian).

176. ST SSFZhT TsV-TsL 09.06-99. Endurance Test Method for Automatic Coupling Draft Gears. - Instead of TM 14-001-91; Introduced on 20.08.1999. Moscow: MCL of Russia, 1999. - 5 p(in Russian).

177. GOST 3475-81. Automatic Coupling Unit for $1,520(1,524) \mathrm{mm}$ Track 
Railway Rolling Stock. Installation Dimensions. - Moscow, 1981.

178. ST SSFZhT TsV-TsL 09.07-99. Cars Collision Test Method for Automatic Coupling Draft Gears. - Instead of TM 14-001-91; Introduced on 20.08.1999. Moscow: MCL of Russia, 1999. - 7 p(in Russian).

179. ST SSFZhT TsV-TsL 09.08-99. Dynamic Train Test Method for Automatic Coupling Draft Gears. - Instead of TM 14-001-91; Introduced on 20.08.1999. Moscow: MCL of Russia, 1999. - 5 p.

180. ST SSFZhT TsV-TsL 09.09-99. Test Method for Automatic Coupling Draft Gears in the Line. - Instead of TM 14-001-91; Introduced on 20.08.1999. Moscow: MCL of Russia, 1999. - 5 p(in Russian).

181. RD 24.050.37-95. Freight and Passenger Cars. Strength and Running Characteristics Test Methods. - Moscow: Gos NIIV RF, 1996. - 102 p(in Russian).

182. Ushkalov V. F., Romen Yu. S., Zavertulyak A. V., Ruban V. I. About the Effect of Horizontal Longitudinal Forces in Side Bogie Frame on the Freight Car Vertical Dynamics Parameters // Abstracts from the Report for $11^{\text {th }}$ International Conference on Railway Transport Mechanics Problems: Rolling Stock Dynamics, Strength and Riding Safety. - Dnipropetrovsk: Full Computer Service, 2004. - P. 173(in Russian).

183. Manashkin L. A., Myamlin S. V., About the Change of Vertical Forces in Freight Cars Bogies // Abstracts from the Report for $11^{\text {th }}$ International Conference on Railway Transport Mechanics Problems: Rolling Stock Dynamics, Strength and Riding Safety. - Dnipropetrovsk: Full Computer Service, 2004. - P. 115(in Russian).

184. Pshin'ko O., Manashkin L., Myamlin S., Bodnar B., Pys'mennyy Y. On measuring vertical forces in freight car bogies // Proc. 9th mini conf. on Vehicle system dynamics, identification and anomalies. Budapest (Hungary). - 2004. - P. 11-12(in Russian).

185. Technical Requirements to Designed Locomotives Basing on Strength, Dynamics and Track Effect Conditions. - Moscow: MCL of the USSR, VNIIZhT, 1964(in Russian).

186. Calculation and Evaluation Norms for Load Bearing Members Strength, Dynamic Characteristics and Effect on Track of Locomotives Operated in 1,520 mm Railway Lines of MCL of RF. -Moscow: MCL of RF, 1998. -145 p(in Russian).

187. Forecasting of the Most Dangerous Regimes of Rolling Stock Testing in the Line / Ye. P. Blokhin, M. L. Korotenko, S. V. Myamlin, R. B. Granovskiy, A. V. Ryzhov, S. G. Kryukov, N. Ya. Garkavi, V. N. Datsenko, Ye. F. Fedorov // Machine Building Bulletin. - 2003. - No. 7. - P. 20-23(in Russian).

188. Feldbaum A. A., Butkovskiy A. G., Automatic Control Theory Methods. Moscow: Nauka, 1971. - 744 p(in Russian).

189. Lenk A., Renitts Yu., Mechanical Testing of Units and Instruments. Moscow: Mir, 1976. - 271 c(in Russian).

190. Volkov Z. T., Sirvidas S. I., About One Algorithm of Fourier Transforma- 
tion Evaluation // Cybernetics. - 1973. - No. 1. - P. 44-52(in Russian).

191. Redko S. F., Ushkalov V. F., Yakovlev V. P., Mechanical Systems Identification. - Kyiv: Naukova Dumka, 1985. - 216 p(in Russian).

192. Simulation of Impact Cars Loadings / N. Ya. Garkavi, L. A. Manashkin, V. Ya. Nechay, A. V. Yurchenko // Issues of Investigation of Reliability and Dynamics of Railway Transport Machines and Rolling Stock Elements. - Tula: Tula Polytechnic Institute, 1979. - P. 30-77(in Russian).

193. Smyslov V. I., About Experimental Methods of Aircrafts Oscillations Analysis // Materials of Central Aerohydrodynamics Institute. - Moscow, 1970. Issue 1217. - P. 3-63(in Russian).

194. Typical Test Methods for Rolling Stock Effect on the Track after Fabrication or before Putting into Operation. - Moscow: VNIIZhT MCL (ITsZhT), 1990. -20 p(in Russian).

195. GSTU 3-06-101-95. Cars for 1,520 mm Railway Lines. Safety Requirements for Freight Cars. - Kyiv, 1995(in Russian).

196. RD 24.050.37-90. Freight and Passenger Cars. Strength and Runnign Characteristics Test Methods.

197. Processing of Results of Railway Cars Testing in the Line for the Purpose of Evaluation of their Dynamic Characteristics / Ye. P. Blokhin, L. A. Manashkin, V. D. Danovich, M. L. Korotenko, R. B. Granovskiy, S. V. Myamlin, N. Ya. Garkavi, Ye. F. Fedorov // Bulletin of the Academy of Engineering Science of Ukraine: Machine Building. - 2002. - No. 4(17). - P. 52-61(in Russian).

198. Connecting Sensors and Data Input Units to IBM PC Computers / Edited by W. Tompkins and G. Webster. - Moscow: Mir, 1992. - 592 p.

199. Korn G., Korn T., Mathematics Reference Book for Scientists and Engineers. -Moscow: Nauka, 1968. - 720 p(in Russian).

200. Fore R., Kofman A., Deni-Papen M., Modern Mathematics. - Moscow: Mir, 1966. - 272 p(in Russian); translation from "Mathematical Hamdbook for Scientists and Engineers", cMGRAW HILL Company, NY, 1961.

201. Skiba I. F., Railway Cars. - Moscow: Transport, 1979. - 304 p(in Russian).

202. Railway Cars. Structures, Theory and Calculation / Edited by L. A. Shadura. - Moscow: Transport, 1980. - 440 p(in Russian).

203. Railway Cars Designing and Calculation / Edited by V. V. Lukin. - Moscow: Transport, 2000. - 728 p(in Russian).

204. Dobrov I. V., Garkavi N. Y., Garkavi O. N., Algorithm for Inter- and Extrapolation of Random Function of Final Argument // System Technologies. 2000. - No. 9. - P. 39-42(in Russian).

205. Lazaryan V. A., Demin Yu. V., Osadchiy G. F., Experimental Verification of Railway Vehicles Riding Stability // Some Problems of High-Speed Land Transport Mechanics. - Kyiv: Naukova Dumka, 1974. - P. 3-13(in Russian).

206. Lazaryan V. A., Vehicles Dynamics. - Kyiv: Naukova Dumka, 1985. $527 \mathrm{p}$ (in Russian).

207. Kulikovskiy K. L., Kuper V. Ya., Measurement Methods and Tools. - 
Moscow: Energoatomizdat, 1986. - 448 p(in Russian).

208. Stukalov Ye. A., Installation for Machine Processing of Rolling Stock Dynamic Tests // Railway Vehicles Dynamic Research: DRTEI Materials. - Dnipropetrovsk, 1975. - Issue 169/21. - P. 77-79(in Russian).

209. Blokhin Ye. P., About Digitizing the Sensor Information during Field Tests of Railway Rolling Stock / Ye. P. Blokhin, S. V. Myamlin, R. B. Granovskiy, V. L. Gorobets, V. V. Glukhov, N. Ya. Garkavi, Ye. F. Fedorov // Bulletin of the Academy of Engineering Science of Ukraine: Machine Building. - 2002. No.4(17). - P. 19-28(in Russian).

210. Marpl S. L., Numeric Spectral Analysis and Its Applications. - Moscow: Mir, 1990. - 584 p(in Russian).

211. OST 24.050.16-85. Passenger Cars. Method for Riding Smoothness Determination (in Russian).

212. GOST 12.2.056-81. Occupational Safety Standards System. Electric and Diesel Locomotives for 1,520 mm Track. Safety Requirements(in Russian).

213. OST 24.050.28-81. Passenger Cars. Method for Measurement and Evaluation of Vibration (in Russian).

214. Calculation and Evaluation Norms for Load Bearing Members Strength and Dynamic Characteristics of Vehicle Part of Motor-Car Rolling Stock of MCL of RF 1,520 mm Track Railways. -Moscow: VNIIZhT, 1997. - 147 c(in Russian).

215. UIC Code $513 \mathrm{R}$. Guidelines for evaluating passenger comfort in relation to vibration in railway vehicles International Union of Railways. - 1995.

216. Gusyev A. S., Structures Fatigue Resistance and Endurance under Random Loadings. - Moscow: Machinebuilding, 1989. - 248 c(in Russian). 


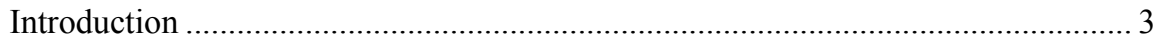

1. Structures of Damping Systems in Railway Vehicles ....................................... 8

1.1. Car Body Bogie Bearing Systems ……….................................................... 8

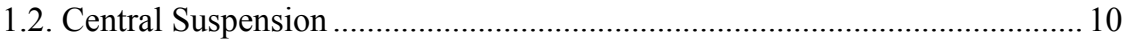

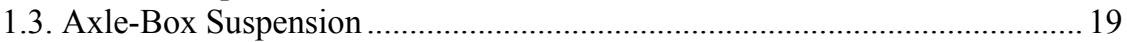

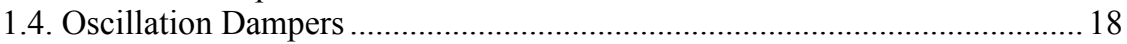

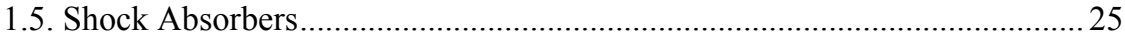

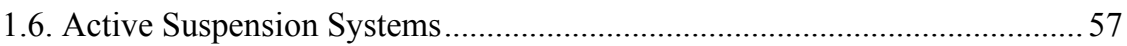

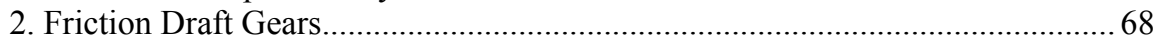

3. Spring Suspension and Friction Oscillation Dampers in Freight Cars Bogies ... 68

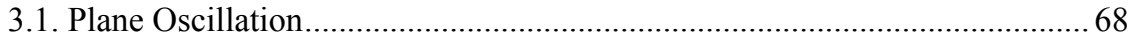

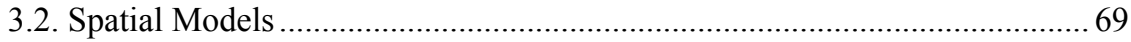

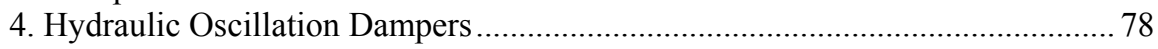

5. Pneumatic Return Mechanisms in Shock Absorbers and Oscillation Dampers 87

6. Hydro-Gas Draft Gear Mathematical Model ...................................................... 88

7. Improved Mathematical Model of Pneumatic Return Mechanisms in Shock Absorbers and Support Bearings......................................................................... 98

8. Hydro-gas draft Gear with Variable Mass Working Medium ............................ 98

9. Approximated Model of Shock Absorbers. Optimal Parameters of Automatic

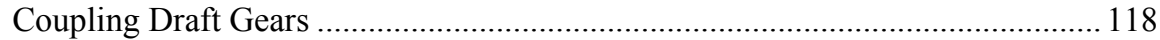

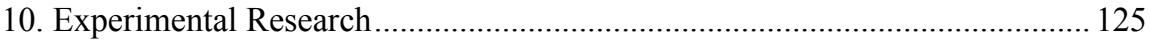

10.1. Test Methods …................................................................................ 131

10.2. Test Method for Measuring Vertical Forces Acting on Freight Cars Bogies

at Wheelset Side ........................................................................................ 137

10.3. Test Method for Determination of Frequency Characteristics of Railway

Vehicles ..................................................................................................... 148

10.4. Method for Analyzing the Results of Railway Vehicles Testing on the Line

10.5. Method for Digitizing the Sensors Information When Testing Railway

Vehicles

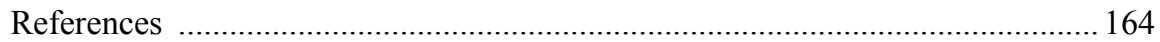


Scientific edition

L. MANASHKIN, S. MYAMLIN, V. PRIKHODKO

\title{
Oscillation Dampers and Shock Absorbers in Railway Vehicles (Mathematical Models)
}

\author{
Monograph \\ (in english)
}

Editor

Markup Zaichenko A.

Cover designer Zaichenko A. 